\title{
LINKING ADVERBIALS IN ENGLISH
}

by

Yin Zihan

\author{
A thesis \\ submitted to the Victoria University of Wellington \\ in fulfilment of the \\ requirements for the degree of \\ Doctor of Philosophy \\ in Applied Linguistics
}

Victoria University of Wellington

2014 


\section{ABSTRACT}

Linking adverbials play an important role in textual cohesion. Applied linguistic studies (e.g. Altenberg \& Tapper, 1998; Bolton, Nelson, \& Hung, 2002; Chen, 2006) have shown that second language learners have difficulty in using linking adverbials appropriately. Biber, Johansson, Leech, Conrad, and Finegan (1999) is to date the only corpus-based reference grammar book which covers all three aspects of usage patterns of linking adverbials, i.e., form, meaning and position. But as the book provides a very comprehensive grammar, there is not room for a detailed account of all three aspects of usage patterns of a small grammar category such as linking adverbials. Also, the previous literature does not agree upon the terms used to refer to linking adverbials and the linguistic elements referred to by linking adverbials and other related terms.

This two-stage study examined research questions of what linking adverbials are and how they are used in different registers using both a qualitative and quantitative approach. In Stage I, a random sample of 67 texts of a total of over 100,000 words from the Wellington Corpora of Written and Spoken New Zealand English (WWC and WSC) were manually analysed, which provided coverage of the target five registers of written academic prose, academic lectures, conversation, written news and broadcast news. In Stage II, the most frequent linking adverbials identified in written registers in Stage I were automatically searched in larger corpora, i.e., the whole WWC, BNC and COCA. The intonation unit was adopted as the analysis unit for spoken data and sound files were needed in deciding intonation units. Thus, automatic search for patterns in spoken data was not viable in Stage II. This study suggests a new definition of linking adverbials and explains the difference between linking adverbials and conjunctions. This study then provides a detailed account of usage patterns of not only the form, meaning and position of linking adverbials but also patterns of types of each form, meaning and position in five registers. Such usage patterns are compared and explained among different written and spoken registers and in different social settings. It is worth noting that a register-specific meaning categorization system and a semantic-pragmatic continuum are suggested in this study. The aforementioned findings contribute to theories of the nature of linking adverbials, and have implications for second language learning and teaching in EAP and ESP contexts and future corpus-based pedagogical grammar studies. 


\section{ACKNOWLEDGEMENTS}

I would like to express my deep gratitude to:

My current supervisors, Dr Elaine Vine and Dr Jean Parkinson, and my previous supervisor, Professor Paul Nation, for their constant encouragement, care and support, and supervision of the research;

Dr Meredith Marra for her guidance into this concise linguistic writing style during my M.A. study;

Dr Stuart Webb for his valuable time for coffee breaks when procrastinating.

I would like to thank New Zealand, this piece of peaceful land, for giving me a very enjoyable, pure experience of the nature. I will cherish my memories of this romantic, touching, remote island country.

Finally, I would like to thank my family for their love and moral support.

I authorise Victoria University of Wellington to lend this thesis to other institutions or individuals for the purpose of scholarly research.

Yin Zihan 


\section{TABLE OF CONTENTS}

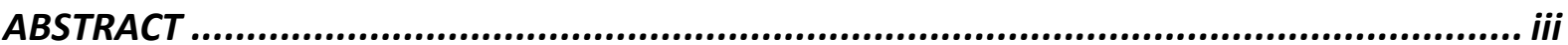

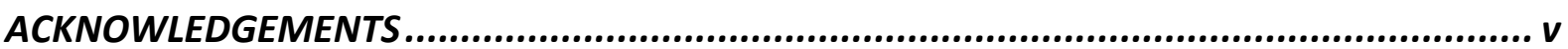

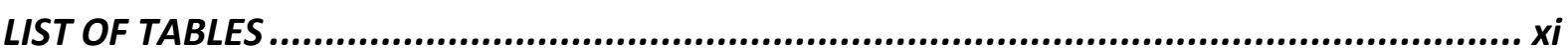

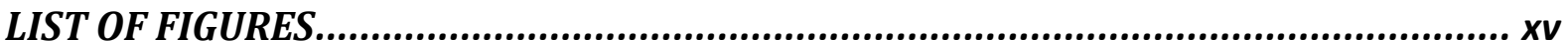

Chapter 1 Introduction..................................................................................................

Chapter 2 Literature review .................................................................................... 5

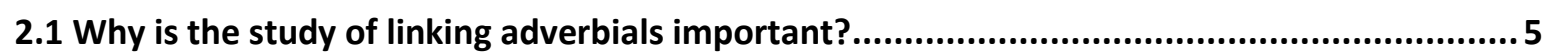

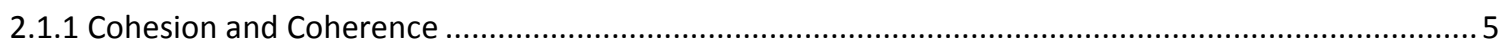

2.1.2 Second language learners' difficulty in using linking adverbials ...................................................... 6

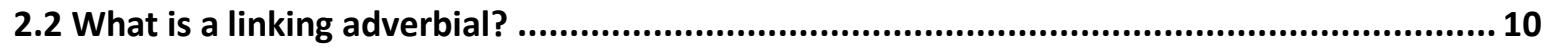

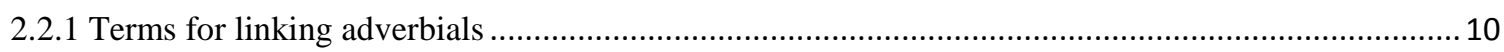

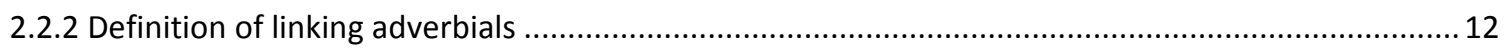

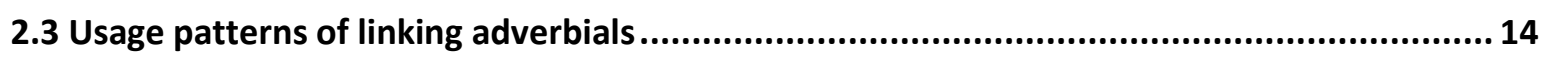

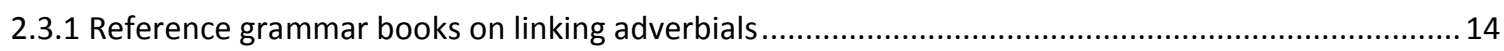

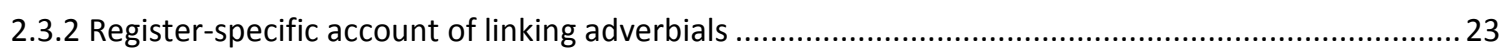

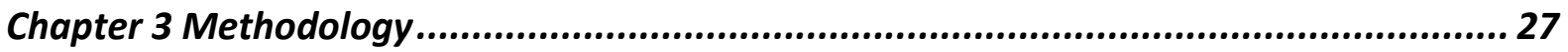

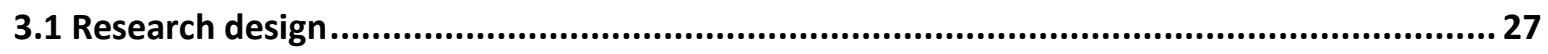

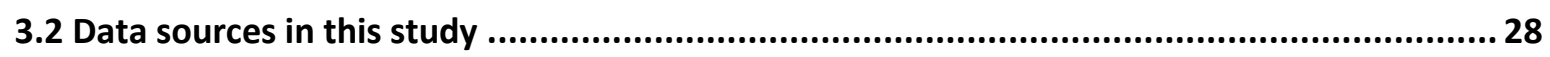

3.2.1 Wellington Corpora of New Zealand Spoken and Written English (WWC \& WSC) ............................... 28

3.2.2 British National Corpus and Corpus of Contemporary American English ......................................... 32

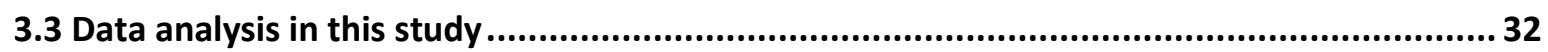

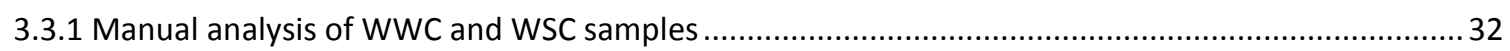

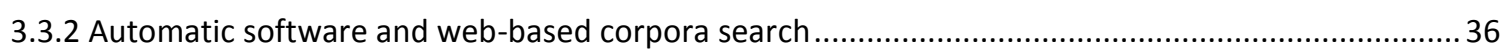

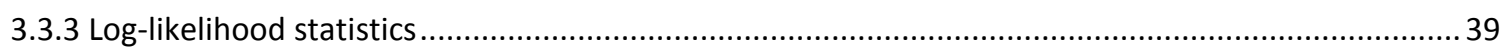

Chapter 4 What is a linking adverbial? .................................................................... 41

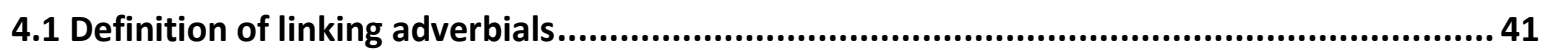

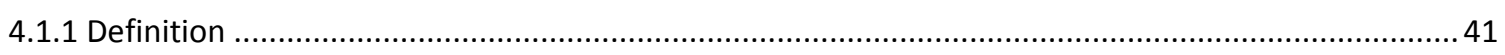

4.1.2 Key components of the definition of linking adverbials ............................................................... 41

4.2 Difference between linking adverbials and conjunctions.................................................... 48

4.2.1 Understanding the difference between linking adverbials and conjunctions ................................... 48

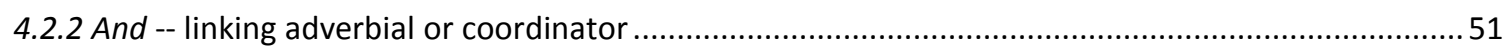

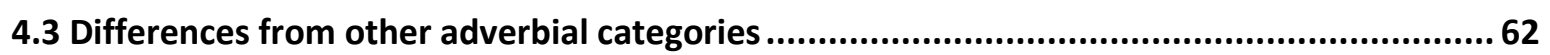

4.3.1 Difference between linking adverbials and circumstance adverbials ...............................................62

4.3.2 Difference between linking adverbials and stance adverbials......................................................63

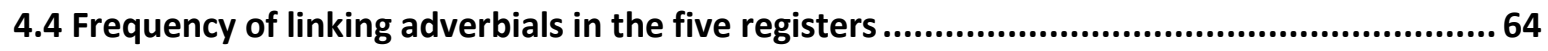

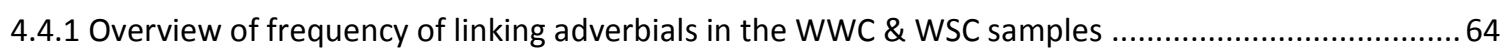




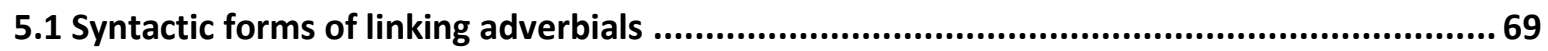

5.2 Frequency of form of linking adverbials in different registers ........................................... 70

5.2.1 Overview of form of linking adverbials in WWC and WSC samples............................................... 70

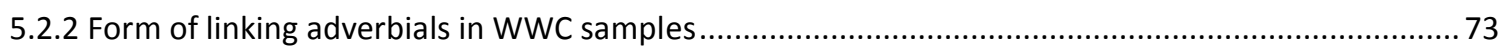

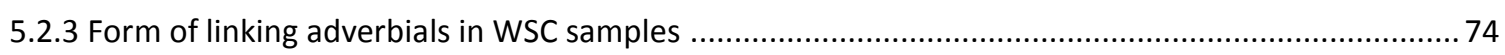

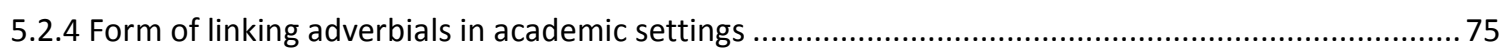

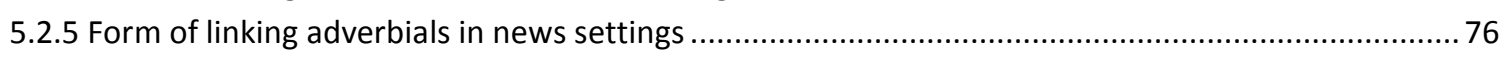

5.3 Types of form of linking adverbials in different registers .................................................... 76

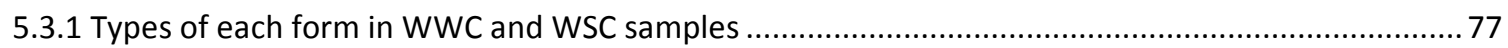

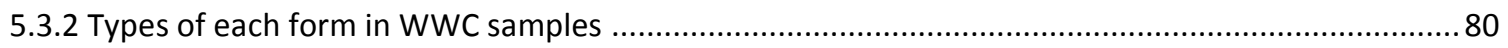

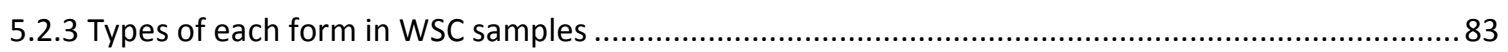

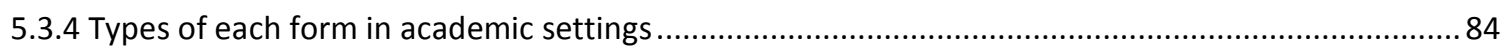

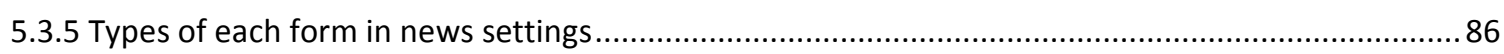

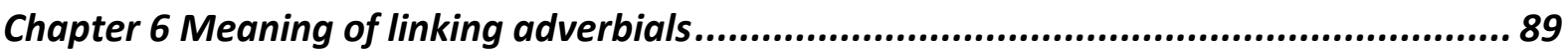

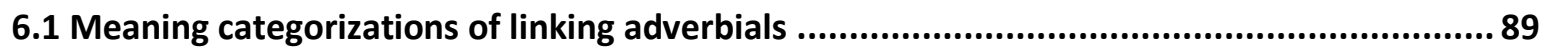

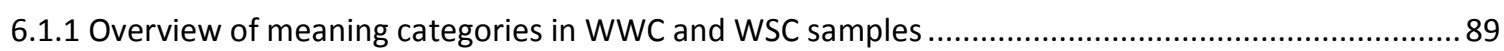

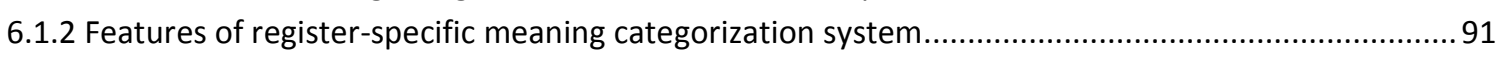

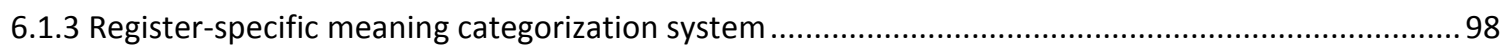

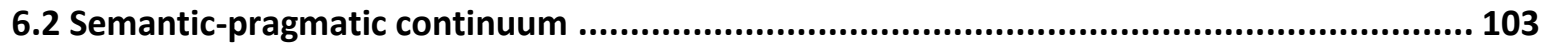

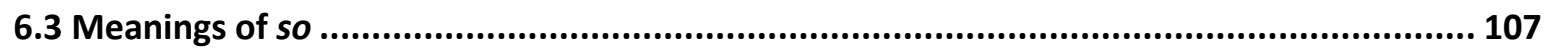

6.3.1 Overview of frequency of linking adverbial so in different registers .............................................. 108

6.3.2 Overview of meanings of $s o$ in the five registers ................................................................... 110

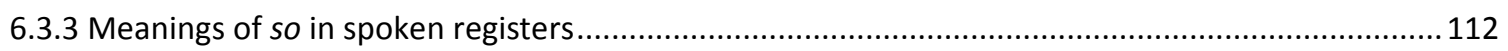

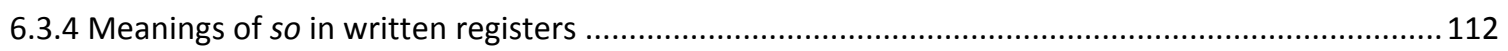

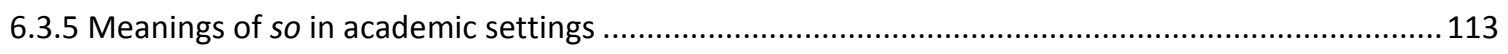

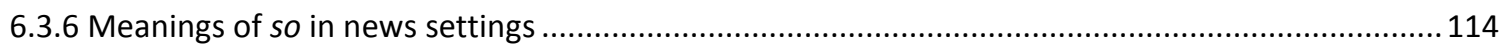

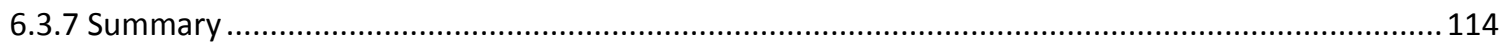

6.4 Frequency of the meanings of linking adverbials ................................................ 115

6.4.1 Frequency of meanings of linking adverbials in five registers ................................................... 115

6.4.2 Frequency patterns of the meanings of linking adverbials in written registers ............................ 119

6.4.3 Frequency patterns of the meanings of linking adverbials in spoken registers ............................. 121

6.4.4 Frequency patterns of the meanings of linking adverbials in academic settings .......................... 125

6.4.5 Frequency patterns of the meanings of linking adverbials in news settings ............................... 126

Chapter 7 Position of linking adverbials .............................................................. 129

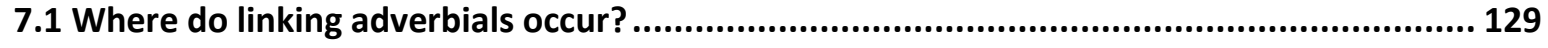

7.2 Register-specific frequency of the position of linking adverbials..................................... 131

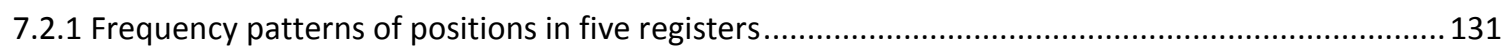

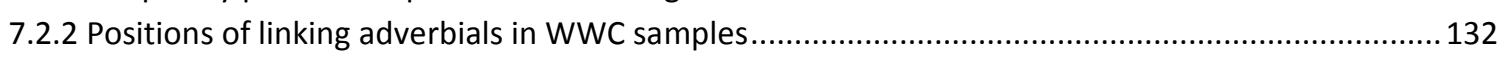

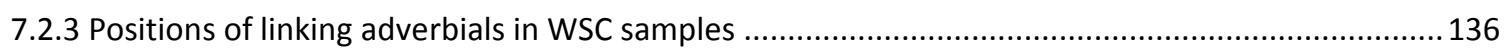

7.2.4 Positions of linking adverbials in academic settings ................................................................ 144

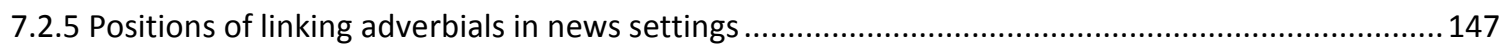

7.3 Do certain linking adverbials occur only in a certain position? ........................................ 149 


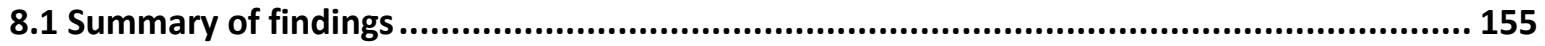

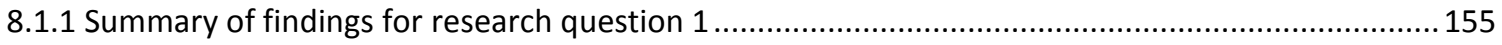

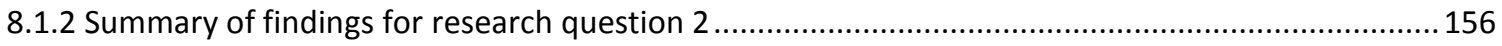

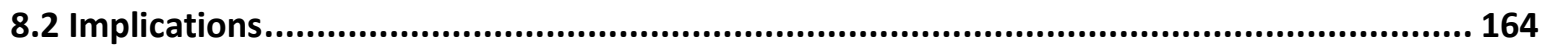

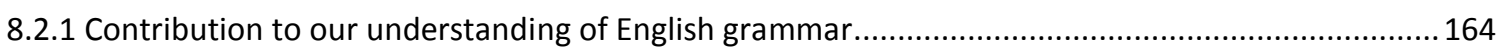

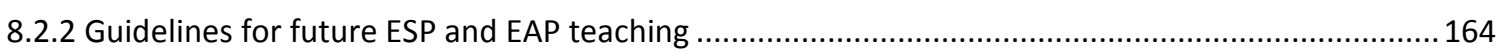

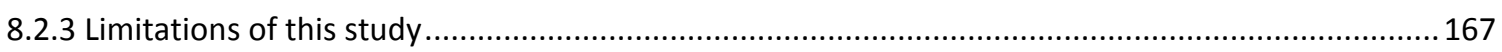

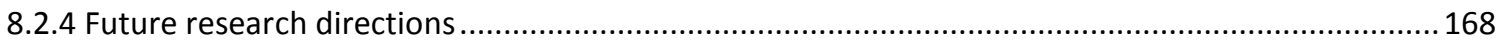

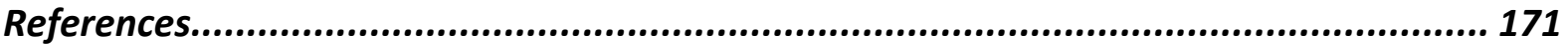




\section{LIST OF TABLES}

Table 1 Conjunctive Adjuncts and Linking Adverbials........................................................ 10

Table 2 Coverage of form, meaning and position in the four grammar books ......................... 15

Table 3 Semantic types of linking adverbials in the four grammar books ............................... 16

Table 4 Summary of semantic types of LAs in the four grammar books .................................20

Table 5 Comparison of Biber et al. (1999) and Liu (2008) ..................................................24

Table 6 Subjects and gender information in the sub-corpus of academic lectures ...................30

Table 7 Occurrence of linking adverbial and and coordinator and in written and spoken data

Table 8 Frequency of linking adverbial and and coordinator and in written registers............52

Table 9 Frequency of linking adverbial and and coordinator and in spoken registers.............55

Table 10 Sound patterns of linking adverbial and and coordinator and in conversation .........56

Table 11 Sound patterns of linking adverbial and and coordinator and in academic lectures 58

Table 12 Sound patterns of linking adverbial and \& coordinator and in broadcast news.......60

Table 13 Frequency of linking adverbials in the five registers.................................................65

Table 14 Frequency of linking adverbials in conversation and written academic prose .........65

Table $15 \mathrm{LL}$ of frequency of linking adverbials in three spoken registers and written

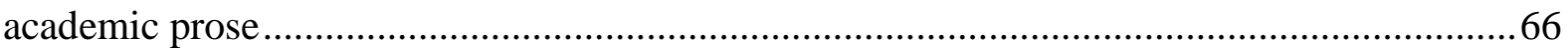

Table 16 Form of linking adverbials in the five registers .................................................... 71

Table 17 Form of linking adverbials in the five registers (per 20,000 words) .........................71

Table $18 \mathrm{LL}$ of the form of single-word adverb and adverb phrase across registers................72

Table 19 Form of linking adverbials in WWC samples …………………………………......73

Table 20 Form of linking adverbials in WSC samples ..........................................................74

Table $21 \mathrm{LL}$ of form of linking adverbials in academic lectures and conversation .................74

Table $22 \mathrm{LL}$ of form of linking adverbials in conversation and broadcast news .....................74

Table $23 \mathrm{LL}$ of form of linking adverbials in academic lectures and broadcast news ............75

Table 24 Form of linking adverbials in academic settings ...................................................

Table 25 Form of linking adverbials in news settings ...........................................................76

Table 26 Types of each form in WWC and WSC samples...................................................77

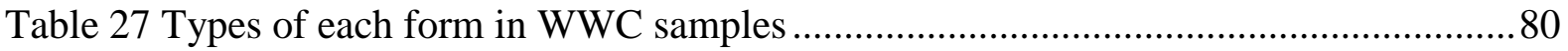

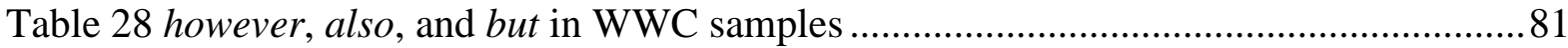

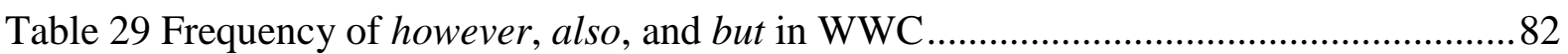


Table 30 Frequency of however, also, and but in BNC.....

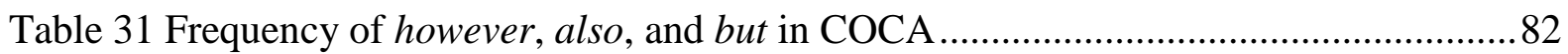

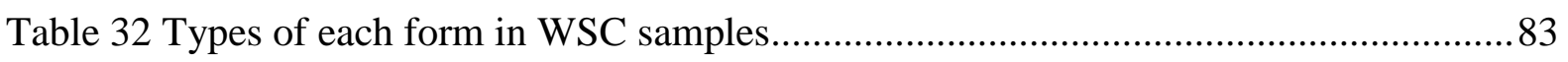

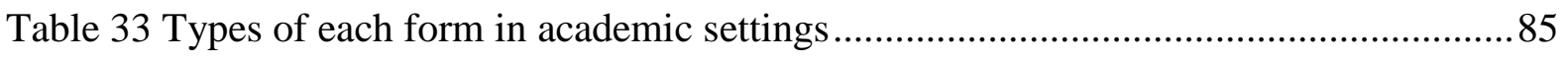

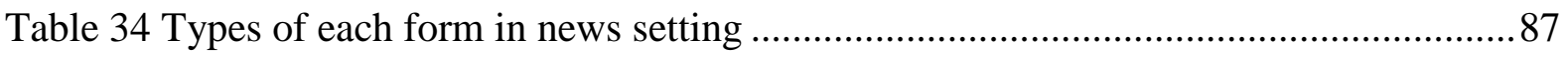

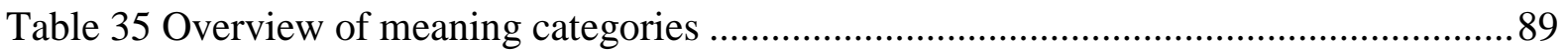

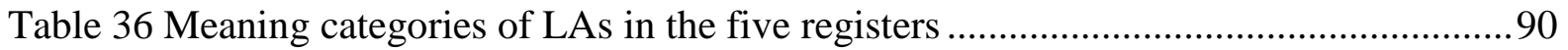

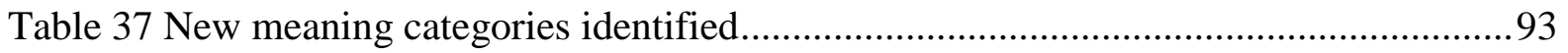

Table 38 Overview of frequency of linking adverbial so in different registers.................... 108

Table 39 Frequency of $s o$ in academic lectures and conversation...................................... 108

Table 40 Frequency of $s o$ in written academic prose and written news ............................... 109

Table 41 Frequency of $s o$ in academic lectures and broadcast news.................................. 109

Table 42 Frequency of $s o$ in academic settings and news settings ..................................... 109

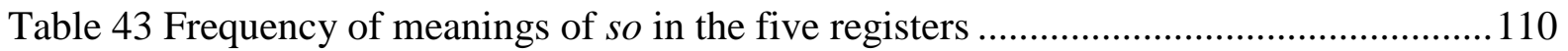

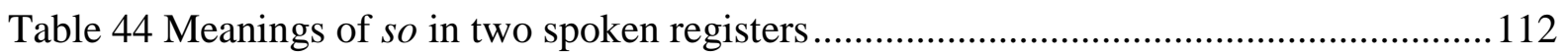

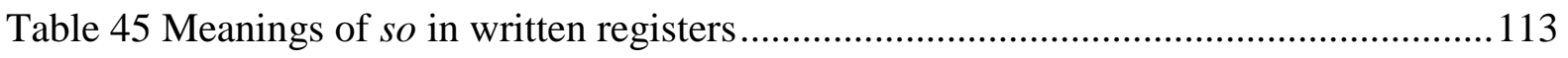

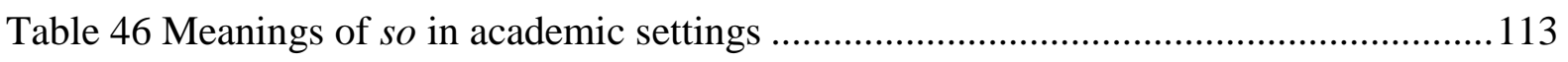

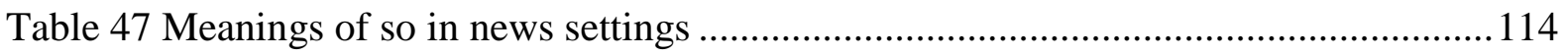

Table 48 Frequency patterns of the meaning of linking adverbials in the five registers ....... 115

Table 49 The four most frequent meaning categories in the five registers..........................116

Table 50 Frequency of types of linking adverbial marking different meaning categories .... 117

Table 51 Frequency patterns of meanings of linking adverbials in written registers ............. 120

Table 52 Frequency patterns of meanings of linking adverbials in spoken registers ............ 121

Table $53 \mathrm{LL}$ of the six meaning categories occurring in all the three spoken registers ........ 122

Table $54 \mathrm{LL}$ of the meaning categories that occur only in academic lectures and conversation

Table $55 \mathrm{LL}$ of the two meaning categories that only occur in broadcast news ................... 124

Table 56 LL of the meaning categories that occur only in conversation.............................. 124

Table 57 LL of the meaning categories that occur only in academic lectures....................... 124

Table 58 Frequency patterns of the meanings of linking adverbials in academic settings .... 125

Table 59 Frequency patterns of the meanings of linking adverbials in the news settings..... 126

Table 60 Raw frequency of positions of linking adverbials in the five registers in WWC and

WSC samples 
Table 61 Standardized frequency of positions of linking adverbials in the five registers in WWC and WSC samples (per 20,000 words)

Table $62 \mathrm{LL}$ of medial and final positions of linking adverbials in conversation

Table 63 Types of linking adverbials in different positions in WWC samples

Table 64 LL of initial position of linking adverbials in written academic prose and written news

Table $65 \mathrm{LL}$ of medial position of linking adverbials in written academic prose and written news

Table 66 LL of final position of linking adverbials in written registers 136

Table 67 LL of initial position of linking adverbials in spoken registers

Table 68 Types of linking adverbials in different positions in WSC samples

Table 69 LL of medial position of linking adverbials in spoken registers 140

Table $70 \mathrm{LL}$ of final position of linking adverbials in spoken registers 142

Table $71 \mathrm{LL}$ of initial position of linking adverbials in academic settings 144

Table 72 Types of linking adverbials in different positions in academic settings 145

Table $73 \mathrm{LL}$ of medial position of linking adverbials in academic settings 146

Table $74 \mathrm{LL}$ of final position of linking adverbials in academic settings 146

Table 75 LL of initial position of linking adverbials in news settings 147

Table 76 Types of linking adverbials in different positions in news settings 147

Table 77 LL of medial position of linking adverbials in news settings 148

Table $78 \mathrm{LL}$ of final position of linking adverbials in news settings 148

Table 79 Raw frequency of positions of however, but and for example in written academic prose in WWC samples (20,128 words)

Table $80 \mathrm{LL}$ of frequency of however in different positions in written academic prose in different corpora.

Table $81 \mathrm{LL}$ of frequency of for example in different positions in written academic prose in different corpora.

Table 82 LL of Frequency of but in different positions in written academic prose in different corpora 


\section{LIST OF FIGURES}

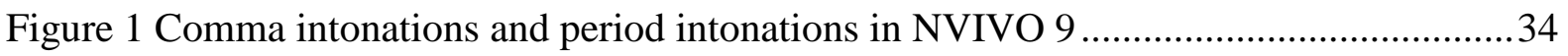

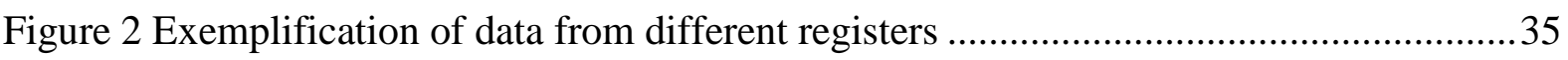

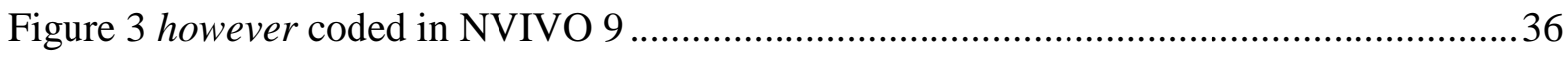

Figure 4 Concordance lines of linking adverbial but in WWC ........................................... 37

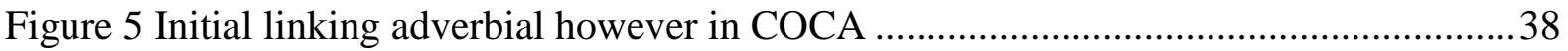

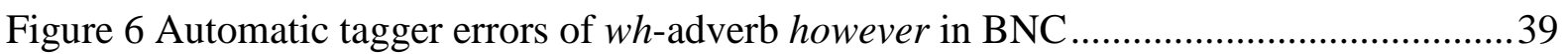

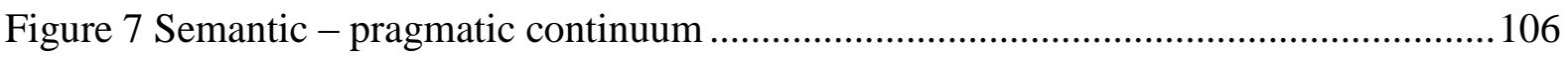




\section{Chapter 1 Introduction}

According to Halliday and Hasan (1976), linking adverbials, one type of explicit cohesive marker, play an important role in textual cohesion. Cohesion has been argued to play a positive role in ease of comprehension (McNamara, 2001; McNamara, Crossley, \& McCarthy, 2010) and facilitate coherent mental processing (Louwerse, 2001; McNamara et al., 2010).

However, applied linguistic studies (Altenberg \& Tapper, 1998; Bolton et al., 2002; Chen, 2006) have shown that second language learners have difficulty in using linking adverbials appropriately. In terms of learning linking adverbials and using them appropriately, three aspects of usage patterns are important for second language learners to understand: form, meaning and position. With teaching English for specific and academic purposes (ESP and EAP) flourishing, register-specific account of usage patterns of linking adverbials will help ESP and EAP learners understand linking adverbials and use them appropriately in different social settings.

Biber et al. (1999) is to date the only corpus-based reference grammar book which covers all three aspects of usage patterns. They analysed four registers: academic writing, fiction, news writing and conversation, but, as the book provides a very comprehensive grammar, there is not room for a detailed account of all three aspects of usage patterns of a small grammar category such as linking adverbials. They reported the overall frequency of linking adverbials and some general findings on the frequency of meanings in the four registers. For form and position, however, they reported only general frequency information in the two registers of academic prose and conversation, where they found the most frequent use of linking adverbials in their corpus.

The findings presented in Biber et al. (1999) give second language learners and teachers guidelines on the general usage patterns of linking adverbials as a grammatical category, but a more detailed account of frequency including not only the form, meaning and position of linking adverbials but also frequency of types of each form, meaning and position would give second language learners more practical guidelines on how a particular linking adverbial can be used and which types are commonly chosen to express a certain meaning in a particular social context. For convenience, 'type' in this study is used as a technical term which means different words or phrases and distinguishes itself from 'tokens' which is used to mean occurrences. For example, in addition and however are two types of linking adverbials and 
moreover and so are two types of the form of single-word adverb while 15 tokens of in addition means in addition occurs 15 times. It is the aim of this thesis to present a detailed account of usage patterns of linking adverbials in English.

Literature which has addressed linking adverbials to some extent has employed different terms. To name a few: 'linking adverbs' (Greenbaum, 1969, p. 35); 'conjunctive' (Halliday \& Hasan, 1976, p. 228); 'linking adverbials' (Biber, Conrad, \& Leech, 2002, p. 389); 'conjunctive adverbials'(Chen, 2006, p. 113); discourse markers (Bell, 2010, p. 1912). These terms do not completely overlap with each other, and this may to some extent confuse other researchers and L2 learners about what a linking adverbial is and what the relationship is between linking adverbials and other related grammatical categories which also have linking functions (e.g. conjunctions and discourse markers). Biber et al. (1999) have given a very detailed definition of linking adverbials, which is based on their analysis of three written registers: academic writing, fiction and written news, and one spoken register: conversation. In their definition, they state that linking adverbials can connect discourse of different sizes, i.e., sentences, paragraphs and units smaller than sentences. A closer examination of linking adverbials, however, particularly with more spoken data in more spoken registers, may result in new findings and more discourse features. Thus, this thesis tests the definition given by Biber et al. (1999) with not only written data but also with more data from more spoken registers.

Meaning is the only aspect of usage patterns which has been covered in all four influential descriptive English grammar books (Biber et al., 1999; Carter \& McCarthy, 2006; Huddleston \& Pullum, 2002; Quirk, 1985). They have all given a classification system based on semantic meaning. Preliminary analysis of some spoken data in this study showed that some words may have different pragmatic meanings in different contexts, however. In addition, the classification systems in previous studies are not register-specific. Thus, this thesis tests the traditional approach in previous grammar books of a classification system based on semantic meaning, and aims to work out a register-specific meaning classification system.

There are two stages in this study. Stage I is a manual analysis, since manual analysis of authentic language data can provide richer and more in-depth information than the quantitative corpus analysis which has been the focus of research to date. Linking adverbials in five registers: academic prose, academic lectures, conversation, written news and broadcast news, are manually analysed. Possible linking adverbials are identified. Form, meaning, and 
position of identified linking adverbials are coded in QSR International's NVIVO 9 software and differences between linking adverbials and other grammatical categories (e.g. conjunctions) are examined.

In total, 67 texts of a total of over 100,000 words were manually analysed. All texts were chosen from the Wellington Corpora of Written and Spoken New Zealand English (WWC and WSC), compiled by School of Linguistics and Applied Language Studies, Victoria University of Wellington, which provided coverage of the target five registers. Texts were chosen randomly from the relevant sections of the corpora.

Stage II is a corpus-based quantitative analysis. The most frequent linking adverbials in written registers identified in the first stage were automatically searched in larger corpora, i.e., the whole WWC, BNC and COCA. In the first stage, for spoken data, intonation unit was adopted as the analysis unit and sound files were needed in deciding intonation units and interpreting uses. Thus, in this second stage, automatic search for patterns in spoken data was not possible and the focus was on written data.

This study aims to answer the following research questions:

1. What is a linking adverbial in English?

1.1 What is the definition of linking adverbials?

1.2 What are the differences between linking adverbials and other related grammatical categories (e.g. conjunctions)?

2. How can linking adverbials be used?

2.1 What are the forms of linking adverbials in different registers?

2.2 How can linking adverbials be classified in terms of meaning in different registers?

2.3 What are positions of linking adverbials in different registers?

Chapter 2 contains a literature review which addresses previous key studies on linking adverbials and key terms used in this study.

Chapter 3 provides a detailed account of methodology of this study. It describes the data sources for this study and how data are analysed in this study.

Chapter 4 presents the results from Stage I and discusses the definition of linking adverbials, differences between linking adverbials and conjunctions, the difference 
between linking adverbials and circumstance adverbials and the difference between linking adverbials and stance adverbials.

Chapter 5 presents and interprets the results from Stages I and II on the form of linking adverbials in different registers. Frequency and types of the form of linking adverbials are discussed and compared within written registers (written academic prose and written news) or among spoken registers (academic lectures, conversation and broadcast news) and social settings (e.g. written academic prose and academic lectures in academic settings).

Chapter 6 presents and discusses the results from Stage I on the meaning of linking adverbials in different registers. A register-specific meaning categorization system and a semantic-pragmatic continuum is presented and discussed. Frequency of meanings in different registers is also interpreted.

Chapter 7 presents and discusses the results from Stages I and II on the position of linking adverbials in different registers. Frequency and types of the position of linking adverbials are discussed and compared within written registers or among spoken registers and social settings.

Chapter 8 draws conclusions from this study, discusses their implications for language description, teaching material design, language teaching and learning (especially in ESP and EAP contexts) and future research. 


\section{Chapter 2 Literature review}

This chapter reviews relevant literature to provide the rationale for this study. It discusses why the study of linking adverbials is important. It also reviews the previous literature on the definition and usage patterns of linking adverbials, explains a gap in the previous literature and then introduces the scope of this study.

\subsection{Why is the study of linking adverbials important?}

This necessity for and importance of this study is addressed by examining the role of linking adverbials in cohesion studies and corpus-based applied linguistic studies.

\subsubsection{Cohesion and Coherence}

In their influential book, Cohesion in English, Halliday and Hasan (1976, p. 2) wrote that texts in English, written or spoken, differ from disconnected sequences of sentences in that they have texture, 'the property of being a text'. They argued that cohesion contributes to such texture and they suggested different types of cohesive ties 'to give a systematic account of its patterns of texture' (Halliday \& Hasan, 1976, p. 4). Cohesive ties are: 'reference, substitution, ellipsis, conjunction, and lexical cohesion'(Halliday \& Hasan, 1976, p. 4). As one type of cohesive tie, conjunction distinguishes itself from others in that they are not primarily devices for reaching out into the preceding (or following) text, but they express certain meanings in which presuppose the presence of other components in the discourse' (Halliday \& Hasan, 1976, p. 226). In other words, while other cohesive ties will indicate a search for previous counterparts, conjunction devices specify the meaning relationship between two meaning units. Examples 1 and 2 below, which are taken from the WWC and WSC data sets for this study, illustrate this difference:

In Example 1, that is one type of cohesive tie, i.e., reference. It indicates a search backwards to find its counterpart, i.e., the expression it refers to.

1. // mister peters says today's superannuitants were led to believe they would be taken care of in their old age/ and that must not be changed// (WSC MSN 031, broadcast news)

In this case, that refers to Mister Peters's statement that today's superannuitants would be taken care of in their old age. 
In Example 2, I mean is another type of cohesive tie, i.e., conjunction. Instead of indicating a search backwards to find its equivalent, it indicates that the following statement has a related pre-statement.

2. I/er very big er formal biblical language/l $i$ mean he uses the word ye rather than the word you and so forth// (WSC MUL 002, academic lectures)

In this context, I mean marks the meaning relationship between two statements, i.e., the second one is an explanation of the one before it.

According to Halliday and Hasan (1976), in contexts such as Example 2, cohesion is achieved through the conjunction expression I mean, but what has the real cohesive power is the underlying semantic relation of explanation between the two statements. Thus, Halliday and Hasan (1976, p. 229) wrote that 'this explains how it is that we are often prepared to recognize the presence of a relation of this kind even when it is not expressed overtly at all'. In other words, conjunction expressions as such are one type of cohesive marker which makes explicit the conjunction relationship between two meaning units.

Linking adverbials are one type of conjunction expression, and they are the research focus of this study because, besides contributing to the texture of a text, cohesion has been argued to play a positive role in ease of comprehension (McNamara, 2001; McNamara et al., 2010). In this context, cohesion specifically refers to 'the presence or absence of cues in the text' (McNamara et al., 2010, p. 60), which should be distinguished from coherence, which may not be explicitly represented in the text. Coherence refers to 'the mental representation of the text that is created by the reader' (McNamara et al., 2010, p. 60). Generally, cohesion facilitates coherent mental processing (Louwerse, 2001; McNamara et al., 2010). Koshik (1999) has described the greater role of explicit cohesive devices in establishing coherence in certain genres such as expository writing or academic lecture, in which the abstract ideas do not always allow their audience to make full use of their background knowledge. Sanders, Land, and Mulder (2007, p. 220) have further shown that explicit markers of coherence improve text comprehension in functional contexts, i.e., "communicative situations in which readers process a text with a communicative goal that fits naturally in the context'.

\subsubsection{Second language learners' difficulty in using linking adverbials}

Linking adverbials not only have their role in texture studies and cognitive linguistics but also have aroused interest from corpus-based applied linguistic studies (e.g.Altenberg \& Tapper, 
1998; Bolton et al., 2002; Chen, 2006) because second language learners have been found to have difficulty in using linking adverbials.

The investigation of cohesive devices including reference, conjunction and lexical ties in students' writings can be traced back to 1980s (e.g.Connor, 1984; Crowhurst, 1987; Fitzgerald \& Spiegel, 1986; Khalil, 1989; McCulley, 1985; Neuner, 1987; Stotsky, 1983; Tierney \& Mosenthal, 1983), following the publication of Halliday and Hasan's Cohesion in English in 1976. In the 1990s, more and more studies have narrowed down their research focus specifically to 'connectors', i.e., linking adverbials in this study. Both experimental and corpus-based approaches have been taken. Flowerdew (2003), for example, compared ESL high school students' use of linking adverbials with native users in Hong Kong through an experimental approach. With the development of learner corpora, a corpus-based investigation of the difference of use of linking adverbials between learner corpora and native speaker corpora has been more evident. Also, as mentioned in Chapter 1, the aim of this thesis is to give a detailed account of the form, meaning and position of linking adverbials in native corpora and thus give ESL learners a practical guide on the usage patterns of linking adverbials. Thus, hereafter, I only review in detail corpus-based studies of linking adverbials in ESL contexts.

Milton and Tsang (1993) compared the use of linking adverbials in Hong Kong students' writing in a four-million-word learner corpus (now larger), the Hong Kong University of Science and Technology corpus of learner English with three native corpora: the Brown Corpus, the London Oslo/Bergen Corpus, and another self-compiled corpus of computer science textbooks. They investigated the frequency of 25 single-word linking adverbials developed from the categorization of Celce-Murcia and Larsen-Freeman (1983) and claimed that students tend to overuse linking adverbials in their writing. They qualitatively interpreted the two cases of moreover and therefore and argued that students' difficulty lay in redundant use (unnecessary) and misuse (misleading).

Granger and Tyson (1996) tested the hypothesis that French learners overuse linking adverbials in their writing by comparing the frequency of linking adverbials in a French subcorpus of the International Corpus of Learner English (ICLE) with a comparable native speaker corpus, the Louvain Corpus of Native Essay Writing (LOCNESS). They investigated 108 linking adverbials derived from the categorization suggested by Quirk (1985). Their hypothesis was not supported by their quantitative results. They found that the French learners underused some linking adverbials (e.g. however and therefore), overused linking 
adverbials such as moreover and for instance and misused linking adverbials such as anyway in writing and thus stylistics need to be noted in writing class.

Altenberg and Tapper (1998) examined the use of linking adverbials in Swedish students' writing by comparing the Swedish component of the ICLE with a control native speaker corpus consisting of 70 essays by third and fourth year students from the University of Surrey, England. Their hypothesis that advanced Swedish learners of English tend to underuse linking adverbials in their writing was supported by their quantitative results. Their further qualitative interpretation suggested that students' underuse of certain linking adverbials in formal registers also raised the importance of using linking adverbials appropriately in a certain register.

Bolton et al. (2002) examined both non-native and native speakers' use of linking adverbials in their writing. They compared the frequency of linking adverbials in data from the Hong Kong component of the International Corpus of English (ICE-HK) and the British component of the International Corpus of English (ICE-GB) with data from a subset of published academic writing in the British component of the International Corpus of English. They suggested that published academic writing provided a better control data set than native students' writing. They reported that both non-native and native learners underuse certain linking adverbials.

Chen (2006) examined the use of linking adverbials by MA students in Taiwan. The author used data from two self-compiled corpora. The learner corpus is composed of $23 \mathrm{MA}$ TESOL students' final papers and the control corpus has a selection of 10 journal articles from two top international TESOL journals. Based on the quantitative results, the author claimed that the students slightly overuse linking adverbials in their writing and the further qualitative analysis suggested that the learners use some of the linking adverbials inappropriately (e.g. therefore).

Lei (2012) is to date the most recent corpus-based study examining ESL learners' use of linking adverbials. The study investigated Chinese doctoral students' use of linking adverbials in their academic writing. The comparison is also based on two self-compiled corpora. The learner corpus contains 20 applied linguistics doctoral dissertations. The control corpus is made up of 120 journal articles in six international applied linguistics journals. The study found that the Chinese doctoral students overused and underused linking adverbials and 
misused some of the linking adverbials (e.g. besides). The most problematic linking adverbials for the doctoral students were the adversative adverbials.

In the previous literature, almost all the existing applied studies address the register of written academic prose (see reviewed studies above). Very few studies look at registers or genres outside written academic writing. Zareva (2011) is to date the only one which investigates the genre of student academic presentations.

Zareva (2011) investigated the use of linking adverbials in academic presentations given by university students, both undergraduate and graduate students, in the U.S.A. The author compiled two corpora of individual presentations. The L1 corpus contains 30,205 words and the L2 corpus 30,269 words. The author found that the two groups do not differ much in choosing linking adverbials in terms of semantic types, forms, frequency and position. In a few cases, the ESL learners overused some types and forms of linking adverbials (e.g. so) in their presentations. The author also suggested that L1 presenters should not be the model for L2 presenters but L2 learners should be made aware of some of those markers used by L1 presenters. This study also claimed that ESL presenters tend to use linking adverbials in the wrong register. They used formal linking adverbials in their oral presentation which are normally used in academic writing.

All the above-reviewed studies claim that second language learners tend to 'over/under/misuse' linking adverbials. When the terms such as 'over/under/misuse' are used in previous literature, they indicate that there is a benchmark against which the frequency of linking adverbials should be examined, but which frequency standard should be the ideal model remains a question. Besides, previous studies based their conclusions mainly on figures resulting from comparing learner corpora with native speaker corpora, but they did not make explicit how each identified linking adverbial is used or give a detailed account of where/when each linking adverbial is used.

As discussed above, the previous applied studies identified that second language users had problem with using linking adverbials but they did not give second language users practical guide on the usage patterns of linking adverbials. Despite this, some of the reviewed studies did raise the importance of register-specific use of linking adverbials (Altenberg \& Tapper, 1998; Granger \& Tyson, 1996; Zareva, 2011). Thus, this thesis will not only aim to give a detailed account of the usage patterns of linking adverbials but also will give a registerspecific discussion. 


\subsection{What is a linking adverbial?}

This section will review terms for linking adverbials and definition of linking adverbials in previous literature.

\subsubsection{Terms for linking adverbials}

The literature (referred to above), which addresses the issue of linking adverbials, adopts different terms. Examples of terms used in previous literature are: 'linking adverbs' (Greenbaum, 1969, p. 35); 'conjunctive adjuncts'(Halliday \& Hasan, 1976, p. 228); 'conjuncts'(Kennedy, 2003, p. 245); 'adverbial conjuncts'(Yeung, 2009, p. 330); 'linking adjuncts' (Carter \& McCarthy, 2006, p. 256); 'conjunctive adverbials'(Chen, 2006, p. 113); 'connectives' (Sanders et al., 2007, p. 219); 'connectors'(Bolton et al., 2002, p. 165); 'linking adverbials'(Biber et al., 1999, p. 765); discourse markers (Bell, 2010, p. 1912); pragmatic markers (Cuenca, 2008, p. 1374).

However, as mentioned in Chapter 1, the linguistic elements those terms refer to do not completely overlap with each other. Table 1 gives an example of how those terms do not overlap with each other by presenting a comparison of the linguistic elements listed by Halliday and Hasan (1976, p. 231) and Biber et al. (1999, p. 884). The left column of Table 1 lists the types of 'conjunctive adjuncts' grouped by Halliday and Hasan (1976, p. 231) who put them into two different categories of forms: adverbs and prepositional phrases. By comparison, the right column presents the types of 'linking adverbials' reported by Biber et al. (1999, p. 884) who grouped linking adverbials according to five different forms: adverbs, adverb phrases, prepositional phrases, finite clauses and non-finite clauses.

\section{Table 1 Conjunctive Adjuncts and Linking Adverbials}

\begin{tabular}{|l|l|}
\hline $\begin{array}{l}\text { Conjunctive adjuncts } \\
\text { (Halliday and Hasan (1976, p. 231) }\end{array}$ & $\begin{array}{l}\text { Linking adverbials } \\
\text { Biber et al. (1999, p. 884) }\end{array}$ \\
\hline $\begin{array}{l}\text { adverbs: but, so, then, next, accordingly, } \\
\text { subsequently, actually, therefore, } \\
\text { thereupon, whereat, furthermore, } \\
\text { nevertheless, anyway, instead, besides }\end{array}$ & $\begin{array}{l}\text { adverbs: anyway, however, nevertheless, so, } \\
\text { though, therefore }\end{array}$ \\
\hline $\begin{array}{l}\text { prepositional phrases: } \text { on the contrary, as } \\
\text { a result, in addition, as a result of that, } \\
\text { instead of that, in addition to that, in } \\
\text { spite of that, because of that }\end{array}$ & $\begin{array}{l}\text { prepositional phrases: by the way, for example, } \\
\text { in addition, in conclusion, on the other hand }\end{array}$ \\
\hline & finite clauses: that is, that is to say \\
\hline & non-finite clauses: added to that, to conclude \\
\hline
\end{tabular}


As shown in Table 1, the two sets of examples of linguistic elements included as 'conjunctive adjuncts' and 'linking adverbials' do not match each other. In a later discussion of conjunctive relations, Halliday and Hasan (1976, p. 243) present a much longer list of conjunctive expressions and include conjunctions (e.g. and, or, for, because), finite clauses (e.g. that is, I mean ) and non-finite clauses (e.g. to sum up, to resume), but they do not discuss whether they consider these expressions to be conjunctive adjuncts. This study will investigate the difference between conjunctions and conjunctive adjuncts (see Chapter 4.2), the latter being called linking adverbials in this study, and the relationship between finite clauses/non-finite clauses and linking adverbials (see Chapter 5).

The many different terms employed imply two different approaches: a structural approach and a discourse approach. A structural approach examines sentence grammar, the syntactic structure within a sentence, while a discourse approach investigates discourse grammar which explains the organizational variables at discourse level, i.e., beyond sentence structure level. In some cases, a linking adverbial may mark a meaning relationship between two clauses within one sentence but it does not form a structural link. Thus, the relationship is beyond sentence structure level and will be included in the discourse approach which the current study takes.

In consideration of the rich spoken data set which this study includes, a structural approach may not be a reliable one because sentence grammar may fail to explain various complicated issues involved in the spoken data, as sentence is not a viable analysis unit in spoken English. Thus, terms which have a strong structural implication, such as linking adverbs, conjuncts, conjunctive adjuncts, adverbial conjuncts, linking adjuncts and conjunctive adverbials, may not be a reasonable choice. Terms sitting on the fence, such as connectives and connectors, may also not be a good option because any expressions which have a connecting function can be called connectives or connectors, and that goes beyond the scope of this study.

Terms like discourse markers and pragmatic markers have strong discourse implications. According to Fraser (1996), pragmatic markers refer to those signals indicating any nonpropositional part of the sentence meaning including discourse markers, basic markers (e.g. I regret), commentary markers (e.g. frankly) and parallel markers (e.g. in god's name). In some literature, discourse markers are also a broad category which includes any signals marking the relationship between the current discourse section with the previous discourse section. This includes not only adverbials but also other word classes such as conjunctions and inserts (see also Fraser, 1998, 1999). For example, well is probably one of the most frequently 
investigated discourse markers (see Cuenca, 2008; Schourup, 2001). However, well differs from linking adverbials (e.g. so, however) in that it is more like an interjection (e.g. um) and could be a speaker's personal comment and not necessary be tied to the previous discourse unit. Linking adverbials like so or however introduce discourse units that are closely tied to previous discourse units (see also Schourup, 2001). Schourup (2001) also argues that 'so never occurs parenthetically within a clause as well does and never takes less than a full clause in its scope' (p. 1040).

However, this study focuses on adverbials, clause elements and only on ones which have a discourse cohesive function. This study also distinguishes adverbials with discourse cohesive function from other word classes (e.g. conjunctions) which also have connecting functions. By examining such differences, it aims to identify distinctive characteristics of such adverbials, which have been referred to inconsistently and confusingly in different literature, and thus to get a clearer picture of the differences between different terms and the relationships between them.

Compared with terms with strong structural implications, such as conjuncts and adjuncts, which remind readers of syntactic trees, 'adverbials' may sound fairly neutral and more familiar. Among the terms having discourse implications, the linguistic elements covered by terms such as pragmatic markers or discourse markers range beyond the scope of this study. Thus, linking adverbials has been chosen as the term to be used in this study to refer to a group of linguistic expressions which have discourse cohesive function and make explicit conjunction relationships.

\subsubsection{Definition of linking adverbials}

Having discussed the range of terms used in previous literature, we now consider in greater detail how the term linking adverbial is used in the literature, and how it will be used in this study. The definition of linking adverbials given by Biber et al. (1999, p. 765) is probably to date the most influential and inclusive one:

The third class of adverbials is linking adverbials. Linking adverbials have a more peripheral relationship with the rest of the clause than circumstance adverbials typically do. Rather than adding additional information to a clause, they serve a connective function. They make explicit the relationship between two units of discourse, as in the following examples:

1. They were kid boots at eight shillings a pair. He, however, thought them the most dainty boots in the world, and he cleaned them with as much reverence as if they had been flowers. (FICT)

2. Some hospitals use their own ethics committees to settle such cases, but a hospital's biases could creep into its committee's decisions, Ms. Yuen says. Furthermore, the 
committee's decision wouldn't be legally binding and wouldn't shield a physician from liability. (NEWS)

3. Now clearly, such semiotics are often manipulated $<\ldots>$. Nonetheless, these Latin and North American "ethno-semantics" capture an important sense in which capitalistic labor is "unproductive" in a material sense. (ACAD)

4. My objectives in this work are twofold: first, to set out a precise yet comprehensive analysis $<\ldots>(\mathrm{ACAD})$

As the above examples illustrate, linking adverbials can connect units of discourse of different sizes. The linked units may be sentences, as in $\mathbf{1}$ and $\mathbf{2}$. The units may also be larger than the sentence, as in $\mathbf{3}$ where nonetheless connects the subsequent sentence with several preceding sentences about such semiotics. Finally, 4 exemplifies a linking adverbial connecting a to-clause to the preceding main clause.

Linking adverbials can express a variety of relationships, including addition and enumeration, summation, apposition, result/inference, contrast/concession, and transition.

In this long definition of linking adverbials, Biber et al. (1999) have pointed out some key features of linking adverbials. First, linking adverbials are one category of adverbials. Second, they serve as discourse connectors, connecting units of discourse of different sizes. Third, they make explicit the relationship between two units of discourse (e.g. summation and apposition).

However, the four examples Biber et al. (1999) gave are all from written English. When they describe units of discourse, they use sentence or paragraph, which are features of written English. In their discussion of semantic roles and use of linking adverbials, they present examples from conversation, which is a spoken register. Spoken data, however, may have their own features of units of discourse which distinguish them from written English and sentence may not still be a viable analysis unit in spoken English.

In their later discussion, Biber et al. (1999) suggest another way of analysing spoken data: 'C-units' (Biber et al., 1999, p. 1069), i.e. clausal and non-clausal units. A clausal unit refers to 'a structure consisting of an independent clause together with any dependent clauses embedded within it' (Biber et al., 1999, p. 1069). Non-clausal units refer to 'segments consisting entirely or partly of non-clausal material' (Biber et al., 1999, p. 1069). Examples 3 and 4 below illustrate clausal units and non-clausal units in conversation ( $\mathrm{C}$-unit boundaries are marked by // and embedded clausal unit boundaries are marked by /):

3 C-units: clausal units // er i'm sorry / that goes on and on and on // (WSC MUL002, academic lectures)

4 C-units: non-clausal units

// um not really// (WSC DPC096, conversation) 
However, in their definition of linking adverbials, Biber et al. (1999) did not make explicit the features of units of discourse in the spoken data. Besides, conversation is the only spoken register Biber et al. (1999) have analysed, but conversation may distinguish itself from other spoken registers in terms of its usage of linking adverbials (e.g. academic lectures, broadcast news). And such differences may need to be considered and included in the definition of linking adverbials and thus make the definition more inclusive and more representative of both written and spoken English. Thus, compared with Biber et al. (1999), more spoken registers are included in this study and the adequacy of Biber et al's (1999) definition is tested in spoken registers.

As discussed above, the terms adopted in the previous literature related with linking adverbials are not uniform. Instead, they are confusing. Besides, potential new features of linking adverbials may be revealed from various spoken registers. Thus, the process of defining linking adverbials through reviewing existing theories and analysing data from both written and spoken English will facilitate the comprehension of the nature of linking adverbials and thus help distinguish linking adverbials with other related fuzzy grammatical categories and sort out the relationship among these related grammatical terms. A new definition based on both written and spoken registers may be more inclusive and thus better represent the features of linking adverbials in both written and spoken English.

However, defining linking adverbials through exploring relevant literature and analysing data is one thing and examining how linking adverbials are used is another aspect. Thus, analysis of usage patterns of linking adverbials is also important.

In the next section, the previous literature on usage patterns of linking adverbials in English will be reviewed.

\subsection{Usage patterns of linking adverbials}

This section will review what influential reference grammar books present as their perspectives on the usage patterns of linking adverbials in English.

\subsubsection{Reference grammar books on linking adverbials}

Four influential reference grammar books have described the usage of linking adverbials, though different terms have been employed: Longman grammar of spoken and written English (Biber et al., 1999); Cambridge grammar of English: a comprehensive guide: spoken and written English grammar and usage (Carter \& McCarthy, 2006); A Comprehensive grammar of the English language (Quirk, 1985); The Cambridge grammar of the English 
language (Huddleston \& Pullum, 2002). I have argued above (Chapter 1) that usage patterns can be described by form, meaning and position. Table 2 below summarizes what has been covered in each of the four grammar books.

Table 2 Coverage of form, meaning and position in the four grammar books

\begin{tabular}{|l|l|l|l|}
\hline Grammar books and terms & Form & Meaning & Position \\
\hline Biber et al. linking adverbials & $\sqrt{ }$ & $\sqrt{ }$ & $\sqrt{ }$ \\
\hline Carter \& McCarthy linking adjuncts & $\sqrt{ }$ & $\sqrt{ }$ & \\
\hline Quirk conjuncts & & $\sqrt{ }$ & \\
\hline Huddleston \& Pullum connective adjuncts & & $\sqrt{ }$ & \\
\hline
\end{tabular}

In the following sections, accounts of form, meaning and position in the four grammar books will be reviewed in turn.

\subsubsection{Reference grammar books on the form of linking adverbials}

As noted in Table 2, only two grammar books addressed the form of linking adverbials, i.e., Biber et al. (1999) and Carter and McCarthy (2006).

Carter and McCarthy (2006, p. 257) explained linking adverbials in terms of their form: "linking adjuncts are a large class which includes single-word and phrasal items"'. In their analysis, they considered linking adverbials as one large class and all the types which have only one word (e.g. again, likewise, too) are put under the category of 'single-word' and all the items which have more than one word (e.g. above all, in particular) are categorized under the term 'phrasal/clausal'.

However, whether the linking adverbial is a (word) class like conjunctions and adverbs, or a type of adverbial, a clause component, as Biber et al. (1999, p. 762) suggest, needs to be further examined (see Section 4.1.2). Furthermore, the form categorization suggested by Carter and McCarthy (2006) is very vague. As mentioned above, under the term 'phrasal/clausal', they grouped together all the items with more than one word, but which item is phrasal and which is clausal remains unclear. Their comment on frequency is also very broad. They reported the frequency of those forms in just one sentence: "most of these linking adjuncts are more frequent in formal styles and in writing, but some (marked with *) are more frequent in informal spoken contexts" (Carter \& McCarthy, 2006, p. 257). Writing can occur in academic settings and also in news settings, for example, and informal spoken contexts can mean different spoken registers such as conversation or classroom teacherstudent interactions. There may be much more variation in the use of linking adverbials in specific registers than their statement suggests. 
Compared with Carter and McCarthy (2006), Biber et al. (1999) have given a much more specific and clearer account of the forms of linking adverbials and their frequencies. They wrote that linking adverbials can be realized by five syntactic structures: single-word adverb (e.g. anyway, however), adverb phrase (e.g. even so, first and foremost), prepositional phrase (e.g. by the way, for example), finite clause (e.g. that is, that is to say) and non-finite clause (e.g. added to that, to conclude) (Biber et al., 1999, p. 884). They reported frequency findings for only two registers: academic prose and conversation, however, which they found to have the most frequent use of linking adverbials in their analysis (Biber et al., 1999, p. 884):

In both conversation and academic prose, the majority of linking adverbials are realized by single adverbs. In conversation, almost all linking adverbials are single adverbs. In academic prose, prepositional phrases are also relatively common as linking adverbials.

In this study, the form of linking adverbials is analyzed with respect to the five syntactic categories suggested by Biber et al. (1999), which are clear and specific. In order to give second language learners more practical guidelines, the frequency of the form and types of each form of linking adverbials are compared in more registers and social settings than in Biber et al. (1999) (see Chapter 5).

In the next section, stance on the meaning of linking adverbials in the four grammar books is reviewed.

\subsubsection{Reference grammar books on the meaning of linking adverbials}

Although different terms have been used, the four grammar books all agree that linking adverbials have a connective function, can conjoin discourse units of various sizes. As shown in Table 2, all four books address the issue of the meaning of linking adverbials and they all take the approach of semantic meaning which is referred to as semantic types in the four books. Table 3 below summarizes all the semantic types of linking adverbials together with types of each semantic type listed in the four grammar books.

Table 3 Semantic types of linking adverbials in the four grammar books

\begin{tabular}{|c|c|}
\hline $\begin{array}{l}\text { Grammar } \\
\text { books }\end{array}$ & Semantic types classification system \\
\hline $\begin{array}{l}\text { Biber et al. } \\
\text { linking } \\
\text { adverbials }\end{array}$ & $\begin{array}{l}\text { Enumeration and Addition } \\
\text { enumeration: first, second, lastly, for one thing, for another, } \\
\text { firstly, secondly, thirdly(etc.), in the first/second place, first of all, for one thing, for } \\
\text { another thing, to begin with, next } \\
\text { addition: in addition, further, similarly, also, by the same token, furthermore, likewise, } \\
\text { moreover } \\
\text { Summation: in sum, to conclude, all in all, in conclusion, overall, to summarize } \\
\text { Apposition: which is to say, in other words, that is, e.g., for example, for instance, } \\
\text { namely, specifically }\end{array}$ \\
\hline
\end{tabular}




\begin{tabular}{|c|c|}
\hline & $\begin{array}{l}\text { Result/inference: } \\
\text { Result: therefore, consequently, thus, so } \\
\text { Inference: then } \\
\text { Contrast/concession: } \\
\text { Contrast: } \text { on the other hand, in contrast, alternatively, conversely, instead, on the } \\
\text { contrary, in contrast, by comparison } \\
\text { Concession: though, anyway, anyhow, besides, nevertheless, still, in any case, at any } \\
\text { rate, in spite of that, after all } \\
\text { Transition: by the way, incidentally }\end{array}$ \\
\hline $\begin{array}{l}\text { Carter \& } \\
\text { McCarthy } \\
\text { linking } \\
\text { adjuncts } \\
\text { (* indicates } \\
\text { item which is } \\
\text { more } \\
\text { frequently used } \\
\text { in informal } \\
\text { spoken } \\
\text { contexts) }\end{array}$ & $\begin{array}{l}\text { Additive } \\
\text { single-word: again, correspondingly, likewise, also, equally, moreover, besides, } \\
\text { furthermore, too } \\
\text { phrasal/clausal: above all, in particular, to crown it all*, as well*, on top of it all*, } \\
\text { what's more*/what is more, in addition, to cap it all* } \\
\text { Resultative } \\
\text { single-word: accordingly, so, therefore, consequently, then, thus, hence } \\
\text { phrasal/clausal: as a consequence, as a result, of course } \\
\text { Contrastive } \\
\text { single-word: alternatively, otherwise, rather, instead } \\
\text { phrasal/clausal: in/by comparison, more accurately/more precisely, on the other hand, } \\
\text { in /by contrast, on the contrary, then again* } \\
\text { Time } \\
\text { single-word: afterwards, meanwhile, subsequently, eventually, originally, then, } \\
\text { meanwhile* } \\
\text { phrasal/clausal: after that, in the meanwhile } \\
\text { Concessive } \\
\text { single-word: admittedly, however, still, anyhow*, nevertheless, though, anyway, } \\
\text { nonetheless, yet, besides, only* } \\
\text { phrasal/clausal: after all, for all that, mind you*, all the same, in any case, of course, } \\
\text { at any rate, in any event, on the other hand, at the same time, in spite of that, that said } \\
\text { Inference } \\
\text { single-word: otherwise, then* } \\
\text { phrasal: in that case } \\
\text { Summative } \\
\text { single-word: altogether, so, therefore, overall, then, thus } \\
\text { phrasal: all in all, in sum, to sum up, in conclusion, in summary, to summarize, in } \\
\text { short, to conclude } \\
\text { Listing } \\
\text { single-word: a,b,c, etc., first(ly)/second(ly)/third(ly), etc., next, finally, lastly, one, two, } \\
\text { three, etc., then } \\
\text { phrasal/clausal: first of all, in the first place/in the second place, on the one hand...on } \\
\text { the other hand, for one thing...for another thing, last of all, to begin with/to start with } \\
\text { Meta-textual } \\
\text { single-word: incidentally, namely, well*, indeed, now } \\
\text { phrasal/clausal: by the way*, in other words, that is, for example, or rather, that is to } \\
\text { say, for instance, so to speak, to put it another way }\end{array}$ \\
\hline $\begin{array}{l}\text { Huddleston \& } \\
\text { Pullum } \\
\text { connective } \\
\text { adjuncts }\end{array}$ & $\begin{array}{l}\text { Types of pure connectives } \\
\text { (a) Ordering : first, firstly, in the first place, first of all, for a start, for one thing, } \\
\text { on the one hand, second, secondly, in the second place, second of all(AmE), } \\
\text { on the other hand, third,..., for another(thing), next, then, finally, last, lastly, } \\
\text { last of all, in conclusion } \\
\text { (b) Addition and comparison(likeness and contrast): alternatively, by contrast, } \\
\text { also, besides, conversely, either, equally, further(more), however, in addition, } \\
\text { in comparison, instead, likewise, moreover, neither, nor, on the contrary, } \\
\text { rather, similarly, too } \\
\text { (c) Elaboration and exemplification: for example, for instance, in other words, } \\
\text { more precisely, that is(to say), }\end{array}$ \\
\hline
\end{tabular}




\begin{tabular}{|c|c|c|}
\hline & \multicolumn{2}{|c|}{$\begin{array}{l}\text { (d) Markers of informational status: by the way, incidentally, parenthetically } \\
\text { Impure connectives } \\
\text { (i) Concession: nevertheless, nonetheless, still, though, yet } \\
\text { (ii) Condition: anyway, in that case, otherwise, then } \\
\text { (iii) Reason/Result: accordingly, as a result, consequently, hence, in } \\
\text { consequence, so, therefore, thus }\end{array}$} \\
\hline $\begin{array}{l}\text { Quirk } \\
\text { conjuncts }\end{array}$ & $\begin{array}{l} \\
\text { Summa } \\
\text { followin } \\
\text { summar } \\
\text { Apposit } \\
\text { words, } \\
\text { (often a } \\
\text { specificc } \\
\text { Resulti } \\
\text { thus }<\text { for } \\
\text { Inferen } \\
\text { Contras } \\
\text { (i) } \\
\text { (ii) } \\
\text { (iii) }\end{array}$ & 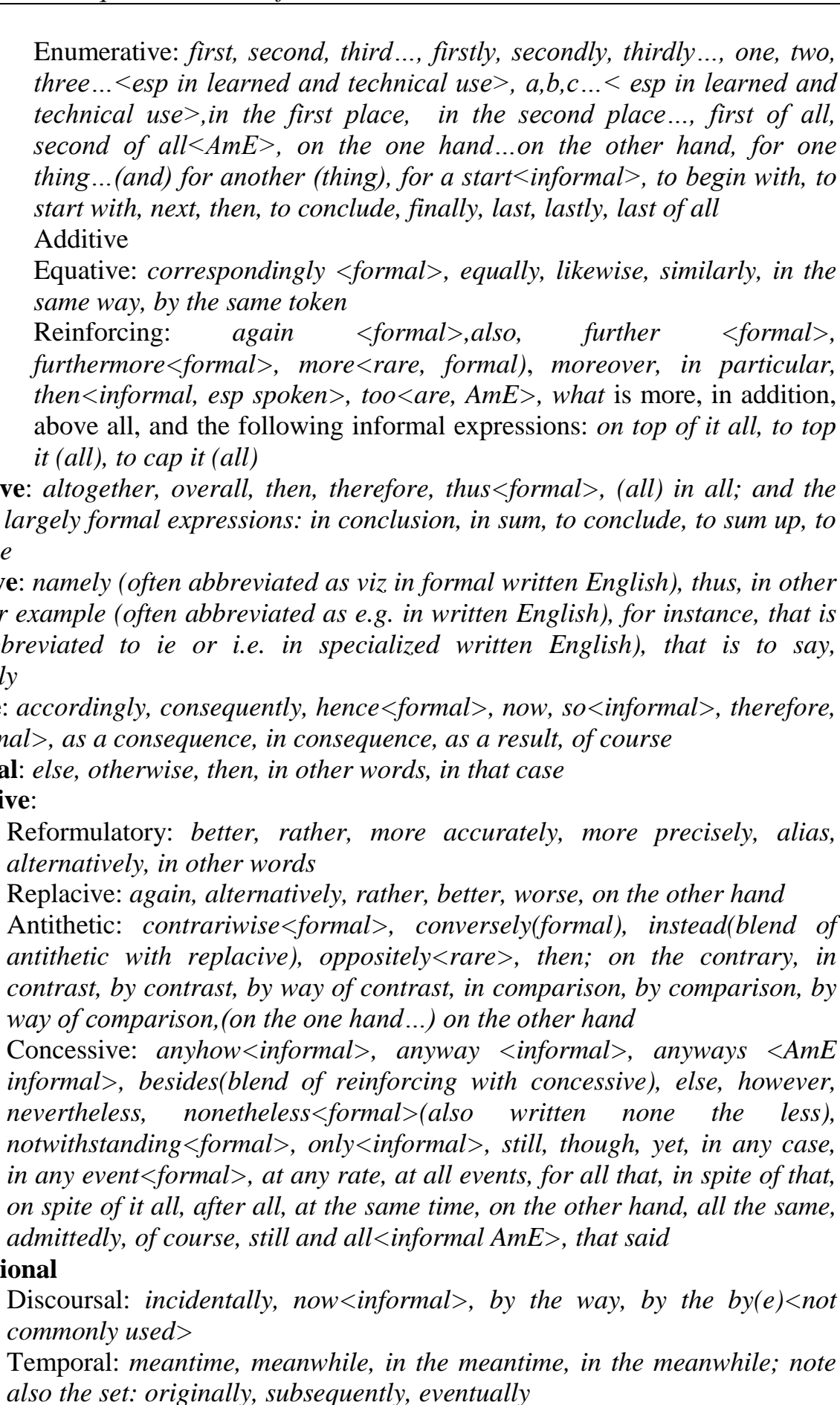 \\
\hline
\end{tabular}

As shown in Table 3 above, the books organise semantic types in different ways. Carter and McCarthy (2006) organise semantic types in a parallel way, one by one in separate categories. Huddleston and Pullum (2002) also organise them in parallel, but they squeeze some 
semantic types into a single category. For example, they put addition and comparison (likeness and contrast) in one category without making explicit which linking adverbials mark the semantic type of addition and which ones mark the semantic type of likeness or contrast.

Biber et al. (1999) and Quirk (1985) have a more hierarchical organization than Carter and McCarthy (2006) and Huddleston and Pullum (2002). They group semantic types, which they consider related, under one general category. In Carter and McCarthy (2006), for example, the semantic types of listing (enumeration) and additive (addition) are presented in two separate categories, i.e., in a parallel way. In Biber et al. (1999), however, the two semantic types of listing (enumeration) and additive (addition), are first presented under one general title 'enumeration and addition', and then subdivided into two sub-categories of 'enumeration' and 'addition' and linking adverbials of each sub-category are presented respectively.

Quirk (1985) suggests a further finer hierarchical system than Biber et al. (1999) do. In Quirk (1985), the semantic type 'contrastive' is subdivided into four smaller categories: 'reformulatory', 'replacive', 'antithetic' and 'concessive' while in Biber et al. (1999), it is only subdivided into two smaller categories: 'contrast' and 'concession'.

While the four grammar books' outlines of semantic types and their possible linking adverbials are valuable, the authors do not make space to give convincing reasons why these different semantic types should be grouped together or presented separately. Ways of presenting may influence second language learners' understanding of the semantic types, especially when they do not have enough prior knowledge of the usage of linking adverbials of the semantic types. Alternatively and by contrast, for example, are both listed under the semantic type of addition and comparison (likeness and contrast). Learners may get confused when trying to figure out which linking adverbial is an appropriate one to use to express addition or comparison. Thus, in this sense, the more specific and detailed the meaning categorization system is, the more helpful it may be for second language learners.

The semantic types listed above in Table 3 also appear to differ in different grammar books with respect to the names given to semantic types and their categories. Table 4 has been developed from Table 3 and shows similarities and overlaps among the categories in a clearer way. The semantic types which have the same or similar meanings are presented together with their names as used in different grammar books. Enumeration, ordering and listing, for example, all mean to number ideas, steps, etc. and thus they are listed together with their 
terms used in all grammar books. Then a check list shows whether each meaning is covered in each grammar book.

Table 4 Summary of semantic types of LAs in the four grammar books

\begin{tabular}{|l|l|l|l|l|}
\hline & $\begin{array}{l}\text { Biber } \\
\text { et.al }\end{array}$ & Quirk & $\begin{array}{l}\text { Huddleson } \\
\text { and Pullum }\end{array}$ & $\begin{array}{l}\text { Carter and } \\
\text { McCarthy }\end{array}$ \\
\hline Enumeration/ordering/listing & $\sqrt{ }$ & $\sqrt{ }$ & $\sqrt{ }$ & $\sqrt{ }$ \\
\hline Addition/additive & $\sqrt{ }$ & $\sqrt{ }$ & $\sqrt{ }$ & $\sqrt{ }$ \\
\hline Summation/summative & $\sqrt{ }$ & $\sqrt{ }$ & & $\sqrt{ }$ \\
\hline $\begin{array}{l}\text { Apposition/appositive/elaboration } \\
\text { and exemplification }\end{array}$ & $\sqrt{ }$ & $\sqrt{ }$ & $\sqrt{ }$ & \\
\hline Result/resultative & $\sqrt{ }$ & $\sqrt{ }$ & $\sqrt{ }$ & $\sqrt{ }$ \\
\hline Inference/inferential/condition & $\sqrt{ }$ & $\sqrt{ }$ & $\sqrt{ }$ & $\sqrt{ }$ \\
\hline Contrast/contrastive & $\sqrt{ }$ & $\sqrt{ }$ & $\sqrt{ }$ & $\sqrt{ }$ \\
\hline Concession/concessive & $\sqrt{ }$ & $\sqrt{ }$ & $\sqrt{ }$ & $\sqrt{ }$ \\
\hline Time/temporal & & $\sqrt{ }$ & & $\sqrt{ }$ \\
\hline $\begin{array}{l}\text { Transition/meta- } \\
\text { textual/discoursal/markers of } \\
\text { informational status }\end{array}$ & $\sqrt{ }$ & $\sqrt{ }$ & $\sqrt{ }$ & \\
\hline
\end{tabular}

As we saw in Table 4, although they use different names for semantic types, the four grammar books agree on eight semantic types: listing, addition, apposition, result, inference, contrast, concession and transition. The eight categories are used as the base meaning categories in the current study and they are tested in the five registers in order to investigate whether they appear in all five registers and whether they are inclusive enough for all five registers, especially spoken registers.

Three semantic types are not universally agreed upon by the four grammar books: summation, apposition and time. In Carter and McCarthy (2006), linguistic expressions, which are considered to mark meaning relationship of apposition in other three grammar books, are grouped as meta-textual markers. The semantic type of summation listed in the other three grammar books is totally absent in Huddleston and Pullum (2002). The semantic type of time listed in Quirk (1985) and Carter and McCarthy (2006) has been considered as circumstance adverbials in Biber et al. (1999, p. 796) and Huddleston and Pullum (2002, p. 698).

Huddleston and Pullum (2002) include neither and nor in their list of pure connectives of addition and comparison, but they are considered to be subordinators by others (e.g.Halliday \& Hasan, 1976). Whether these words are circumstance adverbials, subordinators or linking adverbials may depend on the context(s) in which they are used. They may behave differently in spoken registers from in written registers, for example. Thus, a closer examination of the behaviour of linking adverbials of different meaning categories in more registers, especially 
more spoken registers which as mentioned are overlooked in previous studies, may result in a more comprehensive account of the use of linking adverbials in different registers and a more convincing list of types of linking adverbials in different meaning categories.

Carter and McCarthy (2006) and Quirk (1985) in their systems gave very brief information on which linking adverbials of certain semantic types are more frequently used in written and spoken English. As mentioned in Section 2.3.1.1, there are different written registers (e.g. written academic prose, news and fiction) in written English as there are also in spoken English (e.g. conversation and academic lectures). Whether the meaning of linking adverbials is different in different written or spoken registers still remains a question. Thus, a registerspecific framework of meaning categorization may give a clearer and more detailed account of the meaning of linking adverbials and the usage of linking adverbials of different meaning categories in more specific social contexts. This may give second language learners and teachers, especially in the context of English for specific purposes, more concrete guidelines to follow.

While the four grammar books discussed above mention spoken English, they do not draw on a manual analysis of a large amount of spoken data from different spoken registers and may have overlooked some features that are unique to spoken English and even to different spoken registers. Examples 5 and 6 below are from the spoken data set of this study and illustrate different meanings of linking adverbial $s o$ in different contexts in academic lectures. In example 5 so carries the meaning of result.

5. I/i thought ten seemed too good to be truel/ so we reduced it to eight // (WSC MUL029, academic lectures)

As mentioned above, result is one of the eight common semantic types in the four grammar books, which means that the meaning of result can be accounted for in each of the system presented in Table 3.

In Example 6 below, however, so appears at the beginning of a lecture, and it does not carry the meaning of result. Instead, it functions as a discourse initiator.

6. I/ so first of all a brief history of past attempts at captive breeding // (WSC MULO11, first utterance in an academic lecture)

The systems of meaning presented in Table 3 do not have a category which can account for the usage of so in Example 6. Examples 5 and 6 are both from the register of academic lectures, which indicates that the same word form so can carry totally different meanings in 
different linguistic contexts in the same register. In other words, the same word form may have more than one meaning. Thus, a careful manual analysis of more data from different contexts in the same register or different registers may unveil a new picture of the meaning patterns of linking adverbials. Here, it also raises the question of whether the meaning categorizations based only on semantic types can account for linking adverbial usage in different registers, especially spoken ones which tend to be underinvestigated in previous studies.

When we probe into the meaning of a linguistic item, we refer to either its semantic meaning or pragmatic meaning. How to distinguish between the two types of meaning, however, remains notoriously difficult (Ariel, 2010; Huang, 2007). Bach (1999) claimed that the dichotomy between semantics and pragmatics runs into trouble with linking adverbials since these 'are linguistic expressions whose conventional meaning is closely associated with use' (Huang, 2007, p. 213). If you think of a particular linking adverbial out of context, however, you are likely to associate a particular meaning with it, sometimes strongly. Consider the following examples of linking adverbials out of context:

\section{A. moreover, in addition, besides}

\section{B. however, nevertheless}

We tend to associate a meaning of adding more information with words from group A, and we may expect some additional statement coming after those words. We may also associate the meaning of adversative with words from group B and expect something contrary to your expectation following those words.

Huang (2007) claimed that linking adverbials have conventional implicatures whose meanings are conventionally attached and are not cancellable, i.e., they are 'attached by convention to particular lexical items or linguistic constructions' (Huang, 2007, p. 56) and 'are therefore an arbitrary part of meaning and must be learned ad hoc'(Huang, 2007, p. 56), However, corpus data show that some linking adverbials can carry different meanings in different contexts (see Example 5 and 6 above). In this study, context is taken to include different linguistic environments within the same register and also different linguistic environments from different registers.

Therefore, in this research, meaning is investigated both semantically and pragmatically, i.e. meaning in null context and meaning in context (within the same register and across the registers). The meaning of linking adverbials in both written and spoken registers is examined 
and a register-specific account of the frequency of each meaning category and types of different meaning categories are given. On that basis, a register-specific meaning categorization based on both semantic and pragmatic approach is suggested (see Chapter 6).

In the next section, whether and how the four grammar books account for the position of linking adverbials is reviewed.

\subsubsection{Reference grammar books on the position of linking adverbials}

As shown in Table 2, Biber et al. (1999) is the only one of the four grammar books to touch on the issue of the position of linking adverbials. Biber et al. (1999, pp. 890-891) wrote:

In both conversation and academic prose, the most common position for linking adverbials is initial. In conversation final position is the second most common position; medial positions are very rare. In academic prose, medial positions account for the second highest proportion of occurrences; final position is rare.

Thus, Biber et al. (1999) have reported their corpus findings of the position of linking adverbials in the two registers of conversation and written academic prose. This makes available to language learners some general information on the different patterns in the position of linking adverbials in two registers. But an account of the frequency of the position of linking adverbials in more registers and the frequency of occurrence of particular linking adverbials in each position would give second language learners more comprehensive and practical guidelines on positioning different linking adverbials in different registers. Also, when identifying the positions, the authors use the terms 'initial', 'medial' and 'final' but they do not make explicit whether these are in a clause, a sentence or some other unit of analysis. Thus, this study aims to clarify and develop all these issues regarding positioning (See Chapter 7).

In the next section, register-specific studies of linking adverbials are reviewed.

\subsubsection{Register-specific account of linking adverbials}

Biber et al. (1999) and Liu (2008) are to date the only two studies which have done influential work on register-specific accounts of linking adverbials. Table 5 compares the two studies and summarizes their corpus findings. 
Table 5 Comparison of Biber et al. (1999) and Liu (2008)

\begin{tabular}{|c|c|c|}
\hline $\begin{array}{l}\text { Register- } \\
\text { specific } \\
\text { studies }\end{array}$ & $\begin{array}{l}\text { Biber et al. (1999) } \\
\text { linking adverbials }\end{array}$ & $\begin{array}{l}\text { Liu (2008) } \\
\text { linking adverbials }\end{array}$ \\
\hline Corpus & $\begin{array}{l}\text { LSWE-Longman Spoken and Written } \\
\text { English Corpus }\end{array}$ & BNC- British National Corpus \\
\hline $\begin{array}{l}\text { Registers } \\
\text { analysed }\end{array}$ & $\begin{array}{l}\text { academic writing } \\
\text { fiction } \\
\text { news writing } \\
\text { conversation }\end{array}$ & $\begin{array}{l}\text { academic writing } \\
\text { fiction } \\
\text { news writing } \\
\text { spoken English } \\
\text { other writings }\end{array}$ \\
\hline \multirow[t]{2}{*}{$\begin{array}{l}\text { Corpus } \\
\text { findings }\end{array}$} & $\begin{array}{l}\text { Overall frequency } \\
\text { Linking adverbials are } \\
\text { considerably more common in } \\
\text { conversation and academic } \\
\text { prose than in fiction and news. }\end{array}$ & $\begin{array}{l}\text { Overall frequency } \\
\text { Similar findings to Biber et al. } \\
\text { (1999) } \\
\text { - Academic writing and } \\
\text { speaking boast substantially } \\
\text { more use of LAs than the } \\
\text { other registers while news } \\
\text { has the smallest number of } \\
\text { such items. } \\
\text { New findings } \\
\text { 'Other writings' uses more } \\
\text { LAs than news and fiction } \\
\text { but fewer than academic } \\
\text { writing and speaking. }\end{array}$ \\
\hline & $\begin{array}{l}\text { Semantic types (comparison among } \\
\text { all the four registers) } \\
\text { - Academic prose and } \\
\text { conversation are also similar in } \\
\text { having a large proportion of } \\
\text { their linking adverbials in the } \\
\text { semantic category of } \\
\text { result/inference. } \\
\text { - Academic prose } \\
\text { enumerative/addictive/summativ } \\
\text { e and appositional adverbials } \\
\text { more commonly than the other } \\
\text { registers. } \\
\text { Conversation, fiction, and } \\
\text { academic prose share a similar } \\
\text { level of frequency of } \\
\text { contrast/concession adverbials, } \\
\text { which are less common in news. } \\
\text { Transition adverbials are rare in } \\
\text { all registers. }\end{array}$ & $\begin{array}{l}\text { Semantic types } \\
\text { Similar findings to Biber et al. } \\
\text { (1999) } \\
\text { - News has the smallest } \\
\text { number of linking adverbials } \\
\text { of the } \\
\text { concessive/contrastive) type. } \\
\text { - Academic writing in the } \\
\text { BNC uses many more } \\
\text { additive LAs than the other } \\
\text { registers. } \\
\text { Transitional LAs in the BNC } \\
\text { constitute the smallest } \\
\text { subcategory of all. } \\
\text { New findings } \\
\text { - Use of sequential LAs in } \\
\text { fiction is the highest of all } \\
\text { the registers. } \\
\text { Use of additive LAs in news } \\
\text { is higher than that in } \\
\text { speaking and fiction. } \\
\text { - Use of the sequential LAs in } \\
\text { news is comparable to that in } \\
\text { academic writing. }\end{array}$ \\
\hline
\end{tabular}




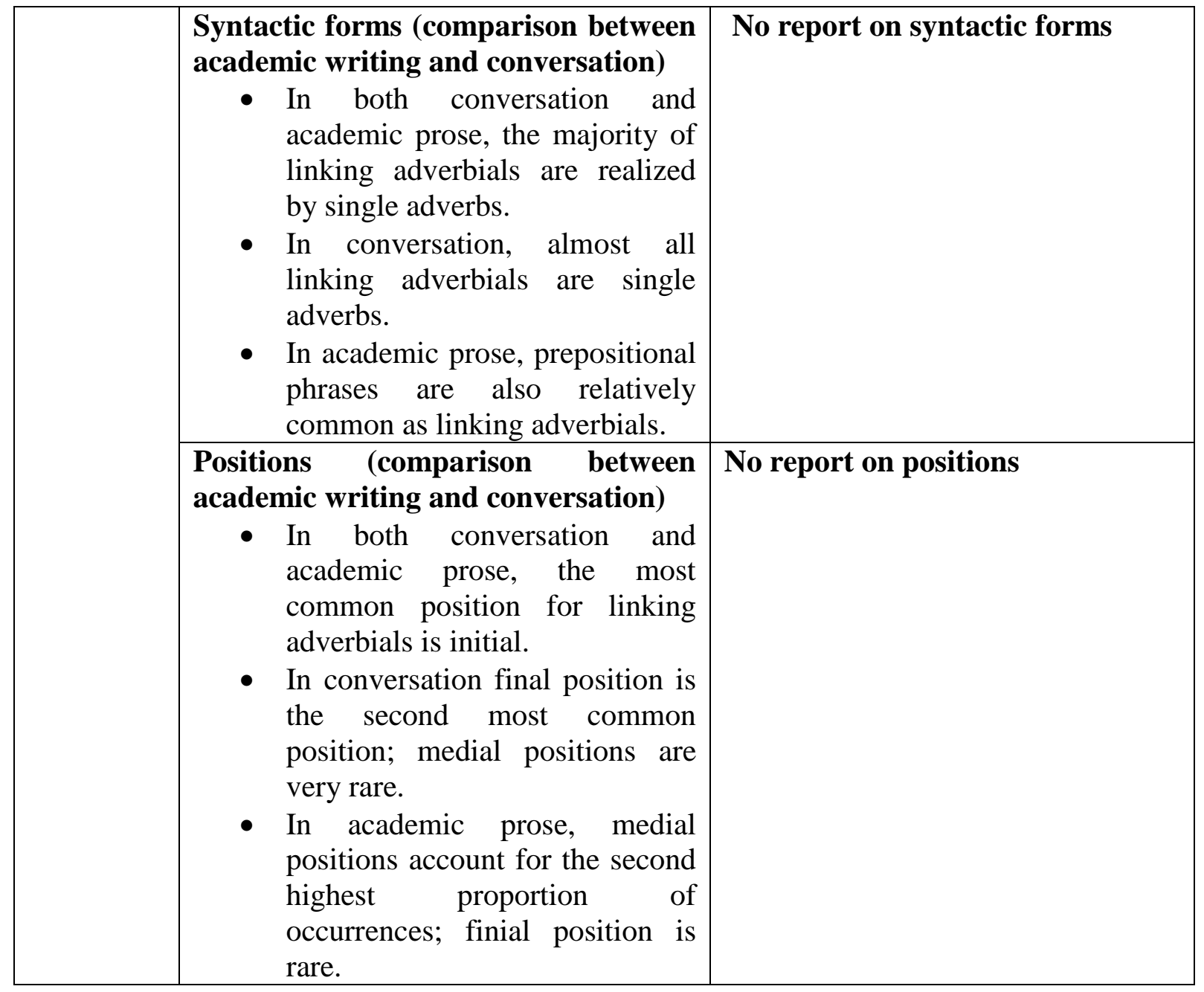

As shown in Table 5, both studies have a more elaborated discussion of written registers than of spoken. Biber et al. (1999) only analysed conversation and Liu (2008) analysed all spoken language as one spoken register. The frequency patterns may be different when more spoken registers are added and a comparison among different spoken registers (e.g. conversation and academic lectures) may initially fill the gap in accounting for the behaviour of linking adverbials in more spoken registers and give second language learners guidelines on the usage patterns of linking adverbials in both written and spoken registers and thus better suit their needs in different social settings.

The new findings identified by Liu (2008) in the two registers of news and fiction which are the common registers investigated by Liu (2008) and Biber et al. (1999) may be due to two reasons: a. different corpus has been searched; b. different semantic type systems were employed. This indicates that a new set of corpus data may yield new findings.

In this chapter, the important role of linking adverbials in providing cohesion and their difficulties for second language learners have justified the importance and necessity of the 
current study. An intention to sort out the fuzzy and confusing related grammatical categories and explore the potential new features from more spoken registers has shaped the scope of this study, i.e., what is a linking adverbial and how to use them appropriately in different registers.

In the next Chapter, the methodology of this study is presented. Chapter 3 will introduce the research design, the data source and how the data are analysed in this study. 


\section{Chapter 3 Methodology}

In order to investigate what linking adverbials are and how they are used, both qualitative and quantitative analyses have been carried out. This chapter will report the research design, the data sources and how the data were collected and analysed.

\subsection{Research design}

As set out in Chapter 1, two research questions will be answered in this study. For convenience, they are repeated here:

1. What is a linking adverbial in English?

1.1 What is the definition of linking adverbials?

1.2 What are the differences between linking adverbials and other related grammatical categories (e.g. conjunctions)?

2. How can linking adverbials be used?

2.1 What are the forms of linking adverbials in different registers?

2.2 How can linking adverbials be classified in terms of meaning in different registers?

2.3 What are positions of linking adverbials in different registers?

The two research questions were investigated in two stages.

$\underline{\text { Stage I Manual analysis }}$

In order to investigate what linking adverbials are and their differences from other related grammatical categories, a closer look at their behaviour in the linguistic context is needed. Qualitative analysis of authentic language data can provide richer and more in-depth data than quantitative corpus analysis which, as noted in Chapter 2.3, has been the focus of descriptive research to date, though some have included qualitative interpretations. Thus, in the first stage, a manual analysis was carried out.

Preliminary answers to the first research question were developed through a review of the literature. Then manual analysis of corpora data was carried out. Manual analysis provided fuller answers to the first research question and also answered question 2.

Five registers, i.e. academic prose, academic lectures, conversation, written news and broadcast news, were analysed. Since it would be too difficult and time-consuming to 
analyse all varieties grammatically' (Biber et al., 1999, p. 15), four major registers have been the focus of previous studies, namely, conversation, fiction, news and academic prose, which are argued to be 'important, highly productive varieties of the language and different enough from one another to represent a wide range of variation' (Biber et al., 1999, p. 16).

The registers included in this study are different from analysed registers in Biber et al. (1999), i.e., academic prose, conversation, written news and fiction. Academic lectures and broadcast news were added because they allow comparison between spoken and written English within academic and news contexts. Fiction was excluded because it usually includes dialogues (written representations of conversations) along with narratives and descriptive texts.

The five registers were chosen as the target analysis registers also because they are familiar to and necessary for many second language learners. They are all closely related with their daily lives, tertiary studies and future jobs as language users for specific purposes (e.g. journalists).

\section{$\underline{\text { Stage II Corpus-based studies }}$}

In order to test the generalisability of some findings of this study, results gained from manual analysis of small corpora (stage I) were checked against larger corpora. Thus, in stage II, the most frequent linking adverbials in written registers identified in the first stage were automatically searched in larger corpora, i.e., the whole WWC, BNC and COCA. In this study, for the spoken data, the intonation unit was adopted as the analysis unit and sound files are needed in deciding intonation units. Thus, at this stage, an automatic search for patterns in spoken data is not possible.

\subsection{Data sources in this study}

In this study, two stages of data collection were carried out. The two stages for data collection will be reported respectively in Section 3.2.1 and Section 3.2.2.

\subsubsection{Wellington Corpora of New Zealand Spoken and Written English (WWC \& WSC)}

In this section, how the data is collected for Stage I, manual analysis of data from Wellington Corpora of New Zealand Spoken and Written English, is explained.

\subsubsection{Rationale for choosing WWC and WSC}

The data sources for Stage I, the manual analysis, are the Wellington Corpora of Spoken and Written New Zealand English, which provide coverage of the target five registers. Holmes, Vine, and Johnson (1998, p. 11) introduced the two corpora as follows: 
One million words of written New Zealand English collected from writings published in the years 1986 to 1990. The WWC has the same basic categories as the Brown Corpus of written American English (1961) and the Lancaster-Oslo-Bergen corpus (LOB) of written British English (1961). The corpus also parallels the structure of the Macquarie Corpus of written Australian English (1986). The WWC consists of 2,000 word excerpts on a variety of topics. Text categories include press material, religious texts, skills, trades and hobbies, popular lore, biography, scholarly writing and fiction.

One million words of spoken New Zealand English were collected in the years 1988 to 1994. Ninety nine percent of the data (545 out of 551 extracts) was collected in the years 1990 to 1994. Of the eight remaining files, four were collected in 1988 (4 oral history interviews) and four in 1989 (4 social dialect interviews). The WSC was formerly known as A Computerised Corpus of English in New Zealand (ACCENZ). The corpus consists of 2,000 word extracts (where possible) and comprises different proportions of formal, semiformal and informal speech. Both monologue and dialogue categories are included and there is broadcast as well as private material collected in a range of settings.

Both the written and spoken corpora are collections of contemporary New Zealand English and are one-million words in size. They were designed to be representative of New Zealand English as a variety. They thus allow further understanding of that variety and also facilitate comparison with other English varieties such as British and American English. Whether the usage of linking adverbials differs much in different English varieties is to some extent examined in stage two of this study.

The written and spoken corpora are also clearly divided into sub-corpora according to different registers. The one-million word spoken corpus, for example, is further divided into sub-corpora of broadcast news, conversation and academic lectures, parliament debate, dialect interview, etc. Such divisions into specific registers are not as well-presented in other popular larger corpora like British National Corpus (BNC) and Corpus of Contemporary America (COCA). Thus, a register-specific qualitative analysis of linking adverbials based on BNC and COCA is not as viable at this stage as it is for the New Zealand corpora.

WSC was chosen as a data source in this study because it offers rich data from different spoken registers, and especially informal conversation. Holmes et al. (1998, p. 6) commented that $75 \%$ of the WSC material is informal dialogue, 'an unusually high proportion for any corpus' and that 'many of the world's spoken English corpora are dominated by broadcast material'. As mentioned in Chapter 1, an analysis of more spoken registers will contribute to further understanding of the functions and behaviours of linking adverbials in English and their difference from written English. WSC was chosen also because of the accessibility of its sound files which is necessary in analysing spoken features. Its coverage of all the three target registers is also another important factor influencing this choice (see Section 3.1 for reasons of choosing the three spoken registers). The coverage of all the three registers of 
conversation, broadcast news and academic lectures is not available in any other general corpus or any specialized spoken corpus such as Michigan Corpus of Academic Spoken English.

\subsubsection{Data selection from WWC and WSC}

Though they are small corpora by today's standards, the WWC and WSC are still far too large for manual analysis. Thus, random sampling from target registers was done to select manageable data sets.

Data from the five above-mentioned registers were selected from the relevant sections of WWC and WSC corpora. In the selection process, both random sampling and variable controlling elements were considered. For registers which have a much smaller number of words, the whole sub-corpus was included to have a comparable size of data set. For registers which have larger sub-corpora, random sampling of the texts was carried out. For example, if there are one hundred numbered texts in a certain register, a random sample of the texts was selected. Texts collected in the corpora are extracts from original sources and the size of each text in each register is similar. Texts in the five registers except broadcast news are all around 2,000 words and texts in broadcast news are around 1,000 words.

The whole data selection followed a series of steps. It started from the sub-corpus of academic lectures, which contains the smallest number (14) of texts in WWC and WSC and thus provided the most restricted range to select from. Table 6 below represents what was available in the sub-corpus of academic lectures. Information in bold represents what was chosen for the corpus for this study.

Table 6 Subjects and gender information in the sub-corpus of academic lectures

\begin{tabular}{|c|c|c|c|}
\hline Subjects & Number of texts & Gender of speakers & $\begin{array}{c}\text { Number of words } \\
\text { (chosen texts) }\end{array}$ \\
\hline law & 5 & 1 female, 4 males & MUL005: 2,082 \\
\hline literary criticism & 1 & male & MUL002: 2,044 \\
\hline sociology & 1 & female & MUL003: 2,249 \\
\hline $\begin{array}{c}\text { technology and } \\
\text { engineering }\end{array}$ & 1 & male & MUL013: 2,322 \\
\hline natural science & 1 & female & MUL011: 2,282 \\
\hline math and computing & 1 & male & MUL007: 2,116 \\
\hline education & 2 & 2 females & $\begin{array}{c}\text { MUL025: 2,370 } \\
\text { MUL030: 2,168 }\end{array}$ \\
\hline history & 1 & male & MUL024: 2,334 \\
\hline linguistics & 1 & male & MUL005: 2,082 \\
\hline Total & 14 & 14 & $\mathbf{2 2 , 0 4 9}$ \\
\hline
\end{tabular}


Academic lecture texts can be subdivided into 9 categories according to the subjects they belong to. The subject of law was overrepresented when compared to other subjects. Thus, only one text was chosen in consideration of the balance of the number of text in each subject. MUL005 was chosen because it was the only one in the five law lectures that was delivered by a female, which also to a large extent balanced gender differences among selected data. Both education lectures were kept, also for the reason of gender balance. The chosen academic lecture extracts total 22,049 words. Thus, the number of 20,000 provided a benchmark for other registers for comparability.

The second step in data selection was to select texts from the register of academic written prose, which was the written counterpart of academic lectures. In WWC, academic written prose is referred to as learned and scientific writings and that section of the corpus includes both journal articles and book extracts. Journal articles were selected rather than book extracts because they are comparable with academic lectures in that they are relatively concise. Journal articles were only chosen from the nine subjects which were identified in the sub-corpus of academic lectures because my preliminary analysis had shown that topic might have an effect on the occurrence of linking adverbials. The number of extracts chosen from each sub-register was thus identical with the register of academic lecture as shown in Table 6 above. The ten chosen journal article extracts total 20,128 words.

The third step was to choose texts from the register of broadcast news, which included both radio and TV news. TV news was excluded because it differed from radio news in that it contained non-verbal features (e.g. facial expressions, body movements) which may influence the interpretation of the target analysis. In order to meet the benchmark of 20,000 words, the full sub-corpus of radio broadcast news was selected, a total of 21,623 words.

The fourth step was to choose texts from the register of written news. Biber and Conrad (2009, p. 124) consider newspaper writing as a general register which could be divided into sub-registers of news report, editorials, letters to the editor and reviews. Thus, texts were only chosen from the category of news reportage because they were most comparable with broadcast news. Ten texts were randomly chosen from daily newspapers in the category of reportage with a constraint that no more than two were from one source. The number of words totals 21,001 . 
The final step was to choose from the register of conversation which does not have a comparable written data set. Texts were chosen randomly from the section of conversation. The Nine chosen texts total 21,279 words.

The entire selected data resulted in 67 texts totalling 106,080 words.

\subsubsection{British National Corpus and Corpus of Contemporary American English}

The data source for quantitative analysis at Stage II was web-based British National Corpus (BNC) and the Corpus of Contemporary American English (COCA) interfaces, developed by Brigham Young University Professor Mark Davies. The web-based BNC and COCA interfaces allowed a register-based search of a particular linguistic item but the researcher can have access only to a small amount of the surrounding linguistic context of the particular items being searched. This limited the observation of the behaviours of linking adverbials as discourse cohesive devices when not enough surrounding linguistic context was available. The most frequent linking adverbials identified in WWC samples were examined in BNC and COCA to investigate the frequency difference or difference of usage patterns in larger corpora and among different English varieties.

\subsection{Data analysis in this study}

As mentioned above, there were two stages of analysis in this study: 1. Manual analysis; 2 . Automatic web-based search. Data collected for Stage I is for manual analysis which is reported in Section 3.3.1. Data source for Stage II is for quantitative analysis which is discussed in Section 3.3.2. The ways the data were analysed in the two stages are reported in this section.

\subsubsection{Manual analysis of WWC and WSC samples}

In this section, unit of analysis and software for manual analysis are explained.

\subsubsection{Unit of analysis}

As mentioned above, both written and spoken data were analysed. In written data the sentence as indicated by writers' use of punctuation to mark sentence boundaries was used as the analysis unit. While there is variation in how writers use punctuation, I have taken their punctuation as an indicator of their intent to signal where sentences begin and end. In my preliminary analysis, I found that punctuation has an effect on identifying multi-functional words (e.g. so) as linking adverbials or conjunctions (see Chapter 4.2) and that linking adverbials can mark meaning relationships at different discourse levels including clause, 
sentence and beyond sentence levels (see Chapter 7.1) while conjunctions can only provide links within sentences.

The sentence, however, is not a viable analysis unit for spoken data since you cannot decide what constitutes a sentence based on punctuation as you do in a written text. The intonation unit was used in this study as the analysis unit in spoken data, but intonation units were not identified in a technical way with special instruments as in most phonology studies. Instead, it was decided that they would be identified from a hearer's perspective for the nature of this research. After a survey of spontaneous spoken texts in a variety of languages, Mithun (1988, p. 332) found that:

A survey of spontaneous spoken texts in a variety of languages indicates that coordination is normally signalled intonationally in two principle ways, whether overt conjunctions are present or not. Coordinate constituents may be combined with no intonation break, or they may be separated by 'comma intonation', usually a pause and a special non-final pitch contour. These two patterns characterize conjoined noun phrases and predicates as well as conjoined clauses.

My preliminary analysis has also shown that intonation units could be a viable indicator of a linking adverbial, and that and which comes after a period intonation may be a linking adverbial. There were some criteria in identifying a comma intonation and a period intonation. The first was that in clear-cut cases, a comma intonation was marked when there was a short pause and sometimes there was a rising pitch indicating something else was coming along (especially in broadcast news). A period intonation was marked when there was a long pause and there was a falling pitch.

Figure 1 shows where comma intonation and period intonation are marked in NVIVO 9. Comma intonation was marked by / and period intonation was marked by //. 
Figure 1 Comma intonations and period intonations in NVIVO 9

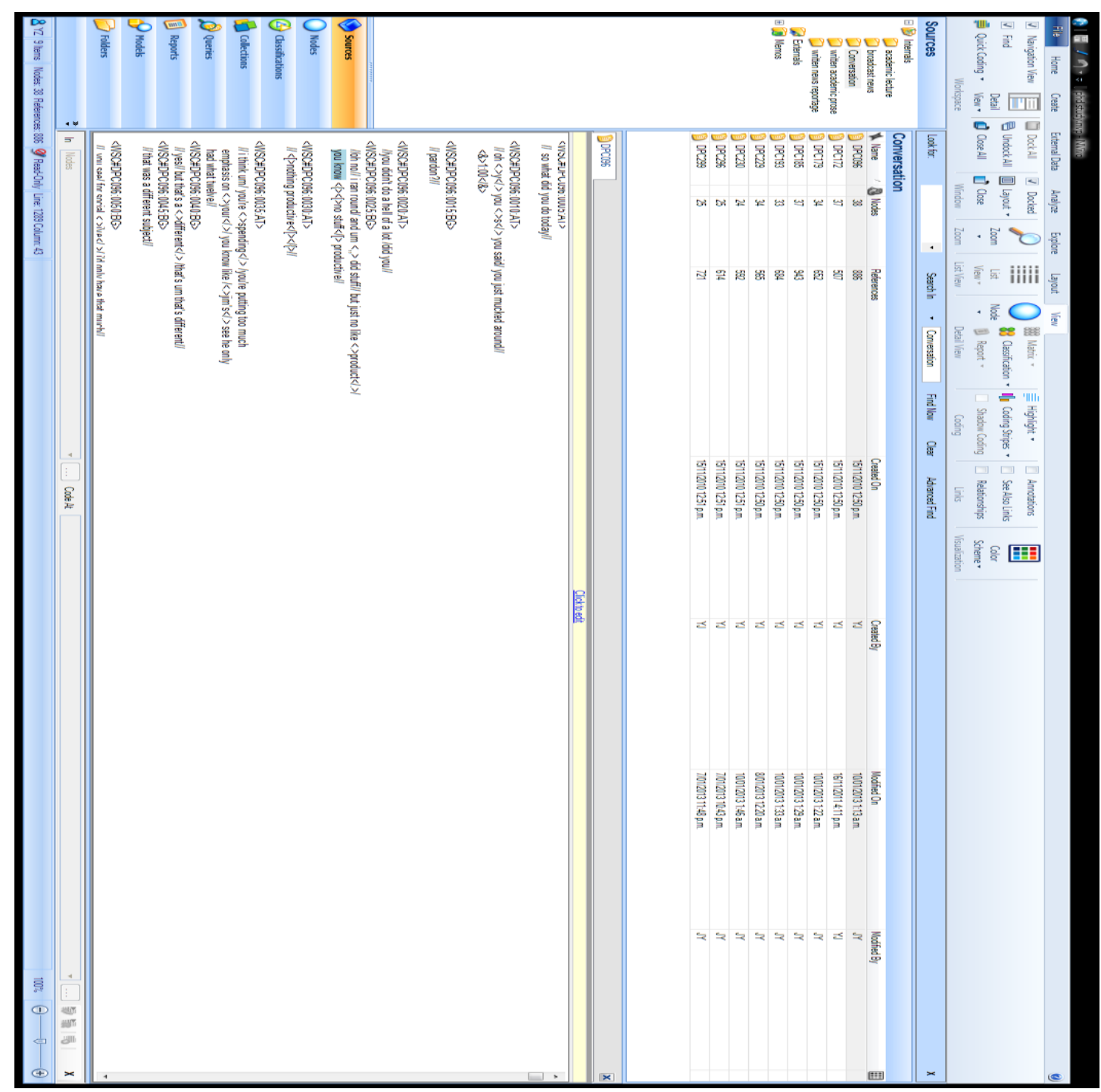

However, a special feature of New Zealand English is that in many cases speakers end an intonation unit in a rising pitch, especially in conversation. In cases where it was hard to decide between comma and period intonation, repeated listenings led to a decision as to whether or not the message was complete. If it was, a period intonation was marked. If not, a comma intonation was marked. Agreement was reached on problematic items during supervision meetings.

\subsubsection{NVIVO 9}

The sample of 67 texts from WWC and WSC of a total of over 100,000 words was manually analysed. QSR International's NVIVO 9 software was used for storing and coding the data. All the selected data was imported into NVIVO 9 according to different registers. This allowed automatic search of a particular coding within the same or among different registers 
using the Query function of NVIVO 9 software, which allowed comparison within and among registers. Figure 2 below exemplifies how the data were stored in NVIVO 9. The left column shows the five target registers: academic lectures, broadcast news, conversation, written academic prose and written news. The right column presents the ten academic lectures selected in the register of academic lectures, with their original text number in the WSC.

\section{Figure 2 Exemplification of data from different registers}

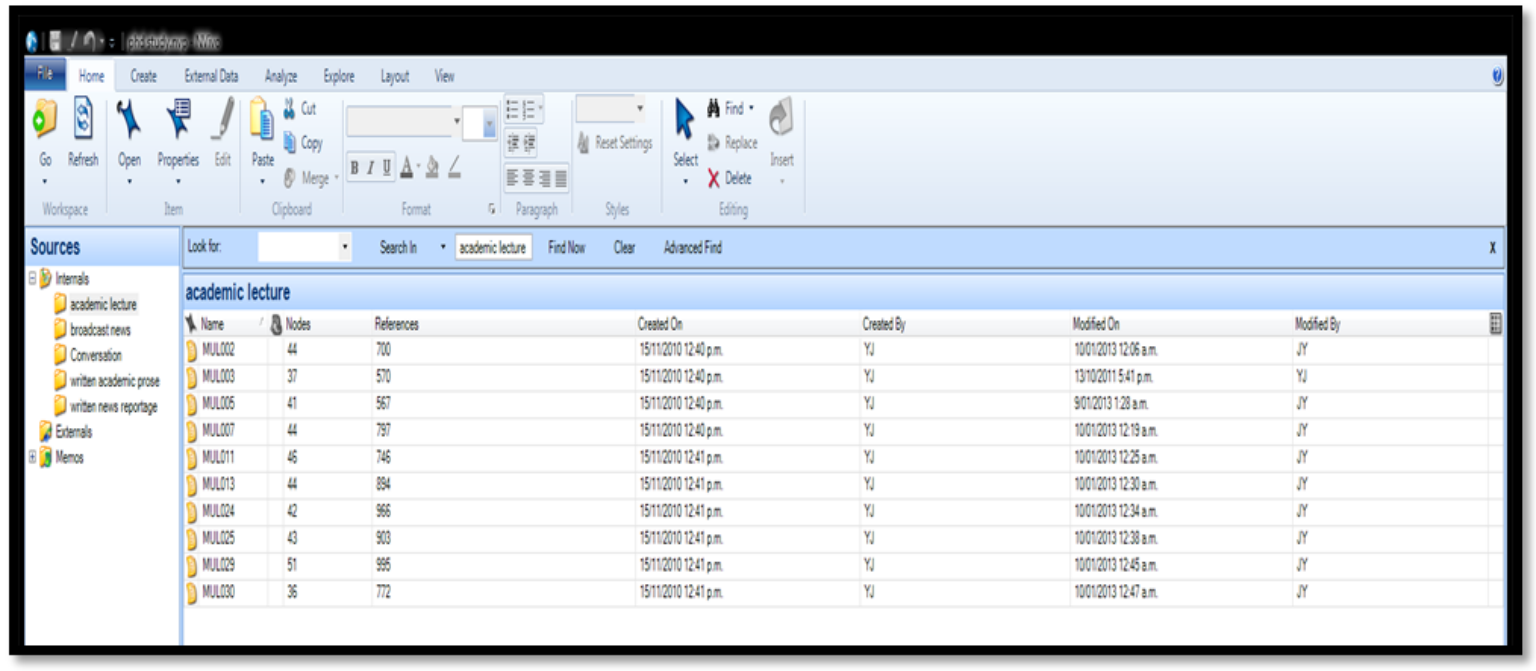

Each linking adverbial was coded using the coding function of NVIVO software. Once a linking adverbial was identified, it was highlighted and coded as a linking adverbial and its form, meaning and position in the analysis unit were also coded. Figure 3 shows how however in the line of A03 012 in the Text A3 in the written news register was coded. The coded bar on the bottom right column shows its features: a linking adverbial; a single-word adverb (form); initial position in a sentence (position) and adversative (meaning). 


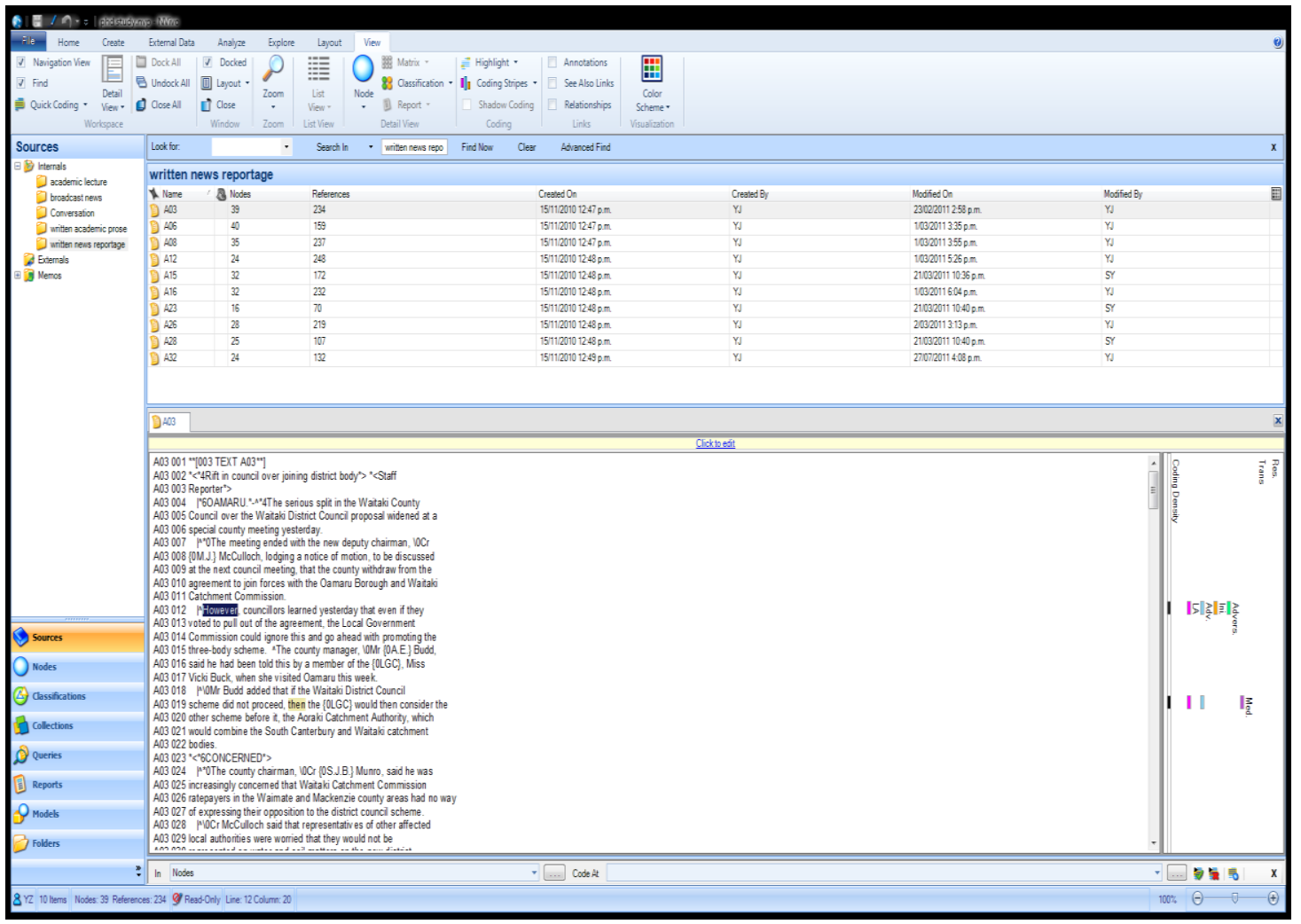

\subsubsection{Automatic software and web-based corpora search}

Stage II of this study was based on the findings from Stage I. Only the most frequent three linking adverbials identified in the WWC samples in Stage I were examined in larger corpora: the whole WWC, BNC and COCA. As mentioned in Section 3.1, using intonation unit as the analysis unit and the unavailability of sound files in BNC and COCA made automatic search of linking adverbials in spoken data in larger corpora not viable.

For the three investigated aspects of usage patterns in this study, i.e., form, meaning and position, only the two aspects of the form and position of the most frequent three linking adverbials identified in the WWC samples were searched and compared in larger corpora. This on the one hand was because for the meaning of linking adverbials, a new pragmatic approach, i.e., meaning in context, was adopted in this study. In larger corpora such as BNC and COCA, meanings were not as carefully coded. On the other hand, part of this study was to develop a meaning categorization system based on the manual analysis of WWC and WSC samples in which a new list of meaning categories was developed. The meaning system adopted to automatically tag the BNC and COCA, was different from the one in this study, which is based on pragmatic analysis and register-specific. These made automatic search of 
meaning difficult and the result of such search not as meaningful as the one with the two aspects of form and position.

Wordsmith 5.0 (Scott, 2008) was used to do a search in the whole WWC of the form and position of the most frequent three linking adverbials identified in WWC samples. Figure 4 below exemplifies the output of the automatic search of but as a linking adverbial in the register of written academic prose in the whole WWC with Wordsmith 5.0.

\section{Figure 4 Concordance lines of linking adverbial but in WWC}

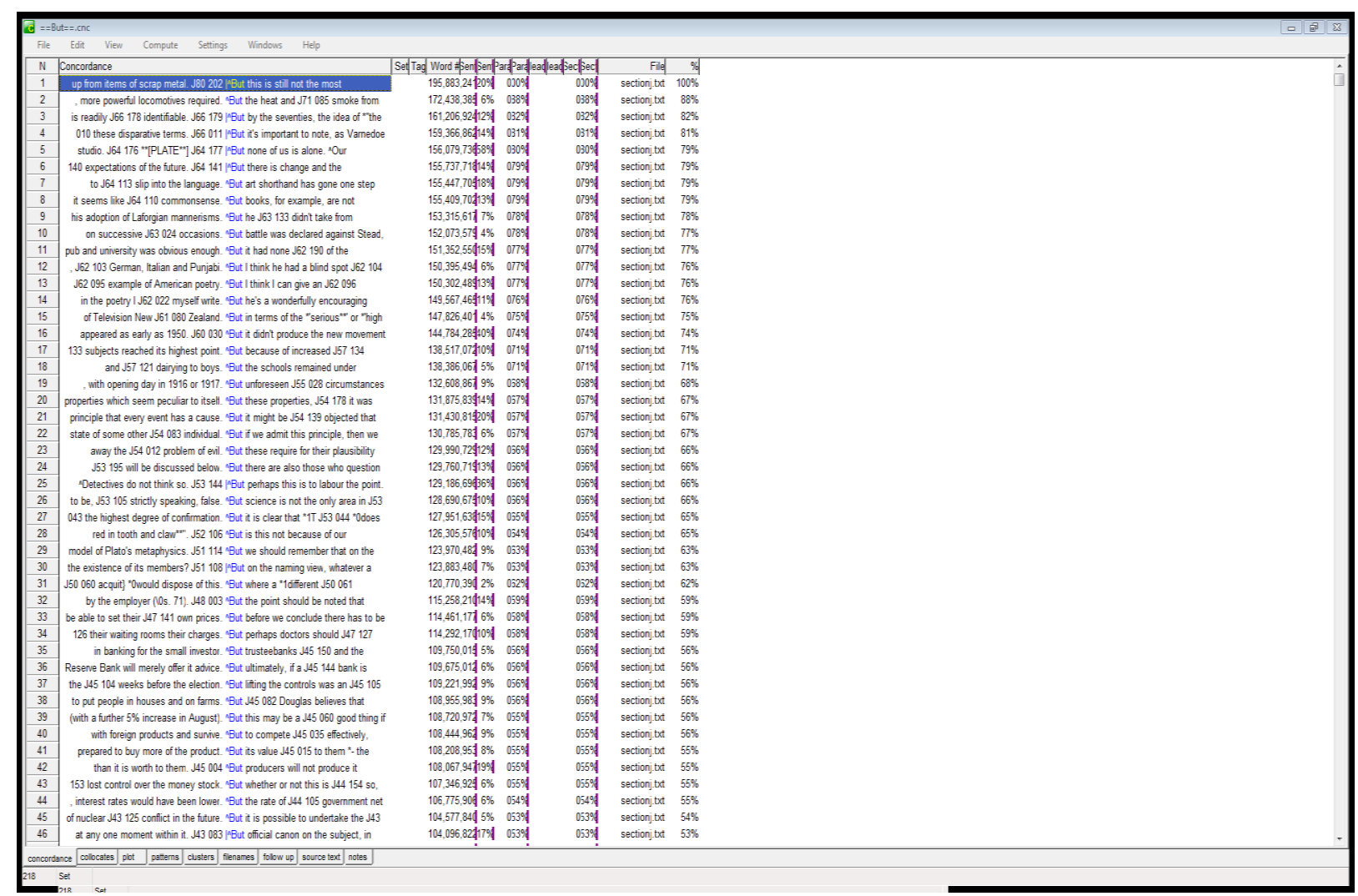

Brigham Young University web interfaces of BNC and COCA were used to do automatic search and compare the frequency of the form and position of the three most frequent linking adverbials in BNC and COCA. Special syntax was used to search for a particular linking adverbial in a particular position. Figure 5 exemplifies the special syntax used in the search and the result of the automatic search of the occurrences of linking adverbial however in initial position of a sentence in the register of written academic prose in COCA. 


\section{Figure 5 Initial linking adverbial however in COCA}

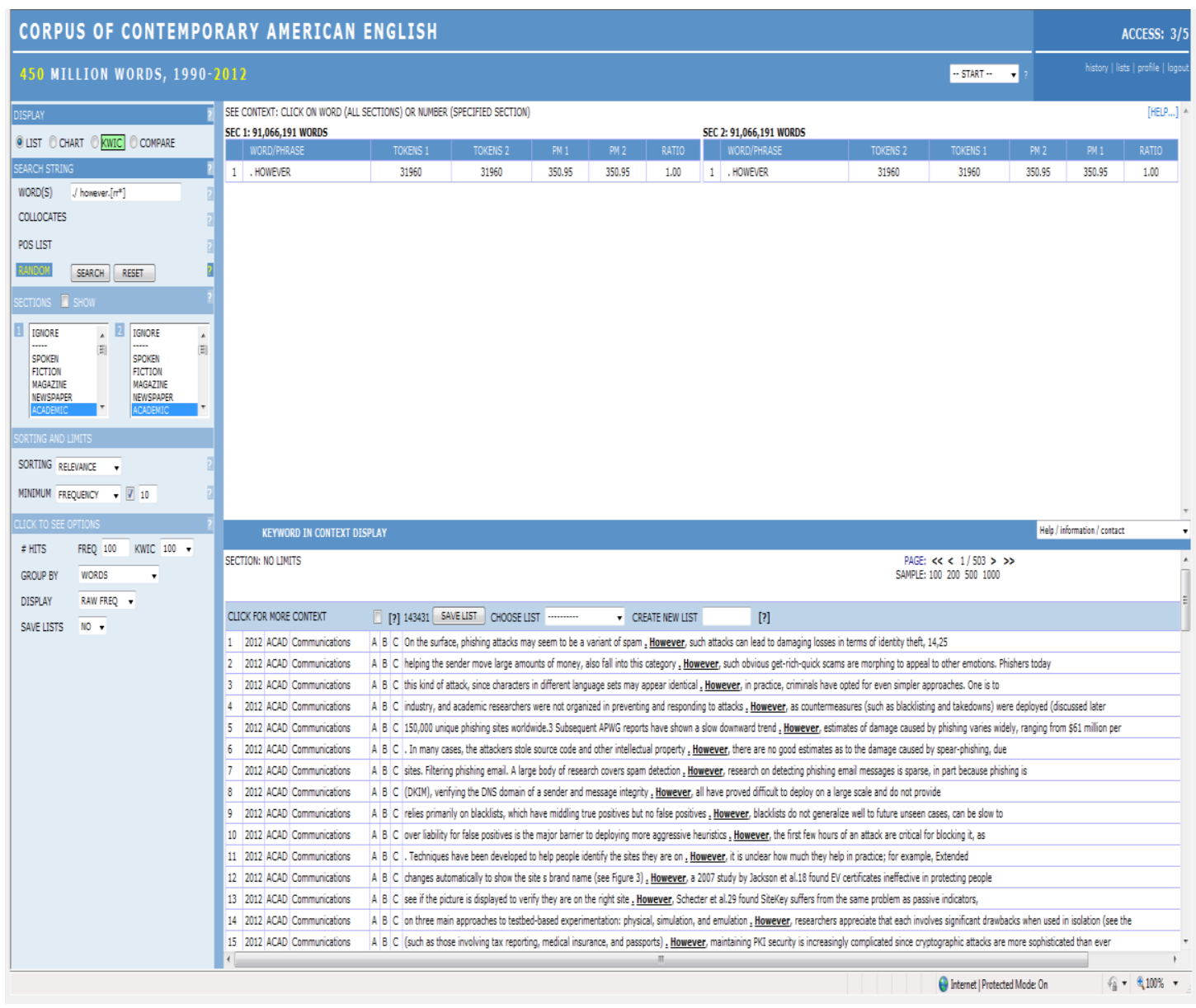

In BNC and COCA, however was automatically tagged as two categories: general adverb and $w h$-adverb. Their general adverb category is what is referred to as linking adverbials in this study. Wh-adverb however is used before an adjective or an adverb to mean 'no matter how', and is not relevant here.

As shown in Figure 5, the top left column shows the syntax (./ however.[rr*]) used to narrow the search for initial position linking adverbial however. ./ however means any however that comes after a full stop, which is in initial position in this context. however.[r**] means a search of the word form however and it is only used as a general adverb, linking adverbial, in this context. But this only indicates a tendency of however used as a linking adverbial since many errors were evident in the automatic tagging. Figure 6 presents the output of search of however used as a wh-adverb in written academic prose in BNC and exemplifies the evidence of such errors (17 errors out of a random sample of 20 entries). 
Figure 6 Automatic tagger errors of $w h$-adverb however in $\mathrm{BNC}$

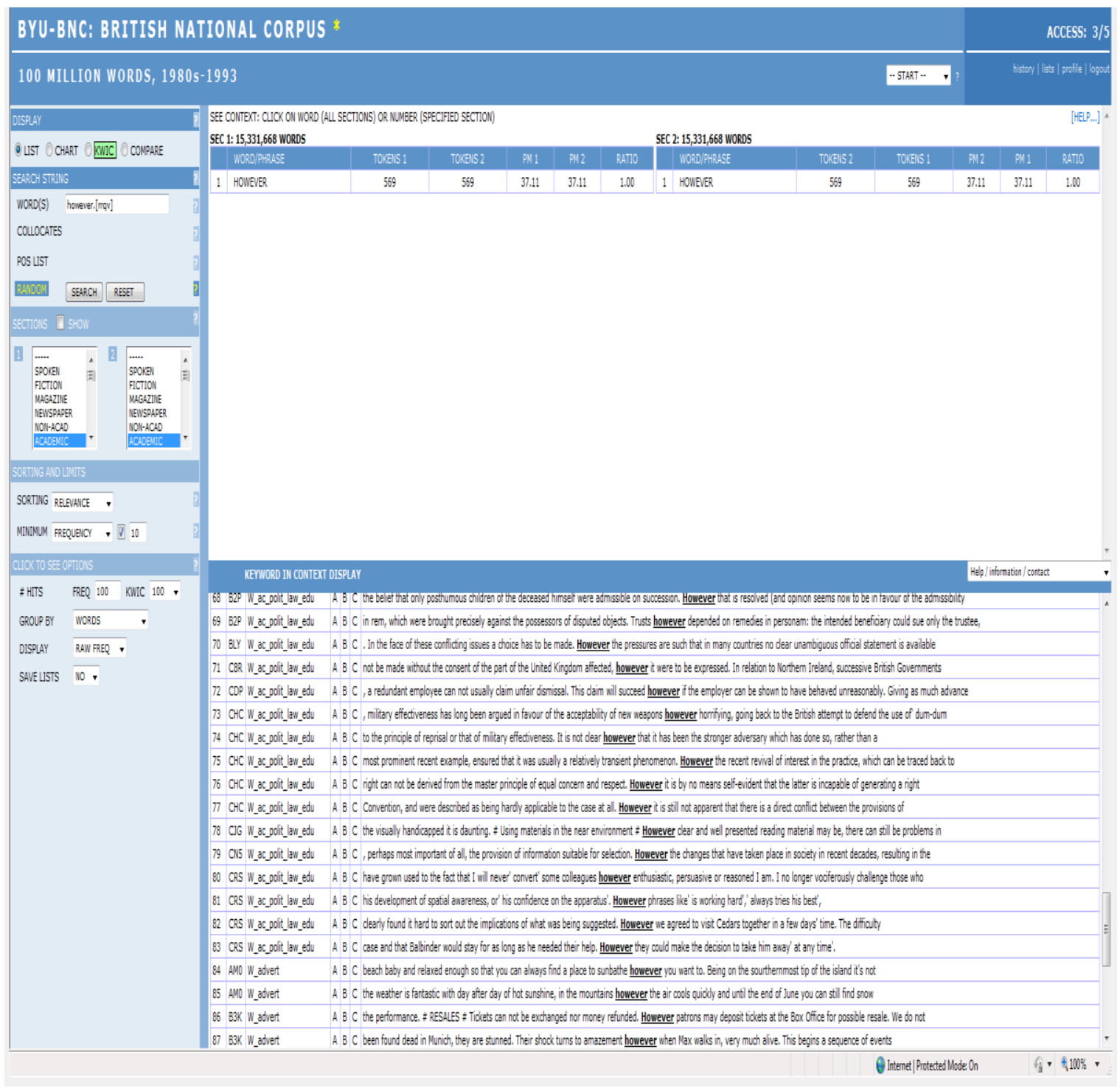

As shown in Figure 6, in many cases, the word form however tagged as wh-adverb in the BNC is actually a linking adverbial. This further indicates that the importance and necessity of a careful manual analysis in describing the usage patterns of grammar items.

\subsubsection{Log-likelihood statistics}

In this study, raw frequencies of some identified linking adverbials were very low and comparisons between a smaller corpus and a much larger one were needed (see Chapter 3.1). Log-likelihood was thus preferred to chi-squared statistics to test the statistical significance of research findings since 'chi-squared value becomes unreliable when the expected frequency is less than 5 and possibly overestimates with high frequency words and when comparing a relative small corpus to a much larger one' (Rayson and Garside, 2000, p. 2). The online loglikelihood calculator provided by Paul Rayson, Lancaster University 
(http://ucrel.lancs.ac.uk/llwizard.html) was used to do the statistical analyses for it provided comparisons between two corpora, a smaller corpus to a larger corpus or two roughly equal corpora, which suited the comparison needs of this study. Comparisons between two variables (e.g. initial vs medial) were preferred to comparisons among three variables (initial vs medial vs final) because comparisons among more than two 'makes the results more difficult to interpret' (Rayson and Garside, 2000, p. 1).

Chapter 3 has reported the methodology of this study. There were two stages in this study. In Stage I, the form, meaning and position of identified linking adverbials were manually coded in NVIVO 9. The sentence was used as the analysis unit in written registers while the intonation unit was used as the analysis unit in spoken registers. In stage II, Wordsmith 5.0 searches in the whole WWC and web-based searches in the BNC and COCA of the usage patterns of the most frequently identified linking adverbials in Stage I were carried out. Loglikelihood test was used to test the statistical significance of the expected frequencies. In the following Chapters 4, 5, 6 and 7, results gained using the methodology presented here are reported and discussed. 


\section{Chapter 4 What is a linking adverbial?}

In this Chapter, the question of what a linking adverbial is is answered by defining linking adverbials and explaining the key components of my proposed definition, the difference between linking adverbials and conjunctions and the difference between linking adverbials and other adverbial categories. An overview of the overall frequency of linking adverbials in the five registers is also given.

\subsection{Definition of linking adverbials}

As mentioned in Chapter 2.2.1, there are many terms which are used to refer to a group of words and phrases which appear to fulfil the function in English grammar of connecting, and there is some confusion about whether and to what extent these terms overlap with each other. Thus, the questions of what a linking adverbial is and how to distinguish this particular group of words and phrases from other categories which also to some extent have similar functions (e.g. conjunctions and discourse markers) are important not only in understanding the scope of this study but also in sorting out the messy relations among different terms in previous literature. Based on my data analysis and drawing on findings from previous literature on structural linguistics, descriptive grammar, discourse studies and pragmatic studies, this section will discuss the definition of linking adverbials that I propose, clearly present the key components of understanding it and justify the difference of the definition in this study from previous literature and the reasons of giving such definition.

\subsubsection{Definition}

The definition of linking adverbial that I propose is:

As clause components, linking adverbials are adverbials, as their name suggests. In terms of their pragmatic functions, they are also a subcategory of discourse markers. Their main function is as a discourse cohesive device rather than a structural link. They are explicit markers of different meaning relationships at various discourse levels in both written and spoken English: within a sentence (or intonation unit in spoken English), between sentences (or intonation units in spoken English), and between paragraphs (or sets of intonation units in spoken English).

\subsubsection{Key components of the definition of linking adverbials}

The above definition of linking adverbials has the following five key components: 


\section{Linking adverbials are adverbials in terms of their grammatical functions.}

Greenbaum (1969, p. 1) argued that in contemporary English, adverbials have 'the functions of those constituents of a clause that are not Subject, Verb, or Complement'. Greenbaum (1969) did not make explicit the meaning of 'Complement'. In some literature, there is a distinction between an object and a complement (e.g. Kennedy, 2003). Kennedy (2003, p. 114) wrote that the major constituents in a clause are 'subject, predicate, object, complement, adverbial'. An object is a noun phrase which follows a verb answering the question (what? or whom?) after the verb while a complement is a noun phrase or an adjective phrase following a copular verb and refers back to the subject (Kennedy, 2003, pp. 116-117). In this study, an adverbial means a clause component which is not subject, verb, object or complement. Biber et al. (1999, p. 763) wrote as follows:

Adverbials can be divided into three major classes by their functions: circumstance adverbial, stance adverbial, and linking adverbials. Although each class is an element of a clause, the classes differ in the extent to which they are integrated into the clause structure and the amount of variability in the precise functions of the class.

Examples 7 and 8 below separately exemplify how a linking adverbial as a clause element is identified in written and spoken English. In example 7, a finite clause that is is used in written academic prose. It is part of a clause, but it is not a subject, a verb or a complement.

7. The particular sections of the Public Utilities Act under consideration were enacted for the benefit of the public; that is, on grounds of public policy in the general sense. (WWC J50, written academic prose)

In this sentence, the subject is The particular sections of the Public Utilities Act under consideration. The verb is were enacted in passive voice. There are three adverbials in this sentence: for the benefit of the public, that is, and on grounds of public policy in the general sense.

Different from other the two adverbials, which add content meaning to the sentence, that is in this case connects two circumstance adverbials and makes explicit the meaning relationship between the two circumstance adverbials without adding significant content to the meaning of the sentence (See key component 2 below for further discussion on pragmatic functions of linking adverbials and Chapter 4.3 for detailed discussion on the difference between circumstance adverbials and linking adverbials).

In example 8, the prepositional phrase in addition is used in an academic lecture. It is part of a clause, but it is not a subject, a verb or a complement. 
8. //they were completely unrelated to them//in addition/ they said they had no intention. of being partners// the court didn't consider/ they had any intention of being partners at all// (WSC MUL005, academic lectures)

In this case, in the intonation unit in addition belongs to, the subject is they (See Chapter 3.2.1 for detailed discussion on intonation units). The verb is said. The object is they had no. intention of being partners. Connecting the current intonation unit with the previous one and making explicit the meaning relationship between the two intonation units, in addition is an adverbial loosely attached to the clause 'they said they had no intention of being partners'.

In 7 and 8, linking adverbials are part of a clause. They are not a subject, a verb or a complement. They are loosely attached to the clause. That may be the reason why they are called sentence adverbials in some literature (e.g.Greenbaum, 1969, p. 2). They do not add content meaning to the clause. Making explicit the grammatical functions of linking adverbials in the current definition indicates why the term linking adverbials is preferred in the current study and helps position this category in the overall picture of the grammar system of English.

\section{They are a type of discourse marker in terms of their pragmatic functions.}

Pragmatic functions refer to meaning in context. Discourse markers is employed as a 'convenient cover term because it seems to be the one with the widest currency and with the least restricted range of application; one that enables us to include a broad variety of elements under a single conceptual umbrella'(Jucker \& Ziv, 1998, p. 2). Fraser (1998, p. 302) defines discourse markers as follows:

Discourse markers are lexical expressions. Although drawn primarily from the syntactic classes of conjunctions, adverbials, and prepositional phrases, they do not play the role in a sentence that their classes would suggest, but instead, they are separate from the propositional content of the sentence and function to signal the relationship between the segment of discourse they introduce, S2, and the prior segment of discourse, S1. Their meaning is procedural, not conceptual, with each discourse marker providing information on how to interpret the message conveyed by S2 vis-a-vis the interpretation of S1.

As exemplified in 7 and 8 , each linking adverbial has a certain meaning in a particular context, but they do not add content meaning to the clauses they belong to. Instead, they are cohesive signals showing the meaning relationships of sections of the discourse before and after them, and they indicate what type of meaning relationship is relevant in the context (See key component 5 for further discussion). In this sense, linking adverbials are a type of discourse marker. 
In some reference grammars (e.g.Biber et al., 1999), the term discourse marker has a narrower definition, which only refers to inserts (e.g. well) in spoken data and which treats them as another grammatical class. Thus, distinguishing between grammatical functions and pragmatic functions in the current definition helps to sort out the implication of the same term in different studies (e.g. descriptive studies vs pragmatics) and makes explicit the relations among adverbials, conjunctions, linking adverbials and discourse markers.

\section{The main function of linking adverbials is to provide a discourse cohesive device rather than a structural link.}

Examples 9 and 10 below demonstrate that linking adverbials provide explicit but not compulsory cohesive links for the discourse. They do not function as structural links in the way that conjunctions do.

In example 9, in addition is a linking adverbial. It signals the cohesive relationship between the two sentences. In other words, it functions as a cohesive device at discourse level (see key component 4 for linkage at different discourse levels).

9. The results are applied to the detection of a discrete frequency component of unknown frequency in a time series. In addition quick methods for finding approximate significance probabilities are given for both the normal and chi-squared cases and applied to the two-phase regression problem in the normal case. (WWC J20, written academic prose)

If in addition is deleted, the sentence is still grammatical.

In example 10, and is a coordinator, not a linking adverbial. It provides a compulsory structural link at sentence level, i.e., linking two relative clauses.

10. A general approach to stock modelling of fisheries when information is scanty is proposed, in which all available relevant information is utilised and in which parameters are examined over feasible ranges. (WWC J09, written academic prose)

If and is deleted, the sentence will be ungrammatical in written English.

Halliday (1994, p. 84) argued that linking adverbials construct semantic relationships 'by cohesion - that is, without creating a structural link between the two parts'. Both the data and Halliday's (1994) argument reveal that textual cohesion is another important feature of linking adverbials. It is worth mentioning in the definition and it helps distinguish linking adverbials from conjunctions which also have linking functions. Such a definition also 
accounts for newly-identified linking adverbials (e.g. and) and the differences in the same form as different grammatical categories, i.e., linking adverbials and conjunctions (See chapter 4.2.2 for a detailed discussion on differences between linking adverbials and coordinators, and as a linking adverbial, and how to identify a linking adverbial in spoken data).

\section{Linking adverbials are markers of various meaning relationships at different discourse levels.}

Examples 11-16 below exemplify how linking adverbials mark different meaning relationships at different discourse levels in both written and spoken English.

In example 11, the linking adverbial therefore marks a meaning relationship of logical consequence in written English.

11. The second feature of the general approach adopted in this study is to acknowledge that in fisheries science few, if any, parameters are known exactly. Therefore a range is chosen for each parameter depending on the accuracy with which it can be estimated from the available data. This will establish a feasible region for solutions. (WWC J09, written academic prose)

The linking adverbial signals a meaning relationship between two sentences, i.e., between the first sentence about the second feature of an approach and the second sentence stating that a range is chosen because of that particular feature. (See Chapter 6.1.2 for a detailed discussion on different meaning relationships)

In example 12 , the linking adverbial so marks a meaning relationship of logical consequence in spoken English.

12. // this man will only do that /if we come to these classes//so just bite your tongue// (WSC MUL003, academic lectures)

The linking adverbial introduces the meaning relationship between two intonation units, i.e., the first intonation unit about the man's possible act upon a certain condition and the second about what the person would need to do as a consequence.

In example 13, the linking adverbial nevertheless marks an adversative meaning relationship in written English.

13. <.....>The importance of frequency of occurrence for the teaching and learning of vocabulary is a case in point. 
Nevertheless, there can be little doubt that teaching a language as communication, as an applied or functioning system, has an intuitive appeal for teachers and learners alike $<\ldots . .>$. (WWC J35, written academic prose)

The linking adverbial makes explicit the meaning relationship between paragraphs, i.e. the previous paragraph about the proposing of communicative teaching approach and the importance of frequency of occurrence and the paragraph after the word nevertheless about the fact that such teaching approach does not necessarily appeal to teachers and learners.

In example 14 , the linking adverbial I mean marks a meaning relationship of explanation in spoken English.

\section{4. //er i'm sorry / that goes on and on and on // but in fact it's quite interesting//}

//i mean / he talks like that around and about // and in fact he's got lots of points very clearly in mind / that he wants to make/l (WSC MUL002, academic lectures)

The linking adverbial signals the meaning relationship between sets of intonation units, i.e., between the two intonation units about someone's interesting waffling and the two intonation units of explanation afterwards.

In example 15, the linking adverbial however marks an adversative meaning relationship in written English.

15. Females are much less inclined to be found in the manual occupations; if they are however, they are more likely to be in the Unskilled group. (WWC J29, written academic prose)

The linking adverbial marks a meaning relationship within one sentence, i.e., a conflict between the if-clause and the previous clause about females.

In example 16, the linking adverbial of for example marks a meaning relationship of explanation in spoken English.

16. // they pick up ANYTHING like/ for example that like that consultant guy/ who was paid a hundred and twenty thousand dollars for a month's work the other week/l (WSC DPC 179, conversation)

The linking adverbial marks a meaning relationship within one intonation unit, i.e., the comma intonation unit before for example and the one which follows and explains further (See Chapter 3.2.1 for more detailed discussion on comma intonation unit). 
In their definition of linking adverbials, Biber et al. (1999, p. 765) took a traditional approach based on written English and wrote that linking adverbials can link units of various size like sentences or paragraphs and express different semantic relationships, though their analysis has spoken data as well. However, as discussed in Chapter 3.2.1, sentences may not be a viable unit in spoken data, and a definition based on both written and spoken data should be inclusive. Thus in the definition of this study, features of spoken data, i.e., intonation units and sets of intonation units, are included, which are necessary in accounting for spoken data.

\section{Linking adverbials are explicit markers of meaning relationships.}

As we have seen in $11-16$, linking adverbials mark certain types of meaning relationship. But when you remove these explicit markers, the underlying conjunction relationships still exist. Halliday (1994, p. 327) argued that implicit conjunction often occurs but without explicit conjunction markers, and when this occurs it may be difficult for a reader to decide whether a conjunction relationship is intended or to interpret a particular type of meaning relationship: One question that arises in the interpretation of a text is what to do about conjunction
that is implicit. It often happens, especially with temporal and causal sequences, that
the semantic relationship is clearly felt to be present but is unexpressed.
It is clear that texture is achieved through conjunctive relations of this kind and there
is no reason not to take account of it. On the other hand, the attempt to include it in
the analysis leads to a great deal of indeterminacy, both as regards whether a
conjunctive relation is present or not and as regards which particular kind of
relationship it is. Consider the extract:

This is a highly cohesive passage; but it is difficult to say what implicit conjunctive relationship would hold between pairs of adjacent sentences.

In that sense, linking adverbials explicitly show that there are conjunction relationships in discourse and what type of meaning relationships they may be. Biber et al. $(1999$, p. 765$)$ also wrote that 'they make explicit the relationship between two units of discourse'. It is not difficult to find in the data and in the previous literature that explicitness of meaning relationship is an important feature of linking adverbials. Thus, in the definition of this study, such a feature is included to indicate the purpose of linking adverbials.

To sum up, the current definition is both data-driven and theory-driven. Data analysis has helped consolidate the definition from previous literature that linking adverbials are explicit markers of various meaning relationships of different sizes of units in a discourse and it has also yielded new findings that a definition based only on units like sentences or paragraphs is not as inclusive, some word forms of conjunctions can function as linking adverbials and that 
linking adverbials can have pragmatic functions. Such new findings have facilitated new ideas and have thus led to digging out theories from some existing literature discussing relevant grammatical categories (e.g. conjunction and discourse markers). Previous literature, however, discussed those features of a particular category at its own sake without combining them in the definition of a linking adverbial, let alone comparing and making explicit the relations among those above-mentioned messy grammar categories.

\subsection{Difference between linking adverbials and conjunctions}

In this section, the difference between linking adverbials and conjunctions is explained. Different functions of the same word form and are also discussed.

\subsubsection{Understanding the difference between linking adverbials and conjunctions}

As mentioned in 4.1.1, linking adverbials are adverbials, which are clause components. They are different from conjunctions, a category of grammatical class which also has connecting functions. In this section, the difference between linking adverbials and conjunctions is explored, with examples from both written and spoken data.

Two arguments are important in understanding differences between linking adverbials and conjunctions in this study:

\section{Linking adverbials mark a meaning relationship at discourse level while conjunctions provide a structural link at clause complex level.}

Linking adverbials, which Rouchota (1998, p. 100) refers to as 'adverbial discourse connectives', 'are set apart from other discourse connectives by a set of properties which assimilate them to sentence adverbials and parenthetical expressions in general'. Examples of sentence adverbials are: confidentially, fortunately, evidently, allegedly (Rouchota, 1998, p. 97). Parenthetical expressions are linguistic constructions, words, phrases or sentences, which occupy a syntactically peripheral position in a sentence, are typically separated from their host clause by comma intonation, and which function as gloss and comment on some aspect of the meaning and examples of parenthetical verbs are: I wonder, I fear, I suppose (Rouchota, 1998, p. 97). Reasons are as follows:

1. Conjunctions (e.g. so in 20) may only occur at the beginning of the clause they belong to while linking adverbials (e.g. so in 17) may occur at the beginning or at the end of clause they belong to, or the in the mid-sentence position (e.g. so in 18) ( (Rouchota, 1998, p. 100), i.e. they are 'syntactically unintegrated devices' 
(Rouchota, 1998, p. 101);

2. Linking adverbials 'are typically separated from their host clause by a noticeable pause, often referred to as comma intonation (in written discourse see comma punctuation)'(Rouchota, 1998, p. 101) (see 4.2.2 for a detailed discussion on sound patterns of linking adverbials and coordinators).

Halliday (1994, p. 50) views the difference between conjunctions and linking adverbials, which he refers to as 'conjunctive adjuncts', as follows:

Conjunctions are items which relate the clause to a preceding clause in the same sentence (the same clause complex). They are similar in meaning to conjunctive (discourse) Adjuncts; but they differ in that, while conjunctive Adjuncts set up a semantic relationship with what precedes, conjunctions set up a relationship which is (not only semantic but also) grammatical - they construct the two parts into a single structural unit.

Instead of linking clauses into one structural unit, linking adverbials connect and make explicit meaning relationship at different discourse levels. Positions of linking adverbials are more flexible than conjunctions (see Chapter 7 for further discussion on positions of linking adverbials).

Examples 17-21 below illustrate how linking adverbials and conjunctions provide different varieties of linkage. Examples 17-19 demonstrate that linking adverbials make meaning relationships at discourse level.

In example 17, so occurs at the beginning of a sentence in written English and it does not provide any structural link within one sentence.

17. Over this period the cost of chemicals, glassware etc has risen by 1300 percent. So the grant per pupil has less than one-eighth the buying power it had 22 years ago. (WWC J38, written academic prose)

It marks a meaning relationship of result between two sentences, i.e., the decreasing buying power described in the sentence after so is the practical outcome of the fact that costs are higher as stated in the sentence before so. Here, so is a linking adverbial in that it can be deleted without causing any grammatical concern in written English.

In example 18 , so is also a linking adverbial.

18. The average worker earned $\$ 11,000$ in a six-month season plus $\$ 8000$ from the dole and so a 40 per cent wage cut would reduce his income to $\$ 14,500$, he said. (WWC A06, written news) 
So occurs in the middle of the sentence but it does not provide a structural link. It is the coordinator and before so that acts as the structural link. So is used to mark that the reasoning of how his income becomes \$ 14,500 is based on the $40 \%$ wage cut out of the average wage described in the clause before and. It marks a meaning relationship between two clauses and thus makes the meaning of logical consequence explicit.

In example 19 , and is a linking adverbial because it occurs at the beginning of an intonation unit.

19. //shepherd er went to his solicitor // and the solicitor advised him to approach a um chris stansfield and son /a organization called stansfields associates// (WSC MUL005, academic lectures)

The linking adverbial and explicitly marks that, beyond the fact that he went to his solicitor, another piece of information is relevant, namely that the solicitor advised him to approach somebody else. The linking adverbial and has a discourse cohesive function here, rather than functioning as a structural link.

Examples 20 and 21 below illustrate how conjunctions link linguistic expressions at clause complex level in written and spoken English respectively.

In example 20, the word form so is used as a subordinator in written English.

20. Parsons and Bennett said they would prefer the matter to be left to the survey of opposition, so the ratepayers could indicate how they felt. (WWC A03, written news)

It connects the main clause and its subordinating clause in a sentence. If so is deleted here, the sentence becomes ungrammatical.

In example 21, and is used as a coordinator in spoken English.

\section{1. // $i$ just go and do it// (WSC DPC 179, conversation)}

The coordinator and links two verbs in one intonation unit (see Chapter 4.2.2 for a detailed discussion on the relationship between pronunciation of and and its grammatical functions). In spoken English, it is difficult to comment on an expression as grammatically right or wrong. In this sense, it is only described as it is.

2. When a word form which can be used as a conjunction (e.g. and, so) is used as a discourse marker, it no longer belongs to the grammatical class of 
conjunctions. Instead, it is a clause component which functions as a linking adverbial grammatically.

As discussed in 4.1.2, some word forms which can belong to the word class of conjunctions can also be used as discourse markers. As shown in examples 17-21, the word forms so and and can sometimes be used as conjunctions and in other contexts can function as linking adverbials, i.e., with discourse cohesive function. They can thus be discourse markers according to Fraser's (1998) definition (see Section 4.1.2, key component 2). If you need to put discourse markers in a grammatical class, they are adverbials, part of a clause, rather than conjunctions, a word class, since they no longer take the properties of conjunctions, i.e., structural link.

\subsubsection{And -- linking adverbial or coordinator}

In this section, and is discussed to exemplify the difference between linking adverbial and coordinator in both written and spoken registers.

\subsubsection{Overview of frequency of linking adverbial 'and' and coordinator 'and' in written and spoken} registers

In total, 1,847 word forms of and in the three spoken registers were found. As shown in Table 7, only 150 random samples of the word form and from the three spoken registers were analysed in detail (including sound patterns) and 74 were found to be linking adverbials and 76 were found to be coordinators (see Table 26, 32 for reports on all and as linking adverbials in spoken registers).

Table 7 Occurrence of linking adverbial and and coordinator and in written and spoken data

\begin{tabular}{|l|l|l|l|l|}
\hline & \multicolumn{2}{|l|}{$\begin{array}{l}\text { Written (1,037 occurrence } \\
\text { of and in approximate } \\
40,000 \text { words total) }\end{array}$} & $\begin{array}{l}\text { Spoken (random sample of 50 } \\
\text { occurrences of and from each of the } \\
\text { three approximate 20, 000 word } \\
\text { register samples) }\end{array}$ \\
\hline Linking adverbial and & 11 & $1 \%$ & 74 & $49 \%$ \\
\hline Coordinator and & 1,026 & $99 \%$ & 76 & $51 \%$ \\
\hline Total & 1,037 & 150 & \multicolumn{2}{|l}{} \\
\hline
\end{tabular}

Only 11 occurrences of linking adverbial and were identified in the written data, $1 \%$ of the total occurrences of and in the two written registers of around 40,000 words total, i.e., written academic prose and written news. 1,026 coordinator and were found in the written registers. 
Linking adverbial and is found much more frequently in the three spoken registers (49\%), i.e., academic lectures, broadcast news and conversation.

Linking adverbial and may occur less frequently in written prose because there are more linguistic options in written registers to express the semantic meaning of addition, which makes the writing appear formal and sophisticated (see chapter 6.1.2 for linking adverbials of addition in different registers).

In order to further explore the differences between linking adverbials and conjunctions, especially in spoken data, the following section will illustrate how you may distinguish linking adverbial and from coordinator and in both written and spoken English.

\subsubsection{Linking adverbial 'and' and coordinator 'and' in written registers}

As shown in Table 8 below, the word form and is used significantly more frequently as coordinator than as linking adverbial in written registers, and there is no significant difference between the two registers.

Table 8 Frequency of linking adverbial and and coordinator and in written registers

\begin{tabular}{|c|c|c|c|c|c|c|}
\hline Register & $\begin{array}{l}\text { Link } \\
\text { and }\end{array}$ & dverbial & $\begin{array}{l}\text { Coor } \\
\text { and }\end{array}$ & & \multicolumn{2}{|l|}{ LL } \\
\hline Written academic prose $(20,128)$ & \multicolumn{2}{|l|}{7} & \multicolumn{2}{|l|}{533} & 673.85 & $\mathrm{p}<0.0001$ \\
\hline Written news $(21,001)$ & \multicolumn{2}{|l|}{4} & \multicolumn{2}{|l|}{493} & 642.44 & $\mathrm{p}<0.0001$ \\
\hline LL & 0.96 & $\mathrm{~ns}$ & 3.72 & ns & & \\
\hline
\end{tabular}

Examples 22-25 illustrate that and used as a coordinator in written English links different sizes and types of linguistic unit (e.g. noun phrases and finite clauses) and thus can only occurs in the middle of a sentence.

In example 22, and is used as a coordinator connecting two relative clauses within one sentence.

22. A general approach to stock modelling of fisheries when information is scanty is proposed, in which all available relevant information is utilised and in which parameters are examined over feasible ranges. (WWC J09, written academic prose)

It is in the medial position of a sentence.

In example 23, and is a coordinator connecting two noun phrases within one sentence.

23. The district council issue also surfaced when the council was considering a schedule of committees and county representatives on various authorities. (WWC A03, written news) 
It is also in the medial position of a sentence.

In example 24 , and is a coordinator connecting two complements within one sentence.

24. They assumed that recruitment plus growth was constant and independent of stock size and structure. (WWC J09, written academic prose)

It also occurs in the medial position of a sentence.

In example 25, and is a coordinator connecting two independent finite clauses within one sentence.

25. Our significance levels are either bounds or approximations to the bounds and it is important to know how accurate they are. (WWC J20, written academic prose)

It is in the medial position of a sentence.

Examples 26-27 demonstrate that and used as linking adverbial in written English makes explicit meaning relationships above sentence level (between sentences and paragraphs), thus it functions at the discourse level, not the grammatical level.

In example 26, and is used as a linking adverbial which makes explicit the meaning relationship of addition between two sentences, i.e., the sentence before and describing that he will be the chair and the sentence after it showing that beyond that he will also visit some places.

26. He will also chair a conference session on sheepmeats. And he will visit New York and Toronto, Canada, to study the operations of Devco and Atlanta, Georgia, to assess the work of the International Wool Secretariat in its promotion of carpet wools. (WWC A26, written news)

It is used at the beginning of a sentence.

In example 27, and is used as a linking adverbial which makes explicit the meaning relationship of addition between two paragraphs, i.e., the one before and describing Albinski's proposal to work at Victoria University and the one after it adding another piece of information on what one of his colleagues had done because of his proposal.

27. Under his original scheme, Albinski proposed to post himself to Victoria University to research New Zealand foreign and defence policy, United States-New Zealand relations and politics of Pacific Island countries.

And one of his Pennsylvania colleagues was to have researched the role of the New 
Zealand press in influencing public opinion on defence, and, especially, New Zealand-United States relations. That project was to expand into a cross-national study of the press and foreign policy formulation. (WWC A12, written news)

It is also used at the beginning of a sentence.

The differences between coordinator and and linking adverbial and in written English can be summarised as: coordinator and occurs in the middle of a sentence and connects grammatical structures within one sentence, while linking adverbial and occurs at the beginning of a sentence and makes explicit the meaning relationship between sentences or paragraphs. Some linking adverbials usually have flexible positioning (e.g. however see Chapter 7) while others tend to have fixed positioning, especially in a certain register (e.g. even so, too in written academic prose see Chapter 7.2). And as a linking adverbial in written registers has to be in the initial position of a sentence, though its positions in spoken registers as a linking adverbial are more flexible (see Chapter 4.2.2.3) than in written registers. And as a coordinator has to be in the middle of a sentence but can be at the beginning of a clause when connecting two independent clauses (see Example 25).

Also in written registers, linking adverbials with the very same meaning usually do not occur at the same time. If in addition is added to and in Example 25, where and occurs at the beginning of a clause but in the middle of the sentence, and is the coordinator conjoining two independent clauses while in addition is the linking adverbial marking the meaning of addition between the two conjoined independent clauses. However, if in addition is added to and in Example 26, where and occurs at the beginning of a clause but at the same time at the beginning of the sentence, and can't be a coordinator since it does not conjoin two clauses within one sentence but two sentences instead. In this case, the value of the cohesive function of in addition has been shifted to the linking adverbial and before it. But the meaning of in addition has been strengthened by the author not only conveying an additional piece of information but also emphasizing that this is an additional activity. In addition here has taken the flavour of a stance adverbial.

The difference between coordinator and and linking adverbial and in spoken English is more complicated. It is further reported and discussed in the next section.

\subsubsection{Linking adverbial 'and' and coordinator 'and' in spoken registers}

As shown in Table 9 below, a random sample of 50 occurrences of and from the WSC data set have been analysed in each spoken register. Ten linking adverbials and 40 coordinators 
are identified in broadcast news, 33 linking adverbials and 17 coordinators in conversation, and 31 linking adverbials and 19 coordinators in academic lectures.

Table 9 Frequency of linking adverbial and and coordinator and in spoken registers

\begin{tabular}{|l|l|l|l|l|l|}
\hline Register & $\begin{array}{l}\text { Linking adverbial } \\
\text { and }\end{array}$ & $\begin{array}{l}\text { Coordinator } \\
\text { and }\end{array}$ & \multicolumn{2}{l|}{ LL } & Total \\
\hline Broadcast news $(21,623)$ & 10 & 40 & 19.27 & $\mathrm{p}<0.0001$ & 50 \\
\hline Conversation $(21,279)$ & 33 & 17 & 5.21 & $\mathrm{p}<0.05$ & 50 \\
\hline $\begin{array}{l}\text { Academic lectures } \\
(22,049)\end{array}$ & 31 & 19 & 2.91 & ns & 50 \\
\hline
\end{tabular}

Conversation and academic lectures share similar patterns, i.e. more occurrences of linking adverbials than coordinators. This is different from the pattern found in written English as discussed in 4.2.2.2, where coordinator and is significantly more frequent than linking adverbial and. This difference may be because, in speech, it is not easy for speakers to finish a long coordinated sentence within one intonation unit. This also demonstrates that compared with written English, naturally-occurring spoken English tends to have simpler grammatical structures.

Broadcast news tends to have a similar pattern with written registers, i.e., significantly more frequent use of coordinator and than linking adverbial and. This may be because broadcast news is normally scripted.

\subsubsection{Sound patterns of linking adverbial 'and' and coordinator 'and' in spoken registers}

In written data, sentence boundaries are clearly marked by punctuation, but the structures in spoken data are less clearly marked. How spoken data are interpreted depends both on what is expressed, i.e. the actual words and phrases articulated, and on how they are expressed, i.e., the pronunciation and intonation of the articulated words and phrases. This makes spoken data both more complicated and more interesting.

In this section, the relationships between sound patterns and grammatical functions of the word form and are illustrated. This approach has the potential to help learners of English to distinguish linking adverbial and from coordinator and in spoken data.

As discussed above, in written English all coordinator and occur in the medial position in a sentence, while all linking adverbial and appear at the beginning of a sentence.

In spoken data, the pattern is different and more complicated. In spoken registers, although all instances of coordinator and also occur in the medial position of an intonation unit, linking adverbial and can happen in an initial, medial or a final position. In most cases it appears in 
the initial position. Also, sound patterns of and differ across registers. In the next three subsections, sound patterns of and in spoken data will be further reported and discussed register by register.

\subsection{Sound patterns of linking adverbial 'and' and coordinator 'and' in conversation}

As shown in Table 10, in conversation, all instances of coordinator and are in the medial position of the intonation units. All instances of coordinator and are not fully pronounced and have an unstressed vowel or no vowel at all, except those after a comma intonation. Linking adverbial and may be or may not be fully pronounced, but, the not-fully-pronounced ones only occur before a comma intonation and have the meaning of continuation. The initial linking adverbials are all fully pronounced and stressed in conversation and have the meaning of adding a further piece of information.

Table 10 Sound patterns of linking adverbial and and coordinator and in conversation

\begin{tabular}{|l|l|l|}
\hline Sound patterns & Linking adverbial and & Coordinator and \\
\hline $\begin{array}{l}\text { Fully pronounced, stressed } \\
\text { and lengthening /ænd / }\end{array}$ & 26 (initial) & $\begin{array}{l}\text { (medial, after a comma } \\
\text { intonation) }\end{array}$ \\
\hline $\begin{array}{l}\text { Fully pronounced and } \\
\text { stressed /ænd/ }\end{array}$ & 2 (final) \\
\hline $\begin{array}{l}\text { Fully pronounced but } \\
\text { unstressed /ond/ }\end{array}$ & $\begin{array}{l}1 \text { (medial, after a comma } \\
\text { intonation) }\end{array}$ \\
\hline $\begin{array}{l}\text { Not fully pronounced but } \\
\text { stressed /æn/ }\end{array}$ & $\begin{array}{l}11 \text { (medial) } \\
\text { Not fully pronounced and } \\
\text { unstressed /on/ }\end{array}$ & comma intonation)
\end{tabular}

Example 28 below illustrates the sound pattern and position of coordinator and.

In example 28, coordinator and is not fully pronounced and it is unstressed. It is in the medial position of the intonation unit.

\section{A: // $i$ just go and do it// (WSC DPC179, conversation)}

It is in the medial position of the intonation unit.

Examples 29 and 30 demonstrate how meanings of linking adverbial and are influenced by their sound patterns. 
In example 29, linking adverbial and is not fully pronounced and is unstressed. It occurs before a comma intonation.

\section{A: //oh my goodness//}

B: //mm// and then he sleeps during the day and/ gets woken up and/

\section{$A: / / m m / /$}

B: sleeps some more and/just goes out and stuff // (WSC DPC299, conversation)

It is a marker of continuation, which signals the speaker is still holding the floor.

In example 30, linking adverbial and is fully pronounced and is stressed. It is in the initial position of an intonation unit.

30. / there was this man/and he /um /ike $i$ was running up this hill/ and he was WALKING// and he waited till i got up the hill // (WSC DPC 172, conversation)

Here and is a marker of addition, which signals that the speaker is adding another piece of information about the man who was walking.

To sum up, in conversation, all coordinator and occur in the middle of an intonation unit and take up to four different sound patterns, i.e., fully pronounced and stressed, not fully pronounced but stressed, not fully pronounced and unstressed and not fully pronounced. Most coordinator and are not fully pronounced and are unstressed. Most linking adverbial and are fully pronounced and are stressed, however. Those which are not fully pronounced and are unstressed carry a different meaning.

In the next section, sound patterns of and in academic lectures are reported and the difference from the register of conversation is discussed.

\subsection{Sound patterns of linking adverbial 'and' and coordinator 'and' in academic lectures}

As shown in Table 11, in academic lectures, all linking adverbial and have a stressed vowel and appear in the initial position of the intonation units while coordinator and can have stressed or unstressed vowels or no vowels at all and appear in the medial position of the intonation units. 
Table 11 Sound patterns of linking adverbial and and coordinator and in academic lectures

\begin{tabular}{|l|l|l|}
\hline Sound patterns & Linking adverbial and & Coordinator and \\
\hline $\begin{array}{l}\text { Fully pronounced, stressed } \\
\text { and lengthening /and/ }\end{array}$ & 5(initial) & \\
\hline $\begin{array}{l}\text { Fully pronounced and } \\
\text { stressed /ænd/ }\end{array}$ & 12(initial) & $\begin{array}{l}\text { 2(medial, after comma } \\
\text { intonation) }\end{array}$ \\
\hline $\begin{array}{l}\text { Fully pronounced but } \\
\text { unstressed /ənd/ }\end{array}$ & $\begin{array}{l}\text { 7(medial, after comma } \\
\text { intonation) }\end{array}$ \\
\hline $\begin{array}{l}\text { Not fully pronounced but } \\
\text { stressed /æn/ }\end{array}$ & 14(initial) & 1(medial) \\
\hline $\begin{array}{l}\text { Not fully pronounced and } \\
\text { unstressed /ən/ }\end{array}$ & & 9 (medial) \\
\hline Not fully pronounced/n/ & 31 & 19 \\
\hline Total & & \\
\hline
\end{tabular}

Different from conversation in which seven instances of linking adverbial and have an unstressed vowel, in academic lectures, none of the instances of linking adverbial and has an unstressed vowel or no vowel at all. And no meanings of marker of continuation were found. This may be because in academic lectures, the lecturer has more power in controlling the right to speak and does not need an explicit marker of continuation to indicate s/he is still holding the floor.

Another interesting sound pattern in academic lectures is that there are more occurrences of fully pronounced, stressed and lengthening and, which may allow the speaker more time to think about what s/he is going to say next or allow the speaker to indicate that a very important piece of information is coming along.

Examples 31 and 32 illustrate that although coordinator and and linking adverbial and can sometimes have the same pronunciation, it is the comma intonation that distinguishes coordinator and from linking adverbial and.

In example 31 , coordinator and is not fully pronounced but it is stressed. It occurs after a comma intonation, i.e. a continuing intonation, which is usually a final rising pitch indicating incompleteness.

31. //they they would be dragged off the street/ and said look do you want to be a policeman/taken into a police station/given a badge and uniform/ and be out on the beat er perhaps with one other person inside ten minutes// (WSC MULO24, academic lectures) 
You can hear incompleteness after the word street before the coordinator and. So the statement after the coordinator and is more attached to the clause before it.

In example 32, linking adverbial and is also not fully pronounced but it is stressed. However, it comes after a period intonation.

32. I/now the next step reduce that to false // but we don't need to put anything in the computation trace corresponding to that // next thing after that took this ffalse then something or other else something or other and replace it by the second something or other/l we don't need to put it in either this is just part of the/part of the machinery//and the next significant thing that happens is that we get this fact three minus one// and in fact there's an extra step in there that i've left out //(WSC MUL007, academic lectures)

You can hear completeness before the linking adverbial and. The statement after it is adding another piece of information and it occurs in a new intonation unit, which signals that is not structurally attached, rather than being structurally more attached to the previous clause as was the case in example 31 .

In academic lectures, no linking adverbial and comes before a comma intonation which means linking adverbial and carries only the meaning of addition, i.e., adding another piece of information (see Chapter 6 for detailed discussion of meanings of linking adverbials). Sound patterns of linking adverbial and and coordinator and in academic lectures are not exactly the same as those in conversation. This means that although the two spoken registers both have more frequent occurrences of linking adverbial and than coordinator and, the actual usage (e.g. meanings being marked by linking adverbial and) is different in the two registers. Such detailed analysis helps understand register variations within spoken registers which have not been fully explored previously. They also have the potential to help second language learners of English understand such variations and thus to use linking adverbial and and coordinator and appropriately in a particular spoken register.

As mentioned above, the spoken register of broadcast news and the written register of written news have similar patterns of frequency of linking adverbial and and coordinator and. The next section reports and discusses sound patterns of and in the spoken register of broadcast news and their differences from the other two spoken registers, i.e. conversation and academic lectures. 


\subsection{Sound patterns of linking adverbial 'and' and coordinator 'and' in broadcast news}

As shown in Table 12, in broadcast news, all instances of linking adverbial and are fully pronounced and have a stressed vowel and appear in the initial position of the intonation units while all instances of coordinator and are fully pronounced with a stressed vowel or are not fully pronounced with a stressed or unstressed vowel or no vowel at all and appear in the medial position of the intonation units.

Broadcast news has far more coordinators than the other two spoken registers and most of them come after a comma intonation, which means this register has more coordinated clauses. This may also mean that broadcast news has the most complicated language structures in terms of coordinated clauses and is the most formal register in all the three registers.

All instances of linking adverbial and occur in the initial position of an intonation unit and are fully pronounced and stressed. This may be because broadcast news is normally scripted and is thus closest to written language.

Table 12 Sound patterns of linking adverbial and \& coordinator and in broadcast news

\begin{tabular}{|l|l|l|}
\hline Sound patterns & Linking adverbial and & Coordinator and \\
\hline $\begin{array}{l}\text { Fully pronounced, stressed } \\
\text { and lengthening /ænd/ }\end{array}$ & 1 (initial) & \\
\hline $\begin{array}{l}\text { Fully pronounced and } \\
\text { stressed /ænd/ }\end{array}$ & 9 (initial) & $\begin{array}{l}18 \text { (medial, after comma } \\
\text { intonation) }\end{array}$ \\
\hline $\begin{array}{l}\text { Fully pronounced but } \\
\text { unstressed /ənd/ }\end{array}$ & $\begin{array}{l}7 \text { (medial, after comma } \\
\text { intonation) }\end{array}$ \\
\hline $\begin{array}{l}\text { Not fully pronounced but } \\
\text { stressed /æn/ }\end{array}$ & 4 (medial) \\
\hline $\begin{array}{l}\text { Not fully pronounced and } \\
\text { unstressed /ən/ }\end{array}$ & & 11 (medial) \\
\hline Not fully pronounced /n/ & 10 & 40 \\
\hline Total & & \\
\hline
\end{tabular}

Examples 33 and 34 demonstrate how coordinator and differs from linking adverbial and in terms of their positions in an intonation unit when they have the same pronunciation (fully pronounced and stressed in these two cases).

In example 33, coordinator and is fully pronounced and stressed.

\section{3. // the hotel's management say they're looking into the matter/and won't comment} further on the causes of the complaints//(WSC MSN111, broadcast news)

It occurs in the medial position of an intonation unit and after a comma intonation. 
In example 34 , linking adverbial and is also fully pronounced and stressed.

34. // eighteen months from now we've got to start thinking about how we're going to win the next election// and we have to answer to our constituents why we did certain things//(WSC MSN020, broadcast news)

However, different from the position of coordinator and in example 33 , it is in the initial position of an intonation unit.

In the register of broadcast news, sound patterns of both coordinator and and linking adverbial and are the most regular among all the three spoken registers, with most fully pronounced and stressed and being identified. This distinguishes the register of broadcast news from the other two spoken registers and broadcast news may be claimed as the most formal spoken register in this sense.

\subsection{Summary}

Based on the above analysis of and in the five registers, the following conclusions could be drawn:

- And is not always a used as a coordinator.

- Linking adverbial and is an explicit marker of conjunction at discourse level with the meaning of addition or marker of continuation. The meaning of marker of continuation occurs only in the register of conversation.

- Coordinator and is a grammatical connector connecting two equivalent structures, which have the same grammatical functions within one sentence or one intonation unit.

- Patterns of occurrence differ with context.

- In terms of position, coordinator and only occurs in a medial position. Linking adverbial and only occurs at the beginning of a sentence in written English but is more flexible in spoken English. It can occur in any position within an intonation unit, i.e. initial, medial or final.

- Linking adverbial and is never pronounced as $/ \mathrm{n} /$.

- Linking adverbial and has a stressed vowel except those few cases with the meaning of holding the floor in conversation while coordinator and is normally not stressed except when it occurs after a comma intonation. 


\subsection{Differences from other adverbial categories}

Biber et al. (1999, p. 763) wrote that adverbials can be divided into three categories according to their functions: circumstance adverbials, stance adverbials and linking adverbials. Having discussed the difference between linking adverbials and a functionally related grammatical class (conjunctions) in previous sections, in the following two sections I will discuss the differences between linking adverbials and the other two categories of adverbials, i.e., circumstance adverbials and stance adverbials, which are also elements of clauses.

\subsubsection{Difference between linking adverbials and circumstance adverbials}

In the data set for this study, some word forms are found to be able to function either as a circumstance adverbial or as a linking adverbial (e.g. then, anyway). Examples 35 and 36 below demonstrate that the same word form then can be either a circumstantial adverbial or linking adverbial in different linguistic contexts.

In example 35 , then is a circumstantial adverbial of time.

35. // i've treaded some of those this morning cos $i$ went to where you were last year// then $i$ went to $h \mathrm{~m}$ six/l then $i$ saw ros running along/ and $i$ thought where goes ros there goes women's studies// so i arrived here// (WSC MUL003, academic lectures)

It means later and adds time information to the clause following the word then with reference to the preceding clause.

In example 36 , then is a linking adverbial of condition, i.e., an assumption leads to a logical result/a certain situation (see Chapter 6 for a detailed discussion on then as a linking adverbial and its meanings in different contexts).

36. Suppose [FORMULA**] is the appropriate test statistic, with large values corresponding to the alternative being true. Then the test statistic we suggest for the case when $1 \backslash 15^{T H}$ is unknown is [FORMULA**], where [*8L, $U^{* 0}$ ] is the range of possible values of $* \backslash 15 T H$. (WWC J20, written academic prose)

The sentence before then made an assumption that a certain formula is the appropriate test statistic and such assumption leads to another formula described in the sentence introduced by then. It makes explicit the meaning relationship between the two sentences but does not add extra content meaning to the clause following the word then.

As shown in examples 35 and 36, linking adverbials make meaning relationships explicit and they make a cohesive flow of discourse, while circumstance adverbials 'add information 
about the action or state that is described in the clause' (Biber et al., 1999, p. 763).

Halliday (1994, p. 84) also had similar idea on the difference between circumstance adverbials, which he refers to as circumstantials, and linking adverbials, which he refers to as Conjunctive Adjuncts.

\begin{abstract}
What is common to the modal and conjunctive Adjuncts, as distinct from the circumstantials, is that they are both constructing a context for the clause. Thus even though the same semantic feature may be involved, for example time, it has a different significance in each case. A modal Adjunct of time, like just, yet, already, relates closely to the primary tense, which is the 'shared time' of speaker and listener; a conjunctive Adjunct of time such as next, meanwhile, locates the clause in time with respect to the preceding textual environment; and both are different from time as a circumstance, such as in the afternoon. And the same item may function sometimes circumstantially and sometimes conjunctively; for example then, at the moment, later on, again.
\end{abstract}

Thus, in English a word form can be multi-functional. In this case, the same word form can either be a linking adverbial or a circumstance adverbial. What distinguishes the two types of adverbials is that linking adverbial does not add extra meaning to the clause/sentence/intonation unit being introduced. Instead, it makes explicit a meaning relationship between the clause/sentence/intonation unit being introduced and the previous related discourse section.

In the next section, the difference between linking adverbials and another adverbial category, stance adverbials, is discussed and the same word form functioning as either linking adverbial or as stance adverbial is exemplified.

\title{
4.3.2 Difference between linking adverbials and stance adverbials
}

In the data set for this study, some word forms are also found to be able to function either as a stance adverbial or as a linking adverbial (e.g. in fact, of course). Examples 37 and 38 will illustrate this.

In example 37, in fact functions more as a linking adverbial, making explicit the meaning relationship between the current intonation unit and the previous intonation unit indicating the following statement introduced by in fact is opposite to the previous.

37. // er i'm sorry / that goes on and on and on // in fact it's quite interesting // (WSC MUL002, academic lectures)

It strengthens the explicitness that the following statement is the opposite to the one before them.

In example 38 , in fact is a stance adverbial of actuality. 
38. //how can i explain being attacked /because i just wanted to stand up and have my say// how can $i$ interpret that personal attack /which in fact was really just a response to the fact that a young maori woman academic wanted to have her say/l (WSC MUL003, academic lectures)

It adds a comment on the characteristics of the statement following in fact that what is stated is really a fact /truth.

As revealed from examples 37 and 38 , linking adverbials make meaning relationships explicit and to some extent facilitate the understanding of the meaning relationship between two parts of a discourse while stance adverbials 'have the primary function of commenting on the content or style of a clause or a particular part of a clause' (Biber et al., 1999, p. 853).

Understanding the differences among the three types of adverbials further consolidates the conception of what a linking adverbial is. A linking adverbial as a clause component has its own properties, which distinguishes it from the other two adverbial categories which are also clause components, i.e. circumstance adverbials and stance adverbials.

Analysing the different functions that the same word forms can perform not only contributes to the description of general grammar and different meanings of a particular lexical item but also has implications for language learning and teaching. For second language learning and teaching, it is not enough to just teach dictionary meanings of a particular word form. Making explicit the meaning difference and different adverbial types related to those meanings will help learners understand the text at a local level and at a discourse organization level and will also help learners to use already-known word forms actively in different grammatical ways: to add extra meaning to the local clause, to comment on the local clause or to link the local clause to a discourse hierarchy.

\subsection{Frequency of linking adverbials in the five registers}

In previous sections, the definition of linking adverbials and their difference from conjunctions, circumstance adverbials and stance adverbials have been discussed. In this section, the overall frequency of linking adverbials in five registers will be reported and discussed.

\subsubsection{Overview of frequency of linking adverbials in the WWC \& WSC samples}

As shown in Table 13, 1,979 linking adverbials have been identified in a data set of 106,080 words, but the frequency of linking adverbials varies across different registers. 
From the raw figures shown in Table 13, you can find that the total words of each of the five registers are not exactly the same. In broadcast news, for example, 21,623 words are analysed and 157 linking adverbials are found while in written news, 21,001 words are analysed and 98 linking adverbials are identified. A standardization of the raw figures is also provided to help interpret the difference of the frequency of linking adverbials in different registers, since the sample sizes of different registers are not exactly the same.

The register of academic lecture has the most frequent use of linking adverbials and written news has the least (Table 13). Biber et al. (1999) and Liu (2008) also found that written news has the least frequent use of linking adverbials in all previous cross-register studies on linking adverbials. But Biber et al. (1999) and Liu (2008) both found that written academic prose has the most frequent use of linking adverbials. Neither of them explored the frequency of linking adverbials in academic lectures.

Table 13 Frequency of linking adverbials in the five registers

\begin{tabular}{|l|l|l|}
\hline Registers & Raw Frequency & Standardized frequency (per 20,000 words) \\
\hline $\begin{array}{l}\text { Academic lectures } \\
(22,049)\end{array}$ & 813 & 737 \\
\hline $\begin{array}{l}\text { Conversation } \\
(21,279)\end{array}$ & 723 & 680 \\
\hline $\begin{array}{l}\text { Written academic prose } \\
(20,128)\end{array}$ & 188 & 187 \\
\hline $\begin{array}{l}\text { Broadcast news } \\
(21,623)\end{array}$ & 157 & 145 \\
\hline $\begin{array}{l}\text { Written news } \\
(21,001)\end{array}$ & 98 & 97 \\
\hline Total $(106,080)$ & 1,979 & 1,841 (per 100,000) \\
\hline
\end{tabular}

Biber et al. (1999) also found that conversation has a lower use of linking adverbials than written academic prose. In the current study, however, as shown in Table 14, conversation has more frequent use of linking adverbials than written academic prose and the difference is significant.

Table 14 Frequency of linking adverbials in conversation and written academic prose

\begin{tabular}{|l|l|l|l|}
\hline Registers & Raw Frequency & LL & p $<0.0001$ \\
\cline { 1 - 2 } $\begin{array}{l}\text { Conversation } \\
(21,279)\end{array}$ & 723 & 306.28 & \\
\cline { 1 - 2 } $\begin{array}{l}\text { Written academic prose } \\
(20,128)\end{array}$ & 188 & & \\
\hline
\end{tabular}


Liu (2008) did not investigate the register of conversation alone, but did explore the spoken registers as a whole, which includes conversations, business/government meetings, radio shows and phone-ins. He found that spoken registers (8,548 per million words) rank second, after written academic prose (9,772 per million words), in terms of the frequency of linking adverbials. However, as shown in Table 15 below, in the current study, spoken registers have significantly more frequent use of linking adverbials than written academic prose.

Table 15 LL of frequency of linking adverbials in three spoken registers and written academic prose

\begin{tabular}{|l|l|l|l|}
\hline Registers & Raw Frequency & \multicolumn{2}{|l|}{ LL } \\
\cline { 1 - 2 } Spoken registers $(64,951)$ & 1,693 & 233.51 & $\mathrm{p}<0.0001$ \\
\cline { 1 - 2 } Written academic prose $(20,128)$ & 188 & & \\
\hline
\end{tabular}

The above stated differences of the findings of the current study from previous studies may be due to two reasons: a. none of the previous studies have included the register of academic lecture; b. some of those newly-identified linking adverbials (e.g. and, but see Section 4.2 and 5.3 for detailed description) are not counted as linking adverbials in previous research and thus their frequencies are not included.

The inherent characteristics of academic lectures as a genre itself, however, would facilitate the use of explicit cohesive markers. McCarthy and O'Keeffe $(2004$, p. 172) did a genre analysis of academic lectures and argued as follows:

A further important aspect of lecture monologue is the metalanguage which tells the audience about the organisation of the lecture. The interplay of the three elements of informing, evaluating, and organising creates the particular character of lecture monologue which several studies of lecture discourse have sought to illuminate.

Words like and, and but, which were traditionally considered as coordinators, are very frequently used in spoken registers. As discussed in 4.2,1 and 4.2.2, they can have a discourse cohesive function and thus can be used as linking adverbials, which will contribute to the overall frequency of linking adverbials in spoken registers in this study.

The different findings in this study from previous research have implications for future research. As discussed in Section 2.1.2, most of the previous corpus-based studies focus on the register of written academic prose since previous studies claimed that it has the most frequent use of linking adverbials. However, this study found that spoken registers, especially the registers of academic lectures and conversation, have significantly more frequent use of linking adverbials than the register of written academic prose. Thus, the usage patterns of 
linking adverbials in both native corpora and learner corpora in the registers of academic lectures and conversation are worth more attention. Michigan Corpus of Academic Spoken English (MICASE), for example, could be a very useful and available data source for future research in the spoken academic settings.

New findings in this research also have implications for second language teaching and learning. In consideration of the register-specific frequency of linking adverbials, it is worthwhile to take account of this frequency information in language teaching and learning. The register of academic lecture, for example, has the most frequent use of linking adverbials, so it will be helpful to deliberately teach second language learners what and how linking adverbials can be used to organize the ideas effectively in the register of academic lectures, especially in the setting of teaching English for academic purposes (EAP). For another example, in the settings of journalism English teaching and learning, less effort will be needed to teach and learn the use of linking adverbials than it is needed in the settings of EAP teaching, since linking adverbials are much less frequently used in both written and broadcast news.

In the following chapters, three aspects of usage of linking adverbials, i.e., form, meaning and position, are explored in detail in all the five registers. An overview of form, meaning and position of linking adverbials in the five registers are reported. The three aspects of usage are also compared within written registers (i.e., written academic prose and written news) and spoken registers (i.e., academic lecture, broadcast news and conversation. They are also compared in particular social settings (e.g. written academic prose and academic lecture in academic setting) to explore the differences between written and spoken English in the same setting. 


\section{Chapter 5 Form of linking adverbials}

Defining linking adverbials helps us understand and shape the boundaries of this particular grammar category. Usage patterns further illustrate this grammar category in a more concrete way than the definition does and also exemplify how linking adverbials are used. As mentioned in Section 2.4, form, meaning and position are three common and important aspects of usage patterns. In this chapter, the form of linking adverbials is discussed. The other two aspects of usage patterns, i.e., meaning and position, are explored in Chapter 6 and Chapter 7 respectively.

\subsection{Syntactic forms of linking adverbials}

Biber et al. (1999, p. 884) found in their corpus that linking adverbials can be realized by five syntactic structures and they list some typical items of each form as follows:

Single adverb - anyway, however, nevertheless, so, though, therefore

Adverb phrases - even so, first and foremost, more precisely

Prepositional phrases - by the way, for example, in addition, in conclusion, on the other hand

Finite clauses - that is, that is to say

Non-finite clauses - added to that, to conclude

Linking adverbials in the data set of WWC and WSC samples for this study are also found to take five different syntactic forms: single-word adverb, adverb phrase, prepositional phrase, finite clause and non-finite clause. The following five examples illustrate the five different forms of linking adverbials identified in this study.

In example 39, however is a single-word adverb.

39. He added, however, that given goodwill and a willingness to change, Railways could be a vital and essential part of the transport industry. (WWC A08, written news)

In example 40, even so is an adverb phrase.

40. The model in the present study was developed for the Bay of Plenty snapper stock. The snapper is New Zealand's most studied marine fish species. Even so, only one attempt has been made to model a snapper stock. (WWC J09, written academic prose)

In example 41, as a result is a prepositional phrase.

41. I/as a result the statistics department has a separate category under the heading jobless which shows that nearly two hundred and forty one thousand people were without work in march// (WSC MSN087, broadcast news) 
In example 42, I mean is a finite clause.

42. // i mean do you want// where's that tea gone// (WSC DPC096, conversation)

In example 43, to summarise is a non-finite clause.

43. // to summarise over the last thirty eight years/ there've been at least ninety adults/ that have been collected for the purposes of display/ and or breeding in the zoo situations//(WSC MUL011, academic lectures)

Findings of the current study echoed the research findings in Biber et al. (1999) that linking adverbials can take five different forms, as presented above. In their discussion, however, they only reported the form of linking adverbials in the two registers which they claim to have the most frequent use of linking adverbials: written academic prose and conversation. But as discussed in Section 4.5, the current study has found that academic lectures and conversation have significantly more frequent use of linking adverbials than other three analysed registers, i.e. written academic prose, written news and broadcast news. Description of the form of linking adverbials in academic lectures may help second language learners understand the usage patterns of linking adverbials in this register. Data on the form of linking adverbials in more registers allows comparison of register-specific usage patterns and may support teaching material design and language teaching and learning for specific and academic purposes.

Thus, in the following sections, the form of linking adverbials in the WWC and WSC samples are reported and compared among the five registers of written academic prose, written news, academic lectures, broadcast news and conversation and within the settings of academic English and news.

\subsection{Frequency of form of linking adverbials in different registers}

In this section, an overview of form of linking adverbials in WWC and WSC samples is given. Frequency patterns of form of linking adverbials are compared among different registers and social settings.

\subsubsection{Overview of form of linking adverbials in WWC and WSC samples}

As mentioned in Chapter 3, a random sample of texts of a total of around 20,000 words from each of five registers from the Wellington Corpora of New Zealand Written and Spoken English (WWC and WSC samples) has been analysed. Manual checking of all occurrences of linking adverbials has been carried out and for multi-functional words; only the linking 
adverbial uses are included here. In Table 16 below, the raw figures for each form in each of the five target registers are reported, along with the overall sample size of each register. In written academic prose, for example, the sample that was analysed totals 20,128 words, in which I identified 153 single-word adverbs, 29 prepositional phrases, four finite clauses and one adverb phrase and no instances of non-finite clause as linking adverbials.

Table 16 Form of linking adverbials in the five registers

\begin{tabular}{|l|l|l|l|l|l|l|}
\hline Form & $\begin{array}{l}\text { Written } \\
\text { academic } \\
\text { prose } \\
(20,128)\end{array}$ & $\begin{array}{l}\text { Written } \\
\text { news } \\
(21,001)\end{array}$ & $\begin{array}{l}\text { Academic } \\
\text { lectures } \\
(22,049)\end{array}$ & $\begin{array}{l}\text { Broadcast } \\
\text { news } \\
(21,623)\end{array}$ & $\begin{array}{l}\text { Conversation } \\
(21,279)\end{array}$ & $\begin{array}{l}\text { Total } \\
(106,08)\end{array}$ \\
\hline $\begin{array}{l}\text { Single- } \\
\text { word } \\
\text { adverb }\end{array}$ & 153 & 95 & 737 & 152 & 627 & 1,764 \\
\hline $\begin{array}{l}\text { Adverb } \\
\text { phrase }\end{array}$ & 1 & 0 & 36 & 0 & 36 & 73 \\
\hline $\begin{array}{l}\text { Finite } \\
\text { clause }\end{array}$ & 4 & 0 & 15 & 0 & 53 & 72 \\
\hline $\begin{array}{l}\text { Preposition } \\
\text { al phrase }\end{array}$ & 29 & 3 & 26 & 4 & 2 & 68 \\
\hline $\begin{array}{l}\text { Non-finite } \\
\text { clause }\end{array}$ & 0 & 0 & 1 & 0 & 0 & 1 \\
\hline Total & 187 & 98 & 815 & 157 & 723 & 1,979 \\
\hline
\end{tabular}

As shown in Table 17, single-word adverb is the most frequent form of linking adverbial in all five registers in the WWC and WSC samples. Log-likelihood statistics in Table 18 demonstrate that the frequency difference between single-word adverbs and the next most frequent form in each register is significant.

Table 17 Form of linking adverbials in the five registers (per 20,000 words)

\begin{tabular}{|l|l|l|l|l|l|}
\hline Form & $\begin{array}{l}\text { Written } \\
\text { academic prose }\end{array}$ & $\begin{array}{l}\text { Written } \\
\text { news }\end{array}$ & $\begin{array}{l}\text { Academic } \\
\text { lectures }\end{array}$ & $\begin{array}{l}\text { Broadcast } \\
\text { news }\end{array}$ & Conversation \\
\hline $\begin{array}{l}\text { Single-word } \\
\text { adverb }\end{array}$ & 152 & 90 & 669 & 141 & 589 \\
\hline Adverb phrase & 1 & 0 & 33 & 0 & 34 \\
\hline Finite clause & 4 & 0 & 14 & 0 & 50 \\
\hline $\begin{array}{l}\text { Prepositional } \\
\text { phrase }\end{array}$ & 29 & 3 & 24 & 4 & 2 \\
\hline $\begin{array}{l}\text { Non-finite } \\
\text { clause }\end{array}$ & 0 & 0 & 1 & 0 & 0 \\
\hline
\end{tabular}


Table $18 \mathrm{LL}$ of the form of single-word adverb and adverb phrase across registers

\begin{tabular}{|l|l|l|l|l|l|}
\hline Form & $\begin{array}{l}\text { Written } \\
\text { academic } \\
\text { prose }(20,128)\end{array}$ & $\begin{array}{l}\text { Written } \\
\text { news } \\
(21,001)\end{array}$ & $\begin{array}{l}\text { Academic } \\
\text { lectures } \\
(22,049)\end{array}$ & $\begin{array}{l}\text { Broadcast } \\
\text { news } \\
(21,623)\end{array}$ & $\begin{array}{l}\text { Conversation } \\
(21,279)\end{array}$ \\
\hline $\begin{array}{l}\text { Single-word } \\
\text { adverb }\end{array}$ & 153 & 95 & 737 & 152 & 627 \\
\hline $\begin{array}{l}\text { Adverb } \\
\text { phrase }\end{array}$ & 1 & 0 & 33 & 0 & 34 \\
\hline LL & 201.42 & 131.70 & 749.99 & 210.72 & 648.34 \\
\cline { 2 - 6 } & $\mathrm{p}<0.0001$ & $\mathrm{p}<0.0001$ & $\mathrm{p}<0.0001$ & $\mathrm{p}<0.0001$ & $\mathrm{p}<0.0001$ \\
\hline
\end{tabular}

As mentioned in Section 5.1, Biber, et al. (1999) presented their corpus findings of distribution of forms but only in the registers of conversation and academic prose. They reported the frequency of single adverb and prepositional phrase only, and they put all the other forms together because of their low percentage in the two registers. They found that in both conversation and written academic prose 'the majority of linking adverbials are realized by single adverbs' (Biber et al., 1999, p. 884). My findings agree with their results in the registers of written academic prose. My study has also yielded new findings in other registers such as academic lectures which are not included or reported in Biber, et al.'s (1999) grammar book. Adverb phrase is the second most frequent form of linking adverbials in academic lectures, for example.

Biber, et al. (1999) also found that in written academic prose, prepositional phrases are also relatively common, which is similar to my findings in the register of written academic prose. However, they list an example of to sum up in written academic prose as follows:

To sum up, the purpose of the present project was initially to make an applied study of some aspects of driver behaviour which might be relevant in the evaluation of measures to prevent wildlife accidents. (ACAD) (p. 885)

This is different from my findings. As shown in Table 16 above, no non-finite clauses as linking adverbials are found in the written academic prose of the WWC samples. A further automatic corpus search of the written academic prose of the whole WWC results in no findings. This difference may be explained by the following two points:

1. Different varieties of English were analysed. Biber, et al. (1999) based their analysis of the Longman Spoken and Written English Corpus, which is a collection of both American and British English. My data is from WWC, which is based on New Zealand English.

2. Larger corpora may result in more variation. LSWE has a total of 5,331,800 words of 
written academic prose, while written academic prose in the whole WWC totals only 196,695 words.

Liu (2008) is another register-specific study on linking adverbials but he did not report his findings on form realizations. Thus, in the following section, the frequency of forms across registers is presented and compared among registers without comparing with previous studies since no information is available beyond that already mentioned above.

In all five registers, non-finite clause is the least frequent form. Table 16 and Table 17 also show that academic lectures have the most variation of forms (five different forms) while the registers of news (written and broadcast) have the least variation (two different forms). Apart from these overall patterns, other frequency patterns of forms are not consistent across registers. Thus, in the following sections, forms are compared and discussed in detail among written registers (WWC), spoken registers (WSC), academic settings and news settings respectively (see Section 4.5 for a discussion on registers and settings).

\subsubsection{Form of linking adverbials in WWC samples}

As shown in Table 19 below, in written academic prose four different forms have been identified in the WWC samples: single-word adverb, prepositional phrase, finite clause and adverb phrase while in written news, only two different forms are found: single-word adverb and prepositional phrase. Biber, et al. in their across-register study also showed that academic prose has a relatively 'varied structural profile' (1999, p. 884).

\section{Table 19 Form of linking adverbials in WWC samples}

\begin{tabular}{|l|l|l|l|l|}
\hline Form & $\begin{array}{l}\text { Written academic prose } \\
(20,128)\end{array}$ & $\begin{array}{l}\text { Written news } \\
(21,001)\end{array}$ & \multicolumn{2}{l|}{ LL } \\
\hline $\begin{array}{l}\text { Single-word } \\
\text { adverb }\end{array}$ & 153 & 95 & 16.27 & $\mathrm{p}<0.0001$ \\
\hline $\begin{array}{l}\text { Prepositional } \\
\text { phrase }\end{array}$ & 29 & 7 & 15.39 & $\mathrm{p}<0.0001$ \\
\hline Finite clause & 4 & 0 & 5.72 & $\mathrm{p}<0.05$ \\
\hline Adverb phrase & 1 & 0 & 1.43 & $\mathrm{~ns}$ \\
\hline Non-finite clause & 0 & 0 & 0 & $\mathrm{~ns}$ \\
\hline
\end{tabular}

As the most frequent form in both registers, single-word adverb is used significantly more frequently in academic prose than in written news. Prepositional phrase is the second most frequently used form in both registers and again it is significantly more frequent in written academic prose. Finite clause is also significantly more frequent in written academic prose than in written news. All are consistent with the pattern that linking adverbials in general are 
more frequently used in written academic prose (see Section 4.5 for the overview of frequency of linking adverbials across registers).

This section has discussed the form of linking adverbials in written English. The next section reports form realizations in spoken registers.

\subsubsection{Form of linking adverbials in WSC samples}

As shown in Table 20 below, in WSC samples academic lectures have the most variation of forms: single-word adverb, prepositional phrase, adverb phrase, finite clause and non-finite clause, while broadcast news has the least: single-word adverb and prepositional phrase only.

Table 20 Form of linking adverbials in WSC samples

\begin{tabular}{|l|l|l|l|}
\hline Form & $\begin{array}{l}\text { Academic lectures } \\
(22,049)\end{array}$ & $\begin{array}{l}\text { Conversation } \\
(21,279)\end{array}$ & $\begin{array}{l}\text { Broadcast news } \\
(21,623)\end{array}$ \\
\hline $\begin{array}{l}\text { Single-word } \\
\text { adverb }\end{array}$ & 737 & 627 & 152 \\
\hline $\begin{array}{l}\text { Prepositional } \\
\text { phrase }\end{array}$ & 26 & 2 & 4 \\
\hline Adverb phrase & 36 & 36 & 0 \\
\hline Finite clause & 15 & 53 & 0 \\
\hline Non-finite clause & 1 & 0 & 0 \\
\hline
\end{tabular}

Academic lectures have the most frequent use of single-word adverb and prepositional phrase while conversation has the most frequent use of finite clause. As shown in Tables 21, 22 and 23 below, these differences are significant.

Table $21 \mathrm{LL}$ of form of linking adverbials in academic lectures and conversation

\begin{tabular}{|l|l|l|l|l|}
\hline Form & $\begin{array}{l}\text { Academic lectures } \\
(22,049)\end{array}$ & $\begin{array}{l}\text { Conversation } \\
(21,279)\end{array}$ & LL \\
\hline Single-word adverb & 737 & 627 & 5.40 & $\mathrm{p}<0.05$ \\
\hline Prepositional phrase & 26 & 2 & 23.56 & $\mathrm{p}<0.0001$ \\
\hline Adverb phrase & 36 & 36 & 0.02 & $\mathrm{~ns}$ \\
\hline Finite clause & 15 & 53 & 23.88 & $\mathrm{p}<0.0001$ \\
\hline Non-finite clause & 1 & 0 & 1.35 & $\mathrm{~ns}$ \\
\hline
\end{tabular}

Table $22 \mathrm{LL}$ of form of linking adverbials in conversation and broadcast news

\begin{tabular}{|l|l|l|l|l|}
\hline Form & $\begin{array}{l}\text { Conversation } \\
(21,279)\end{array}$ & $\begin{array}{l}\text { Broadcast news } \\
(21,623)\end{array}$ & LL \\
\hline Single-word adverb & 627 & 152 & 318.62 & $\mathrm{p}<0.0001$ \\
\hline Prepositional phrase & 2 & 4 & 0.65 & $\mathrm{~ns}$ \\
\hline Finite clause & 53 & 0 & 74.33 & $\mathrm{p}<0.0001$ \\
\hline Adverb phrase & 36 & 0 & 50.49 & $\mathrm{p}<0.0001$ \\
\hline Non-finite clause & 0 & 0 & 0 & $\mathrm{~ns}$ \\
\hline
\end{tabular}


Table 23 LL of form of linking adverbials in academic lectures and broadcast news

\begin{tabular}{|l|l|l|l|l|}
\hline Form & $\begin{array}{l}\text { Academic lectures } \\
(22,049)\end{array}$ & $\begin{array}{l}\text { Broadcast news } \\
(21,623)\end{array}$ & LL & \multicolumn{2}{l|}{} \\
\hline Single-word adverb & 737 & 152 & 407.77 & $\mathrm{p}<0.0001$ \\
\hline Prepositional phrase & 26 & 4 & 17.6 & $\mathrm{p}<0.0001$ \\
\hline Adverb phrase & 36 & 0 & 49.21 & $\mathrm{p}<0.0001$ \\
\hline Finite clause & 15 & 0 & 20.50 & $\mathrm{p}<0.0001$ \\
\hline Non-finite clause & 1 & 0 & 1.37 & $\mathrm{~ns}$ \\
\hline
\end{tabular}

The form of linking adverbials in both written English and spoken English has been reported and compared. The following two sections explain and discuss the form of linking adverbials in academic and news settings.

\subsubsection{Form of linking adverbials in academic settings}

As shown in Table 24 below, written academic prose and academic lectures both have a very varied structure profile, i.e., in written academic prose four different forms are found and in academic lectures five are identified.

Table 24 Form of linking adverbials in academic settings

\begin{tabular}{|l|l|l|l|l|}
\hline Form & $\begin{array}{l}\text { Written academic } \\
\text { prose }(20,128)\end{array}$ & $\begin{array}{l}\text { Academic lectures } \\
(22,049)\end{array}$ & LL & \multicolumn{2}{l|}{} \\
\hline Single-word adverb & 153 & 737 & 365.57 & $\mathrm{p}<0.0001$ \\
\hline Prepositional phrase & 29 & 26 & 0.55 & $\mathrm{~ns}$ \\
\hline Finite clause & 4 & 15 & 5.82 & $\mathrm{p}<0.05$ \\
\hline Adverb phrase & 1 & 36 & 38.98 & $\mathrm{p}<0.0001$ \\
\hline Non-finite clause & 0 & 1 & 1.30 & $\mathrm{~ns}$ \\
\hline
\end{tabular}

The two registers share a similar pattern in that the single-word adverb provides the bulk of the linking adverbial forms used and prepositional phrase is somewhat frequent in both registers.

The two registers differ in that in academic lectures adverb phrase is the second most frequent form of linking adverbial, while in written academic prose it used only once in this data set.

The two registers also differ in that the form of single-word adverb, finite clause and adverb phrase are significantly more frequently used in academic lectures. The difference of the use of the other two forms, i.e., prepositional phrase and non-finite clause is not significant.

The above findings help second language learners further understand and be aware of the form patterns within the register of written academic prose and academic lectures and the difference between written and spoken English in academic settings. 
In the next section, the difference between written and spoken English in the news settings is discussed.

\subsubsection{Form of linking adverbials in news settings}

As shown in Table 25 below, written news and broadcast news share a similar pattern in that only two forms (single-word adverb and prepositional phrase) are found in both registers, with single-word adverb far more frequently used than prepositional phrase. Such similarity may be because broadcast news is normally scripted.

Table 25 Form of linking adverbials in news settings

\begin{tabular}{|l|l|l|l|l|}
\hline Form & $\begin{array}{l}\text { Written news } \\
(21,001)\end{array}$ & $\begin{array}{l}\text { Broadcast news } \\
(21,623)\end{array}$ & \multicolumn{2}{l|}{ LL } \\
\hline Single-word adverb & 95 & 152 & 11.66 & $\mathrm{p}<0.001$ \\
\hline Prepositional phrase & 7 & 4 & 0.92 & $\mathrm{~ns}$ \\
\hline Finite clause & 0 & 0 & 0 & $\mathrm{~ns}$ \\
\hline Adverb phrase & 0 & 0 & 0 & $\mathrm{~ns}$ \\
\hline Non-finite clause & 0 & 0 & 0 & $\mathrm{~ns}$ \\
\hline
\end{tabular}

The only significant difference between the two registers is that single-word adverb is more frequently used in broadcast news. This is consistent with the higher frequency of linking adverbials in spoken registers than in written registers.

The frequency information presented in the above sections will help researchers and language teachers and learners understand the structural profile in each register and will also shed light on language research and teaching in terms of which register, which form should be given priority in future research, teaching material design and classrooms.

For researchers, language teachers and learners, however, frequency information may not be informative enough when they come to practical identification and use of linking adverbials in different registers. Thus in the following sections, types of each form in each register are presented and discussed.

\subsection{Types of form of linking adverbials in different registers}

In this section, an overview of types of different forms of linking adverbials in the five registers is given. Types of different forms of linking adverbials are also compared among different written and spoken registers and within academic and news settings. 


\subsubsection{Types of each form in WWC and WSC samples}

In Table 26 below, all types of linking adverbial forms which occurred in the WWC and WSC data sets are listed and their range and raw frequency in each register are also provided (e.g. and in written academic prose, range: 4, frequency: 7). Range in this context means in how many texts out of the total number of analysed texts a particular linking adverbial occurred. The range information for and in written academic prose is four, which means in the total of 10 texts analysed, and appears in four texts, although the overall frequency of and as a linking adverbial in written academic prose is seven.

\section{Table 26 Types of each form in WWC and WSC samples}

(* number of texts analysed/ number of total words of the random sample; + range/frequency)

\begin{tabular}{|c|c|c|c|c|c|c|c|}
\hline \multirow[t]{30}{*}{$\begin{array}{l}\text { Form } \\
\text { Single-word } \\
\text { adverb }\end{array}$} & Types & $\begin{array}{l}\text { Written } \\
\text { academic } \\
\text { prose } \\
\left(10 / 20,128^{*}\right)\end{array}$ & $\begin{array}{l}\text { Written } \\
\text { news } \\
(10 / 21,001)\end{array}$ & $\begin{array}{l}\text { Academic } \\
\text { lectures } \\
(10 / 22,049)\end{array}$ & $\begin{array}{l}\text { Broadcast } \\
\text { news } \\
(28 / 21,623)\end{array}$ & $\begin{array}{l}\text { Conversation } \\
(9 / 21,279)\end{array}$ & Total \\
\hline & and & $4 / 7+$ & $3 / 4$ & $10 / 292$ & $26 / 73$ & $9 / 264$ & 640 \\
\hline & but & $4 / 11$ & $9 / 26$ & $10 / 78$ & $21 / 45$ & $9 / 192$ & 352 \\
\hline & so & $3 / 8$ & $2 / 3$ & $10 / 175$ & $2 / 3$ & $9 / 121$ & 310 \\
\hline & then & $6 / 24$ & $3 / 5$ & $10 / 77$ & & $3 / 8$ & 114 \\
\hline & also & $10 / 18$ & $8 / 25$ & $10 / 24$ & $13 / 23$ & $3 / 3$ & 93 \\
\hline & now & $1 / 2$ & & $9 / 55$ & & & 57 \\
\hline & however & $10 / 28$ & $7 / 17$ & $1 / 1$ & $2 / 2$ & & 48 \\
\hline & or & $1 / 2$ & $1 / 1$ & $5 / 8$ & & $6 / 12$ & 23 \\
\hline & though & & & & & $5 / 18$ & 18 \\
\hline & therefore & $5 / 8$ & $1 / 2$ & $4 / 7$ & & & 17 \\
\hline & still & & $4 / 4$ & $2 / 6$ & & $1 / 3$ & 13 \\
\hline & thus & $5 / 10$ & $1 / 1$ & & & & 11 \\
\hline & actually & & & $2 / 4$ & & $2 / 3$ & 7 \\
\hline & secondly & $2 / 4$ & & $1 / 2$ & & & 6 \\
\hline & anyway & & $1 / 1$ & $1 / 3$ & & $2 / 2$ & 6 \\
\hline & meanwhile & & $1 / 2$ & & $3 / 3$ & & 5 \\
\hline & first & $3 / 5$ & & & & $1 / 1$ & 6 \\
\hline & alternatively & $3 / 3$ & & & & & 3 \\
\hline & namely & $2 / 3$ & & & & & 3 \\
\hline & yet & $2 / 3$ & & & & & 3 \\
\hline & hence & $2 / 3$ & & & & & 3 \\
\hline & furthermore & $2 / 2$ & $1 / 1$ & & & & 3 \\
\hline & finally & & & & $3 / 3$ & & 3 \\
\hline & otherwise & & & & & $3 / 3$ & 3 \\
\hline & further & $2 / 2$ & & & & & 2 \\
\hline & too & $1 / 2$ & & & & & 2 \\
\hline & similarly & $1 / 2$ & & & & & 2 \\
\hline & firstly & & & $2 / 2$ & & & 2 \\
\hline & thereby & & $1 / 1$ & $1 / 1$ & & & 2 \\
\hline
\end{tabular}




\begin{tabular}{|c|c|c|c|c|c|c|c|}
\hline & rather & & $1 / 1$ & & & & 1 \\
\hline & second & $1 / 1$ & & & & & 1 \\
\hline & consequently & $1 / 1$ & & & & & 1 \\
\hline & accordingly & $1 / 1$ & & & & & 1 \\
\hline & nevertheless & $1 / 1$ & & $1 / 1$ & & & 1 \\
\hline & likewise & $1 / 1$ & & & & & 1 \\
\hline & additionally & $1 / 1$ & & & & & 1 \\
\hline & meantime & & & & $1 / 1$ & & 1 \\
\hline & instead & & & $1 / 1$ & & & 1 \\
\hline & ultimately & & & $1 / 1$ & & & 1 \\
\hline \multirow{16}{*}{$\begin{array}{l}\text { Prepositional } \\
\text { phrase }\end{array}$} & for example & $9 / 15$ & & $3 / 4$ & & $1 / 1$ & 20 \\
\hline & in other words & $2 / 3$ & & $3 / 7$ & & $1 / 1$ & 11 \\
\hline & in fact & $3 / 3$ & & $3 / 6$ & & & 9 \\
\hline & in addition & $2 / 2$ & $1 / 1$ & $1 / 1$ & $1 / 1$ & & 5 \\
\hline & in the meantime & $1 / 1$ & $1 / 1$ & & $1 / 1$ & & 3 \\
\hline & as a result & & $1 / 1$ & & $2 / 2$ & & 3 \\
\hline & of course & & & $2 / 3$ & & & 3 \\
\hline & by the way & & & $2 / 3$ & & & 3 \\
\hline & on the one hand & $1 / 1$ & & & & & 1 \\
\hline & at the same time & $1 / 1$ & & & & & 1 \\
\hline & on the other hand & $1 / 1$ & & $1 / 1$ & & & 2 \\
\hline & in one & $1 / 1$ & & & & & 1 \\
\hline & in the second & $1 / 1$ & & & & & 1 \\
\hline & in short & $1 / 1$ & & & & & 1 \\
\hline & after all & & $1 / 1$ & & & & 1 \\
\hline & for instance & & & $1 / 1$ & & & 1 \\
\hline \multirow[t]{2}{*}{ finite clause } & I mean & & & $4 / 14$ & & $9 / 52$ & 66 \\
\hline & that is & $3 / 4$ & & & & & 4 \\
\hline \multirow[t]{7}{*}{ Adverb phrase } & and then & & & $6 / 19$ & & $9 / 30$ & 49 \\
\hline & first of all & & & $4 / 9$ & & & 9 \\
\hline & but then & & & $1 / 1$ & & $4 / 8$ & 9 \\
\hline & so then & & & $1 / 3$ & & $1 / 1$ & 4 \\
\hline & even so & $1 / 1$ & & & & & 1 \\
\hline & first off & & & $1 / 1$ & & & 1 \\
\hline & and also & & & $1 / 1$ & & & 1 \\
\hline $\begin{array}{l}\text { Non-finite } \\
\text { clause }\end{array}$ & to summarize & & & $1 / 1$ & & & 1 \\
\hline Total & & 188 & 98 & 813 & 157 & 723 & 1,979 \\
\hline
\end{tabular}

Frequency information across registers shows tendencies in how often a particular linking adverbial is used in a particular register, while range information across registers demonstrates how typical a particular linking adverbial is in a particular register. The linking adverbials however, for example, is the most frequently used single-word adverb in written academic prose and it is typical in that it is used as a linking adverbial in all ten texts in the sample. In written news, however is also quite frequently used, though not the most 
frequently. It is also somewhat typical of written news in that it occurs in seven of the 10 texts in the sample. It is very rarely used in spoken registers.

As mentioned above, frequency data only show tendencies. In conversation, for example, the fact that no tokens of however are found in the data set does not necessarily mean that however is not used in conversation at all. In fact, an automatic corpus search of the whole WSC shows one token, but that token may reflect a personal stylistic preference, which is not typical of the register and this in turn shows that range information is necessary and important.

In Table 26 above, the total number of texts and the total number of words in the random samples of each register are also presented, which gives a better idea of the meaning of the range and frequency information of each single linking adverbial when compared to the overall contexts.

In total, 39 different types of single-word adverbs, 16 types of prepositional phrases, two types of finite clauses, seven types of adverb phrases and one type of none-finite clause are found. The variation in terms of different types of words used (e.g. however and then are two different types) within single-word adverb is the biggest. Biber et al. (1999, p. 884) also wrote that 'single adverbs are the most numerous and semantically varied structure that realizes linking adverbials' in their findings of written academic prose and conversation.

Finite clause is frequent in some registers but the variation within it is very small and the distinction between written and spoken registers is clear cut, with that is as the only realization of finite clause in written registers and I mean as the only realization of finite clause in spoken registers.

The most frequent types of linking adverbials across the five registers fall almost exclusively into the category of single-word adverbs, which contributes to the finding that single-word adverb is the most frequent form of linking adverbials in all five registers. In their discussion on findings from written academic prose and conversation, Biber et al. (1999, p. 884) have similar findings that 'the most common linking adverbials are almost exclusively adverbs' and that 'it is thus not surprisingly that adverbs account for the vast majority of linking adverbials'.

Some types (e.g. also, but and and) are uniformly relatively frequently used in all the five registers while some are more frequently used (e.g. for example more frequently used in written academic prose) or exclusively used in a certain register (e.g. though only used in 
conversation). Thus, the following sections compare and discuss the types of each form among written and spoken registers and within academic and news settings.

\subsubsection{Types of each form in WWC samples}

As shown in Table 27 below, when compared with written news, written academic prose shows more varied types of single-word adverbs and prepositional phrases as linking adverbials. In written academic prose, 27 different types of single-word adverbs and 11 different types of prepositional phrases are found while in written news 15 different types of single-word adverbs and four different types of prepositional phrases are identified. This means written academic prose has a more varied repertoire of types of linking adverbials than written news does.

\section{Table 27 Types of each form in WWC samples}

(* number of texts analysed/ number of total words of the random sample; + range/frequency)

\begin{tabular}{|c|c|c|c|}
\hline Form & Types & Written academic prose $(10 / 20,128 *)$ & Written news $(10 / 21,001)$ \\
\hline \multirow[t]{29}{*}{ Single-word adverb } & however & $10 / 28+$ & $7 / 20$ \\
\hline & then & $6 / 24$ & $3 / 5$ \\
\hline & also & $10 / 20$ & $8 / 29$ \\
\hline & but & $4 / 11$ & $9 / 30$ \\
\hline & thus & $5 / 10$ & $1 / 1$ \\
\hline & so & $3 / 8$ & $2 / 4$ \\
\hline & therefore & $5 / 8$ & $1 / 2$ \\
\hline & and & $4 / 7$ & $5 / 6$ \\
\hline & first & $3 / 5$ & \\
\hline & still & & $5 / 5$ \\
\hline & secondly & $2 / 4$ & \\
\hline & further & $3 / 3$ & \\
\hline & alternatively & $3 / 3$ & \\
\hline & namely & $2 / 3$ & \\
\hline & yet & $2 / 3$ & \\
\hline & hence & $2 / 3$ & \\
\hline & furthermore & $2 / 2$ & $1 / 1$ \\
\hline & rather & & $2 / 2$ \\
\hline & or & $1 / 2$ & $1 / 1$ \\
\hline & meanwhile & & $1 / 2$ \\
\hline & again & $1 / 2$ & \\
\hline & now & $1 / 2$ & \\
\hline & too & $1 / 2$ & \\
\hline & similarly & $1 / 2$ & \\
\hline & second & $1 / 1$ & \\
\hline & consequently & $1 / 1$ & \\
\hline & accordingly & $1 / 1$ & \\
\hline & nevertheless & $1 / 1$ & \\
\hline & likewise & $1 / 1$ & \\
\hline
\end{tabular}




\begin{tabular}{|c|c|c|c|}
\hline & additionally & $1 / 1$ & \\
\hline & thereby & & $1 / 1$ \\
\hline & anyway & & $1 / 1$ \\
\hline \multirow[t]{13}{*}{ Prepositional phrase } & for example & $9 / 15$ & \\
\hline & in fact & $3 / 3$ & \\
\hline & in addition & $2 / 2$ & $3 / 3$ \\
\hline & in other words & $2 / 2$ & \\
\hline & at the same time & $1 / 1$ & \\
\hline & in the meantime & $1 / 1$ & $1 / 1$ \\
\hline & in one & $1 / 1$ & \\
\hline & in the second & $1 / 1$ & \\
\hline & in short & $1 / 1$ & \\
\hline & on the one hand & $1 / 1$ & \\
\hline & on the other hand & $1 / 1$ & \\
\hline & as a result & & $1 / 1$ \\
\hline & after all & & $1 / 1$ \\
\hline finite clause & that is & $3 / 4$ & \\
\hline Adverb phrase & even so & $1 / 1$ & \\
\hline
\end{tabular}

But the frequency of each type varies between the two registers. For example, however is the most frequently used single-word adverb in written academic prose and is more frequently used than but, while but is the most frequently used single-word adverb in written news and is more frequently used than however.

In order to investigate the statistical significance of the above-mentioned difference, the following section reports the most frequent types of linking adverbials in larger corpora of different English varieties (e.g. BNC and COCA).

\subsubsection{1 however, also and but in WWC, BNC and COCA}

\section{1. however, also, and but in WWC samples}

As shown in Table 27 above, however, also and but are the only three words that are relatively frequently used and whose range is relatively high in both the register of written academic prose and the register of written news. Table 28 below shows the statistical difference in the frequency of the three words in the two registers of WWC samples. Only but is statistically more frequently used in written news than in written academic prose in WWC samples.

Table 28 however, also, and but in WWC samples

\begin{tabular}{|l|l|l|l|}
\hline $\begin{array}{l}\text { Written academic prose } \\
(20,128)\end{array}$ & $\begin{array}{l}\text { Written news } \\
(21,001)\end{array}$ & LL & \\
\hline however $(28)$ & however $(20)$ & 1.70 & ns \\
\hline also (20) & also (29) & 1.30 & ns \\
\hline but (11) & but (30) & 8.36 & $\mathrm{p}<0.01$ \\
\hline
\end{tabular}




\section{2. however, also, and but in WWC, BNC and COCA}

As shown in Tables 29, 30 and 31 below, the whole WWC, BNC and COCA demonstrate statistical difference in frequency of however, but and also as linking adverbials in written academic prose and written news (see Chapter 2 for a discussion on automatic search for word forms as linking adverbials).

Table 29 Frequency of however, also, and but in WWC

\begin{tabular}{|l|l|l|l|l|}
\hline LA & Register-specific frequency (WWC) & \multicolumn{2}{l|}{} \\
\hline & $\begin{array}{l}\text { Written academic prose } \\
(196,695)\end{array}$ & $\begin{array}{c}\text { Written news } \\
(116,408)\end{array}$ & LL & \multicolumn{2}{l|}{} \\
\hline however & 180 & 55 & 20.46 & $\mathrm{p}<0.0001$ \\
\hline but & 78 & 140 & 65.23 & $\mathrm{p}<0.0001$ \\
\hline also & 255 & 118 & 5.02 & $\mathrm{p}<0.05$ \\
\hline
\end{tabular}

Table 30 Frequency of however, also, and but in BNC

\begin{tabular}{|l|l|l|l|l|}
\hline LA & Register-specific frequency $(\mathrm{BNC})$ & \multicolumn{2}{|l|}{} \\
\hline & $\begin{array}{l}\text { Written academic prose } \\
(15,331,668)\end{array}$ & $\begin{array}{l}\text { Written news } \\
(10,446,422)\end{array}$ & \multicolumn{2}{l|}{ LL } \\
\hline however & 18,062 & 3,934 & 5216.4 & $\mathrm{p}<0.0001$ \\
\hline but & 10,276 & 17,892 & 6037.27 & $\mathrm{p}<0.0001$ \\
\hline also & 13,244 & 24,161 & 8789.61 & $\mathrm{p}<0.0001$ \\
\hline
\end{tabular}

Table 31 Frequency of however, also, and but in COCA

\begin{tabular}{|l|l|l|l|l|}
\hline LA & Register-specific frequency (COCA) & \multicolumn{2}{|l|}{} \\
\hline & $\begin{array}{l}\text { Written academic prose } \\
(91,066,191)\end{array}$ & $\begin{array}{l}\text { Written news } \\
(91,717,452)\end{array}$ & \multicolumn{2}{|l|}{ LL } \\
\hline however & 79,892 & 22,221 & 34983.32 & $\mathrm{p}<0.0001$ \\
\hline but & 44,312 & 98,688 & 20820.45 & $\mathrm{p}<0.0001$ \\
\hline also & 112,905 & 148,511 & 4614.39 & $\mathrm{p}<0.0001$ \\
\hline
\end{tabular}

In WWC, BNC and COCA, the frequency pattern of however and but as linking adverbials in two written registers shows no difference among the three corpora of WWC, BNC and COCA, with however being used statistically more frequently in written academic prose and but being used statistically more frequently in written news. However, the frequency patterns of also vary across corpora. The linking adverbial also is used statistically more frequently in written academic prose in WWC, but more frequently in written news in BNC and COCA. The different frequency pattern of also in different corpora shows a difference between American English, British English and New Zealand English. It also shows the relationship between British English and New Zealand English is closer than the relationship between 
American English and New Zealand English in terms of their use of certain linking adverbials (e.g. also).

\subsubsection{Types of each form in WSC samples}

As shown in Table 32 below, single-word adverb, the most frequent form of linking adverbial in spoken registers, has the most variation in types of single-word adverb in the register of academic lectures and the least variation in broadcast news. In the WSC samples, 17 different types of single-word adverbs are found in the register of academic lecture, eight are identified in the register of broadcast news and 11 are used in the register of conversation.

\section{Table 32 Types of each form in WSC samples}

(* number of texts analysed/ number of total words of the random sample; + range/frequency)

\begin{tabular}{|c|c|c|c|c|}
\hline \multirow{23}{*}{$\begin{array}{l}\text { Form } \\
\text { Single-word } \\
\text { adverb }\end{array}$} & Types & $\begin{array}{l}\text { Academic lecture } \\
(10 / 22049 *)\end{array}$ & Broadcast news $(28 / 21,623)$ & $\begin{array}{l}\text { Conversation } \\
(9 / 21,279)\end{array}$ \\
\hline & and & $10 / 292+$ & $26 / 73$ & $9 / 264$ \\
\hline & but & $10 / 82$ & $21 / 45$ & $9 / 192$ \\
\hline & so & $10 / 172$ & $2 / 3$ & $9 / 123$ \\
\hline & then & $10 / 77$ & & $3 / 10$ \\
\hline & also & $10 / 24$ & $13 / 23$ & $3 / 3$ \\
\hline & however & $1 / 1$ & $2 / 2$ & \\
\hline & therefore & $4 / 7$ & & \\
\hline & still & $2 / 6$ & & $1 / 3$ \\
\hline & secondly & $1 / 2$ & & \\
\hline & or & $5 / 8$ & & $6 / 11$ \\
\hline & meanwhile & & $3 / 3$ & \\
\hline & now & $9 / 55$ & & \\
\hline & nevertheless & $1 / 1$ & & \\
\hline & anyway & $1 / 3$ & & $2 / 2$ \\
\hline & actually & $2 / 4$ & & $2 / 3$ \\
\hline & firstly & $2 / 2$ & & \\
\hline & instead & $1 / 1$ & & \\
\hline & ultimately & $1 / 1$ & & \\
\hline & finally & & $3 / 3$ & \\
\hline & meantime & & $1 / 1$ & \\
\hline & though & & & $5 / 18$ \\
\hline & otherwise & & & $3 / 3$ \\
\hline \multirow{9}{*}{$\begin{array}{l}\text { Prepositional } \\
\text { phrase }\end{array}$} & for example & $3 / 4$ & & $1 / 1$ \\
\hline & in fact & $3 / 6$ & & \\
\hline & in addition & $1 / 1$ & $1 / 1$ & \\
\hline & in other words & $3 / 7$ & & $1 / 1$ \\
\hline & in the meantime & & $1 / 1$ & \\
\hline & on the one hand & $1 / 1$ & & \\
\hline & as a result & & $2 / 2$ & \\
\hline & of course & $2 / 3$ & & \\
\hline & by the way & $2 / 3$ & & \\
\hline
\end{tabular}




\begin{tabular}{|l|l|l|l|l|}
\hline & for instance & $1 / 1$ & & \\
\hline Finite clause & I mean & $4 / 15$ & & $9 / 53$ \\
\hline \multirow{4}{*}{ Adverb phrase } & and then & $6 / 21$ & & $9 / 27$ \\
\cline { 2 - 5 } & first of all & $4 / 9$ & & \\
\cline { 2 - 5 } & so then & $1 / 3$ & & $1 / 1$ \\
\hline & but then & $1 / 1$ & & $4 / 8$ \\
\hline & first off & $1 / 1$ & & \\
\cline { 2 - 5 } & and also & $1 / 1$ & & \\
\hline Non-finite clause & to sum up & $1 / 1$ & & \\
& & & & \\
\hline
\end{tabular}

Despite the variation in single-word adverbs, a few of these have a very high frequency in all three spoken registers. In academic lectures, five single-word adverbs, and, so, but, then and now, occur with high frequency, in broadcast news, and, but and also occur with high frequency and in conversation, and, so and but occur with high frequency. These highfrequency forms may need to be given priority in language teaching and learning in different contexts.

Different from written registers, in which the frequency of each type varies (see Section 5.3.2), in spoken registers, some words are uniformly more frequent across registers. And is the most common type in all three spoken registers. It not only has the highest frequency in all three spoken registers but also its range information indicates that it is uniformly or almost uniformly preferred in all three registers. But is another type commonly used across the three spoken registers, though not as frequent as and. The high frequency of and and but means that understanding the use of and and but as linking adverbials and their usage patterns in spoken registers is important. This is not made explicit in existing comprehensive grammar books or corpus-based studies of linking adverbials.

The variation in types of finite clauses and adverb phrases is much smaller than that of singleword adverbs. I mean is the only realization of a finite clause (as mentioned in Section 5.3.1). The linking adverbial and then is the most frequent type of adverb phrase in both academic lectures and conversation, though academic lecture has a slightly more varied realization of types than conversation does. This also has implications for language teaching and learning in terms of what types of finite clause and adverb phrase can be used to make discourse cohesive in spoken registers and which type should be given priority in classroom.

\subsubsection{Types of each form in academic settings}

As shown in Table 33 below, written academic prose and academic lectures both have very varied types of linking adverbials (27 in written academic prose and 17 in academic lectures). 
But academic lectures have more high frequency types which contribute to the overall frequency of the form of single-word adverb, six in academic lecture (then, also, but, so, and and now) and three in written academic prose (however, then, and also).

Table 33 Types of each form in academic settings

(* number of texts analysed/ number of total words of the random sample; + range/frequency)

\begin{tabular}{|c|c|c|c|}
\hline \multirow{34}{*}{$\begin{array}{l}\text { Form } \\
\text { Single-word } \\
\text { adverb }\end{array}$} & Types & Written academic prose $(10 / 20,128 *)$ & Academic lectures (10/22049) \\
\hline & however & $10 / 28+$ & $1 / 1$ \\
\hline & then & $6 / 24$ & $10 / 77$ \\
\hline & also & $10 / 20$ & $10 / 24$ \\
\hline & but & $4 / 11$ & $10 / 82$ \\
\hline & thus & $5 / 10$ & \\
\hline & so & $3 / 8$ & $10 / 172$ \\
\hline & therefore & $5 / 8$ & $4 / 7$ \\
\hline & and & $4 / 7$ & $10 / 292$ \\
\hline & first & $3 / 5$ & \\
\hline & still & & $2 / 6$ \\
\hline & secondly & $2 / 4$ & $1 / 2$ \\
\hline & further & $3 / 3$ & \\
\hline & alternatively & $3 / 3$ & \\
\hline & namely & $2 / 3$ & \\
\hline & yet & $2 / 3$ & \\
\hline & hence & $2 / 3$ & \\
\hline & furthermore & $2 / 2$ & \\
\hline & or & $1 / 2$ & $5 / 8$ \\
\hline & again & $1 / 2$ & \\
\hline & now & $1 / 2$ & $9 / 55$ \\
\hline & too & $1 / 2$ & \\
\hline & similarly & $1 / 2$ & \\
\hline & second & $1 / 1$ & \\
\hline & consequently & $1 / 1$ & \\
\hline & accordingly & $1 / 1$ & \\
\hline & nevertheless & $1 / 1$ & $1 / 1$ \\
\hline & likewise & $1 / 1$ & \\
\hline & additionally & $1 / 1$ & \\
\hline & anyway & & $1 / 3$ \\
\hline & actually & & $2 / 4$ \\
\hline & firstly & & $2 / 2$ \\
\hline & instead & & $1 / 1$ \\
\hline & ultimately & & $1 / 1$ \\
\hline \multirow{7}{*}{$\begin{array}{l}\text { Prepositional } \\
\text { phrase }\end{array}$} & for example & $9 / 15$ & $3 / 4$ \\
\hline & in fact & $3 / 3$ & $3 / 6$ \\
\hline & in addition & $2 / 2$ & $1 / 1$ \\
\hline & in other words & $2 / 2$ & $3 / 7$ \\
\hline & at the same time & $1 / 1$ & \\
\hline & in the meantime & $1 / 1$ & \\
\hline & in one & $1 / 1$ & \\
\hline
\end{tabular}




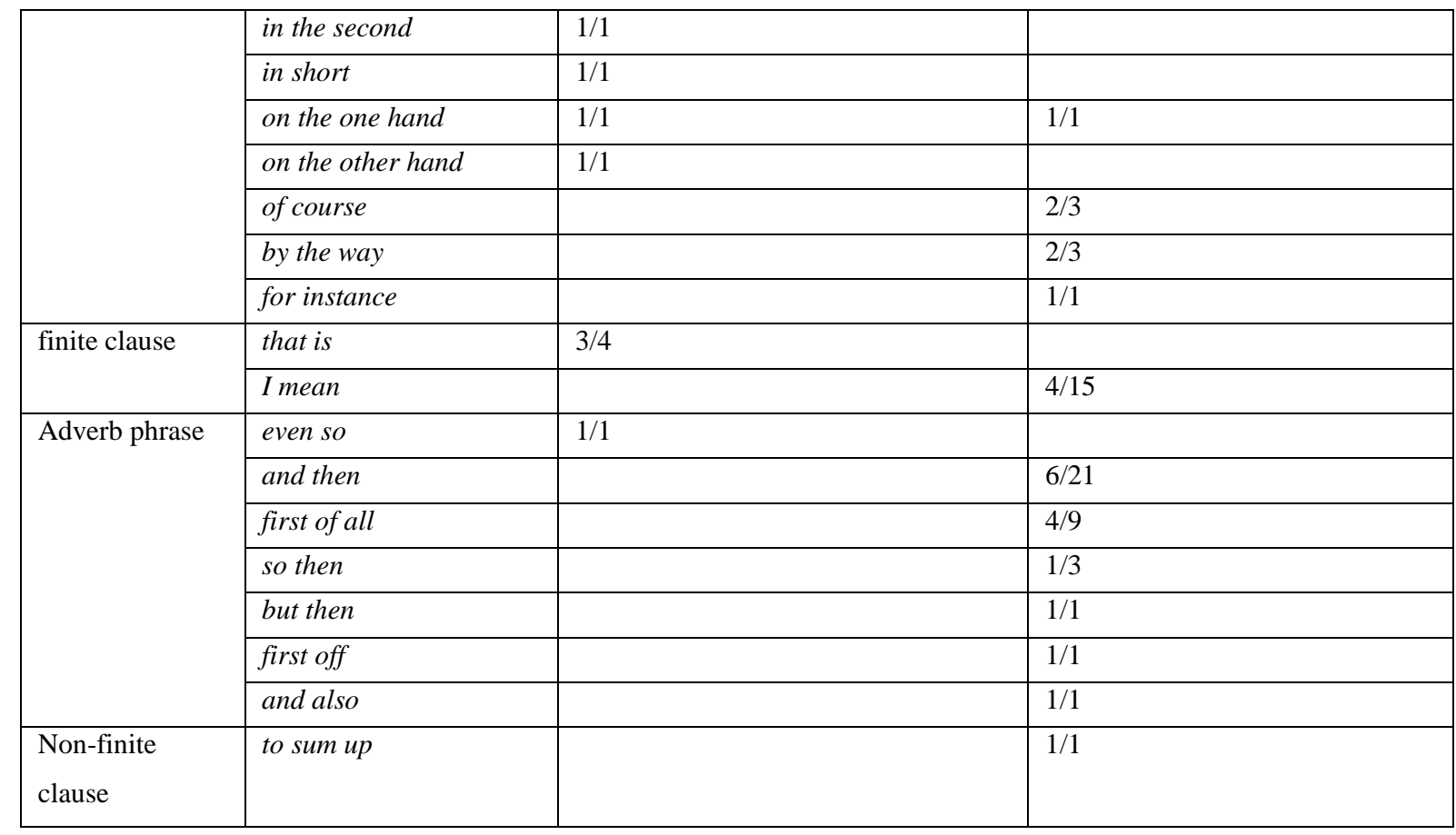

Academic lectures also have more uniformly preferred (used in all texts analysed in a certain register) types than written academic prose does. Five (then, also, but, so, and and) are uniformly used in academic lectures while only two (however, and also) are uniformly adopted in written academic prose.

Some types of single-word adverbs are very frequently used in written academic prose but are very rarely used in academic lectures and vice versa. However is very frequently used in written academic prose but is very rarely used in academic lectures while now is very frequently used in academic lectures but is very rarely used in written academic prose.

The two forms of finite clause and adverb phrase in written academic prose and academic lectures have a very distinctive collection of types. The type even so, for example, is the only adverb phrase used in written academic prose but academic lectures have a totally different collection: and then, first of all, so then, but then, and and also.

The above reported findings demonstrate that in academic setting, there is quite a distinctive difference in using linking adverbials in spoken and written English.

\subsubsection{Types of each form in news settings}

As shown in Table 34 below, the difference in forms and types used in the news setting is not as great as in the academic setting. Written news has more different types of single-word adverb (15) than broadcast news does (8), but the most common types are very similar. Also and but are both very common in both written and broadcast news. 
Table 34 Types of each form in news setting

(* number of texts analysed/ number of total words of the random sample; + range/frequency)

\begin{tabular}{|c|c|c|c|}
\hline \multirow{18}{*}{$\begin{array}{l}\text { Form } \\
\text { Single-word } \\
\text { adverb }\end{array}$} & Types & $\begin{array}{l}\text { Written news } \\
(10 / 21,001 *)\end{array}$ & Broadcast news $(28 / 21,623)$ \\
\hline & however & $7 / 20+$ & $2 / 2$ \\
\hline & then & $3 / 5$ & \\
\hline & also & $8 / 29$ & $13 / 23$ \\
\hline & but & $9 / 30$ & $21 / 45$ \\
\hline & thus & $1 / 1$ & \\
\hline & so & $2 / 4$ & $2 / 3$ \\
\hline & therefore & $1 / 2$ & \\
\hline & and & $5 / 6$ & $26 / 73$ \\
\hline & still & $5 / 5$ & \\
\hline & furthermore & $1 / 1$ & \\
\hline & rather & $2 / 2$ & \\
\hline & or & $1 / 1$ & \\
\hline & meanwhile & $1 / 2$ & $3 / 3$ \\
\hline & thereby & $1 / 1$ & \\
\hline & anyway & $1 / 1$ & \\
\hline & finally & & $3 / 3$ \\
\hline & meantime & & $1 / 1$ \\
\hline \multirow{4}{*}{$\begin{array}{l}\text { Prepositional } \\
\text { phrase }\end{array}$} & in addition & $3 / 3$ & $1 / 1$ \\
\hline & in the meantime & $1 / 1$ & $1 / 1$ \\
\hline & as a result & $1 / 1$ & $2 / 2$ \\
\hline & after all & $1 / 1$ & \\
\hline
\end{tabular}

There are differences as well. However is very frequently used in written news but is very rarely used in broadcast news. And is much more frequently used in broadcast news than in written news.

Similarity between written news and broadcast news is also revealed from the similar collection of types being used. The shared types in written news and broadcast news are: however, also, but, so, and, meanwhile, in addition, in the meantime and as a result.

Such similarities between written news and broadcast news further demonstrate that broadcast news is normally scripted. But as mentioned above, there are differences as well, which exemplify differences between written and spoken English within the same setting.

In Chapter 5, one aspect of usage patterns of linking adverbials, form, has been discussed. Five different syntactic forms of linking adverbials have been identified: single-word adverb, adverb phrase, prepositional phrase, finite clause and non-finite clause. Frequencies of each of these syntactic realizations have been reported, compared and discussed among the five registers and also within written and spoken registers and within academic and news settings. 
Types of each form in the five different registers have also been presented. Differences in the types and frequencies have also been compared and discussed within written and spoken registers and within academic and news settings. In the next two chapters, 6 and 7, the other two aspects of usage patterns, meaning and position, are discussed in turn. 


\section{Chapter 6 Meaning of linking adverbials}

This chapter gives attention to how linking adverbials could be categorized according to their meaning. An overview of meaning categorizations is reported, a detailed register-specific meaning categorization framework is presented and discussed, a semantic-pragmatic continuum of linking adverbials is presented with so as an example and frequencies of different meaning categories are reported and compared among registers and within social settings.

\subsection{Meaning categorizations of linking adverbials}

In this section, an overview of meaning categories in WWC and WSC samples is given, features of register-specific meaning categorization system are discussed and the proposed meaning categorization system is presented.

\subsubsection{Overview of meaning categories in WWC and WSC samples}

As shown in Table 35 below, in the five registers analysed in this study, 21 different meaning categories in total have been identified.

Table 35 Overview of meaning categories

\begin{tabular}{|l|c|}
\hline Registers (5) & Meaning categories (21) \\
\hline Academic lectures & 18 \\
\hline Conversation & 17 \\
\hline Written academic prose & 16 \\
\hline Written news & 9 \\
\hline Broadcast news & 8 \\
\hline
\end{tabular}

No one register has all meaning categories represented. Academic lectures have the most meaning categories (18) while broadcast news has the fewest (8). In written registers, the number of meaning categories in written academic prose is radically different from that in written news (16 vs 9). In spoken registers, the number of meaning categories in academic lectures is similar with that in conversation (18 vs 17) but the number of meaning categories in broadcast news is much different from the other two spoken registers (8 vs 18 and 17). When compared written registers with spoken registers, written academic prose has a similar number of meaning categories with the two spoken registers of academic lectures and conversation (16 vs 18 and 17) while written news differs much from the aforementioned two spoken registers (9 vs 18 and 17) but has a similar number of meaning categories to broadcast 
news (9 vs 8 ). These facts all demonstrate that the total number of meaning categories in each register is not exactly the same.

Further investigation, however, shows registers differ not only in the total number of meaning categories but also in the range of meaning categories used. Table 36 below lists all the meanings and compares their occurrences across the five registers. Table 36 is in order of the range of meaning categories with most registers at the top (5) ordered down to meaning categories represented in fewest registers at the bottom (1).

Table 36 Meaning categories of LAs in the five registers

\begin{tabular}{|c|c|c|c|c|c|}
\hline Meaning & $\begin{array}{c}\text { Written } \\
\text { academic prose }\end{array}$ & $\begin{array}{l}\text { Written } \\
\text { news }\end{array}$ & $\begin{array}{l}\text { Academic } \\
\text { lectures }\end{array}$ & $\begin{array}{c}\text { Broadcast } \\
\text { news }\end{array}$ & Conversation \\
\hline adversative & $\sqrt{ }$ & $\sqrt{ }$ & $\sqrt{ }$ & $\sqrt{ }$ & $\sqrt{ }$ \\
\hline addition & $\sqrt{ }$ & $\sqrt{ }$ & $\sqrt{ }$ & $\sqrt{ }$ & $\sqrt{ }$ \\
\hline result & $\sqrt{ }$ & $\sqrt{ }$ & $\sqrt{ }$ & $\sqrt{ }$ & $\sqrt{ }$ \\
\hline listing & $\sqrt{ }$ & & $\sqrt{ }$ & $\sqrt{ }$ & $\sqrt{ }$ \\
\hline condition & $\sqrt{ }$ & $\sqrt{ }$ & $\sqrt{ }$ & & $\sqrt{ }$ \\
\hline $\begin{array}{l}\text { logical } \\
\text { consequence }\end{array}$ & $\sqrt{ }$ & $\sqrt{ }$ & $\sqrt{ }$ & & $\sqrt{ }$ \\
\hline alternative & $\sqrt{ }$ & $\sqrt{ }$ & $\sqrt{ }$ & & $\sqrt{ }$ \\
\hline opposite & $\sqrt{ }$ & $\sqrt{ }$ & $\sqrt{ }$ & & $\sqrt{ }$ \\
\hline conclusion & $\sqrt{ }$ & $\sqrt{ }$ & $\sqrt{ }$ & & $\sqrt{ }$ \\
\hline $\begin{array}{l}\text { signal of } \\
\text { evidence }\end{array}$ & $\sqrt{ }$ & & $\sqrt{ }$ & $\sqrt{ }$ & $\sqrt{ }$ \\
\hline exemplification & $\sqrt{ }$ & & $\sqrt{ }$ & & $\sqrt{ }$ \\
\hline explanation & $\sqrt{ }$ & 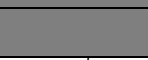 & $\sqrt{ }$ & 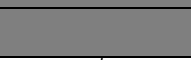 & $\sqrt{ }$ \\
\hline comparison & $\sqrt{ }$ & $\sqrt{ }$ & & $\sqrt{ }$ & \\
\hline summation & $\sqrt{ }$ & & $\sqrt{ }$ & & $\sqrt{ }$ \\
\hline $\begin{array}{l}\text { Initiating a } \\
\text { topic }\end{array}$ & & & $\sqrt{ }$ & $\sqrt{ }$ & $\sqrt{ }$ \\
\hline restatement & & & $\sqrt{ }$ & & $\sqrt{ }$ \\
\hline transition & $\sqrt{ }$ & & $\sqrt{ }$ & & \\
\hline $\begin{array}{l}\text { Marker of } \\
\text { continuation }\end{array}$ & & & $\sqrt{ }$ & & $\sqrt{ }$ \\
\hline $\begin{array}{l}\text { Signal of } \\
\text { returning to the } \\
\text { main thread }\end{array}$ & & & $\sqrt{ }$ & & $\sqrt{ }$ \\
\hline similarity & $\sqrt{ }$ & & & & \\
\hline $\begin{array}{l}\text { Formulaic } \\
\text { ending }\end{array}$ & & & & $\sqrt{ }$ & \\
\hline
\end{tabular}

As shown in Table 36, three meaning categories occur across all five registers: adversative, addition and result. Five meaning categories only occur in spoken registers: signal of returning to the main thread, formulaic ending, marker of continuation, restatement, initiating 
a topic. One meaning category occurs only in written registers: similarity. To be more specific, the meaning of similarity occurs only in the register of written academic prose. Besides the meaning category of similarity, the meaning category of formulaic ending is identified only in one register, i.e., broadcast news. This demonstrates that every register differs from the others in the range of its use of meaning categories for different communication needs and thus a register-specific meaning system is evident.

\subsubsection{Features of register-specific meaning categorization system}

This section will introduce the features of the system suggested in this study and discuss its difference from those described in previous grammar books (See Section 2.3.1.2 for a history of semantic type systems).

Compared with the previous grammar books, the system suggested in this study has the following new features:

\section{Linguistic substitution tests for different meaning categories are provided.}

In the system suggested in this study, in addition to descriptions of the meaning categories, which are also provided in previous grammar books, linguistic tests are suggested. Such tests could be useful for language users to learn and understand the meaning of linking adverbials and help them decide which meaning category should be used in a particular context in their own use. The suggested tests may be especially useful for understanding those words which have different meanings in different contexts. Examples 44 and 45 illustrate this.

In example 44, therefore is used in written academic prose and it is used to introduce a logical consequence.

44. The second feature of the general approach adopted in this study is to acknowledge that in fisheries science few, if any, parameters are known exactly. Therefore a range is chosen for each parameter depending on the accuracy with which it can be estimated from the available data. This will establish a feasible region for solutions. (WWC J09, Written academic prose)

In example 45 , therefore is used in written news and it is used to introduce a result.

45. A meeting between the OPSA and the commission yesterday resulted in no offers being made, and therefore the power stations would remain shut down, the spokesman for the Twizel sub-group of the OPSA, Mr OB.W Davies, said yesterday afternoon. (WWC A03, Written news) 
It may be difficult for some learners to distinguish the two. Therefore, a linguistic test may help. The abstract idea of a logical consequence can be substituted by a more concrete statement such as 'And this will lead logically to the following: ......' while the concept of result could be substituted by the linguistic test 'This results in the practical outcome that ......'.

Such substitution tests may help learners to distinguish the two shades of meaning of therefore, which are to some extent related, in that in academic prose, therefore is used to introduce an outcome in logic while in written news therefore is used to introduce an outcome in reality.

2. Simple, self-evident terms are adopted for the names of different meaning categories.

As explained and justified in Section 2.2.1 and 2.3.1.2, in previous grammar books different terms have been adopted to describe every single semantic type. Simplicity and self-evidence are the criteria in deciding a particular term for each meaning category in the system suggested here. Such criteria would benefit second language learners in that they could make it easier for them to understand a linguistic term and not add too much extra learning burden.

\section{This system presents register-specific types for each meaning category.}

A detailed register-specific analysis has allowed identification of types of each meaning category in different registers which are not specified in previous grammar books. A registerspecific system could be useful for language learners, especially ESP learners, in deciding which linking adverbial is more commonly used in a particular register and thus facilitate them to follow the conventions of language use in a certain situation.

\section{Meaning categories are presented in a parallel way.}

A parallel system is adopted in presenting this categorization. In previous literature, ways of presenting semantic types vary. Some employ a more condensed system (Biber et al., 1999; Halliday \& Hasan, 1976; Huddleston \& Pullum, 2002; Quirk, 1985) while others present categories in a more linear way (Carter \& McCarthy, 2006). Biber et al. (1999, p. 877), for example, put result and inference together and wrote that 'linking adverbials in the result/inference category show that the second unit of discourse states the result or consequence - either logical or practical - of the preceding discourse'. But which one is the logical result or consequence and which is the practical result or inference? The difference between result and inference remains vague. 
In the system suggested here, result and inference are presented and described as two separate categories, which could give second language learners a more explicit explanation. Thus, a parallel system is employed because it allows a more straightforward and more explicit account of the differences among meaning categories and may equip language learners with more specific and clearer guidelines.

\section{Five new meaning categories are identified.}

Compared with previous grammar books, an extra five new meaning categories have been identified in this study. Table 37 below presents the five new meaning categories together with their purposes.

Table 37 New meaning categories identified

\begin{tabular}{|l|l|}
\hline Meanings & Purposes \\
\hline Signal of evidence & to provide evidence in support of a previous claim \\
\hline Formulaic ending & to mark formulaic closing of programme section in broadcasting \\
\hline $\begin{array}{l}\text { Initiating a lecture/ } \\
\text { program/ } \\
\text { conversation }\end{array}$ & to mark the start of lectures, broadcast news or conversations \\
\hline $\begin{array}{l}\text { Marker of } \\
\text { continuation }\end{array}$ & $\begin{array}{l}\text { to signal the flow of conversation and that something else will } \\
\text { continue after the previous discourse and the speaker is still } \\
\text { holding the floor }\end{array}$ \\
\hline $\begin{array}{l}\text { Signal of returning } \\
\text { to the main thread }\end{array}$ & $\begin{array}{l}\text { to signal going back to the main point or the original topic after } \\
\text { talking about something other than the main point or the original } \\
\text { topic or being interrupted by something else (verbal or non- } \\
\text { verbal) }\end{array}$ \\
\hline
\end{tabular}

New categories mean that the five meaning categories presented in Table 37 have not been listed or indicated in any of the four previous grammar books. As described in Table 4 in Section 2.3.1.2, only eight meaning categories which are common in previous grammar books and are used as the base meaning categories for this study. And as presented in Table 35 in Section 6.1.1, 21 meaning categories are identified in all five registers in this study. We then could claim that more new meaning categories are found in this study instead of just five. However, while some meaning categories may not have been explicitly listed as semantic types in previous grammar books, they are indicated or explained somewhere in the literature. Biber et al. (1999, p. 876), for example, listed apposition as a semantic category but when you further explore their argument you will find apposition contains the meanings of explanation and exemplification as presented in my system. Biber et al. (1999, p. 876) wrote that 'an appositive linking adverbial can be used to show that the second unit is to be taken as a restatement of the first, reformulating the information it expresses in some way or 
stating it in more explicit terms', which is the category of explanation in my system. Biber et al. (1999, p. 877) then wrote that 'in many cases, the second unit of text is an example', which is exemplification in my system.

The five new meaning categories result from careful manual analysis of pragmatic meanings in different language contexts. In particular, they result from the large amount of spoken data from different registers which have been included in the study. Four out of the five new meaning categories only occur in spoken data. The exception is the meaning 'signal of evidence', which is used not only in all three spoken registers but also in written academic prose. Some grammar books (e.g.Biber et al., 1999; Carter \& McCarthy, 2006) give some examples of spoken data but none of them list the new meaning categories identified in this study. The following examples will further explain the new categories in the current system:

In example 46, so introduces evidence.

46. //they're sort of tough stone like er chunks of languagel/ and then of course he makes the point /that he himself has his own work to attend to as a poet// so towards the bottom of that first column/ he says to mason leasy for you now man/ you've joined your literary ancestors /whilst i have problems still in finding mine/ lost somewhere in the confusing swirl /now thick /now thin /victoriana missionary fog /hiding legalised land rape /and gentleman thugs/and so on//(WSC MUL002, academic lectures)

The two intonation units before so make a claim that he himself has his own work to attend to as a poet and the intonation units after so provide evidence from his poem to support the claim.

In example 47, and marks a formulaic ending.

\section{7. // and that's our programme for this week// (WSC MSN031, broadcast news)}

It introduces a formulaic ending utterance at the end of a piece of broadcast news.

In examples 48-50, now, so, and and are used respectively to initiate an academic lecture, a conversation and a piece of broadcast news.

48. //now they wanted to raise finance to make this purchase// and they gave shepherd the job of raising the finance// (WSC MUL005, academic lectures)

49. A: // so if we went there for a week// 
B: //and i mean $i$ wouldn't really want to stay in bali long much longer than a week// (WSC DPC229, conversation)

50. // and now join me for nga korero o te wala round up of maori news events// (WSC MSN031, broadcast news)

In example 51, and is a marker of continuation.

51. //i went round to see her this morning before $i$ went off to work and// she was um she was in my bed // (WSC DPC096, conversation)

It occurs at the end of an intonation unit and connects the current intonation unit with the next intonation unit. It shows the speaker hasn't finished his turn and is still holding the floor.

In example 52, so is used as a signal of returning to the main thread.

52. //shepherd er went to his solicitor//and the solicitor advised him to approach a um chris stansfield and son a organisation called stansfields associates//Okay //so in order to get hold of stansfields associates the went to see a person called hill um who was operating locally // (MSC MUL005, academic lectures)

The intonation unit before so states that shephard was advised to approach an organization called stansfields associates, then the flow was interrupted by a non-verbal action, writing on the blackboard, and a verbal non-clausal unit 'okay'. Then so brings the audience back to the main thread again, with information on finding stansfields associates.

\section{This system is based on both semantic and pragmatic meaning, instead of only on semantic meaning as in grammar books.}

As mentioned in Chapter 2, semantic meaning is the meaning inherent in the word itself while pragmatic meaning is the meaning in context which is inferred in different language contexts. Some expressions (e.g. however, in addition) have their inherent meanings and the meanings do not change across contexts and registers. Some others seem to have an inherent meaning (dictionary meaning or most familiar meaning to most language users) but they have different meanings in different language contexts (e.g. and, so). The following examples illustrate these:

In examples 53-56, however is used in different language contexts and in different registers. The surrounding language contexts of however are different and they are from four different registers: written news, written academic prose, broadcast news and academic lectures. 


\section{However}

53. McCulloch said that representatives of other affected local authorities were worried that they would not be represented on water and soil matters on the new district council.

However, the deposed county chairman, Kane, said he would like to see the issue proceed to the stage where a survey of opposition among Waitaki County and Oamaru Borough ratepayers was held. (WWC A03, written news)

54. The amount of running text from each of the two sources was not large enough to make it worthwhile to treat them separately. Informal comparisons, however, did not reveal major differences between the journalistic and academic sources in the amount of quantification.(WWC J35, written academic prose)

55. // earlier reports said mister keating had won over a number of supporters/ but still lacked the numbers to topple mister hawke from the prime ministership//

// however mister hawke is thought to need to win by a wide margin/ if he's to settle the long running issue which has been destabilising his government // (WSC MSN093, broadcast news)

56. // so I realise that some of this stuff will be hotly contested in a place like this// however I do believe it's able/ that it is important for us/ to be able to say these things/ none the less for maori women particularly land to be able to justify OUR position for saying it okay// (MSC MUL003, academic lectures)

In all four examples, however carries its semantic meaning, adversative. The meaning of however does not change across different language contexts and registers.

However, in examples 57-59, the meaning of and changes in different language contexts and in different registers.

\section{And}

In example 57, and is used to introduce an extra piece of information.

57. // shepherd er went to his solicitor// and the solicitor advised him to approach a um chris stansfield and son/ a organisation called stansfields associates// (MSC MUL005, academic lectures) 
In this case, and is similar to in addition. In addition to saying the fact that shepherd went to his solicitor, another piece of information is added about the solicitor that he advised shepherd to approach another person.

In example 58, and is used at the end of an intonation unit and after that intonation unit, there is a long pause.

58. A: //i went round to see her this morning before $i$ went off to work and// she was um she was in my bed //

B: // was she lying in bed// (WSC DPC096, conversation)

In this situation, and is functioning as a marker of continuation, i.e., signal of the flow of the conversation and signalling something else will continue after the previous discourse and the speaker is still holding the floor. In the conversation between A and B, it signals that it is still A's turn to carry on and A is not ready to let B step in.

In example 59, and is used at the end of a program section in broadcast news.

\section{9. // and that's our programme for this week// (WSC MSN031, broadcast news)}

It is a signal of formulaic ending. In the WWC and WSC samples, such usage is only found in the register of broadcast news.

In examples 53-56, we saw that however only carries one meaning, adversative, and most language users would recognise that meaning as its semantic meaning. By contrast, and in examples 57-59 shows different meanings across contexts and registers. Among all the meanings of and exemplified, its semantic meaning remains controversial. You may argue that the meaning of addition could be its semantic meaning because it is the first meaning presented in most dictionaries and it is the most familiar one to most language users, but, as exemplified in examples above, different usages reveal from different language contexts in different registers. Previous studies (Bolden, 2010; Heritage \& Sorjonen, 1994; Schiffrin, 1986; Turk, 2004) have also implied that traditional semantic approach may fail to explain most of the uses of and in conversations.

Thus, in the system suggested here, the term meaning is taken to include both semantic and pragmatic meaning. However, people may have different interpretations of a given text (or word) because meaning to some extent does not exist in the text itself but in the relationship between writer, text, audience and context. This may partly explain the differences among meaning categorizations in previous grammar books (see chapter 2.3.1). One special 
characteristic of the meaning categorization suggested in this study is that it is based on careful analysis of different meaning categories in previous literature which resulted in eight agreed meaning categories (see also chapter 2.3.1). Careful manual analysis was carried out to test the eight basic meaning categories and new meanings arose from the spoken registers which were underinvestigated in previous grammar books.

The next section will present the meaning categorization system suggested in this study.

\subsubsection{Register-specific meaning categorization system}

The meaning categorized system presented in this section carries the characteristics discussed in Section 6.1.2.

In total, 21 different meaning categories are presented. For each meaning category, the name of the meaning, its purpose, a possible substitution test and types of linking adverbials of that particular meaning category in each register are presented.

\section{Meaning category - adversative}

Purpose: to introduce something that is contrary to one's expectation

Substitution test: Despite what has been said or done.../But

\begin{tabular}{|l|l|l|l|l|l|}
\hline Registers & $\begin{array}{l}\text { Written academic } \\
\text { prose }\end{array}$ & Written news & $\begin{array}{l}\text { Academic } \\
\text { lectures }\end{array}$ & $\begin{array}{l}\text { Broadcast } \\
\text { news }\end{array}$ & Conversation \\
\hline Types & $\begin{array}{l}\text { even so, } \\
\text { however, } \\
\text { nevertheless, } \\
\text { but, yet }\end{array}$ & $\begin{array}{l}\text { however, } \\
\text { anyway, } \\
\text { but, after } \\
\text { all, still }\end{array}$ & $\begin{array}{l}\text { but, anyway, of } \\
\text { course, however, } \\
\text { but then, } \\
\text { nevertheless, still }\end{array}$ & $\begin{array}{l}\text { but, } \\
\text { however }\end{array}$ & $\begin{array}{l}\text { but, but then, } \\
\text { though, } \\
\text { anyway, still }\end{array}$ \\
\hline
\end{tabular}

\section{Meaning category - addition}

Purpose: to add more information to/elaborate on previous ideas/statements

Substitution test: Something more can be added, namely ...

\begin{tabular}{|l|l|l|l|l|l|}
\hline Registers & $\begin{array}{l}\text { Written academic } \\
\text { prose }\end{array}$ & Written news & Academic lectures & $\begin{array}{l}\text { Broadcast } \\
\text { news }\end{array}$ & Conversation \\
\hline Types & $\begin{array}{l}\text { in addition, } \\
\text { also, further, } \\
\text { furthermore, } \\
\text { and, } \\
\text { additionally }\end{array}$ & $\begin{array}{l}\text { in addition, } \\
\text { also, } \\
\text { furthermore } \\
\text { and }\end{array}$ & $\begin{array}{l}\text { also, and then, and, } \\
\text { in addition, and } \\
\text { also }\end{array}$ & $\begin{array}{l}\text { also, and, } \\
\text { in } \\
\text { addition, }\end{array}$ & $\begin{array}{l}\text { and, and } \\
\text { then, also }\end{array}$ \\
\end{tabular}




\section{Meaning category - listing}

Purpose: to list a series of steps, procedures, ideas and etc.

Substitution: (1), (2), (3)....

\begin{tabular}{|l|l|l|l|l|l|}
\hline Registers & Written academic prose & $\begin{array}{l}\text { Written } \\
\text { news }\end{array}$ & $\begin{array}{l}\text { Academic } \\
\text { lectures }\end{array}$ & $\begin{array}{l}\text { Broadcast } \\
\text { news }\end{array}$ & Conversation \\
\hline Types & $\begin{array}{l}\text { then, first, secondly, } \\
\text { second, in one, } \text { in the } \\
\text { second, on the one } \\
\text { hand, on the other } \\
\text { hand }\end{array}$ & $\begin{array}{l}\text { then, firstly, first } \\
\text { of all, } \text { ultimately, } \\
\text { secondly, first } \\
\text { off, on the other } \\
\text { hand, so }\end{array}$ & finally & then, first \\
\hline
\end{tabular}

\section{Meaning category - exemplification}

Purpose: to give examples

Substitution: Here is an example/ are examples:...

\begin{tabular}{|l|l|l|l|l|l|}
\hline Registers & $\begin{array}{l}\text { Written academic } \\
\text { prose }\end{array}$ & $\begin{array}{l}\text { Written } \\
\text { news }\end{array}$ & Academic lectures & $\begin{array}{l}\text { Broadcast } \\
\text { news }\end{array}$ & Conversation \\
\hline Types & for example & & $\begin{array}{l}\text { for example, for } \\
\text { instance }\end{array}$ & for example \\
\hline
\end{tabular}

\section{Meaning category - condition}

Purpose: to reveal that the previous statement is a condition for the following statement (an assumption leads to a logical result/a certain situation).

Substitution: If that is/isn't the case, then...

\begin{tabular}{|l|l|l|l|l|l|}
\hline Registers & $\begin{array}{l}\text { Written academic } \\
\text { prose }\end{array}$ & $\begin{array}{l}\text { Written } \\
\text { news }\end{array}$ & $\begin{array}{l}\text { Academic } \\
\text { lectures }\end{array}$ & $\begin{array}{l}\text { Broadcast } \\
\text { news }\end{array}$ & Conversation \\
\hline Types & then & then & then & & $\begin{array}{l}\text { otherwise, } \\
\text { then }\end{array}$ \\
\hline
\end{tabular}

\section{Meaning category - logical consequence}

Purpose: to mark a line of reasoning, something leads to something else (a fact leads to a logical result).

Substitution: And this will lead to the following thing in logic, namely ...

\begin{tabular}{|l|l|l|l|l|l|}
\hline Registers & $\begin{array}{l}\text { Written academic } \\
\text { prose }\end{array}$ & Written news & $\begin{array}{l}\text { Academic } \\
\text { lectures }\end{array}$ & $\begin{array}{l}\text { Broadcast } \\
\text { news }\end{array}$ & Conversation \\
\hline Types & $\begin{array}{l}\text { therefore, hence, } \\
\text { consequently, thus, so }\end{array}$ & so & $\begin{array}{l}\text { so, so...then, } \\
\text { then }\end{array}$ & so \\
\hline
\end{tabular}




\section{Meaning category - result}

Purpose: to reveal the following statement is a practical outcome of the previous statement(s)

Substitution: This results in a practical outcome, namely

\begin{tabular}{|l|l|l|l|l|l|}
\hline Registers & $\begin{array}{l}\text { Written academic } \\
\text { prose }\end{array}$ & Written news & $\begin{array}{l}\text { Academic } \\
\text { lectures }\end{array}$ & $\begin{array}{l}\text { Broadcast } \\
\text { news }\end{array}$ & Conversation \\
\hline Types & $\begin{array}{l}\text { so, therefore, } \\
\text { thus, } \\
\text { accordingly }\end{array}$ & $\begin{array}{l}\text { so, thus, } \\
\text { therefore, } \\
\text { thereby, as a } \\
\text { result }\end{array}$ & $\begin{array}{l}\text { so, } \\
\text { therefore, } \\
\text { then }\end{array}$ & $\begin{array}{l}\text { as a result, } \\
\text { so }\end{array}$ & so, so then \\
\hline
\end{tabular}

\section{Meaning category - restatement}

Purpose: to restate a previous stated term/idea

Substitution: This can also be put this way:...

\begin{tabular}{|l|l|l|l|l|l|}
\hline Registers & $\begin{array}{l}\text { Written academic } \\
\text { prose }\end{array}$ & $\begin{array}{l}\text { Written } \\
\text { news }\end{array}$ & $\begin{array}{l}\text { Academic } \\
\text { lectures }\end{array}$ & $\begin{array}{l}\text { Broadcast } \\
\text { news }\end{array}$ & Conversation \\
\hline Types & & & so & & so \\
\hline
\end{tabular}

\section{Meaning category - explanation}

Purpose: to explain a previous stated term/idea by restating it with simpler or more detailed words or renaming it but not necessarily more concise

Substitution: This means...

\begin{tabular}{|l|l|l|l|l|l|}
\hline Registers & Written academic prose & $\begin{array}{l}\text { Written } \\
\text { news }\end{array}$ & $\begin{array}{l}\text { Academic } \\
\text { lectures }\end{array}$ & $\begin{array}{l}\text { Broadcast } \\
\text { news }\end{array}$ & Conversation \\
\hline Types & $\begin{array}{l}\text { that } \text { is }, \text { namely, in } \\
\text { other } \text { words }\end{array}$ & $\begin{array}{l}\text { I mean, in other } \\
\text { words }\end{array}$ & & $\begin{array}{l}\text { I mean, in } \\
\text { other words }\end{array}$ \\
\hline
\end{tabular}

\section{Meaning category - alternative}

Purpose: to give alternative option, opinion, reason, etc.

Substitution: or

\begin{tabular}{|l|l|l|l|l|l|}
\hline Registers & $\begin{array}{l}\text { Written academic } \\
\text { prose }\end{array}$ & $\begin{array}{l}\text { Written } \\
\text { news }\end{array}$ & $\begin{array}{l}\text { Academic } \\
\text { lectures }\end{array}$ & $\begin{array}{l}\text { Broadcast } \\
\text { news }\end{array}$ & Conversation \\
\hline Types & alternatively, or & or & or & & or \\
\hline
\end{tabular}

\section{Meaning category - similarity}

Purpose: to introduce a similar situation

Substitution: Let's imagine a similar situation...

\begin{tabular}{|l|l|l|l|l|l|}
\hline Registers & Written academic prose & Written news & Academic lectures & Broadcast news & Conversation \\
\hline Types & likewise, similarly, too & & & & \\
\hline
\end{tabular}




\section{Meaning category - transition}

Purpose: to transit from current subject to introduce a new subject

Substitution: Let's talk about something else...

\begin{tabular}{|l|l|l|l|l|l|}
\hline Registers & $\begin{array}{l}\text { Written academic } \\
\text { prose }\end{array}$ & $\begin{array}{l}\text { Written } \\
\text { news }\end{array}$ & $\begin{array}{l}\text { Academic } \\
\text { lectures }\end{array}$ & $\begin{array}{l}\text { Broadcast } \\
\text { news }\end{array}$ & Conversation \\
\hline Types & now & & now, by the way & & \\
\hline
\end{tabular}

\section{Meaning category - comparison}

Purpose: to compare two aspects of a situation

Substitution: at the same time

\begin{tabular}{|l|l|l|l|l|l|}
\hline Registers & $\begin{array}{l}\text { Written academic } \\
\text { prose }\end{array}$ & Written news & $\begin{array}{l}\text { Academic } \\
\text { lectures }\end{array}$ & Broadcast news & Conversation \\
\hline Types & $\begin{array}{l}\text { in the } \\
\text { meantime, at } \\
\text { the same time }\end{array}$ & $\begin{array}{l}\text { meanwhile, in } \\
\text { the meantime }\end{array}$ & $\begin{array}{l}\text { meanwhile, } \\
\text { meantime, } \text {, } \\
\text { the meantime }\end{array}$ & & \\
\hline
\end{tabular}

\section{Meaning category - opposite}

Purpose: to imply the following statement is opposite to the previous

Substitution: Actually, the opposite is true

\begin{tabular}{|l|l|l|l|l|l|}
\hline Registers & $\begin{array}{l}\text { Written academic } \\
\text { prose }\end{array}$ & $\begin{array}{l}\text { Written } \\
\text { news }\end{array}$ & Academic lectures & $\begin{array}{l}\text { Broadcast } \\
\text { news }\end{array}$ & Conversation \\
\hline Types & in fact & rather & $\begin{array}{l}\text { in fact, instead, } \\
\text { actually }\end{array}$ & & actually \\
\hline
\end{tabular}

\section{Meaning category - summation}

Purpose: to sum up/draw a conclusion from what has been said /mentioned/ discussed before/above

Substitution: To sum up, ......

\begin{tabular}{|l|l|l|l|l|l|}
\hline Registers & Written academic prose & Written news & Academic lectures & Broadcast news & Conversation \\
\hline Types & in short, so, thus & & so, to summarize & & so \\
\hline
\end{tabular}

\section{Meaning category - conclusion}

Purpose: to draw a conclusion based on what has been said/mentioned/discussed before/above; discourse follows the pattern of claim--evidence--conclusion; add some extra information and normally logic follows

Substitution: To conclude, .......

\begin{tabular}{|l|l|l|l|l|l|}
\hline Registers & $\begin{array}{l}\text { Written academic } \\
\text { prose }\end{array}$ & $\begin{array}{l}\text { Written } \\
\text { news }\end{array}$ & $\begin{array}{l}\text { Academic } \\
\text { lectures }\end{array}$ & $\begin{array}{l}\text { Broadcast } \\
\text { news }\end{array}$ & Conversation \\
\hline Types & hence, so & so & so, therefore & & so \\
\hline
\end{tabular}


17. Meaning category - signal of evidence

Purpose: to provide evidence in support of a previous claim

Substitution: Here's the evidence: .......

\begin{tabular}{|l|l|l|l|l|l|}
\hline Registers & Written academic prose & Written news & Academic lectures & Broadcast news & Conversation \\
\hline Types & thus & & so & so & so \\
\hline
\end{tabular}

18. Meaning category - formulaic ending

Purpose: to mark formulaic closing of programme section in broadcasting news

Substitution: Here is the end of the program.....

\begin{tabular}{|l|l|l|l|l|l|}
\hline Registers & Written academic prose & Written news & Academic lectures & Broadcast news & Conversation \\
\hline Types & & & & and & \\
\hline
\end{tabular}

19. Meaning category - initiating a lecture/ program/ conversation

Purpose: to mark the start of lectures, broadcast news or conversations

Substitution: We are going to talk about this......

\begin{tabular}{|l|l|l|l|l|l|}
\hline Registers & Written academic prose & Written news & Academic lectures & Broadcast news & Conversation \\
\hline Types & & & now, so & and & so \\
\hline
\end{tabular}

20. Meaning category - marker of continuation

Purpose: to signal the flow of conversation and that something else will continue after the previous discourse and the speaker is still holding the floor

Substitution: I still have something to say that ......

\begin{tabular}{|l|l|l|l|l|l|}
\hline Registers & Written academic prose & Written news & Academic lectures & Broadcast news & Conversation \\
\hline Types & & & & & and \\
\hline
\end{tabular}

21. Meaning category - signal of returning to the main thread

Purpose: to signal going back to the main point or the original topic after talking about something other than the main point or the original topic or being interrupted by something else (verbal or non-verbal)

Substitution: Let's go back to the original topic that...

\begin{tabular}{|l|l|l|l|l|l|}
\hline Registers & Written academic prose & Written news & Academic lectures & Broadcast news & Conversation \\
\hline Types & & & so & & so \\
\hline
\end{tabular}

This meaning categorization system provides a detailed and practical guideline for second language teachers and learners. The purpose statement and substitution test for each meaning category may be helpful for them when they try to work out the meaning of a particular linking adverbial in a particular linguistic context, especially in the case of word forms with can express more than one meaning. The list of register-specific types of linking adverbials of each 
meaning category may help learners decide which linking adverbials can be used to appropriately mark a certain meaning relationship in a particular register. However, teachers and learners may need to be aware of the difference between receptive and productive knowledge when using the suggested meaning categorization system. When learners and teachers need to use a linking adverbial, detailed guidelines on usage patterns may be helpful. Teachers need to be selective while teaching linking adverbials. Presenting learners with all the detailed information without scaffolding and selection can be overwhelming. Teachers can use information about frequency and register variation (see Chapter 6.4) to help them select appropriate items to be included in classroom teaching.

As shown in the meaning system presented above, some words have two meanings (e.g. hence) and some have more than two meanings (e.g. so). A semantic-pragmatic continuum to show such variation is suggested and discussed in Section 6.2.

\subsection{Semantic-pragmatic continuum}

Many words, phrases and clausal units, when used as linking adverbials, have a stable meaning which does not change across contexts and registers (e.g. however, even so, in addition, that is, to summarize).

However, some words, when used as linking adverbials, can have different meanings in different linguistic contexts and registers. It is worth noting that all linking adverbials which carry more than one meaning are single words. This might be because that phrases and clausal units are formed by more than one word and such formulation may have constrained their usage and their meaning may be influenced by the interplay of the meaning of each word in the phases or clausal units. Examples 60-68 illustrate the fact that some words can have more than one meaning when used as linking adverbials by exemplifying the meaning of now, thus and then in different contexts and registers:

Examples 60 and 61 below exemplify the two different shades of meaning of now in different contexts in the same register of academic lectures.

\section{now}

In example 60, now carries the meaning of transition, i.e., moving on from the current subject to introduce a new subject.

60. //okay// well there's our while program//our task is to construct an equivalent recursive program//now what are we going to dol/obviously we we're going to have to 
define a function somewherell and we're going to have to define a function that is going to return z// (WSC MUL007, academic lectures)

The intonation units before now introduce their task and the intonation units after it discuss what they are going to do.

In example 61, now occurs at the beginning of a lecture.

61. //now the question is / can we define the computation meaning for reCURsive programs in a comparable way // (WSC MUL007, academic lectures)

It functions as the initiator of a lecture.

Examples 62-64 show different meanings of thus in different contexts and different registers. thus

In example 62, thus is used in written academic prose and carries the meaning of logical consequence, i.e., a fact leads to a logical result.

62. More to the point, the purpose of the analysis is to make comparisons over time and between population groups and thus consistency of classification is more important than marginal classification decisions. (WWC J29, written academic prose)

The clause before thus introduces the purpose of the analysis and the clause after it claims that consistency of classification is more important, which is because of the purpose aforementioned.

In example 63, thus is used in the register of written news and introduces a practical result.

63. The third proposes changes in the Ranfurly Shield rules consequent upon the creation of the third division of the national provincial championship; and the fourth, which is to cause no excitement whatever, urges that North Otago, Otago and Southland be created as a fourth district within the jurisdiction of the Maori Advisory Board, thus splitting Te Waipounamu (the South Island) into two. (WWC A15, written news)

The clause before thus introduces a change in the Ranfurly Shield rules that North Otago, Otago and Southland be created as a fourth district, and this change results in a practical outcome described in the clause after thus that it splits the South Island.

In example 64, thus is also used in the register of written academic prose but in a different context. In this context, it introduces evidence for the previous claim.

64. The author recorded under a headword every occurrence of a word or construction which seemed to be quantifying in a particular context. Thus, 'He won a fistful of prizes in 1977' has the word 'fistful' recorded as the headword or 'type'. (WWC J35, written academic prose) 
The sentence before thus is a claim that the author records under a headword every occurrence of a particular quantifying term. The sentence after it gives evidence of the previous claim that when fistful is used as a quantifying term, it is recorded as the headword. Examples 65-67 exemplify different meanings of then in different contexts in the same register of academic lectures.

\section{then}

In example 65, then is used together with 'so' to introduce a logical consequence.

65. I/but they're not the ONLY way in which we can look at theory// so what $i$ want to set out here today then is an attempt/just an attempt to sketch out the framework of some key elements that $i$ think are necessary for a theory of maori women's studies // (WSC MUL003, academic lectures)

The intonation unit before it presents a fact that they are not the only way of looking at theory and the intonation unit containing then introduces one way of looking at a theory, i.e, to outline the framework of some key elements that the author considers as necessary for a theory of maori women's studies.

In example 66, then is used with 'if' to introduce the meaning of condition.

66. //because if you say um you know a word includes/ um/ only / only the inflectional forms of the stem/ plus the inflectional forms/ then you get quite a different answer to that question/ than if you include/ um/ derivational forms as well// (WSC MUL029, academic lectures)

The comma intonation unit before then presents an assumption introduced in an if-clause and this leads to a logical result introduced by then that a different answer will be arrived at based on that assumption.

Condition and logical consequence both lead to a logical result but they differ in that logical consequence results from a presented fact, as in example 65 , while condition results from an assumption as in example 66.

In example 67, then is used to introduce a list of steps.

67. I/now the next step reduce that to falsell but we don't need to put anything in the computation trace corresponding to that// next thing after that took this ffalse/ then something or other else something or other and replace it by the second something or other// we don't need to put it in either// this is just part of / part of the machinery// and the next sigNIficant thing that happens is that we get this three minus onell and in 
fact there's an extra step in there that i've left out// is there// (WSC MUL007, academic lectures)

The above intonation units introduce the steps of calculating a formula. Linking adverbial then is used with 'next' to introduce a sequence of steps.

The above examples have demonstrated that some linking adverbials carry only one meaning, some can carry two meanings and others can have more than two meanings. Thus, a semantic - pragmatic continuum is suggested and presented in Figure 7.

Figure 7 Semantic - pragmatic continuum

\section{Semantic}

pragmatic

however

even so

in addition

that is

to summarize now

hence

and thus

then

therefore

As exemplified in Figure 5, expressions falling at the semantic end can take various forms, i.e., single-word adverbs, adverb phrases, prepositional phrases, finite clauses and non-finite clauses. Only one word falls on the far pragmatic end, i.e., so, which in this study is found to have the most meaning variation across contexts and registers (see Section 6.3 for further discussion on the meaning of $s o$ in different contexts and registers).

Other words in between the semantic and pragmatic ends are all single-word adverbs and their position on the continuum depends on the total number of meanings identified in this study. For example, now and hence are both found to carry two different meanings across contexts and registers. Thus, they are put in the same position on the continuum. The word thus is found to carry four meanings in different contexts and registers (see Section 6.1.3). Thus, it is positioned closer to the pragmatic end than now and hence.

The suggestion of a semantic-pragmatic continuum not only results from data analysis but is also consistent with pragmatic theories. Linking adverbials, having 'discourse deictic function' according to Huang (2007, p. 173), are claimed to have conventional implicature with respect to which meanings are conventionally attached and are not cancellable (Huang, 
2007); i.e., they are 'attached by convention to particular lexical items or linguistic constructions' (Huang, 2007, p. 56) and 'are therefore an arbitrary part of meaning and must be learned ad hoc' (Huang, 2007, p. 56). Whether the study of conventional meaning falls in the field of semantics or pragmatics, however, will depend on how semantics and pragmatics are defined. Huang (2007, p. 214) has claimed:

If semantics is taken to be concerned with those aspects of meaning that affect truth conditions, then the investigation of conventional implicature falls on the pragmatic side of the divide rather on the semantic side, since conventional implicature does not make any contribution to truth conditions. On the other hand, if pragmatics is conceived of as dealing with those inferences that are non-conventional, hence cancellable, then conventional implicature falls within the province of semantics but outside that of pragmatics, since it cannot be defeated.

By reviewing various influential theories on the relationship between semantics and pragmatics, Huang (2007, p. 211) admits that 'the complementarist viewpoint, which sees semantics and pragmatics as complementary though distinct subdisciplines of linguistics, shedding light on different aspects of meaning, is more widely accepted'. Huang (2007) also agrees with Bach (1999) that the dichotomy between semantics and pragmatics runs into trouble with linking adverbials since these 'are linguistic expressions whose conventional meaning is closely associated with use' (Huang, 2007, p. 213). As discussed above, in this study, meanings of linking adverbials change in different contexts and registers and the number of meanings of different linking adverbials also varies across contexts and registers. Therefore, a semantic-pragmatic continuum can address this notoriously difficult problem.

As discussed above, many linking adverbials tend not to change their meaning in different contexts or across registers. Some are positioned in different places on the continuum (see Figure 7 above) because of different numbers of meanings they carry (exemplified in examples 1-9). The word so is the only linking adverbial positioned right at the pragmatic end of the continuum because it is a linking adverbial which is found to carry the most meanings in different contexts and registers.

In the next section, the various meanings of $s o$ as a linking adverbial are further reported and discussed.

\subsection{Meanings of so}

Linking adverbial so, positioned at the pragmatic end of the semantic-pragmatic continuum, varies the most among all linking adverbials in terms of its meanings in different contexts and 
registers. In this section, such variation will be reported and compared among different registers and settings.

\subsubsection{Overview of frequency of linking adverbial so in different registers}

As shown in Table 38 below, in the five registers, so occurs as a linking adverbial a total of 310 times. Among the five registers analyzed, academic lectures have the most frequent use of linking adverbial so (159 per 20,000 words). The register of conversation ranks the second in terms of the frequency of linking adverbial so (111 per 20,000). Written academic prose has far less use of linking adverbial so ( 8 per 20,000 words), followed by the news settings, where written news and broadcast news each have three occurrences of linking adverbial so per 20,000 words.

Table 38 Overview of frequency of linking adverbial so in different registers

\begin{tabular}{|l|l|l|}
\hline Registers & Raw Frequency & Standardized frequency (per 20,000) \\
\hline $\begin{array}{l}\text { Academic lectures } \\
(22,049)\end{array}$ & 175 & 159 \\
\hline $\begin{array}{l}\text { Conversation } \\
(21,279)\end{array}$ & 121 & 111 \\
\hline $\begin{array}{l}\text { Written academic prose } \\
(20,128)\end{array}$ & 8 & 8 \\
\hline $\begin{array}{l}\text { Written news } \\
(21,001)\end{array}$ & 3 & 3 \\
\hline $\begin{array}{l}\text { Broadcast news } \\
(21,623)\end{array}$ & 3 & 3 \\
\hline Total $(106,080)$ & 310 & 284 \\
\hline
\end{tabular}

Biber et al. (1999) found so most frequently used in conversation and Liu (2008) found so most frequently used in speaking without explicitly pointing out which spoken registers he included. Neither study included the register of academic lectures. The current study has yielded a new finding that academic lectures have significantly more frequent use of linking adverbial so than conversation (see Table 39).

Table 39 Frequency of so in academic lectures and conversation

\begin{tabular}{|c|c|c|c|c|}
\hline LA & \multicolumn{2}{|c|}{ Register-specific frequency (WSC) } & & \\
\hline & $\begin{array}{l}\text { Academic lectures } \\
(22,049)\end{array}$ & $\begin{array}{c}\text { Conversation } \\
(21,279)\end{array}$ & LL & \\
\hline so & 175 & 121 & 8.08 & $p<0.01$ \\
\hline
\end{tabular}

BNC data analyzed by Liu (2008) showed that written academic prose and written news have similar frequency of so. The current study does confirm that finding, as no significant difference between the two registers was found (see Table 40). 
Table 40 Frequency of so in written academic prose and written news

\begin{tabular}{|c|c|c|c|c|}
\hline LA & \multicolumn{2}{|c|}{ Register-specific frequency (WWC) } & & \\
\hline & $\begin{array}{l}\text { Written academic } \\
\text { prose }(20,128)\end{array}$ & Written news $(21,001)$ & \multicolumn{2}{|l|}{ LL } \\
\hline so & 8 & 3 & 2.58 & $\mathrm{~ns}$ \\
\hline
\end{tabular}

However, while there is no significant difference between written academic prose and written news, that is not the case in the spoken registers in those settings (see Table 41).

Table 41 Frequency of $s o$ in academic lectures and broadcast news

\begin{tabular}{|c|c|c|c|c|}
\hline \multirow[t]{2}{*}{ LA } & \multicolumn{2}{|c|}{ Register-specific frequency } & & \\
\hline & $\begin{array}{l}\text { Academic } \\
\text { lectures }(22,049)\end{array}$ & $\begin{array}{l}\text { Broadcast } \\
\text { news }(21,623)\end{array}$ & LL & \\
\hline so & 175 & 3 & 212.97 & $\mathrm{p}<0.0001$ \\
\hline
\end{tabular}

As shown in Table 41, the frequency of linking adverbial so is significantly more frequently used in academic lectures than in broadcast news.

Within the two settings, there is also a significant difference between spoken and written use of $s o$ in academic settings, while in the news settings there is none (see Table 42).

Table 42 Frequency of so in academic settings and news settings

\begin{tabular}{|l|l|l|l|c|}
\hline LA & \multicolumn{2}{|l|}{ Register-specific frequency } & \multicolumn{2}{l|}{ Register-specific frequency } \\
\hline & $\begin{array}{l}\text { Academic } \\
\text { lectures } \\
(22,049)\end{array}$ & $\begin{array}{l}\text { Written } \\
\text { academic prose } \\
(20,128)\end{array}$ & $\begin{array}{c}\text { Written news } \\
(21,001)\end{array}$ & $\begin{array}{c}\text { Broadcast news } \\
(21,623)\end{array}$ \\
\hline so & 175 & 8 & 3 & 3 \\
\hline LL & $173.12(\mathrm{p}<0.0001)$ & $0.00(\mathrm{~ns})$ & \\
\hline
\end{tabular}

This may be explained by the fact that broadcast news is scripted and thus it uses more written patterns while academic lectures are processed more spontaneously and thus use more spoken patterns.

Apart from broadcast news, spoken registers use linking adverbial so much more frequently than written registers. The more frequent use of so in academic lectures and conversation demonstrates an appropriate choice in these two registers, i.e., so is frequently employed as an explicit discourse cohesive marker and is thus worth attention in language teaching for these contexts. 


\subsubsection{Overview of meanings of $s o$ in the five registers}

In total, nine different meanings of so are found in the five analyzed registers: result, restatement, conclusion, summation, logical consequence, signal of returning back to the main thread, initiating a topic/ a turn, signal of evidence, and listing (ordered according to their overall raw frequency in the five registers) (see Table 43 ).

Table 43 Frequency of meanings of $s o$ in the five registers

\begin{tabular}{|l|c|c|c|c|c|c|}
\hline Meaning & $\begin{array}{c}\text { Academi } \\
\text { c lectures } \\
(22,049)\end{array}$ & $\begin{array}{c}\text { Conversation } \\
(21,279)\end{array}$ & $\begin{array}{c}\text { Written } \\
\text { academic } \\
\text { prose } \\
(20,128)\end{array}$ & $\begin{array}{c}\text { Written } \\
\text { news } \\
(21,001)\end{array}$ & $\begin{array}{c}\text { Broadcast } \\
\text { news } \\
(21,623)\end{array}$ & $\begin{array}{c}\text { Total } \\
(106,080)\end{array}$ \\
\hline result & 34 & 33 & 1 & 1 & 2 & 71 \\
\hline restatement & 39 & 21 & 0 & 0 & 0 & 60 \\
\hline conclusion & 31 & 15 & 1 & 1 & 0 & 48 \\
\hline summation & 34 & 3 & 1 & 0 & 0 & 38 \\
\hline $\begin{array}{l}\text { logical } \\
\text { consequence }\end{array}$ & 14 & 13 & 5 & 1 & 0 & 25 \\
\hline $\begin{array}{l}\text { signal of } \\
\text { returning } \\
\text { back to the } \\
\text { main thread }\end{array}$ & 11 & 14 & 0 & 0 & 0 & 21 \\
\hline $\begin{array}{l}\text { initiating a } \\
\text { topic/ a turn }\end{array}$ & 1 & 20 & 0 & 0 & 0 & 11 \\
\hline $\begin{array}{l}\text { signal of } \\
\text { evidence }\end{array}$ & 8 & 2 & 0 & 0 & 1 & 310 \\
\hline $\begin{array}{l}\text { listing } \\
\text { Total }\end{array}$ & 3 & 0 & 0 & 0 & 0 & 3 \\
\hline
\end{tabular}

Among the nine different meanings, result is the most frequent meaning of so and it is the only meaning that occurs across all the five registers. Thus, in English, result is the most common and the most widespread meaning of so and this may explain why in previous grammar books, which base their taxonomies only on semantic meanings, so as a linking adverbial has always been put in the semantic category of result (see Section 2.3.1).

Restatement is the second most frequent meaning of so and conclusion is the third. Listing is the least common meaning of so and it occurs only in academic lectures. The frequent occurrences of meaning of so as restatement and other meanings demonstrate that so can be frequently used as marker of meanings other than result, the predominant meaning of so in 
grammar books, and thus that a suggested semantic-pragmatic meaning continuum is needed. In this study, including more spoken registers and adopting manual analysis has yielded new findings, i.e., beyond signaling result, so can be used to introduce a range of meaning relationships in different contexts.

The more frequent or sole use of some of the meanings of so in academic lectures and conversation to some extent has revealed some of the discourse features of these two registers. In other words, the patterns of appearance of a certain meaning in a certain register may be because of the distinctive features of that particular register. As shown in Section 6.1.4, the meaning 'signal of back to the main thread', for example, only occurs in the two registers of academic lectures and conversation and so is the only linking adverbial used to mark this meaning.

However, that some meanings are absent in written registers in Table 43 does not necessarily mean that such meanings do not occur in those registers. In written registers, those meanings may be signaled by other linking adverbials or other linguistic expressions (e.g. verbs). In written academic prose, the meaning 'logical consequence' is of similar frequency (raw frequency: 15) as in academic lectures (raw frequency: 17) (see Section 6.4). But in academic lectures, logical consequence is 14 times signaled by so while in written academic prose, only a small proportion of logical consequence meanings are introduced by so (raw frequency: 5) and the others are signaled by other linking adverbials such as therefore, hence, consequently, and thus. By contrast, the meaning 'conclusion' is not frequently signaled by linking adverbials in written academic prose (raw frequency: 3 ) but it does occur and it is signaled in the data by other linguistic devices such as a verb phrase as in Example 68 below.

In example 68, the meaning 'conclusion' is expressed by the verb conclude, not a linking adverbial.

68. Since most of the treaty negotiators were missionaries or, as in the case of Henry's son, Edward, closely associated with them, it seems reasonable to conclude that the general sense conveyed in explaining pre-emption was a protective one. (WWC J56, written academic prose)

It is used in the register of written academic prose. 


\subsubsection{Meanings of $s o$ in spoken registers}

The above discussion has given an overview of the frequency of different meanings of so in the five registers. This section will compare spoken registers to further examine if spoken registers differ much in the usage of meanings of so. As mentioned in 6.3.2, broadcast news resembles written registers in this regard. Thus, in this section, only the two registers of academic lectures and conversation will be compared.

As shown in Table 44 below, summation, conclusion, restatement and listing occur significantly more frequently in academic lectures than in conversation while initiating a topic/a turn is significantly more frequent in conversation than in academic lectures. Other meanings show no significant difference.

Table 44 Meanings of so in two spoken registers

\begin{tabular}{|l|l|l|l|l|}
\hline Meaning & $\begin{array}{l}\text { Academic } \\
\text { lectures (22,049) }\end{array}$ & $\begin{array}{l}\text { Conversation } \\
(21,279)\end{array}$ & LL & \multicolumn{2}{l|}{} \\
\hline restatement & 39 & 21 & 4.86 & $\mathrm{p}<0.05$ \\
\hline summation & 34 & 3 & 29.38 & $\mathrm{p}<0.0001$ \\
\hline conclusion & 31 & 15 & 5.13 & $\mathrm{p}<0.05$ \\
\hline listing & 3 & 0 & 4.05 & $\mathrm{p}<0.05$ \\
\hline initiating a topic/ a turn & 1 & 20 & 21.75 & $\mathrm{p}<0.0001$ \\
\hline result & 34 & 33 & 0.00 & $\mathrm{~ns}$ \\
\hline logical consequence & 14 & 13 & 0.01 & $\mathrm{~ns}$ \\
\hline $\begin{array}{l}\text { signal of returning back to } \\
\text { the main thread }\end{array}$ & 11 & 14 & 0.48 & $\mathrm{~ns}$ \\
\hline signal of evidence & 8 & & & \\
\hline Total & 175 & 2 & 3.64 & $\mathrm{~ns}$ \\
\hline
\end{tabular}

Such differences may be explained by different discourse features and communication purposes inherent in the two registers of academic lectures and conversation. In academic lectures, in order to communicate abstract ideas, explicit signals of summation, conclusion, restatement and listing may help the audience to comprehend the logical flow. By contrast, in conversation turn-taking happens frequently and thus the meaning 'initiating a turn' is frequently used.

\subsubsection{Meanings of $s o$ in written registers}

In this section, frequencies of meanings of so are compared between two written registers. Not surprisingly, given the very small numbers of occurrences in the written data sets, no significant differences were found (see Table 45). 
Table 45 Meanings of so in written registers

\begin{tabular}{|l|l|l|l|l|}
\hline Meaning & $\begin{array}{l}\text { Written academic } \\
\text { prose }(20,128)\end{array}$ & $\begin{array}{l}\text { Written news } \\
(21,001)\end{array}$ & \multicolumn{2}{l|}{ LL } \\
\hline logical consequence & 5 & 1 & 3.08 & ns \\
\hline summation & 1 & 0 & 1.43 & ns \\
\hline result & 1 & 1 & 0.00 & ns \\
\hline conclusion & 1 & 1 & 0.00 & ns \\
\hline Total & 8 & 3 & 2.58 & ns \\
\hline
\end{tabular}

However, as discussed in 6.3.2, logical consequence is very frequent in written academic prose, but it is also signaled by other linking adverbials (e.g. therefore, hence and thus), while in written news it is only signaled by so and occurs only once.

This is of value in understanding language use in different registers and also in language teaching and learning. It is worthwhile to focus on logical consequence of so and other ways of expressing such meaning relationship in academic writing class but less effort is needed in journalism English teaching since it is very rare in written news and did not occur in the broadcast news data set.

\subsubsection{Meanings of $s o$ in academic settings}

In this section, meanings of so are compared between the two academic registers. As noted above, the number of occurrences of linking adverbial so in written academic prose is very small (8).

As shown in Table 46, result, restatement, summation, conclusion, signal of returning back to the main thread, signal of evidence and listing are significantly more frequently expressed by the word so in academic lectures than in written academic prose.

Table 46 Meanings of so in academic settings

\begin{tabular}{|l|l|l|l|l|}
\hline Meaning & $\begin{array}{l}\text { Written academic } \\
\text { prose } \\
(20,128)\end{array}$ & $\begin{array}{l}\text { Academic } \\
\text { lectures } \\
(22,049)\end{array}$ & \multicolumn{2}{l|}{} \\
\hline restatement & 0 & 39 & 50.59 & $\mathrm{p}<0.0001$ \\
\hline result & 1 & 34 & 36.50 & $\mathrm{p}<0.0001$ \\
\hline summation & 1 & 34 & 36.50 & $\mathrm{p}<0.0001$ \\
\hline conclusion & 1 & 31 & 32.79 & $\mathrm{p}<0.0001$ \\
\hline $\begin{array}{l}\text { signal of returning back to } \\
\text { the main thread }\end{array}$ & 0 & 11 & 14.27 & $\mathrm{p}<0.001$ \\
\hline signal of evidence & 0 & 8 & 10.38 & $\mathrm{p}<0.01$ \\
\hline listing & 0 & 3 & 3.89 & $\mathrm{p}<0.05$ \\
\hline logical consequence & 5 & 14 & 3.66 & $\mathrm{~ns}$ \\
\hline initiating a topic/ a turn & 0 & 1 & 1.30 & $\mathrm{~ns}$ \\
\hline Total & 8 & 175 & 173.12 & $\mathrm{p}<0.0001$ \\
\hline
\end{tabular}


This demonstrates a great difference between academic writing and academic lectures. Some of those meanings are not signaled by so but are expressed by other linking adverbials in written academic prose. Signal of evidence, for example, is marked by thus in written academic prose (see Chapter 6.4 for further discussion of register-specific frequency of meanings of linking adverbials).

\subsubsection{Meanings of $s o$ in news settings}

Given the very small numbers of occurrences in the news settings, no significant difference is found between written news and broadcast news (see Table 47).

Table 47 Meanings of so in news settings

\begin{tabular}{|l|l|l|l|l|}
\hline Meaning & $\begin{array}{l}\text { Written news } \\
(21,001)\end{array}$ & $\begin{array}{l}\text { Broadcast news } \\
(21,623)\end{array}$ & \multicolumn{2}{l|}{ LL } \\
\hline result & 1 & 2 & 0.31 & $\mathrm{~ns}$ \\
\hline logical consequence & 1 & 0 & 1.42 & $\mathrm{~ns}$ \\
\hline conclusion & 1 & 0 & 1.42 & $\mathrm{~ns}$ \\
\hline signal of evidence & 0 & 1 & 1.36 & $\mathrm{~ns}$ \\
\hline Total & 3 & 3 & 0.00 & $\mathrm{~ns}$ \\
\hline
\end{tabular}

This provides additional evidence of the resemblance between spoken and written English in the news settings, though with the small numbers, it is not strong evidence.

\subsubsection{Summary}

This section has given an account of so as an example of a linking adverbial which carries a range of pragmatic meanings. It can carry up to nine different meanings, more than other linking adverbials identified in this study. The analysis has shown that patterns of use of meaning of so vary across registers and settings. This study has given a detailed account of meaning variations of so in academic lectures based on corpus data which has not been done in previous studies.

The analysis and comparisons presented here may be informative for ESP and EAP course material design. They may help course material writers decide which aspects of so meanings should be focused on. They may also help ESP and EAP teachers decide which meanings of so should be deliberately taught and given priority in class time. As well, they may give ESP and EAP learners useful guidelines on various usages of so and how those meanings can be used appropriately in different registers.

In the next section, frequencies of meaning categories of linking adverbials are reported and compared among different registers and settings. 


\subsection{Frequency of the meanings of linking adverbials}

In this section, the frequency patterns of the meanings of linking adverbials across registers in WWC and WSC samples are reported. Then, their frequencies are compared and discussed among registers (e.g. written academic prose and written news) and social settings (e.g. written academic prose and academic lectures in academic settings).

\subsubsection{Frequency of meanings of linking adverbials in five registers}

As mentioned in Section 6.1.4, 21 different meaning categories have been identified in the five registers. But the identified meanings have different frequency patterns in different registers. Table 48 below presents the frequencies of the meanings of linking adverbials in all five registers. The rows of the table are ordered according to the total occurrences of linking adverbials of a particular meaning category and the columns of the tables are ordered according to the total frequency of linking adverbials in different registers.

Table 48 Frequency patterns of the meaning of linking adverbials in the five registers

\begin{tabular}{|c|c|c|c|c|c|c|}
\hline Meaning & $\begin{array}{l}\text { Academic } \\
\text { lectures }\end{array}$ & Conversation & $\begin{array}{l}\text { Written } \\
\text { academic } \\
\text { prose }\end{array}$ & $\begin{array}{l}\text { Broadcast } \\
\text { news }\end{array}$ & $\begin{array}{l}\text { Written } \\
\text { news }\end{array}$ & Total \\
\hline addition & 337 & 167 & 32 & 84 & 31 & 651 \\
\hline adversative & 96 & 223 & 44 & 47 & 49 & 459 \\
\hline $\begin{array}{l}\text { marker of } \\
\text { continuation }\end{array}$ & & 130 & & & & 130 \\
\hline result & 43 & 33 & 9 & 4 & 6 & 95 \\
\hline explanation & 21 & 53 & 9 & & & 83 \\
\hline listing & 50 & 2 & 21 & 3 & & 76 \\
\hline condition & 40 & 10 & 18 & & 5 & 73 \\
\hline transition & 58 & & 2 & & & 60 \\
\hline restatement & 39 & 21 & & & & 60 \\
\hline conclusion & 32 & 15 & 3 & 0 & 1 & 51 \\
\hline $\begin{array}{l}\text { logical } \\
\text { consequence }\end{array}$ & 17 & 14 & 15 & & 1 & 47 \\
\hline summation & 35 & 3 & 3 & & & 41 \\
\hline alternative & 8 & 12 & 5 & & 1 & 26 \\
\hline initiating a topic & 2 & 20 & & 4 & & 26 \\
\hline $\begin{array}{l}\text { signal of returning } \\
\text { to the main thread }\end{array}$ & 11 & 14 & & & & 25 \\
\hline exemplification & 5 & 1 & 15 & & & 21 \\
\hline opposite & 11 & 3 & 3 & & 1 & 18 \\
\hline signal of evidence & 8 & 2 & 2 & 1 & & 13 \\
\hline comparison & & & 2 & 5 & 3 & 10 \\
\hline formulaic ending & & & & 9 & & 9 \\
\hline similarity & & & 5 & & & 5 \\
\hline Total & 813 & 723 & 188 & 157 & 98 & 1,979 \\
\hline
\end{tabular}


As shown in Table 48, the most frequent three meaning categories in the five registers are: addition, adversative and marker of continuation. The least frequent meaning categories are: comparison, formulaic ending and similarity.

Table 49 below further demonstrates that the total frequency difference among the three most frequent meaning categories and other meaning categories is significant (see Table 49).

Table 49 The four most frequent meaning categories in the five registers

\begin{tabular}{|l|l|l|l|}
\hline Meaning & $\begin{array}{l}\text { Total frequency in the five registers } \\
(106,080)\end{array}$ & LL \\
\hline addition & 651 & 33.38 & $\mathrm{p}<0.0001$ \\
\hline adversative & 459 & \\
\hline
\end{tabular}

\begin{tabular}{|l|l|l|l|}
\hline adversative & 459 & 194.77 & $\mathrm{p}<0.0001$ \\
\cline { 1 - 2 } marker of continuation & 130 & & \\
\hline
\end{tabular}

\begin{tabular}{|l|l|l|l|}
\hline marker of continuation & 130 & 5.47 & $\mathrm{p}<0.05$ \\
\hline result & 95 & & \\
\hline
\end{tabular}

\begin{tabular}{|l|l|l|l|}
\hline result & 95 & 0.81 & ns \\
\cline { 1 - 2 } explanation & 83 & & \\
\hline
\end{tabular}

This shows that in English, the three meaning categories of addition, adversative and marker of continuation are significantly more frequently made explicit while other meaning categories are less frequently signalled explicitly by linking adverbials.

However, despite the higher frequency of the three above-mentioned meaning categories, only two of them occur across all five registers: addition and adversative. The meaning of marker of continuation only occurs in the register of conversation and the meaning category has only one linking adverbial and (see Sections 6.1.4 and 4.2.2). Besides the meaning of marker of continuation, only two other meaning categories, similarity and formulaic ending, occur in just one register, with the former only occurring in the register of written academic prose and the latter only appearing in the register of broadcast news. Five meaning categories only occur in spoken registers: signal of returning to the main thread, formulaic ending, marker of continuation, restatement and initiating a topic. These indicate that different varieties of meanings are made explicit in different registers. This may reflect the communicative needs inherent in a certain register. Similarity, for example, is used only in 
written academic prose to present similar arguments while formulaic ending is only used in broadcast news as a signal of the end of the program.

We have seen that the frequency of each meaning category is different, and it is also the case that the types of linking adverbial used to make explicit the meanings are different. Table 50 below presents a register-specific summary of the types of linking adverbials making explicit different conjunction meanings along with their frequencies in the brackets next to them.

Table 50 Frequency of types of linking adverbial marking different meaning categories

\begin{tabular}{|c|c|c|c|c|c|}
\hline Meaning & $\begin{array}{l}\text { Academic } \\
\text { lectures }\end{array}$ & Conversation & $\begin{array}{l}\text { Written } \\
\text { academic } \\
\text { prose }\end{array}$ & $\begin{array}{l}\text { Broadcast } \\
\text { news }\end{array}$ & Written news \\
\hline addition & $\begin{array}{l}\text { and (292), } \\
\text { also (24), } \\
\text { and then (19), } \\
\text { and also (1) } \\
\text { in addition (1) }\end{array}$ & $\begin{array}{l}\text { and (134), } \\
\text { and then (30) }\end{array}$ & $\begin{array}{l}\text { also (18), and } \\
\text { (7), } \\
\text { furthermore } \\
\text { (2), further } \\
\text { (2), } \\
\text { additionally } \\
\text { (3) }\end{array}$ & $\begin{array}{l}\text { and (73), } \\
\text { also (23), } \\
\text { in addition } \\
\text { (1) }\end{array}$ & $\begin{array}{l}\text { also (25), } \\
\text { and (4), } \\
\text { in addition } \\
\text { (1), } \\
\text { furthermore } \\
\text { (1) }\end{array}$ \\
\hline adversative & $\begin{array}{l}\text { but (78), anyway } \\
\text { (3), however (1), } \\
\text { nevertheless (1), } \\
\text { of course (1) }\end{array}$ & $\begin{array}{l}\text { but(192), } \\
\text { though } \\
\text { (18), but then } \\
\text { (8), still (3), } \\
\text { anyway (2) }\end{array}$ & $\begin{array}{l}\text { however (28), } \\
\text { but }(11), \text { yet } \\
(3), \\
\text { even so (1) } \\
\text { nevertheless } \\
\text { (1) }\end{array}$ & $\begin{array}{l}\text { but (45), } \\
\text { however( } 2 \text { ) }\end{array}$ & $\begin{array}{l}\text { but (26), } \\
\text { however } \\
\text { (17), still (4), } \\
\text { anyway (1), } \\
\text { after all (1) }\end{array}$ \\
\hline $\begin{array}{l}\text { marker of } \\
\text { continuation }\end{array}$ & & and (130) & & & \\
\hline result & $\begin{array}{l}\text { therefore (6), so } \\
\text { (34) }\end{array}$ & so (33) & $\begin{array}{l}\text { thus (4), } \\
\text { therefore (3), } \\
\text { so (1) } \\
\text { accordingly } \\
\text { (1) }\end{array}$ & $\begin{array}{l}\text { as a result } \\
\text { (2), so (2) }\end{array}$ & $\begin{array}{l}\text { therefore } \\
(2), \text { so (1) as } \\
\text { a result (1) } \\
\text { thereby (1), } \\
\text { thus (1) }\end{array}$ \\
\hline explanation & $\begin{array}{l}\text { I mean (14), in } \\
\text { other words (7) }\end{array}$ & $\begin{array}{l}\text { I mean (52) } \\
\text { in other words } \\
\text { (1) }\end{array}$ & $\begin{array}{l}\text { that is (4), } \\
\text { namely (3), } \\
\text { in other words } \\
\text { (3) }\end{array}$ & & \\
\hline listing & $\begin{array}{l}\text { then (37), first } \\
\text { of all (6) } \\
\text { firstly (2), } \\
\text { secondly (2), } \\
\text { first off (1), } \\
\text { ultimately (1), } \\
\text { on the other } \\
\text { hand (1) }\end{array}$ & $\begin{array}{l}\text { then (1), } \\
\text { first(1) }\end{array}$ & $\begin{array}{l}\text { then } \\
\text { (7), secondly } \\
\text { (4), } \\
\text { first (4), } \\
\text { second (2), } \\
\text { first (1), in one } \\
\text { (1), in the } \\
\text { second (1), } \\
\text { on the one } \\
\text { hand (1), on } \\
\text { the other hand } \\
\text { (1) }\end{array}$ & finally (3) & \\
\hline
\end{tabular}




\begin{tabular}{|c|c|c|c|c|c|}
\hline condition & then (40) & $\begin{array}{l}\text { then (7), } \\
\text { otherwise (3) }\end{array}$ & then (18) & & then (5) \\
\hline transition & $\begin{array}{l}\text { now (55), } \\
\text { by the way (3) }\end{array}$ & & now (2), & & \\
\hline restatement & so (39) & so (21) & & & \\
\hline conclusion & $\begin{array}{l}\text { so }(31), \\
\text { therefore (1) }\end{array}$ & so (15) & $\begin{array}{l}\text { hence (2), so } \\
\text { (1) }\end{array}$ & & so (1) \\
\hline $\begin{array}{l}\text { logical } \\
\text { consequence }\end{array}$ & $\begin{array}{l}\text { so (14), so ... } \\
\text { then(3) }\end{array}$ & so (14) & $\begin{array}{l}\text { therefore (5), } \\
\text { so (5), thus } \\
\text { (3), } \\
\text { consequently } \\
\text { (1), hence (1) }\end{array}$ & & so (1) \\
\hline summation & $\begin{array}{l}\text { so (34), to } \\
\text { summarize (1) }\end{array}$ & so (3) & $\begin{array}{l}\text { in short (1), } \\
\text { thus (1), so (1) }\end{array}$ & & \\
\hline alternative & or $(8)$ & or (12) & $\begin{array}{l}\text { alternatively } \\
(3), \text { or }(2)\end{array}$ & & or (1) \\
\hline $\begin{array}{l}\text { initiating a } \\
\text { topic }\end{array}$ & now (1), so (1) & so (20) & & and (4) & \\
\hline $\begin{array}{l}\text { signal of } \\
\text { returning to } \\
\text { the main } \\
\text { thread }\end{array}$ & so (11) & so (14) & & & \\
\hline $\begin{array}{l}\text { exemplificatio } \\
\mathrm{n}\end{array}$ & $\begin{array}{l}\text { for example (4), } \\
\text { for instance (1) }\end{array}$ & $\begin{array}{l}\text { for example } \\
\text { (1) }\end{array}$ & $\begin{array}{l}\text { for example } \\
\text { (15) }\end{array}$ & & \\
\hline opposite & $\begin{array}{l}\text { in fact (6), } \\
\text { actually (4), } \\
\text { instead (1) }\end{array}$ & actually (3) & in fact (3) & & rather (1) \\
\hline $\begin{array}{l}\text { signal of } \\
\text { evidence }\end{array}$ & so $(8)$ & so (2) & thus (2) & so (1) & \\
\hline comparison & & & $\begin{array}{l}\text { at the same } \\
\text { time (1), in the } \\
\text { meantime (1) }\end{array}$ & $\begin{array}{l}\text { meanwhile } \\
(3), \text { in the } \\
\text { meantime } \\
(1), \\
\text { meantime (1) }\end{array}$ & $\begin{array}{l}\text { meanwhile } \\
\text { (2), } \\
\text { in the } \\
\text { meantime (1) }\end{array}$ \\
\hline $\begin{array}{l}\text { formulaic } \\
\text { ending }\end{array}$ & & & & $\operatorname{and}(9)$ & \\
\hline similarity & & & $\begin{array}{l}\text { similarly (2), } \\
\text { likewise (1), } \\
\text { too (2) }\end{array}$ & & \\
\hline Total & 813 & 723 & 188 & 157 & 98 \\
\hline
\end{tabular}

This table provides second language learners with a linguistic bank from which they can draw different linking adverbials to express a certain meaning in a particular register and the frequency information (in number of tokens of each type) gives them a practical guide on which type of linking adverbial is commonly used to make explicit meanings in a certain register.

The meaning of addition, for example, is most commonly marked by the linking adverbial also in written registers while such meaning is most commonly marked by the linking adverbial and in spoken registers. 
Although the total frequency of each of the three meaning categories of addition, adversative and marker of continuation is significantly higher than that of each of the remaining meaning categories, the types of linking adverbial used to mark the afore-mentioned three meaning categories are not more than that used to mark the other less frequent meanings. For example, five types of linking adverbial (but, however, nevertheless, anyway, of course) are used to mark the meaning category of adversative in academic lectures while seven types of linking adverbial (then, first of all, firstly, secondly, first off, ultimately, on the other hand) are used to mark a much less frequent meaning category in academic lectures, i.e., listing.

Furthermore, some meaning categories are marked by only one particular type of linking adverbial. For example, and is the only type of linking adverbial identified to make explicit the meaning of marker of continuation in conversation. Some meaning categories are marked by one particular type of linking adverbial across registers. For example, so is the sole type of linking adverbial used to make explicit the meanings of restatement and signal of returning to the main thread in different registers. Some meaning categories have a distinctive type of linking adverbial to make explicit the conjunction meaning in spoken or written registers. For example, so is the only type of linking adverbial used to make explicit the meaning of signal of evidence in all the three spoken registers while thus is the only type of linking adverbial used to mark such meaning in written academic prose (the meaning was not identified in written news).

In the next section, frequency patterns of the meanings of linking adverbials in written registers is compared and reported.

\subsubsection{Frequency patterns of the meanings of linking adverbials in written registers}

As shown in Table 51 below, the use of seven meaning categories in written academic prose is significantly different from their use in written news: listing, condition, logical consequence, exemplification, explanation, similarity and summation. Of the seven meaning categories, five are used only in written academic prose: listing, exemplification, explanation, similarity and summation. These exclusive meaning categories in academic prose in written registers allow various ways of organizing ideas: to list arguments/steps, to give examples, to explain a certain definition, to introduce similar situations and to summarize arguments. Biber et al. (2002, p. 392) also wrote that 'a very important aspect of academic prose is presenting and supporting explanation and argument'. 
Table 51 Frequency patterns of meanings of linking adverbials in written registers

\begin{tabular}{|l|l|l|l|l|}
\hline Meaning & $\begin{array}{l}\text { Written academic } \\
\text { prose }(20,128)\end{array}$ & $\begin{array}{l}\text { Written news } \\
(21,001)\end{array}$ & LL \\
\hline listing & 21 & & 30.01 & $\mathrm{p}<0.0001$ \\
\hline condition & 18 & 5 & 8.36 & $\mathrm{p}<0.01$ \\
\hline logical consequence & 15 & 1 & 15.3 & $\mathrm{p}<0.0001$ \\
\hline exemplification & 15 & & 21.44 & $\mathrm{p}<0.0001$ \\
\hline explanation & 9 & & 12.86 & $\mathrm{p}<0.001$ \\
\hline similarity & 5 & & 7.15 & $\mathrm{p}<0.01$ \\
\hline summation & 3 & & 4.29 & $\mathrm{p}<0.05$ \\
\hline adversative & 44 & 49 & 0.10 & $\mathrm{~ns}$ \\
\hline addition & 32 & 31 & 0.09 & $\mathrm{~ns}$ \\
\hline result & 9 & 6 & 0.74 & $\mathrm{~ns}$ \\
\hline alternative & 5 & 1 & 3.08 & $\mathrm{~ns}$ \\
\hline conclusion & 3 & 1 & 1.13 & $\mathrm{~ns}$ \\
\hline transition & 2 & & 2.86 & $\mathrm{~ns}$ \\
\hline opposite & 3 & 1 & 1.13 & $\mathrm{~ns}$ \\
\hline signal of evidence & 2 & & 2.86 & $\mathrm{~ns}$ \\
\hline comparison & 2 & 3 & 0.16 & $\mathrm{~ns}$ \\
\hline Total & 188 & 98 & & \\
\hline
\end{tabular}

The remaining nine meaning categories which are identified in written registers show no significant difference in their frequency in written academic prose and written news: adversative, addition, result, alternative, conclusion, transition, opposite, signal of evidence and comparison.

Among the nine categories, two meaning categories are the most frequent in both written academic prose and written news: adversative and addition. Biber, et al. (1999) did not report on their findings in the register of written news but they did write that in academic prose result/inference, apposition and contrast/concessive are the most frequent meaning categories. This difference of the most frequent meaning categories between their and my findings in written academic prose is likely to be firstly due to the fact that in their analysis, Biber, et al. (1999) took a semantic approach, i.e., one meaning for each form. In the current study, however, a pragmatic approach has been taken and one form (e.g. so, therefore) can have different meanings in different linguistic contexts (see Section 6.2). Thus, what Biber, et al. (1999) counted in the result/inference category may be distributed here between the categories of result, logical consequence, logical step, summation, conclusion, signal of evidence and condition. If the numbers of linking adverbials in those categories are added together and included in the category of result, result would be one of the most frequent meaning categories in the current study as well. 
A second possible reason for the difference is that some linking adverbials identified in the current study in the addition (e.g. sentence-initial And) and adversative (e.g. sentence-initial But) categories were not counted as linking adverbials in Biber, et al.'s (1999) system. They treated them as conjunctions, whereas the current study has found that sentence-initial And or But has a discourse cohesive function while conjunctions provide a structural link in the middle of a sentence (see Section 4.2). The frequency of linking adverbial and and but will contribute to the overall frequency of the two most frequent meaning categories in this study: addition and adversative.

In the next section, frequencies of the meanings of linking adverbials are compared among spoken registers.

\subsubsection{Frequency patterns of the meanings of linking adverbials in spoken registers}

As shown in Table 52 below, six meaning categories occur in all three spoken registers: addition, adversative, listing, result, signal of evidence and initiating a topic.

Table 52 Frequency patterns of meanings of linking adverbials in spoken registers

\begin{tabular}{|l|l|l|l|}
\hline Meaning & $\begin{array}{l}\text { Academic lectures } \\
(22,049)\end{array}$ & $\begin{array}{l}\text { Conversation } \\
(21,279)\end{array}$ & $\begin{array}{l}\text { Broadcast news } \\
(21,623)\end{array}$ \\
\hline addition & 337 & 167 & 84 \\
\hline adversative & 96 & 223 & 47 \\
\hline listing & 50 & 2 & 3 \\
\hline result & 43 & 33 & 4 \\
\hline signal of evidence & 8 & 2 & 1 \\
\hline initiating a topic & 2 & 20 & 4 \\
\hline condition & 40 & 10 & \\
\hline restatement & 39 & 21 & \\
\hline summation & 35 & 3 & \\
\hline conclusion & 32 & 15 & \\
\hline explanation & 21 & 53 & \\
\hline logical consequence & 17 & 14 & \\
\hline $\begin{array}{l}\text { signal of returning to the main } \\
\text { thread }\end{array}$ & 11 & 14 & \\
\hline opposite & & 3 & \\
\hline alternative & 11 & 12 & \\
\hline exemplification & 8 & 1 & \\
\hline transition & 5 & & \\
\hline marker of continuation & 58 & 130 & \\
\hline comparison & & & \\
\hline formulaic ending & & & \\
\hline
\end{tabular}

This demonstrates the common discourse features of the three spoken registers in that they all to some extent make explicit the six conjunction meanings and this may also reflect their 
common communication needs of adding an extra piece of information, expressing ideas contrary to one's expectation, stating a practical result, giving an evidence of a particular claim and initiating a new topic/a new turn in their communication process. The frequency of each of the six meaning categories, however, differs among the three registers (see Table 53).

Table $53 \mathrm{LL}$ of the six meaning categories occurring in all the three spoken registers

\begin{tabular}{|l|l|l|l|l|}
\hline Meaning & $\begin{array}{l}\text { Academic lectures } \\
(22,049)\end{array}$ & $\begin{array}{l}\text { Conversation } \\
(21,279)\end{array}$ & LL & \multicolumn{2}{|l|}{} \\
\hline addition & 337 & 167 & 52.6 & $\mathrm{p}<0.0001$ \\
\hline adversative & 96 & 223 & 56.6 & $\mathrm{p}<0.0001$ \\
\hline listing & 50 & 2 & 53.44 & $\mathrm{p}<0.0001$ \\
\hline initiating a topic & 2 & 20 & 17.74 & $\mathrm{p}<0.0001$ \\
\hline result & 43 & 33 & 0.99 & $\mathrm{~ns}$ \\
\hline signal of evidence & 8 & 2 & 3.64 & $\mathrm{~ns}$ \\
\hline
\end{tabular}

\begin{tabular}{|l|l|l|l|l|}
\hline Meaning & $\begin{array}{l}\text { Conversation } \\
(21,279)\end{array}$ & $\begin{array}{l}\text { Broadcast } \\
\text { news } \\
(21,623)\end{array}$ & LL & \multicolumn{2}{l|}{} \\
\hline addition & 167 & 84 & 29.32 & $\mathrm{p}<0.0001$ \\
\hline adversative & 223 & 47 & 127.5 & $\mathrm{p}<0.0001$ \\
\hline result & 33 & 4 & 26.41 & $\mathrm{p}<0.0001$ \\
\hline initiating a topic & 20 & 4 & 11.9 & $\mathrm{p}<0.001$ \\
\hline listing & 2 & 3 & 0.19 & $\mathrm{~ns}$ \\
\hline signal of evidence & 2 & 1 & 0.36 & $\mathrm{~ns}$ \\
\hline
\end{tabular}

\begin{tabular}{|l|l|l|l|l|}
\hline Meaning & $\begin{array}{l}\text { Academic lectures } \\
(22,049)\end{array}$ & $\begin{array}{l}\text { Broadcast } \\
\text { news } \\
(21,623)\end{array}$ & LL & \multicolumn{2}{l|}{} \\
\hline addition & 337 & 84 & 157.95 & $\mathrm{p}<0.0001$ \\
\hline adversative & 96 & 47 & 16.19 & $\mathrm{p}<0.0001$ \\
\hline listing & 50 & 3 & 49.50 & $\mathrm{p}<0.0001$ \\
\hline result & 43 & 4 & 37.04 & $\mathrm{p}<0.0001$ \\
\hline signal of evidence & 8 & 1 & 6.06 & $\mathrm{p}<0.05$ \\
\hline initiating a topic & 2 & 4 & 0.72 & $\mathrm{~ns}$ \\
\hline
\end{tabular}

The meaning of addition is significantly more frequent in academic lectures than in conversation and broadcast news and it is significantly more frequent in conversation than in broadcast news. The meaning of adversative is significantly more frequent in conversation than in academic lectures and broadcast news and it is also significantly more frequent in academic lectures than in broadcast news.

The meaning of listing is significantly more frequent in academic lectures than in conversation and broadcast news, but its frequency difference between conversation and 
broadcast news is not significant. The meaning of result is significantly more frequent in academic lectures and conversation than in broadcast news, but its frequency difference between academic lectures and conversation is not significant.

The above findings of the difference of meaning frequencies show that spoken registers differ in using linking adverbials to make explicit different conjunction relationships. Academic lectures and conversation, for example, use more explicit cohesive markers, linking adverbials, to make explicit the meaning of adding an extra piece of information and conjunction and adversative than broadcast news does.

As shown in Table 52, ten meaning categroies occur only in academic lectures and conversation: condition, restatement, summation, conclusion, expalanation, logical consequence, signal of returning to the main thread, opposite, alternative and exemplification. This demonstrates resemblance between academic lectures and conversation in that the aforementioned meanings tend to be made explicit in the two registers. In other words, compared with broadcast news, academic lectures have some similar discourse features to conversation. That is in both registers, there is a need to indicate that an assumption will lead to a logical result, to restate a previous idea, to summarize, to draw conclusions, to explain ideas, to give a line of reasoning, to return to the main point or original topic after interruption, to imply an opposite statement, to give alternative option/opinion/ideas and to give examples.

However, the frequencies of the ten meanings differ in the two registers. As shown in Table 54 below, five out of ten are significantly more frequent in academic lectures than in conversation: condition, restatement, summation, conclusion and opposite. The meaning of explanation is significantly more frequent in conversation than in academic lectures. There is no significant difference between academic lectures and conversation in the frequency of four meaning categories: logical consequence, signal of returning to the main thread, alternative and exemplification. This demonstrates that academic lectures and conversation resemble each other in using linking adverbials to express the aforementioned four meanings. 
Table $54 \mathrm{LL}$ of the meaning categories that occur only in academic lectures and conversation

\begin{tabular}{|l|l|l|l|l|}
\hline Meaning & $\begin{array}{l}\text { Academic lectures } \\
(22,049)\end{array}$ & $\begin{array}{l}\text { Conversation } \\
(21,279)\end{array}$ & \multicolumn{2}{l|}{ LL } \\
\hline condition & 40 & 10 & 18.22 & $\mathrm{p}<0.0001$ \\
\hline restatement & 39 & 21 & 4.86 & $\mathrm{p}<0.05$ \\
\hline summation & 35 & 3 & 30.56 & $\mathrm{p}<0.0001$ \\
\hline conclusion & 32 & 15 & 5.70 & $\mathrm{p}<0.05$ \\
\hline opposite & 11 & 3 & 4.58 & $\mathrm{p}<0.05$ \\
\hline explanation & 21 & 53 & 15.47 & $\mathrm{p}<0.0001$ \\
\hline logical consequence & 17 & 14 & 0.19 & $\mathrm{~ns}$ \\
\hline $\begin{array}{l}\text { signal of returning to the } \\
\text { main thread }\end{array}$ & 11 & 14 & 0.48 & $\mathrm{~ns}$ \\
\hline alternative & 8 & 12 & & \\
\hline exemplification & 5 & 1 & 0.95 & $\mathrm{~ns}$ \\
\hline
\end{tabular}

Also shown in Table 52 above, four meaning categories occur in only one particular register. Comparison and formulaic ending only occur in broadcast news, marker of continuation only occurs in conversation and transition only occurs in academic lectures. The differences are significant (Table 55, 56 and 57).

Table $55 \mathrm{LL}$ of the two meaning categories that only occur in broadcast news

\begin{tabular}{|l|l|l|l|l|}
\hline Meaning & $\begin{array}{l}\text { Academic lectures } \\
(22,049)\end{array}$ & $\begin{array}{l}\text { Broadcast news } \\
(21,623)\end{array}$ & \multicolumn{2}{|l|}{ LL } \\
\hline comparison & & 5 & 7.03 & $\mathrm{p}<0.01$ \\
\hline formulaic ending & & 9 & 12.65 & $\mathrm{p}<0.001$ \\
\hline
\end{tabular}

\begin{tabular}{|l|l|l|l|l|}
\hline Meaning & $\begin{array}{l}\text { Conversation } \\
(21,279)\end{array}$ & $\begin{array}{l}\text { Broadcast news } \\
(21,623)\end{array}$ & \multicolumn{2}{|l|}{ LL } \\
\hline comparison & & 5 & 6.85 & $\mathrm{p}<0.01$ \\
\hline formulaic ending & & 9 & 12.33 & $\mathrm{p}<0.001$ \\
\hline
\end{tabular}

Table $56 \mathrm{LL}$ of the meaning categories that occur only in conversation

\begin{tabular}{|l|l|l|l|l|}
\hline Meaning & $\begin{array}{l}\text { Academic lectures } \\
(22,049)\end{array}$ & $\begin{array}{l}\text { Conversation } \\
(21,279)\end{array}$ & \multicolumn{2}{|c|}{ LL } \\
\hline marker of continuation & & 130 & 184.88 & $\mathrm{p}<0.0001$ \\
\hline
\end{tabular}

Table 57 LL of the meaning categories that occur only in academic lectures

\begin{tabular}{|l|l|l|l|l|}
\hline Meaning & $\begin{array}{l}\text { Academic lectures } \\
(22,049)\end{array}$ & $\begin{array}{l}\text { Conversation } \\
(21,279)\end{array}$ & \multicolumn{2}{|c|}{ LL } \\
\hline transition & 58 & & 78.36 & $\mathrm{p}<0.0001$ \\
\hline
\end{tabular}


This demonstrates that the three spoken registers all have their own discourse features and unique meaning categories which distinguish them from the other spoken registers.

In the next section, frequency patterns of the meaning of linking adverbials in academic settings are reported and compared.

\subsubsection{Frequency patterns of the meanings of linking adverbials in academic settings}

As shown in Table 58 below, in academic settings, academic lectures differ significantly from written academic prose in 14 meaning categories: adversative, addition, listing, condition, result, explanation, conclusion, summation, opposite, transition, signal of returning to the main thread, restatement, exemplification and similarity.

Table 58 Frequency patterns of the meanings of linking adverbials in academic settings

\begin{tabular}{|l|l|l|l|l|}
\hline Meaning & $\begin{array}{l}\text { Written academic } \\
\text { prose } \\
(21,001)\end{array}$ & $\begin{array}{l}\text { Academic } \\
\text { lectures } \\
(22,049)\end{array}$ & \multicolumn{2}{l}{ LL } \\
\hline adversative & 44 & 96 & 17.34 & $\mathrm{p}<0.0001$ \\
\hline addition & 32 & 337 & 279.28 & $\mathrm{p}<0.0001$ \\
\hline listing & 21 & 50 & 10.83 & $\mathrm{p}<0.001$ \\
\hline condition & 18 & 40 & 7.52 & $\mathrm{p}<0.001$ \\
\hline result & 9 & 43 & 22.55 & $\mathrm{p}<0.0001$ \\
\hline explanation & 9 & 21 & 4.37 & $\mathrm{p}<0.05$ \\
\hline conclusion & 3 & 32 & 26.65 & $\mathrm{p}<0.0001$ \\
\hline summation & 3 & 35 & 30.15 & $\mathrm{p}<0.0001$ \\
\hline opposite & 3 & 11 & 4.48 & $\mathrm{p}<0.05$ \\
\hline transition & 2 & 58 & 62.95 & $\mathrm{p}<0.0001$ \\
\hline $\begin{array}{l}\text { signal of returning to } \\
\text { the main thread }\end{array}$ & & 11 & 14.72 & $\mathrm{p}<0.001$ \\
\hline restatement & & & & \\
\hline exemplification & 15 & 39 & 52.19 & $\mathrm{p}<0.0001$ \\
\hline similarity & 5 & 5 & 5.73 & $\mathrm{p}<0.05$ \\
\hline logical consequence & 15 & & 7.18 & $\mathrm{p}<0.01$ \\
\hline alternative & 5 & 17 & 0.05 & $\mathrm{~ns}$ \\
\hline signal of evidence & 2 & 8 & 0.56 & $\mathrm{~ns}$ \\
\hline comparison & 2 & 8 & 3.57 & $\mathrm{~ns}$ \\
\hline initiating a topic & & & 2.87 & $\mathrm{~ns}$ \\
\hline Total & 188 & 2 & 2.68 & $\mathrm{~ns}$ \\
\hline
\end{tabular}

Ten of these 14 meaning categories are significantly more frequent in academic lectures than in written academic prose. Two out of 14 are only used in academic lectures: signal of returning to the main thread and restatement. The meaning of exemplification is significantly more frequent in written academic prose than in academic lectures. The meaning of similarity only occurs in written academic prose and the difference is significant. The two 
registers in academic settings do not differ much in the frequency of five meaning categories: logical consequence, alternative, signal of evidence, comparison and initiating a topic.

This has shown that in academic settings, written and spoken English vary in most cases in explicitly marking conjunction meanings. Aacademic lectures tend to be more explicit in expressing meanings by using linking adverbials to organize their discourse. There is also a big difference between written and spoken English in how they organize their discourse in order to communcate various ideas in academic settings. For example, in order to explain an idea, written academic prose tends to use more written examples while academic lectures tend to restate an argument or idea in a simpler or more detailed way or rename it.

In the next section, frequency patterns of the meaning of linking adverbials in news settings are reported and compared.

\subsubsection{Frequency patterns of the meanings of linking adverbials in news settings}

As shown in Table 59 below, in news settings, written news differs significantly from broadcast news in five meaning categories: addition, formulaic ending, initiating a topic, listing and condition. The meaning of addition is significantly more frequent in broadcast news than in written news. Three meanings are only used broadcast news and the difference is also significant: formulaic ending, initiating a topic and listing. Only one of the five, the meaning of condition is significantly more frequent in written news than in broadcast news.

Table 59 Frequency patterns of the meanings of linking adverbials in the news settings

\begin{tabular}{|l|l|l|l|l|}
\hline Meaning & Written news & Broadcast news & LL & \multicolumn{2}{l|}{} \\
\hline addition & 31 & 84 & 23.85 & $\mathrm{p}<0.0001$ \\
\hline $\begin{array}{l}\text { formulaic } \\
\text { ending }\end{array}$ & & 9 & 12.22 & $\mathrm{p}<0.001$ \\
\hline initiating a topic & & 4 & 5.43 & $\mathrm{p}<0.05$ \\
\hline listing & & 3 & 4.07 & $\mathrm{p}<0.05$ \\
\hline condition & 5 & & 7.08 & $\mathrm{p}<0.01$ \\
\hline adversative & 49 & 47 & 0.12 & $\mathrm{~ns}$ \\
\hline result & 6 & 4 & 0.46 & $\mathrm{~ns}$ \\
\hline alternative & 1 & & 1.42 & $\mathrm{~ns}$ \\
\hline conclusion & 1 & & 1.42 & $\mathrm{~ns}$ \\
\hline $\begin{array}{l}\text { logical } \\
\text { consequence }\end{array}$ & 1 & & 1.42 & $\mathrm{~ns}$ \\
\hline opposite & 1 & & 1.42 & $\mathrm{~ns}$ \\
\hline $\begin{array}{l}\text { signal of } \\
\text { evidence }\end{array}$ & & 1 & 1.36 & $\mathrm{~ns}$ \\
\hline Total & 98 & 157 & & \\
\hline
\end{tabular}


The frequencies of seven meaning categories do not show any significant difference between written and spoken English in news settings: adversative, result, alternative, conclusion, logical consequence, opposite and signal of evidence.

This demonstrates that in news settings, written and spoken English differ in their use of linking adverbials to make certain meaning relationships explicit (e.g. addition and condition). Although scripted, broadcast news does contain some features that are exclusive to spoken English. For example, linking adverbials are used to mark the end of a program and to initiate the program in broadcast news which is not marked at all in written news.

This has also shown that in news settings, the differences between written and spoken English in how they organize their meaning relationships are not as strong as they are in academic settings. In academic settings, 14 meaning categories are significantly different in written and spoken English while in news settings only five meaning categories are significantly different in written and spoken English.

Chapter 6 has reported and discussed the findings about the meanings of linking adverbials in WWC and WSC samples. Of the total of 21 meaning categories identified in the five registers, the number of meaning categories in each register differs. The types of linking adverbials in each meaning category are also register-specific. Thus, a register-specific meaning categorization system has been suggested. A semantic-pragmatic continuum has also been suggested to complement the meaning categorization system since the same word form can have more than one and even up to nine different meanings (e.g. so) in different linguistic contexts and registers. Frequency patterns of the meaning of linking adverbials and types of linking adverbials marking the meaning relationships are also register-specific and settingspecific.

In the next Chapter, the positions of linking adverbials are explained and discussed. 


\section{Chapter 7 Position of linking adverbials}

In Chapters 5 and 6, two aspects of usage of linking adverbials, form and meaning, have been explored. In the current chapter, another aspect of usage of linking adverbials, position, is explained. In Section 7.1, patterns of the position of linking adverbials are exemplified. In Section 7.2, register-specific frequency of the position of linking adverbials is reported and compared. In Section 7.3, the question of whether certain linking adverbials occur in a certain position is addressed.

\subsection{Where do linking adverbials occur?}

In this study position means where linking adverbials occur in a particular sentence in written English and where they appear in an intonation unit in spoken English. Linking adverbials can occur in three positions in written and spoken English: initial, medial and final. Initial position means the first word (e.g. so) or set of words (e.g. even so) in a sentence or an intonation unit. Medial position refers to any word or set of words between the first and final word or set of words in a sentence. Final position means the final word or set of words in a sentence.

Examples 69-74 illustrate the three possible positions in written and spoken English.

In example 69, even so occurs in initial position in a sentence in written academic prose.

69. Even so, only one attempt has been made to model a snapper stock. (WWC J09, written academic prose)

In example 70, in addition occurs in medial position in a sentence in written news.

70. As at March 31 shareholders' funds totalled $+\$ 53,433,000$, and in addition the investment fluctuation reserve stood at $+\$ 8,142,000$. (WWC A32, written news)

In example 71, as a result occurs in final position in a sentence in written news.

71. A disqualified driver who took his hands from the steering wheel to check his new car's wheel alignment hit two other cars as a result. (WWC A28, written news)

In example 72, so appears in initial position in an intonation unit in academic lectures.

72. // so now how can we turn THAT into a sequence of tests and assignments // (WSC MUL007, academic lectures) 
In example 73, also appears in medial position in an intonation unit in broadcast news.

73. //kay fellows representing the protest group says/ they're also scared at the prospect of personal injury/ but are prepared to risk it to make the point // (WSC MSNO20, broadcast news)

In example 74, though appears in final position in an intonation unit in conversation.

74. A: // i mean the waitangi tribunal's doing a lot to fix that which is good//

B: // what/ what are you saying// why do you disagree with the claim though// (WSC DPC179, conversation)

As exemplified in examples 69-74, linking adverbials can occur in initial, medial or final position in either a sentence in written English or in an intonation unit in spoken English. But the same position may mark meaning relationships at different discourse levels. In other words, the scope of meaning units connected by linking adverbials does not depend on the positions of the linking adverbials. For example, medial position does not necessarily indicate that the linking adverbial marks a meaning relationship within a sentence or an intonation unit, as shown in examples 75-78:

In example 75 , however is used in a medial position in written academic prose.

75. Occupational data for the Maori population have been available at the two-digit level since 1956. They have not, however, been available by employment status. (WWC J29, written academic prose)

It marks adversative meaning relationship between two sentences, i.e., the sentence in which it appears and the previous sentence.

In example 76 , by the way occurs in a medial position in an intonation unit in an academic lecture.

76. //so somehow his reaction to the death/is to displace everything into this/ er biblical love tale/l you can see/ by the way/ how it makes sense/ when he says/ the king james bible was where i learnt my english// (WSC MUL002, academic lectures)

It marks meaning relationship between two intonation units. The intonation unit in which it appears is a transition from the previous intonation unit.

In example 77 , however also occurs in the middle of a sentence in written academic prose.

77. Although the broad trend of male and female employment change is the same, Table 2 
highlights the substantial differences in the occupational distribution of males and females on which Smith (1981, 1983, 1984) and Moir (1977) have commented. Females are much less inclined to be found in the manual occupations; if they are however, they are more likely to be in the Unskilled group. (WWC J29, written academic prose)

Instead of marking a meaning relationship between two sentences, it marks an adversative meaning relationship within one sentence, i.e., between the preceding main clause and the ifclause.

There are also linking adverbials in medial positions which mark meaning relationships between elements within an intonation unit, as shown in example 78 .

In example 78 , for example occurs in the middle of an intonation unit in a conversation.

78. // they pick up ANYTHING like/ for example that like that consultant guy/ who was paid a hundred and twenty thousand dollars/ for a months' work the other week// (WSC DPC179, conversation)

Instead of marking a meaning relationship between two intonation units, it marks a meaning relationship of exemplification within the same intonation unit, i.e., the material before the comma intonation unit and material after the comma intonation.

Linking adverbials can be used in all three positions in both written and spoken English: initial, medial and final. The same position may mark meaning relationships at different discourse levels (e.g. between sentences and within the same sentence).

In the next section, register-specific frequency of the position of linking adverbials is reported and compared.

\subsection{Register-specific frequency of the position of linking adverbials}

In this section, frequency patterns of the position of linking adverbials across registers in WWC and WSC samples are reported. Then, frequency patterns are compared and discussed among registers (e.g. written academic prose and written news) and social settings (e.g. written academic prose and academic lectures in the academic settings).

\subsubsection{Frequency patterns of positions in five registers}

Tables 60 and 61 present the raw frequencies and standardized frequencies of positions of linking adverbials in the five registers in WWC and WSC samples. 
Table 60 Raw frequency of positions of linking adverbials in the five registers in WWC and WSC samples

\begin{tabular}{|l|l|l|l|l|}
\hline Positions & initial & medial & final & Total \\
\hline Academic lectures (22,049) & 658 & 152 & 3 & 813 \\
\hline Conversation $(21,279)$ & 637 & 40 & 46 & 723 \\
\hline Written academic prose $(20,128)$ & 105 & 81 & 2 & 188 \\
\hline Broadcast news $(21,623)$ & 138 & 19 & 0 & 157 \\
\hline Written news (21,001) & 49 & 46 & 3 & 98 \\
\hline Total $(106,080)$ & 1,587 & 338 & 54 & 1,979 \\
\hline
\end{tabular}

Table 61 Standardized frequency of positions of linking adverbials in the five registers in WWC and WSC samples (per 20,000 words)

\begin{tabular}{|l|l|l|l|}
\hline Positions & initial & medial & final \\
\hline Academic lectures (22,049) & 597 & 138 & 3 \\
\hline Conversation $(21,279)$ & 599 & 38 & 43 \\
\hline Written academic prose (20,128) & 104 & 80 & 2 \\
\hline Broadcast news (21,623) & 128 & 18 & 0 \\
\hline Written news (21,001) & 47 & 44 & 3 \\
\hline
\end{tabular}

Initial position is the most frequent in all the five registers. Medial position is the next most frequent position and final position is very rare, except in the register of conversation in which the frequency of medial position and final position is relatively close (see Table 62).

Table $62 \mathrm{LL}$ of medial and final positions of linking adverbials in conversation

\begin{tabular}{|l|l|l|l|l|}
\hline Register & medial & final & \multicolumn{2}{|l|}{ LL } \\
\hline Conversation $(21,279)$ & 40 & 46 & 0.42 & ns \\
\hline
\end{tabular}

The following two sections examine positions of linking adverbials in more detail in the WWC and WSC samples respectively.

\subsubsection{Positions of linking adverbials in WWC samples}

Table 63 presents types of linking adverbials in different positions in written academic prose and written news. Numbers in bracket are occurrences of linking adverbials in a certain position in a particular register. Then (13) in written academic prose, for example, means in written academic prose then occurred 13 times in initial position. 
Table 63 Types of linking adverbials in different positions in WWC samples

\begin{tabular}{|c|c|c|}
\hline Positions & Written academic prose & Written news \\
\hline \multirow[t]{4}{*}{ initial } & $\begin{array}{l}\text { Single-word adverb: then (13), but } \\
\text { (11), however (10), and (7), thus (6), } \\
\text { so (5), first (4), therefore (3), } \\
\text { alternatively (3), secondly (3), hence } \\
\text { (3), or (2), furthermore (2), further } \\
\text { (2), now (2), similarly (2), also (1), } \\
\text { additionally (1), second (1), } \\
\text { nevertheless (1), likewise (1), } \\
\text { accordingly (1), }\end{array}$ & $\begin{array}{l}\text { Single-word adverb: but (26), however } \\
\text { (10), and (4), meanwhile (2), so (2), } \\
\text { therefore (1), furthermore (1), or (1), } \\
\text { rather (1) }\end{array}$ \\
\hline & $\begin{array}{l}\text { Prepositional phrase: for example } \\
\text { (7), in other words (2), in fact (2), in } \\
\text { addition (1), at the same time (1), in } \\
\text { the meantime (1), in one (1), in the } \\
\text { second (1), in short (1), on the one } \\
\text { hand (1), on the other hand (1) }\end{array}$ & Prepositional phrase: in the meantime (1) \\
\hline & Adverb phrase: even so (1) & \\
\hline & Finite clause: that is (1) & \\
\hline \multirow[t]{3}{*}{ medial } & $\begin{array}{l}\text { Single-word adverb: however (18), } \\
\text { also (17), then (11), therefore (5), } \\
\text { thus (4), so (3), namely (3), yet ( } 3) \text {, } \\
\text { consequently (1), first (1), secondly } \\
\text { (1) }\end{array}$ & $\begin{array}{l}\text { Single-word adverb: also (25), however } \\
(6), \text { then (5), still (4), therefore (1), } \\
\text { thereby (1), so (1), thus (1) }\end{array}$ \\
\hline & $\begin{array}{l}\text { Prepositional phrase: for example } \\
\text { (8), in other words (1), in fact (1), in } \\
\text { addition (1) }\end{array}$ & $\begin{array}{l}\text { Prepositional phrase: in addition (1), } \\
\text { after all (1) }\end{array}$ \\
\hline & Finite clause: that is (3) & \\
\hline \multirow[t]{2}{*}{ final } & Single-word adverb: too (2) & $\begin{array}{l}\text { Single-word adverb: anyway (1), } \\
\text { however (1) }\end{array}$ \\
\hline & & Prepositional phrase: as a result (1) \\
\hline
\end{tabular}

This will give second language teachers and learners detailed frequency information not only on what types of linking adverbials can be used at a certain position in a certain register but also on how commonly those types are used.

Written academic prose has a significantly more frequent use of linking adverbials in initial position than written news (Table 64).

Table $64 \mathrm{LL}$ of initial position of linking adverbials in written academic prose and written news

\begin{tabular}{|l|l|l|l|}
\hline Register & initial & LL \\
\hline Written academic prose $(20,128)$ & 105 & 23.29 & $\mathrm{p}<0.0001$ \\
\hline Written news $(21,001)$ & 49 & & \\
\hline
\end{tabular}


As shown in Table 63, written academic prose also has a larger and more complicated repertoire of types of linking adverbials in initial position than written news. In written academic prose, 37 different linking adverbials were found in initial position while only 10 different linking adverbials were identified in initial position in written news. Of the 10 different linking adverbials in initial position in written news, $90 \%$ are single-word adverbs and $10 \%$ are prepositional phrases. Linking adverbials in initial position, however, have more varied grammatical forms in written academic prose. Four different forms occurred in initial position: single-word adverb, prepositional phrase, adverb phrase and finite clause.

Even for the two grammatical forms that occur in both written registers, written academic prose has more choices within each grammatical form. For example, in the meantime is the only prepositional phrase which occurred in written news, while in written academic prose, several different prepositional phrases occurred: in addition, at the same time, in the meantime, in other words, in the meantime, in one, in the second, in short, on the one hand, on the other hand.

Two grammatical forms occur in initial position in written academic prose but are not found in the register of written news: adverb phrase and finite clause.

In example 79, even so, an adverb phrase, occurs in initial position in a sentence in written academic prose.

79. The snapper is New Zealand's most studied marine fish species. Even so, only one attempt has been made to model a snapper stock. (WWC J09, written academic prose)

It takes the grammatical form of adverb phrase.

In example 80 , that is, a finite clause, appears in initial position in a sentence in written academic prose. Note that in this example, [FORMULA] has been used in the corpus to signal that a scientific formula has been deleted here.

80. We observe [FORMULA], where the $1 X ; j$ are independently normally distributed with unit variances and with [FORMULA]. That is, [FORMULA] is a sequence of independent standard normal variables on to which has been superimposed a cyclic effect with period $1 \backslash 15 p \wedge 15 T H .(W W C$ J20, written academic prose)

Its grammatical form is finite clause.

Examples 79 and 80 demonstrate that phrasal (e.g. even so) and clausal (e.g. that is) linking adverbials can occur in initial position in written academic prose but not in written news. 
In written registers, linking adverbials are significantly more frequent in medial position in written academic prose than in written news (Table 65), which follows the same pattern of linking adverbials in initial position in written registers (Table 64).

Table 65 LL of medial position of linking adverbials in written academic prose and written news

\begin{tabular}{|l|l|l|l|}
\hline Register & medial & LL \\
\cline { 1 - 2 } Written academic prose $(20,128)$ & 81 & 11.31 & $\mathrm{p}<0.001$ \\
\cline { 1 - 2 } Written news $(21,001)$ & 46 & & \\
\hline
\end{tabular}

Written academic prose also has more types of linking adverbials in medial position than written news (Table 63). Sixteen types of linking adverbials occur in medial position in written academic prose while 10 types of linking adverbials occur in medial position in written news.

Linking adverbials in medial position also take more varied grammatical forms in written academic prose. The 16 types of linking adverbials in medial position in written academic prose take three different grammatical forms: single-word adverb, prepositional phrase and finite clause. The 10 medial position types in written news only take two grammatical forms: single-word adverbs and prepositional phrases.

For the two grammatical forms that occur in both written registers, written academic prose has more types of each form. Written academic prose, for example, has ten different types of single-word adverbs while written news has eight types.

One grammatical form that occurs in medial position in written academic prose but not in written news is finite clause.

In example 81 , that is, a finite clause is used in a medial position in a sentence in written academic prose.

81. The particular sections of the Public Utilities Act under consideration were enacted for the benefit of the public; that is, on grounds of public policy in the general sense.(WWC J50, written academic prose)

It takes the grammatical form of finite clause.

Example 81 shows that clausal linking adverbials (that is) can occur in medial position in written academic prose but not in written news. 
Numbers of occurrences of linking adverbials in final position are very small and there is little difference in frequency between the two written registers (Table 66).

Table $66 \mathrm{LL}$ of final position of linking adverbials in written registers

\begin{tabular}{|l|l|l|l|}
\hline Register & final & LL \\
\hline Written academic prose $(20,128)$ & 2 & 0.16 & ns \\
\hline Written news $(21,001)$ & 3 & & \\
\hline
\end{tabular}

However, the linguistic expressions used in final position in the register of written news are more varied than in written academic prose.

In example 82, anyway is used in final position in a sentence, which is a quote in written news.

82. "I was one of the instigators, and if I'm not appointed I'll attend the meetings anyway" he said, adding that this was permitted under standing orders. (WWC A03,written news)

In example 83 , however is used in final position in a sentence in written news.

83. He reassured about 40 people at a meeting on university education that nothing had been formally decided about making students pay for their courses. Cost recovery from education was a problem, however. (WWC A08,written news)

In example 84 , as a result is used in final position in a sentence in written news.

84. A disqualified driver who took his hands from the steering wheel to check his new car's wheel alignment hit two other cars as a result. (WWC A28, written news)

In example 85 , too is used in final position in a sentence in written academic prose.

85. So I went to show after show in the Dunedin Town Hall. That seems pretty incongruous in retrospect, too. (WWC J62, written academic prose)

Examples 82-85 illustrate that three different expressions are used in final position in written news while only one is used in final position in written academic prose.

In the next section, positions of linking adverbials in WSC samples are reported and discussed.

\subsubsection{Positions of linking adverbials in WSC samples}

As we saw in Table 67, in the three spoken registers investigated in this study, linking adverbials occur in a similar frequency in initial position in academic lectures and 
conversation and they occur significantly more frequently in initial position in academic lectures and conversation than in broadcast news.

Table $67 \mathrm{LL}$ of initial position of linking adverbials in spoken registers

\begin{tabular}{|l|l|l|l|}
\hline Register & initial & LL & \multicolumn{2}{|l|}{} \\
\hline Academic lectures $(22,049)$ & 658 & 0.00 & ns \\
\hline Conversation $(21,279)$ & 637 & & \\
\hline
\end{tabular}

\begin{tabular}{|l|l|l|l|}
\hline Register & initial & LL & \multicolumn{2}{|l|}{} \\
\hline Conversation $(21,279)$ & 637 & 356.34 & $\mathrm{p}<0.0001$ \\
\hline Broadcast news $(21,623)$ & 138 & & \\
\hline
\end{tabular}

\begin{tabular}{|l|l|l|l|}
\hline Register & initial & LL & \\
\hline Academic lectures $(22,049)$ & 658 & 359.21 & $\mathrm{p}<0.0001$ \\
\cline { 1 - 2 } Broadcast news $(21,623)$ & 138 & & \\
\hline
\end{tabular}

This indicates that academic lectures resemble conversation in their position of linking adverbials in initial position while broadcast news differs radically from the other two spoken registers in its position of linking adverbials in initial position.

However, academic lectures are distinguished from conversation in the number of linguistic expressions used as linking adverbials in initial position and in grammatical forms of linking adverbials in initial position. As shown in Table 68, 28 different linguistic expressions (e.g. and, so, but, now, then, in other words) can be used as linking adverbials in initial position in academic lectures while 11 different linguistic expressions (e.g. and, but, so, or, otherwise, I mean) can be used as linking adverbials in initial position in conversation.

Table 68 Types of linking adverbials in different positions in WSC samples

\begin{tabular}{|c|c|c|c|}
\hline Position & Conversation & $\begin{array}{l}\text { Academic } \\
\text { lectures }\end{array}$ & Broadcast news \\
\hline \multirow[t]{5}{*}{ Initial } & $\begin{array}{l}\text { Single-word adverb: and } \\
\text { (243), but (188), so (113), } \\
\text { or (9), otherwise (2), then } \\
\text { (1), actually (1) }\end{array}$ & $\begin{array}{l}\text { Single-word adverb: and (292), so } \\
\text { (147), but (78), now (55), then } \\
\text { (13), or (8), also (4), anyway (3), } \\
\text { firstly (2), therefore (2), instead } \\
\text { (1), however (1), nevertheless (1) }\end{array}$ & $\begin{array}{l}\text { Single-word adverb: } \\
\text { but (45), and (73), } \\
\text { also (7), however (2), } \\
\text { so (3), meanwhile } \\
\text { (3), meantime (1) }\end{array}$ \\
\hline & & $\begin{array}{l}\text { Prepositional phrase: in other } \\
\text { words (5), for example (2), in fact } \\
\text { (1), of course (1), in addition (1), } \\
\text { for instance (1) }\end{array}$ & $\begin{array}{l}\text { Prepositional phrase: } \\
\text { as a result (2), in the } \\
\text { meantime (1), in } \\
\text { addition (1) }\end{array}$ \\
\hline & Finite clause: I mean (41) & Finite clause: I mean (11) & \\
\hline & $\begin{array}{l}\text { Adverb phrase: and then } \\
\text { (30), but then (8), so then } \\
\text { (1) }\end{array}$ & $\begin{array}{l}\text { Adverb phrase: and then (19), } \\
\text { so... then (3), first of all (3), but } \\
\text { then (1), first off (1), and also (1) }\end{array}$ & \\
\hline & & $\begin{array}{l}\text { Non-finite clause: to summarize } \\
\text { (1) }\end{array}$ & \\
\hline
\end{tabular}




\begin{tabular}{|c|c|c|c|}
\hline \multirow[t]{4}{*}{ Medial } & $\begin{array}{l}\text { Single-word adverb: and } \\
\text { (9), so (7), also (3), still } \\
\text { (3), then (2), though (2), } \\
\text { anyway (1) first (1), } \\
\text { otherwise (1) }\end{array}$ & $\begin{array}{l}\text { Single-word adverb: } \\
\text { then (62), so (28), also (20), still } \\
\text { (6), therefore (5), actually (4), } \\
\text { secondly (2), thereby (1), } \\
\text { ultimately (1) }\end{array}$ & $\begin{array}{l}\text { Single-word adverb: } \\
\text { also (16), finally (3) }\end{array}$ \\
\hline & $\begin{array}{l}\text { Prepositional phrase: for } \\
\text { example (1) }\end{array}$ & $\begin{array}{l}\text { Prepositional phrase: in fact (5), } \\
\text { by the way (3), in other words (2), } \\
\text { for example (2), of course (1), on } \\
\text { the other hand (1) }\end{array}$ & \\
\hline & Finite clause: I mean (10) & Finite clause: I mean (3) & \\
\hline & & Adverb phrase: first of all (6) & \\
\hline \multirow[t]{3}{*}{ Final } & $\begin{array}{l}\text { Single-word adverb: } \\
\text { though (16), and (12), then } \\
\text { (5), but (4), or (3), actually } \\
\text { (2), so (1), anyway (1) }\end{array}$ & Single-word adverb: then (2) & \\
\hline & $\begin{array}{l}\text { Prepositional phrase: in } \\
\text { other words (1) }\end{array}$ & Prepositional phrase: of course (1) & \\
\hline & Finite clause: I mean (1) & & \\
\hline
\end{tabular}

Linking adverbials in initial position in academic lectures take five grammatical forms: single-word adverb, prepositional phrase, finite clause, adverb phrase and non-finite clause while linking adverbials in initial position in conversation take three grammatical forms: single-word adverb, finite clause and adverb phrase.

Examples 86-90 illustrate the five different grammatical forms of linking adverbials in initial position in academic lectures.

In example 86, so is used in initial position in an intonation unit in academic lectures.

86. //so first of all/ a brief history of past attempts/ at captive breeding // (WSC MUL011, academic lectures)

It takes the grammatical form of single-word adverb.

In example 87, to summarise is used in the initial position of an intonation unit in academic lectures.

87. I/to summarise /over the last thirty eight years/ there've been at least ninety adults /that have been collected for the purposes of display/ and or breeding in the zoo situations//(WSC MUL011, academic lectures)

It takes the grammatical form of non-finite clause.

In example 88 , and then is used in the initial position of an intonation unit in academic lectures. 
88. //and then there are some others places otorohanga /where there are several animals/ in large outdoor colonies/ in this case four males and four females together// (WSC MUL011, academic lectures)

It takes the grammatical form of adverb phrase.

In example 89 , for instance is used in initial position in an intonation unit in academic lectures.

89. I/firstly/ um/ high adult mortality/ lack of appropriate physical cues for reproduction/ lack of social interactions// for instance males and females have often been in pairs /with just one other member of the opposite sex//(WSC MUL011, academic lectures)

It takes the grammatical form of prepositional phrase.

In example 90, I mean is used in initial position in an intonation unit in academic lectures.

90. // er i'm sorry / that goes on and on and on //in fact it's quite interesting//i mean / he talks like that around and about //(WSC MUL002, academic lectures)

It takes the grammatical form of finite clause.

As mentioned above, academic lectures and conversation differ in the total number and grammatical forms of linguistic expressions used as linking adverbials in initial position. But academic lectures and conversation do have some common linking adverbials which are used in initial position (and, so, but, or, I mean, and then) (Table 68), though the frequency of each of the aforementioned linking adverbials may not be the same (e.g. but occurs 188 times in initial position in conversation while it occurs only 78 times in initial position in academic lectures).

Different from academic lectures and conversation, linking adverbials in initial position in broadcast news only take two grammatical forms: single-word adverb and prepositional phrase. Broadcast news also has some linking adverbials in initial position which are unique to its own and not found in academic lectures and conversation (meanwhile, meantime, as a result, in the meantime, in addition).

As shown in Table 69, the difference of the frequency of linking adverbials in medial position among the three spoken registers is significant. Academic lectures have the most frequent use of linking adverbials in medial position while broadcast news has the least frequent use of linking adverbials in medial position. 
Table $69 \mathrm{LL}$ of medial position of linking adverbials in spoken registers

\begin{tabular}{|l|l|l|l|}
\hline Register & medial & LL & \\
\cline { 1 - 2 } Academic lectures $(22,049)$ & 152 & 65.74 & $\mathrm{p}<0.0001$ \\
\cline { 1 - 2 } Conversation $(21,279)$ & 40 & & \\
\hline
\end{tabular}

\begin{tabular}{|l|l|l|l|}
\hline Register & medial & LL & \\
\cline { 1 - 3 } Conversation $(21,279)$ & 40 & 7.98 & $\mathrm{p}<0.01$ \\
\cline { 1 - 2 } Broadcast news $(21,623)$ & 19 & & \\
\hline
\end{tabular}

\begin{tabular}{|l|l|l|l|}
\hline Register & medial & LL & \\
\cline { 1 - 2 } Academic lectures $(22,049)$ & 152 & 115.18 & $\mathrm{p}<0.0001$ \\
\cline { 1 - 2 } Broadcast news $(21,623)$ & 19 & & \\
\hline
\end{tabular}

Academic lectures not only have the most frequent use of linking adverbials in medial position in spoken registers but also have the largest number of linguistic expressions used as linking adverbials in medial position (Table 68). Linking adverbials in medial position have 16 different linguistic expressions in academic lectures, 11 in conversation and two in broadcast news.

The 16 linguistic expressions in medial position in academic lectures take four grammatical forms: single-word adverb, prepositional phrase, finite clause and adverb phrase. The 11 linguistic expressions in medial position in conversation take three different grammatical forms: single-word adverb, prepositional phrase and finite clause. The two linguistic expressions in medial position in broadcast news take only one grammatical form, i.e., singleword adverb.

Examples 91-94 illustrate the four grammatical forms of medial position linking adverbials in academic lectures.

In example 91, then is used in medial position in an intonation unit in academic lectures.

91. // theory can be seen from that kind of / layout then/ as the sum/total of our observations/ interpretations /clarification//(WSC MUL003, academic lectures)

It takes the grammatical form of single-word adverb.

In example 92 , by the way is used in medial position in an intonation unit in academic lectures.

92. //i should have commented/ by the way that /um/ there are a number of reasons for looking at this relationship between programs just as there was in looking at the 
relationship between while programs and flow chart programs//(WSC MUL007, academic lectures)

It takes the grammatical form of prepositional phrase.

In example 93, I mean is used in medial position in an intonation unit in academic lectures.

93. //he was thought to be a dangerous subversive //you know/ as if THIS poem which/ is /i mean/ if you read it /forgetting about the fact of the death of the father //(WSC MUL002, academic lectures)

It takes the grammatical form of finite clause.

In example 94, first of all is used in medial position in an intonation unit in academic lectures.

94. I/what $i$ want to do/ first of all/ is battle with technology //(WSC MUL025, academic lectures)

It takes the grammatical form of adverb phrase.

Although the ratio of the total number of linguistic expressions used as linking adverbials in medial position in academic lectures and conversation is $16: 11$, only five of the linguistic expressions are commonly used by both registers (so, also, still, for example and I mean) (Table 68).

Broadcast news uses also in medial position as linking adverbials too. As mentioned above, only two linguistic expressions are used as linking adverbials in medial position in broadcast news. The other one is finally, which does not appear in other two spoken registers as linking adverbials. The ratio of medial position also and finally is 16:3.

Examples 95-96 illustrate the two medial position linking adverbials in broadcast news.

In example 95, also is used in medial position in an intonation unit in broadcast news.

95. //the police are concerned someone may get hurt/ if a confrontation erupts/ where firearms are legally in use//kay fellows representing the protest group says/ they're also scared at the prospect of personal injury/ but are prepared to risk it to make the point // (WSC MSN020, broadcast news)

It takes the grammatical form of single-word adverb.

In example 96, finally is used in medial position in an intonation unit in broadcast news. 
96. // and finally britain's former women's cricket skipper Rachael heyhoeflint is an angry woman today//(WSC MSN119, broadcast news)

It takes the grammatical form of single-word adverb.

It is worth noting that the three occurrences of finally as linking adverbials in broadcast news all concur with and to mark the last piece of news in the program. This marking close-to-theend feature does not appear in the other two spoken registers and this may explain why finally is only used in broadcast news as linking adverbials but not in academic lectures and conversation.

As shown in Table 70, the difference of the frequency of linking adverbials in final position among the three spoken registers is also significant. The frequency patterns of final position of the three spoken registers, however, are different from initial and medial position. In initial position, academic lectures and conversation have a relative close frequency of linking adverbials and they both have significantly more frequent use of linking adverbials than broadcast news. In medial position, academic lectures have the most frequent use of linking adverbials while broadcast news has the least frequent use of linking adverbials.

Table $70 \mathrm{LL}$ of final position of linking adverbials in spoken registers

\begin{tabular}{|l|l|l|l|}
\hline Register & final & LL \\
\cline { 1 - 2 } Academic lectures $(22,049)$ & 3 & 46.90 & $\mathrm{p}<0.0001$ \\
\cline { 1 - 2 } Conversation $(21,279)$ & 46 & & \\
\hline
\end{tabular}

\begin{tabular}{|l|l|l|l|}
\hline Register & final & LL \\
\cline { 1 - 2 } Conversation $(21,279)$ & 46 & 64.51 & $\mathrm{p}<0.0001$ \\
\cline { 1 - 2 } Broadcast news $(21,623)$ & 0 & & \\
\hline
\end{tabular}

\begin{tabular}{|l|l|l|l|}
\hline Register & final & \multicolumn{2}{|l|}{ LL } \\
\hline Academic lectures $(22,049)$ & 3 & 4.10 & $\mathrm{p}<0.05$ \\
\hline Broadcast news $(21,623)$ & 0 & & \\
\hline
\end{tabular}

But as shown in Table 70, in final position, conversation has the most frequent use of linking adverbials in the three spoken registers and broadcast news has no use of linking adverbials. Final position linking adverbials are also very rare in academic lectures.

In final position, linking adverbials in conversation take three different grammatical forms: single-word adverb, prepositional phrase and finite clause while linking adverbials in academic lectures take two grammatical forms: single-word adverb and prepositional phrase. 
Examples 97-100 illustrate the grammatical forms of final position linking adverbials in conversation and academic lectures.

In example 97, though occurs twice in final position in an intonation unit in conversation.

97. A:// wouldn't get a very good park though//

B: // mm/you wouldn't be able to get a p// it's friday though// (WSC DPC096, conversation)

They take the form of single-word adverb.

In example 98 , in other words appears in final position in an intonation unit in conversation.

98. A: //from another room// yeah// but $i$ didn't want to walk back and forth//

$$
\begin{aligned}
& \text { B: //yeah// } \\
& \text { C: //so it's called laziness in other words// (WSC DPC172, conversation) }
\end{aligned}
$$

It takes the form of prepositional phrase.

In example 99, I mean appears in final position in an intonation unit in conversation.

99. A: //waipuk // no// she didn't live in London// she lived in Canterbury// no// raewyn lived in sussex//

B: //sussex// yeah//oh/was it //yeah//that's right//

\section{A: //yeah//yeah//}

$B: / / G O D / /$

A: //to waipuk i mean// (WSC DPC193, conversation)

It takes the form of finite clause.

In example 100, of course is used in the final position of an intonation unit in academic lectures.

100. // and $i$ think /it's probably the most interesting /er /source of information about his writing/ other than reading the poems of course // (WSC MULO02, academic lectures)

It takes the form of prepositional phrase.

In example 101, then is used in the final position of an intonation unit in academic lectures. 
101. // okay //then/ we'll call it a low level then//(WSC MUL029, academic lectures)

It takes the form of single-word adverb.

It is worth noting that a large part of the overall frequency (46) of final position linking adverbials in conversation is contributed by two single-word adverbs though (16) and and (12) while the only two linguistic expressions of final position linking adverbials (then, of course) in academic lectures are comparatively equally distributed (2:1).

In the next section, positions of linking adverbials in academic settings are reported and discussed.

\subsubsection{Positions of linking adverbials in academic settings}

As shown in Table 71 below, in academic settings, academic lectures have significantly more frequent use of linking adverbials in initial position than written academic prose does.

Table $71 \mathrm{LL}$ of initial position of linking adverbials in academic settings

\begin{tabular}{|l|l|l|l|}
\hline Register & initial & \multicolumn{2}{|l|}{ LL } \\
\cline { 1 - 2 } Academic lectures $(22,049)$ & 658 & 397.59 & $\mathrm{p}<0.0001$ \\
\cline { 1 - 2 } Written academic prose (20,128) & 105 & & \\
\hline
\end{tabular}

This indicates that in academic settings, spoken and written English differ significantly in their use of initial position linking adverbials to make explicit various conjunction relationships and thus facilitate coherence (see Section 2.1.1 for relationship between cohesion and coherence).

Although the frequency of initial position linking adverbials is much higher in academic lectures, academic lectures (27) have a smaller number of linguistic expressions used as linking adverbials in initial position than written academic prose does (35) (Table 72). This means, in academic settings, written English has a more varied linguistic repertoire as initial position linking adverbials than spoken English.

In written academic prose, the frequency of each linguistic expression in initial position is relatively close when compared with the frequency of each linguistic expression in initial position in academic lectures. Then, but, however, for example, are the three most frequent linguistic expressions in initial position in written academic prose and the frequency of each word is: 13, 11 and 10. The three numbers are relative close when compared with the frequency of the three most frequent linguistic expressions in initial position in academic lectures. In academic lectures, the three most frequent linguistic expressions in initial position 
are: and, so, but and the frequency of the three words are 292, 147 and 78 respectively. The gaps among the three numbers are bigger than the gaps among the three numbers of 13,11 and 10, which as mentioned above are the respective frequency of the three most frequent linking adverbials in initial position in written academic prose. This shows that in academic settings, in spoken English certain linking adverbials are particularly frequently used in initial position to make explicit certain meaning relationships (see Table 50 for types of linking adverbials marking various meaning relationships).

\section{Table 72 Types of linking adverbials in different positions in academic settings}

\begin{tabular}{|c|c|c|}
\hline Positions & Written academic prose & Academic lectures \\
\hline \multirow[t]{5}{*}{ initial } & $\begin{array}{l}\text { Single-word adverb: then (13), but } \\
\text { (11), however (10), and ( } 7), \text { thus (6), } \\
\text { so (5), first (4), therefore ( } 3) \text {, } \\
\text { alternatively (3), secondly (3), hence } \\
\text { (3), or (2), furthermore (2), further } \\
\text { (2), now (2), similarly (2), also (1), } \\
\text { additionally (1), second (1), } \\
\text { nevertheless (1), likewise (1), } \\
\text { accordingly (1) }\end{array}$ & $\begin{array}{l}\text { Single-word adverb: and (292), so } \\
\text { (147), but (78), now (55), then (13), or } \\
\text { (8), also (4), anyway (3), firstly (2), } \\
\text { therefore (2), instead (1), however (1), } \\
\text { nevertheless (1) }\end{array}$ \\
\hline & $\begin{array}{l}\text { Prepositional phrase: for example (7), } \\
\text { in other words (2), in fact (2), in } \\
\text { addition (1), at the same time (1), in } \\
\text { the meantime (1), in one (1), in the } \\
\text { second (1), in short (1), on the one } \\
\text { hand (1), on the other hand (1) }\end{array}$ & $\begin{array}{l}\text { Prepositional phrase: in other words } \\
\text { (5), for example (2), in fact (1), of } \\
\text { course (1), in addition (1), for instance } \\
\text { (1) }\end{array}$ \\
\hline & Finite clause: that is (1) & Finite clause: I mean (11) \\
\hline & Adverb phrase: even so (1) & $\begin{array}{l}\text { Adverb phrase: and then (19), so... then } \\
\text { (3), first of all (3), but then (1), first off } \\
\text { (1), and also (1) }\end{array}$ \\
\hline & & Non-finite clause: to summarize (1) \\
\hline \multirow[t]{4}{*}{ medial } & $\begin{array}{l}\text { Single-word adverb: however (18), } \\
\text { also (17), then (11), therefore (5), thus } \\
\text { (4), so (3), namely (3), yet (3), } \\
\text { consequently (1), first (1), secondly } \\
\text { (1) }\end{array}$ & $\begin{array}{l}\text { Single-word adverb: then (62), so (28), } \\
\text { also (20), still (6), therefore (5), actually } \\
\text { (4), secondly (2), thereby (1), ultimately } \\
\text { (1) }\end{array}$ \\
\hline & $\begin{array}{l}\text { Prepositional phrase: for example (8), } \\
\text { in other words (1), in fact (1), in } \\
\text { addition (1) }\end{array}$ & $\begin{array}{l}\text { Prepositional phrase: in fact (5), by the } \\
\text { way (3), in other words (2), for example } \\
\text { (2), of course (1), on the other hand (1) }\end{array}$ \\
\hline & & Adverb phrase: first of all (6) \\
\hline & Finite clause: that is (3) & Finite clause: I mean (3) \\
\hline \multirow[t]{2}{*}{ final } & Single-word adverb: too (2) & Single-word adverb: then (2) \\
\hline & & Prepositional phrase: of course (1) \\
\hline
\end{tabular}

In academic settings, some linguistic expressions are used in initial position as linking adverbials in both written and spoken English. Then, but, however, and, so, also, nevertheless, 
for example, in other words, in fact and in addition are linguistic expressions that can be used as initial position linking adverbials in both written and spoken registers in academic settings, though the frequency of a certain linguistic expression as initial position linking adverbial may differ. For example, the two linguistic expressions in other words and for example can be used as initial position linking adverbials in both written and spoken English in academic settings. For example is more frequently used as initial position linking adverbial in written academic prose (7) than in academic lectures (2) while in other words is more frequently used as initial position linking adverbials in academic lectures (5) than in written academic prose (2).

There are also linguistic expressions which are used as initial position linking adverbials in only written or spoken English in academic settings. For example, alternatively, that is and even so are only used as initial position linking adverbials in written academic prose while $I$ mean and and then are only used as initial position linking adverbials in academic lectures.

As shown in Table 73 below, academic lectures have significantly more frequent use of linking adverbials in medial position than written academic prose does.

Table $73 \mathrm{LL}$ of medial position of linking adverbials in academic settings

\begin{tabular}{|l|l|l|l|}
\hline Register & medial & LL & \\
\hline Academic lectures $(22,049)$ & 152 & 15.99 & $\mathrm{p}<0.0001$ \\
\hline Written academic prose $(20,128)$ & 81 & & \\
\hline
\end{tabular}

This means in academic settings, spoken English also differs significantly from written English in its use of medial position linking adverbials.

In academic settings, the most frequent linguistic expressions used as medial position linking adverbials are also different in the two registers. Then (62) is the most frequent medial position linking adverbials in academic lectures while however (18) is the most frequent medial position linking adverbials in written academic prose.

As shown in Table 74, the frequencies of final position linking adverbials in academic lectures and written academic prose are close.

Table $74 \mathrm{LL}$ of final position of linking adverbials in academic settings

\begin{tabular}{|l|l|l|l|}
\hline Register & final & LL & \multicolumn{2}{l|}{} \\
\cline { 1 - 2 } Academic lectures $(22,049)$ & 3 & 0.12 & ns \\
\cline { 1 - 2 } Written academic prose $(20,128)$ & 2 & & \\
\hline
\end{tabular}


This means in academic settings, spoken English is similar with written English in their use of final position linking adverbials.

In terms of linguistic expressions used in both registers in academic settings, different types of final position linking adverbials are used: too (2) in written academic prose and of course (2) and then (1) in academic lectures.

In Section 7.2.5, positions of linking adverbials in news settings are explained and discussed.

\subsubsection{Positions of linking adverbials in news settings}

As we saw in Table 75, initial position linking adverbials occur significantly more frequently in broadcast news than in written news.

Table $75 \mathrm{LL}$ of initial position of linking adverbials in news settings

\begin{tabular}{|l|l|l|l|}
\hline Register & initial & LL & \\
\cline { 1 - 2 } Broadcast news $(21,623)$ & 138 & 41.56 & $\mathrm{p}<0.0001$ \\
\cline { 1 - 2 } Written news $(21,001)$ & 49 & & \\
\hline
\end{tabular}

This indicates in news settings, spoken English also differs significantly from written English in their use of initial position linking adverbials.

As shown in Table 76 below, linguistic expressions of initial position linking adverbials in the two registers in news settings both take two grammatical forms: single-word adverb and prepositional phrase.

Table 76 Types of linking adverbials in different positions in news settings

\begin{tabular}{|l|l|l|}
\hline Positions & Written news & Broadcast news \\
\hline initial & $\begin{array}{l}\text { Single-word adverb: but (26), however (10), } \\
\text { and (5), meanwhile (2), so (2), therefore (1), } \\
\text { furthermore (1), or (1), rather (1) }\end{array}$ & $\begin{array}{l}\text { Single-word adverb: but (45), } \\
\text { and (73), so (10), also (7), } \\
\text { however (2), meanwhile (3) }\end{array}$ \\
\cline { 2 - 3 } Prepositional phrase: in the meantime (1) & $\begin{array}{l}\text { Prepositional phrase: in the } \\
\text { meantime (2), in addition (1), } \\
\text { as a result (2) }\end{array}$ \\
\hline medial & $\begin{array}{l}\text { Single-word adverb: also (25), however (6), } \\
\text { still (6), then (5), therefore (1), thereby (1), } \\
\text { so (1), thus (1) }\end{array}$ & $\begin{array}{l}\text { Single-word adverb: } \\
\text { also (17), finally (3) }\end{array}$ \\
\cline { 2 - 3 } & $\begin{array}{l}\text { Prepositional phrase: in addition (1), } \\
\text { after all (1) }\end{array}$ & \\
\hline final & Single-word adverb: anyway (1), however (1) & \\
\cline { 2 - 3 } & Prepositional phrase: as a result (1) & \\
\hline
\end{tabular}

However, linguistic expressions of each form are different. Written news has a larger number of types of single-word adverbs ( 9 vs 6 ) while broadcast news has a larger number of types of 
prepositional phrases ( 3 vs 1 ). The most frequent initial position linking adverbials are also not exactly the same. But, and and so occur most frequently in initial position in broadcast news while but, however and and occur most frequently in initial position in written news.

As shown in Table 77, medial position linking adverbials occur significantly more frequently in written news than in broadcast news. Written news has more varied grammatical forms of medial position linking adverbials and a larger number of linguistic expressions of medial position linking adverbials than broadcast news (Table 76). In written news, the ten linguistic expressions of medial position linking adverbials take two grammatical forms of single-word adverb and prepositional phrase while the two linguistic expressions of medial position linking adverbials in broadcast news only occur in the grammatical form of single-word adverb. It is also worth noting that also is the most frequent medial position linking adverbial in both registers in news settings.

Table 77 LL of medial position of linking adverbials in news settings

\begin{tabular}{|l|l|l|l|}
\hline Register & medial & LL \\
\cline { 1 - 2 } Broadcast news $(21,623)$ & 19 & 12.36 & $\mathrm{p}<0.001$ \\
\cline { 1 - 2 } Written news $(21,001)$ & 46 & & \\
\hline
\end{tabular}

As shown in Table 78, final position linking adverbials only occur in written news and the difference between spoken and written English in news setting is significant. The three linguistic expressions identified take two forms of single-word adverb and prepositional phrase, though the frequency is very low (3) (Table 76).

Table $78 \mathrm{LL}$ of final position of linking adverbials in news settings

\begin{tabular}{|l|l|l|l|}
\hline Register & final & LL \\
\cline { 1 - 2 } Broadcast news $(21,623)$ & 0 & 4.25 & $\mathrm{p}<0.05$ \\
\cline { 1 - 2 } & 3 & & \\
\hline
\end{tabular}

The WWC and WSC samples have shown that linking adverbials occur most frequently in initial position in all registers and least frequently in final position in most registers except in conversation which has a close number of medial position and final position linking adverbials. The WWC and WSC samples have also demonstrated that linguistic expressions of linking adverbials in three positions in different registers vary. And linguistic expressions of linking adverbials in different positions can take different grammatical forms.

In Section 7.3, data from larger corpora are reported and discussed. 


\subsection{Do certain linking adverbials occur only in a certain position?}

In this section, the question of whether certain linking adverbials occur in a certain position will be explored through data from larger corpora: the whole WWC, BNC and COCA. The findings are compared with those from the WWC samples. Only written registers were examined, because in this study data from spoken registers were manually analysed and sound files were used to help decide intonation units. Thus, an automatic search of positions of linking adverbials in spoken registers is not possible for larger corpora. In this section, only written academic prose is investigated, since linking adverbials occur significantly more frequently in written academic prose than in written news (see Section 4.4). Positions of the three most frequent linking adverbials in written academic prose in the WWC samples, namely, however, but and for example are reported and compared.

Some word forms can have more than one grammatical function in different linguistic contexts. Examples 102 and 103 illustrate this.

In example 102, however is a linking adverbial.

102. The only questionable aspect of using the plaster is that it is difficult (especially on the upper loading strip) to make an absolutely consistent and uniform application for numerous specimens, however the small variations which inevitably do occur are not considered to be of significant consequence. (WWC J73, written academic prose)

It carries the adversative meaning.

In example 103, however is a wh-degree adverb used with an adjective or an adverb.

103. At this level, however deliberately theatrical, grotesque, comic, and doubleconscious her art may seem, it is profoundly, deadly, serious. (WWC J66, written academic prose)

It means 'to whatever degree'.

In this section, only their occurrences as linking adverbials (see Section 3.3.2 for a discussion on automatic search of linking adverbial however and wh-degree adverb however) are reported. Table 79 below shows the frequency of positions of the three most frequently used linking adverbials in written academic prose in WWC samples. 
Table 79 Raw frequency of positions of however, but and for example in written academic prose in WWC samples (20,128 words)

\begin{tabular}{|l|l|l|l|}
\hline Word forms & Initial & Medial & final \\
\hline however & 10 & 18 & 0 \\
\hline but & 11 & 0 & 0 \\
\hline for example & 7 & 8 & 0 \\
\hline
\end{tabular}

In WWC samples, however occurs most frequently in medial position. Initial position however is the next frequent one and no final position however occurs. But occurs only in initial position and for example can appear in both initial and medial position. Parallel data for these three linking adverbials from larger corpora are reported and compared below.

Table 80 below presents the frequency of positions of linking adverbial however in four different data sets.

Table $80 \mathrm{LL}$ of frequency of however in different positions in written academic prose in different corpora

\begin{tabular}{|l|l|l|l|l|}
\hline Corpus & Initial & Medial & LL & \\
\hline WWC samples $(20,128)$ & 10 & 18 & 2.32 & ns \\
\hline WWC $(196,695)$ & 90 & 89 & 0.01 & ns \\
\hline BNC $(15,331,668)$ & 7,987 & 8,818 & 41.11 & $\mathrm{p}<0.0001$ \\
\hline COCA $(91,066,191)$ & 31,961 & 40,220 & 947.07 & $\mathrm{p}<0.0001$ \\
\hline
\end{tabular}

\begin{tabular}{|l|l|l|l|l|}
\hline Corpus & Medial & Final & LL & \\
\hline WWC samples $(20,128)$ & 18 & 0 & 24.95 & $\mathrm{p}<0.0001$ \\
\hline WWC $(196,695)$ & 89 & 1 & 113.78 & $\mathrm{p}<0.0001$ \\
\hline BNC $(15,331,668)$ & 8,818 & 180 & 10709.25 & $\mathrm{p}<0.0001$ \\
\hline COCA $(91,066,191)$ & 40,220 & 1,483 & 45003.90 & $\mathrm{p}<0.0001$ \\
\hline
\end{tabular}

\begin{tabular}{|l|l|l|l|l|}
\hline Corpus & Initial & Final & LL & \\
\hline WWC samples $(20,128)$ & 10 & 0 & 13.86 & $\mathrm{p}<0.001$ \\
\hline WWC $(196,695)$ & 90 & 1 & 115.14 & $\mathrm{p}<0.0001$ \\
\hline BNC $(15,331,668)$ & 7,987 & 180 & 9592.50 & $\mathrm{p}<0.0001$ \\
\hline COCA $(91,066,191)$ & 31,961 & 1,483 & 34222.50 & $\mathrm{p}<0.0001$ \\
\hline
\end{tabular}

As shown in Table 80, the results reported in the whole WWC echoed the findings in WWC samples, that is, linking adverbial however is used at a very similar frequency in initial and medial position and it is rarely used in final position. Findings from BNC and COCA have shown a different pattern, that is, linking adverbial however is used significantly more frequently in medial position than in the other two positions. Similar with findings from WWC samples and WWC, in BNC and COCA, final position is also the least frequent position of linking adverbial however. 
This may indicate the different frequency patterns of linking adverbial however in initial and medial position in written academic prose in different varieties of English. In New Zealand English, there is no preference in positioning linking adverbial however in initial or medial position in written academic prose while in British and American English, linking adverbial however is preferred in medial position in written academic prose.

Examples 104-106 illustrate the three positions of linking adverbial however.

In example 104, however is used in initial position.

104. The area fished and point of landing definitions are not perfectly consistent. However, since the net amount of snapper caught in the Bay and landed at outside ports or vice versa does not appear to have been great.(WWC J09, written academic prose)

In example 105, however is used in medial position.

105. The venue, the Institution of Mechanical Engineers' own building, deserves a small mention as it is a lovely old building with memorabilia of past presidents and events located throughout the rooms. The conference facilities, however, were of the highest modern standard and even included a video projector. (WWC J80, written academic prose)

In example 106, however is used in final position

106. In the late fifties I recognised that at least two kinds of stress must be recognised for Maori - I called them contour stress and primary stress - but failed to find any general rules applying to either. The discovery, by Pat Hohepa in 1960, of ordered rules for determining primary word stress did the trick, however. (WWC J32, written academic prose)

Linking adverbial for example shares a similar pattern with linking adverbial however in terms of positions in three corpora, i.e., WWC samples, WWC and BNC. Table 81 presents frequency of positions of linking adverbial for example in different corpora. 
Table $81 \mathrm{LL}$ of frequency of for example in different positions in written academic prose in different corpora

\begin{tabular}{|l|l|l|l|l|}
\hline Corpus & Initial & Medial & LL \\
\hline WWC samples $(20,128)$ & 7 & 8 & 0.07 & ns \\
\hline WWC $(196,695)$ & 42 & 37 & 0.32 & ns \\
\hline BNC $(15,331,668)$ & 2,655 & 4,801 & 626.49 & $\mathrm{p}<0.0001$ \\
\hline COCA $(91,066,191)$ & 19,820 & 16,308 & 341.94 & $\mathrm{p}<0.0001$ \\
\hline
\end{tabular}

\begin{tabular}{|l|l|l|l|l|}
\hline Corpus & Medial & Final & LL \\
\hline WWC samples $(20,128)$ & 8 & 0 & 11.09 & $\mathrm{p}<0.0001$ \\
\hline WWC $(196,695)$ & 37 & 1 & 43.43 & $\mathrm{p}<0.0001$ \\
\hline BNC $(15,331,668)$ & 4,801 & 148 & 5530.36 & $\mathrm{p}<0.0001$ \\
\hline COCA $(91,066,191)$ & 16,308 & 538 & 18589.13 & $\mathrm{p}<0.0001$ \\
\hline
\end{tabular}

\begin{tabular}{|l|l|l|l|l|}
\hline Corpus & Initial & Final & LL \\
\hline WWC samples $(20,128)$ & 7 & 0 & 9.70 & $\mathrm{p}<0.01$ \\
\hline WWC $(196,695)$ & 42 & 1 & 50.11 & $\mathrm{p}<0.0001$ \\
\hline BNC $(15,331,668)$ & 2,655 & 148 & 2727.13 & $\mathrm{p}<0.0001$ \\
\hline COCA $(91,066,191)$ & 19,820 & 538 & 23251.02 & $\mathrm{p}<0.0001$ \\
\hline
\end{tabular}

Similar to linking adverbial however, linking adverbial for example has no significant difference between initial and medial positions in WWC samples and WWC and it is used least frequently in final position in all four corpora. In BNC, linking adverbial for example is significantly more frequently used in medial position than in initial position while in COCA, linking adverbial for example is used significantly more frequently in initial position than in medial position.

This may have shown that in different varieties of English, linking adverbial for example has its own frequency patterns of positions.

Examples 107-109 illustrate the three positions of linking adverbial for example.

In example 107, for example appears in initial position.

107. Delivery of other resources has been delayed, reducing their effectiveness.

For example, in 1986 a brand new mathematics course was available in the 7th form which required all teachers to break new ground. (WWC J38, written academic prose) 
In example 108, for example appears in medial position.

108. Gross rural-urban differences can be seen clearly enough. In the last quarter of 1908, for example, the rates of attendance in one-or two-teacher schools were $84.9 \%$ for boys and $83.3 \%$ for girls. (WWC J39, written academic prose)

In example 109, for example appears in final position.

109. It is clear from the reports of successive committees set up over the past twenty-five years to review the Standing Orders of the House (1962, 1967, 1972, 1979 and 1984-7), that the existing procedures, despite some important changes, still do not work as well as might be hoped. There continue to be difficulties at the first reading stage, for example. (WWC J40, written academic prose)

Linking adverbials however and for example can both occur in all three positions: initial, medial and final. Corpora data, however, have demonstrated that linking adverbial but only occurs in initial position, as shown in Table 82.

Table $82 \mathrm{LL}$ of Frequency of but in different positions in written academic prose in different corpora

\begin{tabular}{|l|l|l|l|l|}
\hline Corpus & Initial & Medial & LL & \\
\hline WWC samples $(20,128)$ & 11 & 0 & 15.25 & $\mathrm{p}<0.0001$ \\
\hline WWC $(196,695)$ & 78 & 0 & 108.13 & $\mathrm{p}<0.0001$ \\
\hline BNC $(15,331,668)$ & 10,276 & 0 & 14245.56 & $\mathrm{p}<0.0001$ \\
\hline COCA $(91,066,191)$ & 44,313 & 0 & 61430.86 & $\mathrm{p}<0.0001$ \\
\hline
\end{tabular}

\begin{tabular}{|l|l|l|l|l|}
\hline Corpus & Medial & Final & LL \\
\hline WWC samples $(20,128)$ & 0 & 0 & 0.00 & ns \\
\hline WWC $(196,695)$ & 0 & 0 & 0.00 & ns \\
\hline BNC $(15,331,668)$ & 0 & 0 & 0.00 & ns \\
\hline COCA $(91,066,191)$ & 0 & 0 & 0.00 & ns \\
\hline
\end{tabular}

\begin{tabular}{|l|l|l|l|l|}
\hline Corpus & Initial & Final & LL & \\
\hline WWC samples $(20,128)$ & 11 & 0 & 15.25 & $\mathrm{p}<0.01$ \\
\hline WWC $(196,695)$ & 78 & 0 & 108.13 & $\mathrm{p}<0.0001$ \\
\hline BNC $(15,331,668)$ & 10,276 & 0 & 14245.56 & $\mathrm{p}<0.0001$ \\
\hline COCA $(91,066,191)$ & 44,313 & 0 & 61430.86 & $\mathrm{p}<0.0001$ \\
\hline
\end{tabular}

As shown in Table 82, linking adverbial but is always used in initial position. Example 110 illustrates linking adverbial but in initial position.

In example 110 , but is used in initial position.

110. Now cohort sizes are declining but social change continues with the numbers 
in form 6, and form 7, still increasing especially the numbers of females. But we still lag behind comparable changes in most OECD countries. (WWC J38, written academic prose)

Findings from larger corpora have consolidated the results from WWC samples that linking adverbial but only occurs in initial position and that linking adverbial however and linking adverbial for example can occur either in initial or in medial position, though the frequency patterns vary in different corpora. Larger corpora have also yielded new findings that linking adverbial however and linking adverbial for example can also occur in final position.

In Chapter 7, the third aspect of usage patterns of linking adverbials, i.e., position, has been explained and exemplified. Analysis and discussion of the three aspects of usage patterns (form, meaning and position) have shown that linking adverbials can take five different forms: single-word adverb, adverb phrase, prepositional phrase, finite clause and non-finite clause. They can carry 21 different categories of meaning in different registers. They can occur in three positions (initial, medial and final) either in a sentence or in an intonation unit. A summary of findings and a discussion of implications of this study are discussed in Chapter 8 . 


\section{Chapter 8 Summary and Implications}

In this chapter, the major findings of this study are summarized in relation to the two research questions set out in Chapter 1. Implications from this study for second language teaching and learning, limitations and future research are also discussed.

\subsection{Summary of findings}

This study has provided a definition of linking adverbials by examining current literature and through data analysis. In order to give second language learners detailed guidelines on the usage patterns of linking adverbials, especially in ESP and EAP contexts, this study has also given a detailed account of the form, meaning and position of linking adverbials in five registers: written academic prose, written news, academic lectures, broadcast news and conversation and compared the usage patterns between two written registers, among three spoken registers and between written and spoken English in similar social settings (e.g. academic settings).

Two research questions have been answered by manually analysing 67 texts, a total of 100,000 words, randomly chosen from the Wellington Corpora of Written and Spoken New Zealand English (WWC and WSC) and automatic search of the most frequent items identified in WWC and WSC samples in larger corpora, i.e., the whole WWC, BNC and COCA.

Summaries of the findings with respect to the two research questions are presented respectively in sections 8.1.1 and 8.1.2.

\subsubsection{Summary of findings for research question 1}

For convenience, I repeat research question 1 here:

1. What is a linking adverbial in English?

1.1 What is the definition of linking adverbials?

1.2 What are the differences between linking adverbials and other related grammatical categories (e.g. conjunctions)?

The new definition of linking adverbials given in this study is based on the following definition provided by Biber et al. (1999, p. 765): 
The third class of adverbials is linking adverbials. Linking adverbials have a more peripheral relationship with the rest of the clause than circumstance adverbials typically do. Rather than adding additional information to a clause, they serve a connective function. They make explicit the relationship between two units of discourse. Linking adverbials can connect units of discourse of different sizes. Linking adverbials can express a variety of relationships, including addition and enumeration, summation, apposition, result/inference, contrast/concession, and transition.

Based on their definition and my data analysis, especially manual analysis of three spoken registers, this study proposes the following new definition of linking adverbials:

As clause components, linking adverbials are adverbials, as their name suggests. In terms of their pragmatic functions, they are also a subcategory of discourse markers. Their main function is as a discourse cohesive device rather than a structural link. They are explicit markers of different meaning relationships at various discourse levels in both written and spoken English: within a sentence (or intonation unit in spoken English), between sentences (or intonation units in spoken English), and between paragraphs (or sets of intonation units in spoken English).

This definition has the following new features:

1. In describing the main function of linking adverbials, i.e., to provide discourse cohesive devices at different discourse levels, the notion of intonation units has been included to account for the analysis units in spoken data which are different from the analysis units, sentences and paragraphs, in written data.

2. It accounts for the difference between linking adverbials and conjunctions, which also have linking functions, i.e., a linking adverbial is a discourse cohesive device rather than a structural link as is the case for conjunctions.

3. It makes explicit the difference between linking adverbials and discourse markers: linking adverbials are one type of discourse marker in terms of their pragmatic functions.

\subsubsection{Summary of findings for research question 2}

Research question 2 is as follows:

2. How can linking adverbials be used?

2.1 What are the forms of linking adverbials in different registers?

2.2 How can linking adverbials be classified in terms of meaning in different registers?

2.3 What are positions of linking adverbials in different registers? 
Research question 2 examines the usage patterns of linking adverbials in three aspects: form, meaning and position. This section summarizes the findings about frequencies and the form, meaning and position of linking adverbials respectively.

\subsubsection{Findings about frequency of linking adverbials}

By including more spoken registers in the analysis, this study has yielded the following new findings:

1. The register of academic lecture has the most frequent use of linking adverbials among all five analysed registers.

2. Conversation has significantly more frequent use of linking adverbials than written academic prose.

3. Spoken registers have significantly more frequent use of linking adverbials than written academic prose.

\subsubsection{Form}

In terms of form, findings from WWC and WSC samples in this study are as follows:

1. Linking adverbials in WWC and WSC samples take five different syntactic forms: singleword adverb, adverb phrase, prepositional phrase, finite clause and non-finite clause.

2. Single-word adverbs are the most frequent form across registers in the WWC and WSC samples.

3. This study has also yielded new findings in other registers such as academic lectures and broadcast news which are not included, reported or compared in Biber, et al.'s (1999) grammar:

(a) Academic lectures have the most variation of forms while the registers of news (written and broadcast) have the least variation.

(b) In written academic prose, four different forms have been identified in the WWC samples: single-word adverb, prepositional phrase, finite clause and adverb phrase while in written news, only two different forms are found: single-word adverb and prepositional phrase.

(c) As the most frequent form in both registers, single-word adverb is used significantly more frequently in academic prose than in written news. Prepositional phrase is the second most frequently used form in both registers and it is significantly more 
frequent in written academic prose than in written news. Finite clause is also significantly more frequently used in written academic prose than in written news.

(d) In WSC samples, academic lectures have the most variation in forms: single-word adverb, prepositional phrase, adverb phrase, finite clause and non-finite clause, while broadcast news has the least: single-word adverb and prepositional phrase only. This means in spoken registers, academic lectures have the most varied structural profile and broadcast news has the simplest structural repertoire of linking adverbials.

(e) Academic lectures have the most frequent use of single-word adverb and prepositional phrase while conversation has the most frequent use of finite clause.

(f) Written academic prose and academic lectures both have a very varied structure profile, i.e., in written academic prose four different forms are found and in academic lectures five are identified.

(g) Written academic prose and academic lectures share a similar pattern in that the single-word adverb makes up the bulk of the forms used and prepositional phrase is relatively frequent in both registers.

(h) Written academic prose and academic lectures differ in that in academic lectures adverb phrase is the second most frequent while in written academic prose it is the least frequent.

(i) Written academic prose and academic lectures also differ in that the forms of singleword adverb, finite clause and adverb phrase are significantly more frequently used in academic lectures.

(j) Written news and broadcast news share a similar pattern: only two forms (singleword adverb and prepositional phrase) are found in both registers, with single-word adverb far more frequently used than prepositional phrase.

(k) The only difference between the two registers of written news and broadcast news is that single-word adverb is significantly more frequently used in broadcast news.

(l) When compared with written news, written academic prose shows more varied types of single-word adverbs and prepositional phrases. This means written academic prose has a more varied vocabulary repertoire in terms of the variation of the types of a certain form than written news does. 
Frequencies of the three linking adverbials that are relatively frequently used and whose range is relatively high in both written academic prose and written news from larger corpora are as follows:

1. In WWC, BNC and COCA, the frequency pattern of however and but as linking adverbials in two written registers is similar among the three corpora, the WWC, BNC and COCA, with however being used significantly more frequently in written academic prose and but being used significantly more frequently in written news.

2. The frequency pattern of also in COCA is different. It is used significantly more frequently in written academic prose than in written news in WWC, but the reverse is the case in BNC and COCA.

3. This indicates that there are differences among American English, British English and New Zealand English. There appears to be a closer relationship between British English and New Zealand English than between American English and New Zealand English in terms of the frequency of certain linking adverbials (e.g. also).

\subsubsection{Meaning}

Findings about the meaning of linking adverbials are as follows:

1. Twenty-one different meaning categories have been identified in the five registers. Five new meaning categories are identified: signal of evidence, formulaic ending, initiating a lecture/ program/ conversation, marker of continuation and signal of returning to the main thread. Four of them (except signal of evidence) occur only in spoken registers.

2. The most frequent three meaning categories in the five registers are: addition, adversative and marker of continuation. The least frequent meaning categories are: comparison, formulaic ending and similarity.

3. The three meaning categories of addition, adversative and marker of continuation are significantly more frequently made explicit while other meaning categories are less frequently signalled explicitly by linking adverbials.

4. A less frequent meaning category may have a larger linguistic repertoire of types of linking adverbials than a more frequent meaning category.

5. Some meaning categories are marked by only one particular type of linking adverbial. And, for example, is the only type of linking adverbial identified to make explicit the meaning of marker of continuation in conversation. 
6. Some meaning categories are marked by one particular type of linking adverbial across registers. For example, so is the sole type of linking adverbial used to make explicit the meanings of restatement and signal of returning to the main thread in different registers.

7. Some meaning categories have a distinctive type of linking adverbial to make explicit the conjunction meaning in spoken or written registers. For example, so is the only type of linking adverbial used to make explicit the meaning of signal of evidence in all the three spoken registers while thus is the only type of linking adverbial used to mark such meaning in written academic prose (the meaning was not identified in written news).

8. Among the three most frequent meaning categories, only two occur across all five registers: addition and adversative. The meaning of marker of continuation only occurs in the register of conversation.

9. Three meaning categories only occur in only one register: similarity (written academic prose), marker of continuation (conversation) and formulaic ending (broadcast news).

10. Five meaning categories occur only in spoken registers: signal of returning to the main thread, formulaic ending, marker of continuation, restatement, initiating a topic.

11. Different varieties of meanings are made explicit in different registers. This may reflect the communicative needs inherent in a certain register.

12. A register-specific meaning categorization system has been developed and is necessary since different registers differ not only in the total number of meaning categories but also in types of meaning markers.

13. A semantic-pragmatic meaning continuum has been suggested since different linking adverbials vary in the number of meanings they carry in different linguistic contexts and different registers.

14. In the written registers, two meaning categories are the most frequent in both written academic prose and written news: adversative and addition. Seven meaning categories are used significantly differently in written academic prose from they are in written news: listing, condition, logical consequence, exemplification, explanation, similarity and summation. Of the seven meaning categories, five are used only in written academic prose: listing, exemplification, explanation, similarity and summation. These exclusive meaning categories in academic prose in written registers allow 
various ways of organizing ideas: to list arguments/steps, to give examples, to explain a certain definition, to introduce similar situations and to summarize arguments.

15. In spoken registers, six meaning categories occur in all three spoken registers: addition, adversative, listing, result, signal of evidence and initiating a topic. This demonstrates the common discourse features of the three spoken registers in that they all to some extent make explicit the six conjunction meanings and this may also reflect their common communication needs of adding an extra piece of information, expressing ideas contrary to one's expectation, stating a practical result, giving an evidence of a particular claim and initiating a new topic/a new turn in their communication process.

16. In spoken registers, the frequency of each of the six meaning categories differs among the three registers. The meaning of addition is significantly more frequent in academic lectures than in conversation and in conversation than in broadcast news. The meaning of adversative is significantly more frequent in conversation than in academic lectures and in academic lectures than in broadcast news.

17. The meaning of listing is significantly more frequent in academic lectures than in conversation and broadcast news, but its frequency difference between conversation and broadcast news is not significant. The meaning of result is significantly more frequent in academic lectures and conversation than in broadcast news, but its frequency difference between academic lectures and conversation is not significant.

18. Ten meaning categories occur only in academic lectures and conversation: condition, restatement, summation, conclusion, explanation, logical consequence, signal of returning to the main thread, opposite, alternative and exemplification. This demonstrates resemblance between academic lectures and conversation in that the aforementioned meanings tend to be made explicit in the two registers.

19. Five out of ten meaning categories are significantly more frequent in academic lectures than in conversation: condition, restatement, summation, conclusion and opposite. By contrast, the meaning of explanation is significantly more frequent in conversation than in academic lectures.

20. In spoken registers, four meaning categories only occur in one particular register. Comparison and formulaic ending only occur in broadcast news, transition only occurs in academic lectures and marker of continuation only occurs in conversation.

21. In academic settings, academic lectures differ significantly from written academic prose in 14 meaning categories: adversative, addition, listing, condition, result, 
explanation, conclusion, summation, opposite, transition, signal of returning to the main thread, restatement, exemplification and similarity.

22. Ten of these 14 meaning categories are significantly more frequent in academic lectures than in written academic prose. Two out of 14 are only used in academic lectures: signal of returning to the main thread and restatement. The meaning of exemplification is significantly more frequent in written academic prose than in academic lectures. The two registers in academic settings do not differ much in the frequency of five meaning categories: logical consequence, alternative, signal of evidence, comparison and initiating a topic.

23. In news settings, written news differs significantly from broadcast news in five meaning categories: addition, formulaic ending, initiating a topic, listing and condition. The meaning of addition is significantly more frequent in broadcast news than in written news. Three meanings are used only in broadcast news and the difference is also significant: formulaic ending, initiating a topic and listing. Only one of the five, the meaning of condition is significantly more frequent in written news than in broadcast news.

\subsubsection{Position}

Findings about the position of linking adverbials in WWC and WSC samples are as follows:

1. Frequency of linking adverbials in different positions in different registers varies: initial position

academic lectures $>$ conversation $>$ broadcast news $>$ written academic prose $>$ written news;

$\underline{\text { medial position }}$

academic lectures $>$ written academic prose $>$ written news $>$ conversation $>$ broadcast news;

final position

conversation $>$ written news $=$ academic lectures $>$ academic prose $>$ broadcast news .

2. Number of types of linking adverbials in different positions in different registers varies:

initial position

written academic prose (37) > academic lectures (28) > conversation (11) > written news $(10)>$ broadcast news (9); 
$\underline{\text { medial position }}$

academic lectures (19)> written academic prose (16) > conversation (11) > written news (10)> broadcast news (2);

final position

conversation (10) > written news (3) > academic lectures (2)> written academic prose (1) $>$ broadcast news (0).

3. Number of grammatical forms of linking adverbials in different positions in different registers varies:

initial position

academic lectures $(5)>$ written academic prose $(4)>$ conversation $(3)>$ broadcast news (2) > written news (2);

$\underline{\text { medial position }}$

academic lectures $(4)>$ written academic prose $(3)=$ conversation $(3)>$ written news (2) > broadcast news (1);

final position

conversation $(2)=$ academic lectures $(2)=$ written news $(2)>$ written academic prose (1) > broadcast news (0).

Positions of the three most frequent linking adverbials in written academic prose from larger corpora are as follows:

1. In WWC, linking adverbial however is used at a very similar frequency in initial and medial position and it is rarely used in final position. Findings from BNC and COCA have shown a different pattern, that is, linking adverbial however is used significantly more frequently in medial position than in the other two positions. In all three corpora, final position is the least frequent position of linking adverbial however.

2. In WWC, linking adverbial for example has no significant difference between initial and medial positions and it is used least frequently in final position in all three corpora. In BNC, linking adverbial for example is significantly more frequently used in medial position than in initial position while in COCA, linking adverbial for example is used significantly more frequently in initial position than in medial position.

3. In all three corpora, linking adverbial but only occurs in initial position. 


\subsection{Implications}

The major part of this study, careful manual analysis of WWC and WSC samples in five different registers, has provided a new definition of linking adverbials, and has identified some usage patterns which are either different from previous studies (Biber et al., 1999; Liu, 2008) or are not included or compared in previous studies. These findings have implications for future research and second language teaching and learning, especially in ESP and EAP contexts.

\subsubsection{Contribution to our understanding of English grammar}

The new definition proposed here benefits from a close examination of the features of linking adverbials by careful manual analysis of authentic corpus data, especially by having included a fairly large amount of spoken data. Making explicit the difference between linking adverbials and conjunctions and between linking adverbials and discourse markers helps researchers and second language teachers and learners further understand the functions of linking adverbials and helps clarify the confusion caused by related grammatical categories which also have linking functions (conjunctions) and by related terms (e.g. discourse markers) in previous literature.

These new findings indicate that careful manual analysis of language items is necessary in grammar description even when corpus-based grammar description is possible after the appearance of different native corpora of spoken and written English and the development of automatic taggers. These two approaches can be complementary to each other. Corpus-based grammar description allows immediate identification of language patterns in large data sets of millions or billions of words. Careful manual analysis allows careful examination of the nature of a particular language or grammar item and the definition or system developed in such analysis facilitate the development of grammar theory and thus provide a more solid base for future automatic tagger development.

\subsubsection{Guidelines for future ESP and EAP teaching}

The current corpus study of linking adverbials in English also has implications for English language teaching and learning, especially in ESP and EAP contexts. One aspect of the strengths of corpus use in language teaching lies in that it highlights the typicalness of a certain linguistic item and provides us with large amount of authentic language examples (Römer, 2011). Römer (2011) made a useful distinction between indirect and direct applications of corpora in second language teaching, with indirect applications referring to 
the effect of corpora on the teaching syllabus and teaching material design and direct applications referring to data-driven learning with corpora and concordances.

Kennedy (1998, p. 281) wrote that 'there is increasing evidence from corpus studies of English to suggest which language items and processes are most likely to be encountered by language users, and which therefore may deserve more investment of time instruction'. Kennedy (1998, p. 281) also suggested that 'curriculum designers and classroom teachers need to have access to this information through better reference materials and syllabuses'. The frequency information of linking adverbials provided in this study informs teaching syllabus and teaching materials designers which items should be considered for pedagogical prominence. The detailed account and comparison of frequency of the forms, meanings and positions of linking adverbials in different registers and social settings provides guidelines on designing ESP and EAP syllabus and teaching materials.

Many textbooks have been developed based on the Academic Word List (Coxhead, 2000). ESP and EAP teaching materials can also take consideration of the detailed account of the register-specific description of the forms, meanings and positions of linking adverbials given in this study. Teaching materials such as Use linguistic tools to deliver cohesive academic lectures or Connect your meaning units -- cohesive devices in your oral or written discourse in academic settings/news settings can be developed based on the findings in this research. The ready-to-use tables of types of each form, meaning and position in WWC and WSC samples (e.g. Tables 26, 27, 32, 33) and comparison tables of types of each form, meaning and position in spoken and written English in academic and news settings (e.g. Tables 58, 59) can be easily copied into different teaching materials and thus give second language learners very detailed and practical guidelines on which and how linguistic items can be employed as explicit cohesive markers to facilitate the flow of their oral or written discourse in the five registers analysed in this study. Detailed frequency information provided for each type gives second language learners very concrete information on how common a particular type is used to express a certain meaning and where it can be placed. Authentic language examples from different registers from the analysed corpora can be given to exemplify how and in which discourse contexts a particular type can be used. The frequency information in different registers may also influence the order of the presentation of the content (see Reppen, 2010).

New findings resulting from careful manual analysis of three spoken registers carried out in this study can also raise ESP and EAP syllabus and teaching material designers' awareness of the importance of linking adverbials in spoken registers. The register of academic lecture is 
found to have the most frequent use of linking adverbials among all the five analysed registers and the type and is found extremely frequently employed in academic lectures. Thus, ESP and EAP syllabus and teaching material designers should give space to linking adverbials to help learners organize their spoken discourse. The detailed account of the correlation of sound patterns of and with its grammatical and pragmatic functions provided in this study (Chapter 4.2.2) can be transformed into teaching materials to inform learners how and can be pronounced to provide a structural link or a discourse link and how its pronunciation can influence its pragmatic function, i.e., meaning in context. The detailed account of the meanings of so (Chapter 6.3), another frequent type in spoken discourse, can also be converted into teaching materials to help learners to signal various discourse meanings using a simple word form so.

Data-driven learning is the direct aspect of applying corpora in language teaching, in which learners work as linguistic researchers while teachers work as facilitators. Based on a review of studies of data-driven learning, Römer (2011) concluded that many researchers agreed that data-driven learning empowers learners and raises learners' language awareness and its effectiveness has been indicated in previous studies. Reppen (2010) has suggested very practical activities and online corpora resources that can be used in the language classroom such as using MICASE for teaching spoken English. As mentioned in Chapter 2.1.2, applied linguistic studies (Altenberg \& Tapper, 1998; Zareva, 2011) have found that second language learners use linking adverbials in the wrong register. Thus, the register-specific account of usage patterns of linking adverbials given in study will inform learners which linking adverbials are commonly used in a certain register. My study suggests online corpora such as BNC, COCA and MICASE and concordance tools (e.g. Wordsmith, AntConc) can be introduced to learners to explore the usage patterns of linking adverbials in different registers in the classroom.

Concordance output, however, is normally read vertically, which thus has been criticised for encouraging 'a more bottom-up rather than top-down processing of text' (Flowerdew, 2009, p. 393). Linking adverbials, as defined in Chapter 4.1, are discourse cohesive devices which indicate that the discourse context surrounding a certain linking adverbial is important for understanding its function. In this sense, vertical examination of concordance output may not be able to fully demonstrate the cohesive function of a linking adverbial, i.e., its meaning in context. Thus, when concordance output is used to teach the meaning of linking adverbials in the classroom, the teacher should encourage the students to read the output horizontally and 
get enough surrounding discourse context from the corpora when necessary. Vertical examination of concordance out, however, is useful for learners to gain a straightforward image of the form and position of a certain linking adverbial in a certain register.

Data-driven learning cannot be applied in the same way to teach all the three aspects of usage patterns of linking adverbials, i.e., form, meaning and position, nor can it be suitable for learners of all English levels. Learners of lower proficiency (e.g. intermediate learners) may be able to work out or pick up the various forms of linking adverbials and positions of a certain type with appropriate instruction, but it may be difficult for them to tease out different meanings of a certain linking adverbial with multi-functions (e.g. so). Thus, direct teaching of pragmatic meanings identified in this study may be preferred to save valuable classroom time. Corpora data and context information of the data (e.g. genders, disciplines, and social settings), however, can be used to show how a certain linking adverbial is used to express a certain meaning and discuss how the context information may interact with the conveyed meaning. For advanced learners, more thought-provoking classroom tasks such as investigating what linking adverbials are used and how they are used to express the meaning of logical consequence in journal article writing and academic lectures in your discipline can be designed for learners to facilitate their understanding of the nature of linking adverbials and raise their awareness of register and genre variation of language use.

\subsubsection{Limitations of this study}

In order to understand the nature of linking adverbials in both written and spoken registers, a careful manual analysis of comparatively small-scale corpora is needed and doable. This study has checked findings from smaller corpora against larger corpora, but that process means that some potential linking adverbials in larger corpora may have been neglected. A careful manual analysis of an equivalent random sample from comparable larger corpora and then comparison between the findings from two manual analyses may to some extent help resolve the problem. However, this would be very time-consuming and may still overlook some potential linking adverbials.

Also in the second stage of this study, only the most frequent items in written registers have been checked against larger corpora. All the linking adverbials identified in Stage I could have been checked in larger written corpora to test the generalizability of usage patterns of all linking adverbials identified in this study in larger corpora and possibly to identify any differences among different English varieties. 
In spoken registers, the intonation unit has been used as the analysis unit in spoken data and it has been decided from the listener's perspective. Addressing inter-rater reliability was well beyond the scope of this study, but the useful findings from this study may make it worth training raters and testing inter-rater reliability in a future study.

\subsubsection{Future research directions}

1. As discussed in Section 2.1.2, most recent corpus-based studies focus on the register of written academic prose since previous studies claimed that it has the most frequent use of linking adverbials. However, this study found that spoken registers, especially the registers of academic lectures and conversation, have significantly more frequent use of linking adverbials than the register of written academic prose. Thus, the usage patterns of linking adverbials in both native speaker corpora and learner corpora in the registers of academic lectures and conversation warrant more attention. Michigan Corpus of Academic Spoken English (MICASE) can be a very useful and available data source for research in the spoken academic settings.

2. Register-specific meaning categorization developed in this study can provide a new framework for future corpus study of linking adverbials. A new approach of semantic-pragmatic continuum may shed light on future design of automatic taggers.

3. An investigation of usage patterns of subsections of a certain register will give second language learners even finer guidelines. There are different subsections in journal article writing: introduction, literature review, methodology, result, discussion and conclusion. There are also different disciplines in academic settings. It is worthwhile to further explore the usage patterns of linking adverbials in these subsections, and in the subsections of other genres.

4. Future research can also be done to investigate how corpus findings of linking adverbials (e.g. frequency, register variation) are represented in learners' textbooks and if there is a large gap between corpus findings and textbook material, and thus shed light on future teaching material design.

5. A research question such as how does the presence/absence of linking adverbials affect native and non-native English speakers' interpretation of text could help further investigate the nature of linking adverbials and the importance of linking adverbials in reading comprehension. Case studies of native speakers and nonnative speakers listening to/reading and understanding texts could be carried out. Introspective techniques (e.g. self-report, think-aloud) and stimulated recall (in 
response to a video-taped recording of reading/listening) could be adopted as methods to collect rich qualitative data. Experiments can be designed and carried out to collect quantitative data.

6. A closer examination of the influence of sound patterns of multifunctional words (e.g. so) on their grammatical functions and pragmatic functions in spoken registers will help build up our theoretical knowledge of these tricky but frequent word forms and better help second language learners with their use of these word forms in oral English to covey target meaning appropriately.

The findings from this study have permitted various insights into the fuzzy nature of linking adverbials as a grammar category and have applications for second language learners' acquisition of linking adverbials. Other researchers may carry out more research in this area in the future to further advance our knowledge of understanding, teaching and learning of linking adverbials. I have suggested several different approaches of doing research related with linking adverbials. Further research on linking adverbials from different perspectives will contribute to the field of pedagogical grammar, pragmatics, discourse studies, corpus-linguistics and second language acquisition. 


\section{References}

Altenberg, B., \& Tapper, B. (1998). The use of adverbial connectors in advanced Swedish learners' written English. In S. Granger (Ed.), Learner English on computer (pp. 8093). London: Longman.

Ariel, M. (2010). Defining pragmatics. Cambridge: Cambridge University Press.

Bach, K. (1999). The semantics-pragmatics distinction: what it is and why it matters. In K. Bach (Ed.), The semantics-pragmatics interface from different points of view (pp. 6484). Oxford: Elsevier.

Bell, D. M. (2010). Nevertheless, still and yet: Concessive cancellative discourse markers. Journal of Pragmatics, 42(7), 1912-1927.

Biber, D., \& Conrad, S. (2009). Register, Genre, and Style. Leiden: Cambridge University Press.

Biber, D., Conrad, S., \& Leech, G. (2002). Longman student grammar of spoken and written English. Harlow, England: Pearson/Longman.

Biber, D., Johansson, S., Leech, G., Conrad, S., \& Finegan, E. (1999). Longman grammar of spoken and written English. London: Longman.

Bolden, G. B. (2010). 'Articulating the unsaid' via and-prefacing formulations of others' talk Discourse Studies, 12(1), 5-32.

Bolton, K., Nelson, G., \& Hung, J. (2002). A corpus-based study of connectors in student writing. International Journal of Corpus Linguistics, 7(2), 165-182.

Carter, R., \& McCarthy, M. (2006). Cambridge grammar of English. Cambridge ; New York: Cambridge University Press.

Celce-Murcia, M., \& Larsen-Freeman, D. (1983). The grammar book: An ESL-EFL teacher's course. Rowley, Mass: Newbury House.

Chen, W. Y. C. (2006). The use of conjunctive adverbials in the academic papers of advanced Taiwanese EFL learners. International Journal of Corpus Linguistics, 11(1), 113-130.

Connor, U. (1984). A study of cohesion and coherence in English as a second language students' writing. Paper in Linguistics, 17(3), 301-316.

Coxhead, A. (2000). A new academic word list. TESOL Quarterly, 34, 213-238.

Crowhurst, M. (1987). Cohesion in argument and narration at three level grade levels. Research in the Teaching of English, 21(2), 185-201.

Cuenca, M.J. (2008). Pragmatic markers in contrast: the case of well. Journal of Pragmatics, 40, 1373-1391.

Fitzgerald, J., \& Spiegel, D. L. (1986). Textual cohesion and coherence in children's writing. Research in the Teaching of English, 20(3), 263-280.

Flowerdew, L. (2003). A combined corpus and systemic-functional analysis of the problemsolution pattern in a student and professional corpus of technical writing. TESOL Quarterly, 37(3), 489-511.

Flowerdew, L. (2009). Applying corpus linguistics to pedagogy: A critical evaluation. International Journal of Corpus Linguistics, 14(3), 393-417. 
Fraser, B. (1996). Pragmatic markers. Pragmatics, 6(2), 167-190.

Fraser, B. (1998). Contrastive discourse markers in English. In A. H. Jucker \& Y. Ziv (Eds.), Discourse markers: descriptions and theory (pp. 301-326). Amsterdam/Philadelphia: John benjamins publishing company.

Fraser, B. (1999). What are discourse markers?. Journal of Pragmatics, 31(7), 931-952.

Granger, S., \& Tyson, S. (1996). Connector usage in the English essay writing of native and non-native EFL speakers of English. World Englishes, 15(1), 17-27.

Greenbaum, S. (1969). Studies in English adverbial usage. London and Harlow: Longmans, Green and Co Ltd.

Halliday, M. A. K. (1994). An introduction to functional grammar. New York: Edward Arnold.

Halliday, M. A. K., \& Hasan, R. (1976). Cohesion in English. New York: Longman.

Heritage, J., \& Sorjonen, M.-L. (1994). Constituting and maintaining activities across sequences: And-prefacing as a feature of question design. Language in Society, 23(1), $1-29$.

Holmes, J., Vine, B., \& Johnson, G. (1998). Guide to the Wellington Corpus of Spoken New Zealand English. Wellington: School of Linguistics and Applied Language Studies, Victoria University of Wellington.

Huang, Y. (2007). Pragmatics. New York: Oxford University Press.

Huddleston, R. D., \& Pullum, G. K. (2002). The Cambridge grammar of the English language. New York: Cambridge University Press.

Jucker, A. H., \& Ziv, Y. (1998). Discourse markers: Introduction. In A. H. Jucker \& Y. Ziv (Eds.), Discourse markers: descriptions and theory (pp.1-12). Amsterdam/Philadelphia: John Benjamins publishing company.

Kennedy, G. (1998). An introduction to corpus linguistics. London and New York: Longman.

Kennedy, G. (2003). Structure and meaning in English: A guide for teachers. Harlow, England: Pearson/Longman.

Khalil, A. (1989). A study of cohesion and coherence in Arab EFL college students' writing. System, 17(3), 359-371.

Koshik, I. (1999). A preliminary investigation into the effect of grammatical cohesive devices - their absence and their misuse - on native speaker comprehension of non-native speaker speech and writing. Issues in Applied Linguistics, 10(1), 3-25.

Lei, L. (2012). Linking adverbials in academic writing on applied linguistics by Chinese doctoral students. Journal of English for Academic Purposes, 11(3), 267-275.

Liu, D. L. (2008). Linking adverbials: An across-register corpus study and its implications. International Journal of Corpus Linguistics, 13(4), 491-518.

Louwerse, M. (2001). An analytic and cognitive parameterization of coherence relations. Cognitive Liguistics, 12(3), 291-315.

McCarthy, M., \& O'Keeffe, A. (2004). Research in the teaching of speaking Annual Review of Applied Linguistics, 24, 26-43. 
McCulley, G. A. (1985). Writing quality, coherence, and cohesion. Research in the Teaching of English, 19(3), 269-282.

McNamara, D. S. (2001). Reading both high and low coherence texts: Effects of text sequence and prior knowledge. Canadian Journal of Experimental Psychology, 55, $51-62$.

McNamara, D. S., Crossley, S. A., \& McCarthy, P. M. (2010). Linguistic features of writing quality. Written Communication, 27(1), 57-86.

Milton, J., \& Tsang, E. S. C. (1993). A corpus-based study of logical connectors in EFL students' writing: directions for future research. In R. Pemberton \& E. S. C. Tsang (Eds.), Studies in lexis (pp. 215-246). Hong Kong: The Hong Kong Unversity of Science and Technology Language Centre.

Mithun, M. (1988). The grammaticization of coordination. In J. Haiman \& S. A. Thompson (Eds.), Clause combining in grammar and discourse (pp. 331-359) Amsterdam, Philadelphia: John Benjamins Publishing Company.

Neuner, J. L. (1987). Cohesive ties and chains in good and poor freshman essays. Research in the Teaching of English, 21(1), 92-105.

Quirk, R. (1985). A Comprehensive grammar of the English language. London ;New York: Longman.

Rayson, P. and Garside, R. (2000). Comparing corpora using frequency profiling. In proceedings of the workshop on Comparing Corpora, held in conjunction with the 38th annual meeting of the Association for Computational Linguistics (ACL 2000). 18 October 2000, Hong Kong, pp. 1 - 6.

Römer, U. (2011). Corpus research applications in second language teaching. Annual Review of Applied Linguistics, 31, 205-225.

Reppen, R. (2010). Using corpora in the language classroom. New York: Cambridge University Press.

Rouchota, V. (1998). Procedural meaning and parenthetical discourse markers. In A. H. Jucker \& Y. Ziv (Eds.), Discourse markers: descriptions and theory (pp. 97-126). Amsterdam/Philadelphia: John Benjamins publishing company.

Sanders, T., Land, J., \& Mulder, G. (2007). Linguistic markers of coherence improve text comprehension in functional contexts. Information Design Journal, 15(3), 219-235.

Schiffrin, D. (1986). Functions of and in discourse. Journal of Pragmatics, 10, 41-66.

Scott, M. (2008). WordSmith Tools version 5. Liverpool: Lexical Analysis Software.

Stotsky, S. (1983). Types of lexical cohesion in expository writing: implications for developing the vocabulary of academic discourse. College Composition and Communication, 34(4), 430-446.

Schourup, L. (2001). Rethinking well. Journal of Pragmatics, 33, 1025-1060.

Tierney, R. J., \& Mosenthal, J. H. (1983). Cohesion and textual coherence. Research in the Teaching of English, 17(3), 215-229.

Turk, M. J. (2004). Using and in conversational interaction. Research on Language and Social Interaction, 37(2), 219-250. 
Yeung, L. (2009). Use and misuse of 'besides': A corpus study comparing native speakers' and learners' English System, 37, 330-342

Zareva, A. (2011). 'And so that was it': linking adverbials in student academic presentations. RELC Journal, 42(1), 5-15. 